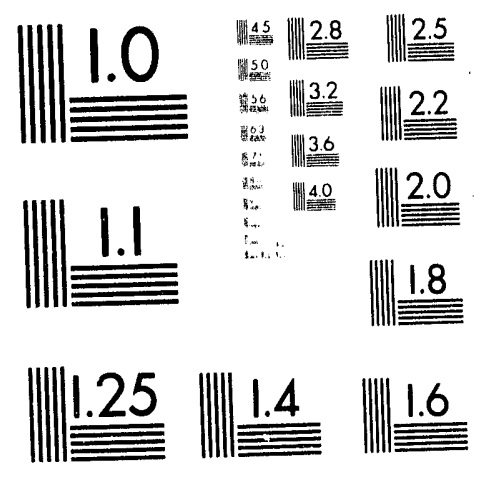



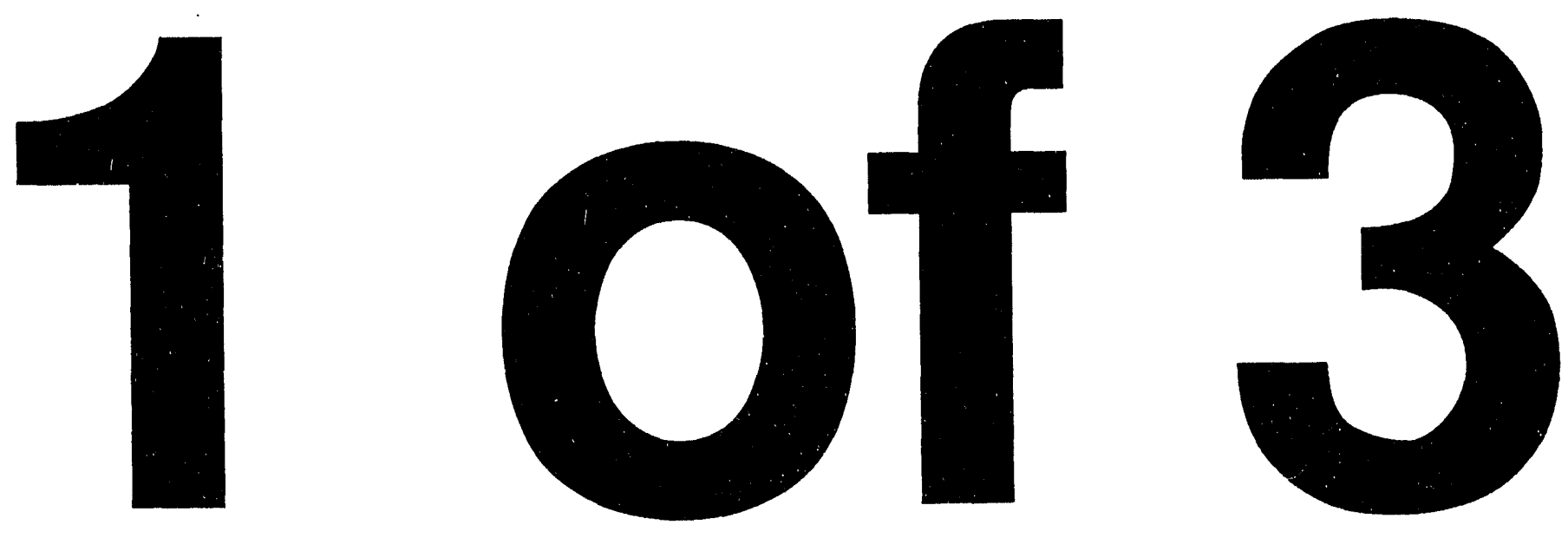
LBL-34881

UC-404

\title{
Double Rotation NMR Studies of Zeolites and Aluminophosphate Molecular Sieves
}

\author{
Raz Jelinek \\ Department of Chemistry \\ University of California \\ and \\ Materials Sciences Division \\ Lawrence Berkeley Laboratory \\ University of California \\ Berkeley, California 94720
}

July 1993

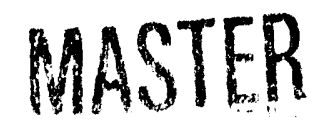

This work was supported by the Director, Office of Energy Research, Office of Basic Energy Sciences, Materials Sciences Division, of the U.S. Department of Energy under Contract No. DE-AC03-76SF00098. 


\title{
Double Rotation NMR Studies of Zeolites and Aluminophosphate Molecular Sieves
}

\author{
Copyright (C) 1993
}

by

Raz Jelinek

The Goverment reserves for itself and others acting on its behalf a royalty free, nonexclusive, irrevocable, world-wide license for goverrmental purposes to publish, distribute, translate, duplicate, exhibit, and perform any such data copyrighted by the contractor. 


\title{
Double Rotation NMR Studies of Zeolites and
}

\section{Aluminophosphate Molecular Sieves}

by

\author{
Raz Jelinek
}

\begin{abstract}
The unique feature of zeolite molecular sieves is the uniform size and shape of their cavities and channels, which mostly accounts for their chemical selectivity and reactivity. A central question one faces is the nature of interactions and chemical activation of adsorbed species within the porous framework of zeolite materials. Understanding the physical and chemical properties of zeolites is highly important for further scientific and technological applications of these materials. The goal of this work is the investigation of organization and structures of guest atoms and molecules, and their reactions upon the internal surfaces within the pores of zeolites and aluminophosphate molecular sieves.

${ }^{27} \mathrm{Al}$ and ${ }^{23} \mathrm{Na}$ double rotation NMR (DOR) is the analytical tool used in this study. The DOR technique removes the anisotropic broadening in NMR spectra of quadrupolar nuclei, thus providing a significantly increased resolution, compared, for example, with conventional methods such as magic angle spinning (MAS). The higher spectral resolution achieved in the DOR experiments is exploited to probe structural and dynamical aspects which involve ${ }^{23} \mathrm{Na}$ and ${ }^{27} \mathrm{Al}$ nuclei in zeolites.
\end{abstract}


Specifically, this work concentrates on probing the environments and organization of aluminum framework atoms in aluminophosphate molecular sieves, and sodium extraframework cations in porous aluminosilicates. In aluminophosphates, the ordering and electronic environments of the framework ${ }^{27} \mathrm{Al}$ nuclei are modified upon adsorption of water molecules within the channels. A relationship is sought between the topolgy of the sieves' channels, and the organization of adsorbed water, as well as the interaction between the aluminum nuclei and the $\mathrm{H}_{2} \mathrm{O}$ moelcules. Extraframework $\mathrm{Na}^{+}$cations are directly involved in adsorption processes and reactions in zeolite cavities. ${ }^{23} \mathrm{Na}$ DOR experiments yield valuable information on the distribution, structures, and dynamical aspects of guest species adsorbed in sodalites and sodium zeolite Y. DOR experiments, carried out at more than a single magnetic field strength, enable one to extract NMR parameters, which can be related to the local symmetry and electronic charge distributions at the nuclear sites. 


\section{Contents}

1 Introduction 1

2 NMR Studies of Spin-Half Quadrupolar Nuclei in Porous Molecular Sieves $\quad 5$

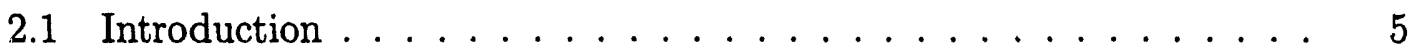

2.2 Framework Nuclei . . . . . . . . . . . . . . . 7

$2.2 .1{ }^{27}$ Al Studies . . . . . . . . . . . . . . 7

Site Identification . . . . . . . . . . . . . 8

Aluminophosphate Molecular Sieves . . . . . . . . . . 11

Aluminum Ordering and Correlations to Structural Parameters 15

Studies of Adsorption Processes . . . . . . . . . . . 16

2.2.2 Framework Nuclei Other Than ${ }^{27} \mathrm{Al} \ldots \ldots 18$

2.3 Extraframework Nuclei . . . . . . . . . . . . . . . 19

$2.3 .1{ }^{23} \mathrm{Na}$ Studies . . . . . . . . . . . . . . 21

Dynamics of Extraframework $\mathrm{Na}^{+}$Cations . . . . . . 23

3 Investigation of the Aluminophosphates $\mathrm{AlPO}_{4}-21$ and $\mathrm{AlPO}_{4}-25$ by ${ }^{27} \mathrm{Al}$ Double Rotation $\quad 28$ 
3.1 Abstract ............................ 28

3.2 Introduction . . . . . . . . . . . . . . . . . . 29

3.3 Experimental Considerations . . . . . . . . . . . . . . . 31

$3.4 \mathrm{AlPO}_{4}-21 \ldots \ldots \ldots \ldots \ldots \ldots \ldots$

$3.5 \mathrm{AlPO}_{4}-25 \ldots \ldots \ldots \ldots \ldots$

3.5.1 Water Adsorption in $\mathrm{AlPO}_{4}-25 \ldots . . \ldots 42$

3.6 Conclusions . . . . . . . . . . . . . . . . . 46

4 Adsorption Effects in Aluminophosphate Molecular Sieves Studied by ${ }^{27} \mathrm{Al}$ Double-Rotation $\quad 47$

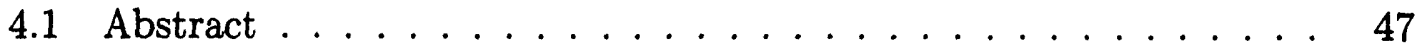

4.2 Introduction . . . . . . . . . . . . . . 48

4.3 Experimental Considerations . . . . . . . . . . . . . . . 49

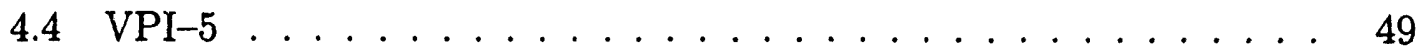

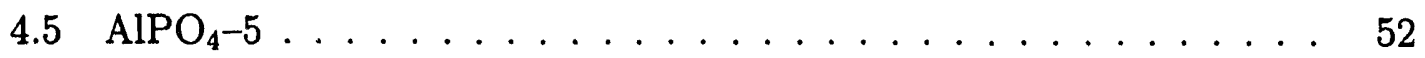

$4.6 \mathrm{AlPO}_{4}-8 \ldots \ldots \ldots \ldots \ldots \ldots$

4.7 Conclusions .......................... 59

5 Multinuclear NMR Study of the Synthesis and Assembly of a So$\begin{array}{lr}\text { dalite Semiconductor Superlattice } & \mathbf{6 0}\end{array}$

5.1 Abstract .......................... 60

5.2 Introduction . . . . . . . . . . . . . . . . 61

5.3 Experimental Considerations . . . . . . . . . . . . . . 64

5.4 Crystallization of Sodium, bromo-Sodalite . . . . . . . . . 66

5.5 Halo-Sodalites ................... 75

5.6 Mixed-Halide Sodalites . . . . . . . . . . . . . . . . 80 
$5.7 \mathrm{Ag}^{+}$Exchange of Sodium,bromo-Sodalites ........... ${ }^{\mathrm{v}}$

5.7.1 Cation Distribution ............... 86

5.7.2 Structural and Electronic Effects of $\mathrm{Ag}^{+}$Cation-Exchange . 90

5.8 Conclusions ....................... 97

$6{ }^{23} \mathrm{Na}$ DOR Studies of Cation Exchange and Molecular Adsorption in $\mathrm{Na}_{56} \mathrm{Y}$-zeolite $\quad 99$

6.1 Abstract . . . . . . . . . . . . . . . . . 99

6.2 Introduction . . . . . . . . . . . . . . . . 100

6.3 Experimental Considerations . . . . . . . . . . . . . . . . . 101

6.4 Adsorption of $\mathrm{Mo}(\mathrm{CO})_{6}$ in $\mathrm{Na}_{56} \mathrm{Y}$-zeolite . . . . . . . . . . . . . 102

$6.5 \mathrm{Tl}^{+}$and $\mathrm{Ca}^{2+}$ Cation Exchange .............. 109

$6.5 .1 \mathrm{Tl}^{+}$Ion Exchange . . . . . . . . . . . . . . 109

$6.5 .2 \mathrm{Ca}^{2+}$ Ion Exchange . . . . . . . . . . . 112

6.6 Molecular Adsorption in $\mathrm{Na}_{56} \mathrm{Y}$-zeolite . . . . . . . . . . . . 114

$6.6 .1 \mathrm{H}_{2} \mathrm{O}$ Adsorption . . . . . . . . . . . . . 114

$6.6 .2 \mathrm{P}\left(\mathrm{CH}_{3}\right)_{3}$ Adsorption . . . . . . . . . . 117

7 Intrazeolitic Reactions in $\mathrm{Na}_{56} \mathrm{Y}$-Zeolite Studied by ${ }^{23} \mathrm{Na}$ DOR 121

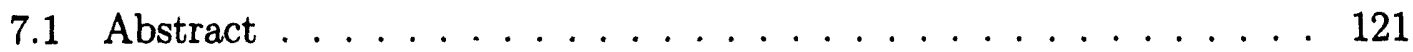

7.2 Introduction . . . . . . . . . . . . . . . . . 122

7.3 Experimental Considerations . . . . . . . . . . . . . 123

7.4 Ligand Substitution of $\mathrm{CO}$ by $\mathrm{P}\left(\mathrm{CH}_{3}\right)_{3}$ in $8\left\{\mathrm{Mo}(\mathrm{CO})_{6}\right\}-\mathrm{Na}_{56} \mathrm{Y}$. . . 124

7.4.1 Spin-Lattice Relaxation Measurements . . . . . . . . . . 130

7.5 Photooxidation of $\mathrm{Mo}(\mathrm{CO})_{6}$ and $\mathrm{W}(\mathrm{CO})_{6}$ Encapsulated in $\mathrm{Na}_{56} \mathrm{Y} \quad{ } \quad 135$

7.5.1 Intrazeolite Oxidation of $\mathrm{Mo}(\mathrm{CO})_{6} \ldots \ldots 139$ 
7.5.2 Intrazeolite Oxidation of $\mathrm{W}(\mathrm{CO})_{6} \ldots \ldots \ldots 14$

8 Conclusions

A Spin Interactions and Motional Averaging 149

A.1 Introduction . . . . . . . . . . . . . . . . 149

A.2 Spin Hamiltonians . . . . . . . . . . . . . . . . 150

A.3 Internal Hamiltonians in a High External Field . . . . . . . . . 155

A.3.1 Chemical Shift . . . . . . . . . . . . . 156

Motional Averaging-Magic Angle Spinning . . . . . . . . . . 158

A.3.2 Quadrupolar Interaction ... . . . . . . . . . . 161

First Order Correction . . . . . . . . . . . . . 161

Second Order Correction . . . . . . . . . . . . . . 162

Single Axis Spinning . . . . . . . . . . . . . . 165

A.3.3 Double Rotation . . . . . . . . . . . . . . . 169

B Practical Aspects of DOR Experiments 


\section{List of Figures}

1.1 Zeolite Structures $\ldots \ldots \ldots \ldots \ldots \ldots \ldots \ldots \ldots$

$2.1{ }^{27} \mathrm{Al}$ MAS Spectrum of $\mathrm{AlPO}_{4}-21 \ldots \ldots \ldots \ldots$

$2.2{ }^{27} \mathrm{Al}$ MAS Spectrum of Hydrated $\mathrm{AlPO}_{4}-5 \ldots \ldots \ldots \ldots$

$2.3{ }^{27} \mathrm{Al}$ MAS Spectra of Dehydrated and Hydrated VPI-5 . . . . . . 14

$2.4{ }^{27} \mathrm{Al}$ MAS Spectra of Partially Hydrated Hydroxide-Sodalite $\ldots . .17$

$2.5{ }^{71} \mathrm{Ga}$ MAS Spectrum of Cloverite $\ldots \ldots \ldots \ldots \ldots$

2.6 Schematic Drawing of $\mathrm{Na}_{56} \mathrm{Y}$-zeolite Supercage $\ldots \ldots \ldots \ldots$

$2.7{ }^{23} \mathrm{Na}$ MAS Spectra of $\mathrm{Na}_{56} \mathrm{Y}$-zeolite $\ldots \ldots \ldots \ldots \ldots$

2.8 Schematic Pictures of Sodalite and Zeolite A . . . . . . . . . . 25

$2.9{ }^{23} \mathrm{Na}$ MAS Spectra of Dehydrated and Hydrated $\mathrm{Na}_{56} \mathrm{Y}$-zeolite . . . 26

3.1 Diagram of $\mathrm{AlPO}_{4}-21$ Framework $\ldots \ldots \ldots \ldots$

3.2 Powder XRD Pattern of $\mathrm{AlPO}_{4}-21 \ldots \ldots \ldots \ldots$

$3.3{ }^{31} \mathrm{P}$ and ${ }^{27} \mathrm{Al}$ MAS Spectra of $\mathrm{AlPO}_{4}-21 \ldots \ldots \ldots \ldots$

$3.4{ }^{27} \mathrm{Al}$ DOR Spectrum of $\mathrm{AlPO}_{4}-21 \ldots \ldots \ldots \ldots \ldots$

$3.5{ }^{27} \mathrm{Al}$ MAS Spectrum, and Computer Simulations of $\mathrm{AlPO}_{4}-21 \ldots 37$

3.6 Diagram of $\mathrm{AlPO}_{4}-25$ Framework . . . . . . . . . . . . 39

$3.7{ }^{31} \mathrm{P}$ and ${ }^{27} \mathrm{Al}$ MAS Spectra of Dehydrated $\mathrm{AlPO}_{4}-25 \ldots \ldots \ldots$ 
viii

$3.8{ }^{27} \mathrm{Al}$ DOR Spectra of Dehydrated $\mathrm{AlPO}_{4}-25 \ldots \ldots . \ldots 4$

$3.9{ }^{27} \mathrm{Al}$ DOR Spectra of Hydrated $\mathrm{AlPO}_{4}-25 \ldots \ldots \ldots$

$4.1{ }^{27}$ Al DOR Spectra of VPI-5 ............... 50

$4.2{ }^{27} \mathrm{Al}$ DOR Spectra of $\mathrm{AlPO}_{4}-5 \ldots \ldots \ldots$

$4.3{ }^{27} \mathrm{Al}$ DOR Spectra of $\mathrm{AlPO}_{4}-8 \ldots \ldots \ldots$

4.4 TEM Image of $\mathrm{AlPO}_{4}-8 \ldots \ldots \ldots \ldots$

5.1 Schematic Drawings of Sodalite, and a $\mathrm{M}_{4} \mathrm{X}$ Cluster in Sodalite Cage 62

5.2 Powder XRD Patterns of $\mathrm{Na}_{8} \mathrm{Br}_{2}$-sodalite Crystallization Products 67

$5.3{ }^{29} \mathrm{Si}$ MAS Spectrum of $\mathrm{Na}_{8} \mathrm{Br}_{2}$-sodalite Precursor . . . . . . . . . 68

$5.4{ }^{27} \mathrm{Al}$ MAS Spectra of $\mathrm{Na}_{8} \mathrm{Br}_{2}$-sodalite Crystallization Products . . . 69

$5.5{ }^{23} \mathrm{Na}$ MAS Spectra of $\mathrm{Na}_{8} \mathrm{Br}_{2}$-sodalite Crystallization Products . . . 71

$5.6{ }^{23} \mathrm{Na}$ MAS Spectra of Hydrated, and Dehydrated, $\mathrm{Na}_{8} \mathrm{Br}_{2}$-sodalite . $\quad 73$

$5.7{ }^{23} \mathrm{Na}$ MiAS Spectra of Hydrated, and Dehydrated, $\mathrm{Na}_{6} \cdot n \mathrm{H}_{2} \mathrm{O}$-sodalite 74

$5.8{ }^{27} \mathrm{Al}$ DOR Spectra of $\mathrm{Na}_{8} \mathrm{X}_{2}$-sodalite (Where $\mathrm{X}=\mathrm{Cl}, \mathrm{Br}, \mathrm{I}$ ) $\ldots . . .77$

$5.9{ }^{23} \mathrm{Na}$ MAS and DOR Spectra of $\mathrm{Na}_{8} \mathrm{X}_{2}$-sodalite (Where $\mathrm{X}=\mathrm{Cl}, \mathrm{Br}, \mathrm{I}$ ) 78

5.10 Powder XRD Patterns, and Mid-IR Spectra of Mixed-Halide Sodalites 82

5.11 Far-IR Spectra of Mixed-Halide Sodalites . . . . . . . . . . . 83

$5.12{ }^{27} \mathrm{Al}$ and ${ }^{23} \mathrm{Na}$ DOR Spectra of Mixed-Halide Sodalites . . . . . . 85

$5.1{ }^{23} \mathrm{Na}$ DOR Spectra of $\mathrm{Ag}^{+}-$Exchanged Sodalites Containing Hydroxide Cages ........................ 87

$5.14{ }^{23} \mathrm{Na}$ DOR Spectra of $\mathrm{Ag}^{+}$-Exchanged Sodalites Containing AnionEmpty Cages ....................... 88

$5.15{ }^{23} \mathrm{Na}$ DOR Spectra of $\mathrm{Ag}^{+}$-Exchanged Sodium,bromo-sodalites . . 91 
5.16 Isotropic Chemical Shifts, and Quadrupolar Parameters of ${ }^{23} \mathrm{Na}$ in $\mathrm{Ag}^{+}$-Exchanged Sodium, bromo-sodalites . . . . . . . . . . . 93

$5.17{ }^{81} \mathrm{Br}$ MAS Spectra of $\mathrm{Ag}^{+}$-Exchanged $\mathrm{Na}_{8} \mathrm{Br}_{2}$-sodalite . . . . . . 95

$5.18{ }^{81} \mathrm{Br}$ MAS Spectra of $\mathrm{Ag}^{-}$- Exchanged Sodium,bromo-sodalite Containing Anion-Free Cages _. . . . . . . . . . . . . . . . . 96

6.1 Schematic Drawing of $\mathrm{Na}_{56} \mathrm{Y}$-zeolite Structure . . . . . . . . . . 103

$6.2{ }^{23} \mathrm{Na}$. MAS and DOR Spectra of dehydrated $\mathrm{Na}_{56} \mathrm{Y}$-zeolite . . . . 104

$6 .{ }^{23} \mathrm{Na}$ DOR Spectra of Adsorbed $\mathrm{Mo}(\mathrm{CO})_{6}$ in $\mathrm{Na}_{56} \mathrm{Y}$-zeolite . . . . 106

$6.4{ }^{23} \mathrm{Na}$ DOR Spectra of $\mathrm{Tl}_{x} \mathrm{Na}_{56-x} \mathrm{Y} \ldots \ldots \ldots$. . . . . . . . . 110

$6.5{ }^{23} \mathrm{Na}$ Synchronized DOR Spectra of $\mathrm{Ca}_{x} \mathrm{Na}_{56-2 x} \mathrm{Y} \ldots \ldots$. . . . . 113

$6.6{ }^{23} \mathrm{Na}$ DOR Spectra of $\mathrm{Na}_{56} \mathrm{Y} \cdot x \mathrm{H}_{2} \mathrm{O} \ldots \ldots \ldots \ldots$

$6.7{ }^{23} \mathrm{Na}$ DOR Spectra of $\mathrm{Na}_{56} \mathrm{Y} \cdot x \mathrm{P}\left(\mathrm{CH}_{3}\right)_{3} \ldots \ldots \ldots \ldots$

7.1 ${ }^{23} \mathrm{Na}$ DOR Spectra of Materials Produced in the Ligand Substitution of $8\left\{\mathrm{Mo}(\mathrm{CO})_{6}\right\}-\mathrm{Na}_{56} \mathrm{Y} \ldots \ldots \ldots \ldots$

$7.2{ }^{23} \mathrm{Na}$ DOR Inversion-Recovery Spectra of $8\left\{\mathrm{Mo}(\mathrm{CO})_{6}\right\}-\mathrm{Na}_{56} \mathrm{Y} \ldots \ldots$

$7.3{ }^{23} \mathrm{Na}$ DOR Inversion-Recovery Results for $8\left\{\mathrm{Mo}(\mathrm{CO})_{6}\right\}-\mathrm{Na}_{56} \mathrm{Y}$ and $8\left\{\mathrm{Mo}(\mathrm{CO})_{6}\right\}, 16\left\{\mathrm{PMe}_{3}\right\}-\mathrm{Na}_{56} \mathrm{Y} \ldots \ldots \ldots . \ldots . \ldots 134$

7.4 Schematic Drawings of Intrazeolite Molybdenum-carbonyl and Molybdenum-oxides . . . . . . . . . . . . . . . 136

7.5 Schematic Drawings of Intrazeolite Tungsten-carbonyl and Tungstenoxides ........................... 137

${ }^{23} \mathrm{Na}$ DOR Spectra of Intrazeolite Molybdenum-carbonyl Photooxidation/Reduction . . . . . . . . . . . . . . . . . . 140 
$7.7{ }^{23} \mathrm{Na}$. DOR Spectra of Intrazeolite Tungsten-carbonyl Photooxidation/Reduction ....................... 142

$7.8{ }^{23} \mathrm{Na}$ DOR Spectra of $\mathrm{n}\left\{\mathrm{WO}_{2}\right\}-\mathrm{Na}_{56} \mathrm{Y} \ldots \ldots \ldots \ldots$

A.1 The Euler Angles . . . . . . . . . . . . . . . . . 152

A.2 Static Chemical Shift Powder Pattern . . . . . . . . . . . 158

A.3 Single Axis Spinning Diagram . . . . . . . . . . . . . . . . . . 160

A.4 Quadrupolar Energy Levels in a Magnetic Field . . . . . . . . . . . 163

A.5 Static and Spinning Powder Patterns of the Central Transition . . . 166

A.6 Second and Fourth Legendre Polynomials . . . . . . . . . . . 168

A.7 Double Rotation . . . . . . . . . . . . . . 170

C.1 Schematic Design of the DOR Apparatus . . . . . . . . . . . . 175

C.2 Stator Body . . . . . . . . . . . . . . . . 176

C.3 Stator Caps . . . . . . . . . . . . . . . . . 177

C.4 Stator Aluminum Supports . . . . . . . . . . . . . . . . . . 178

C.5 Stator, Miscellaneous . . . . . . . . . . . . . . . 179

C.6 Outer Rotor Body . . . . . . . . . . . . . . . . . . . 180

C.7 Outer Rotor End Pieces . . . . . . . . . . . . . . . . . . 181

C.8 Inner Rotor Sleeve . . . . . . . . . . . . . . . . . . . 182

C.9 Caps of the Inner Rotor Sleeve . . . . . . . . . . . . . . . . 183

C.10 Inner Rotor . . . . . . . . . . . . . . . . . . . . . 184

C.11 Screws and Connectors . . . . . . . . . . . . . . . . 185

C.12 Magic Angle Adjust . . . . . . . . . . . . . . . . . . . . . . . 186 


\section{List of Tables}

3.1 NMR Parameters of Aluminum Sites in $\mathrm{AlPO}_{4}-21 \ldots \ldots$

3.2 NMR Parameters of Aluminum Sites in $\mathrm{AlPO}_{4}-25 \ldots . . . . . . .45$

5.1 Parameters Used in the NMR Experiments on Sodalites . . . . . . 65

5.2 NMR Parameters of ${ }^{23} \mathrm{Na}$ in Sodium,halo-sodalites . . . . . . . 80

5.3 NMR Parameters of ${ }^{23} \mathrm{Na}$ in $\mathrm{Ag}^{+}$Cation-Exchanged Sodium, bromosodalites ......................... . . 92

7.1 NMR Parameters of $\mathrm{Na}^{+}$Cations in the Supercages of $\mathrm{Na}_{56} \mathrm{Y}$-zeolite, in the Intrazeolite Ligand Substitution Reaction . . . . . . . . . . 129

A.1 Reduced Wigner Matrix Elements . . . . . . . . . . . . . . . 153

A.2 Spherical Spin Tensor Operators . . . . . . . . . . . . . 153 


\section{Acknowledgments}

It is difficult to summarize such a full and exciting period as my past five years here at Berkeley. First and foremost I want to acknowledge Professor Alexander Pines, my research director. His enthusiasm, scientific approach, and energy have made being in the Pines Group a unique and unforgettable experience. I am greatly indebted to him for his support of me to pursue diverse independent scientific projects and collaborations during my graduate studies.

I owe special thanks to Professor Goeffrey A. Ozin, and his research group at the University of Toronto, for extremely useful and enjoyable scientific collaboration. The various projects we pursued together make up roughly half of this thesis, and have essentially introduced me to the depths of the amazing "nano-world" of zeolites. I am grateful to my other "oversees" colleagues for their guidance and collaboration: Dr. Jack Klinowski, Dr. Patrick J. Barrie, Professors John E. Fischer, Mark E. Davis, Subhash Risbud and their research students.

Former and present colleagues in the Pines group have significantly contributed to my education and research. I am more than thankful to Jay H. Baltisberger for interesting discussions and constant help, in particular his timely warning to back up my data [two weeks before the ultimate death of the hard disk of the CMX500...]. Yue $\mathrm{Wu}$ introduced me to the wizzardry of double rotation, and helped me a lot during my first years. A very fruitful scientific exchange and collaboration I also had with Brad F. Chmelka, Phil J. Grandinetti and Henry W. Long. My 
sincere thanks to all the other members of the Pines Group; the page is too short to mention all their names here.

I would like to acknowledge, however, one of the most unique features of my experience in the Pines Group. Somehow, it seemed that during the momentous world events in the last five years, there was always a "representative" in the Group from the "relevant country" at the time. We shared the Tienamen Square Killings with Boqin, Wu, and Peng; the upheavels in [what was...] U.S.S.R. with Ago Samoson; the first democratic experience in Poland with Zbig. We saw the falling of the Berlin Wall through the eyes of Claudia, Thomas and Günther, and we experience now the "mini-revolution" in Italy with Stefano. Notwithstanding myself, being Israeli, watching on TV the Scud missiles falling on Tel Aviv during the Gulf War. Overall, coming to lab each morning was undoubtedly much more than just a scientific experience...

Last but not least, as a foreigner who had never before been in America, I am grateful for all the "extracurricular" experiences this country offered me. Berkeley's hospitality and exuberance; San Francisco's character and beauty; the magnificent forests, mountains and deserts in this big and striking state, California, which provided seemingly endless opportunities for hiking and travelling. This has indeed been a wonderful time!

This work was supported by the Director, Office of Energy Research, Office of Basic Energy Sciences, Materials and Chemical Sciences Division, U.S. Department of Energy, under Contract No. DE-AC03-76SF00098. 
To my Family, and to Nancy 


\section{Chapter 1}

\section{Introduction}

Zeolites are a remarkable class of materials, both from scientific and practical technological points of view. These materials exhibit numerous structures and configurations, with the unique property of organized arrays of cavities, windows, and channels. The porous and rigid nature of the zeolite framework has sparked much interest in these materials. The shape-, and size-selectivity of zeolite materials enable their use in molecular sieving, catalysis, gas adsorption and separation, ionexchange [1], and recently as hosts for semiconductor building blocks, which might be used in semiconductor technology [2]. Schematic drawings of several zeolite frameworks are shown in Figure 1.1.

Diverse approaches and methodologies have been used to characterize structures and adsorption properties of zeolites. Analytical measurements, diffraction techniques, and optical spectroscopies have all been employed in order to elucidate

various aspects in zeolite science and technology $[1,3,4]$. NMR spectroscopy has been particularly attractive in studies of zeolites. The short range ordering which exists in these materials makes the application of NMR very useful in probing the 


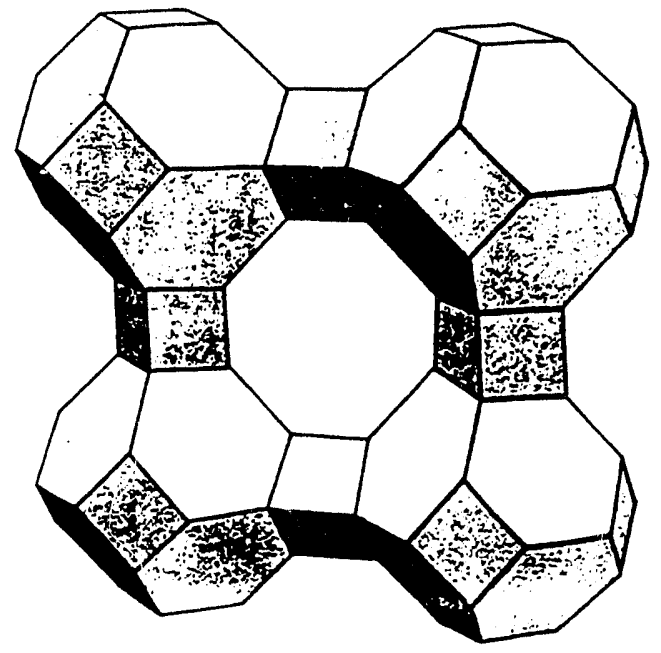

(a)

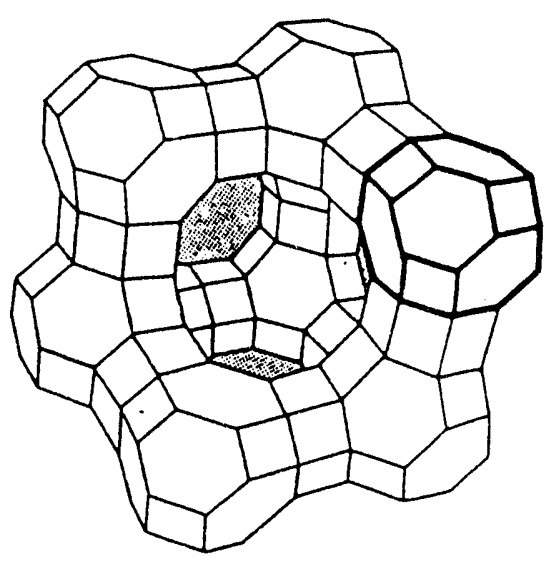

(b)

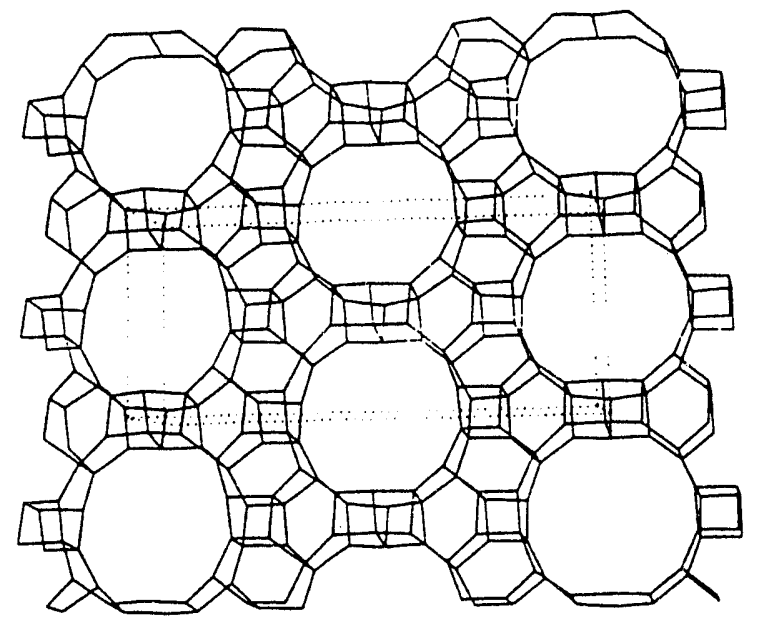

(c)

Figure 1.1: Schematic drawings of zeolite structures: (a) zeolite A; (b) zeolite $\mathrm{Y}$; (c) $\mathrm{AlPO}_{4}-8$ 
local environments of the various atomic constituents. The versatility of NMR has allowed its use to probe structural and dynamical properties in diverse classes of porous materials, and to investigate chemical processes associated with these materials $[5,6]$. NMR studies of zeolites, for example, have employed spin- $\frac{1}{2}$ nuclei such as ${ }^{29} \mathrm{Si},{ }^{31} \mathrm{P}$ and ${ }^{1} \mathrm{H}$, and quadrupolar nuclei like ${ }^{2} \mathrm{H},{ }^{23} \mathrm{Na}$ and ${ }^{27} \mathrm{Al}$.

NMR studies of quadrupolar nuclei in zeolites and other solid materials. however, have often been limited by the reduced resolution of the spectra, due to the interaction between the quadrupole moment of the nuclei and electric field gradients [5]. Quadrupolar nuclei at sites of low symmetry usually give rise to broad spectral lines, even upon application of narrowing techniques such as magic angle spinning (MAS) [7]. The newly developed double rotation (DOR) and dynamic angle spinning (DAS) techniques, however, provide significantly increased spectral resolution for quadrupolar nuclei with spin greater than one [8]. These two techniques open the way to a new realm of applications for high resolution solid state NMR in zeolite characterization.

This work describes applications of DOR, combined with MAS, in the study of zeolites, and the related, newly synthesized, porous aluminophosphate molecular sieves [which are also part of the "zeolite" class of materials [9]]. A survey of the main issues and challenges in NMR studies of quadrupolar nuclei in zeolite materials is provided in Chapter 2. Specific DOR experiments, designed to address some of the questions raised in Chapter 2, are described in the following chapters. These experiments include the investigation of water adsorption onto aluminum sites in the framework of aluminophosphate molecular sives, and structural order/disorder of the water molecules within the channels [Chapters 3 and 4]. 
A different perspective on zeolites' inner surface is achieved through the exploration of structural and dynamical aspects of extraframework, charge balancing, $\mathrm{Na}^{+}$cations. Chapters 5-7 contain detailed examinations of ion-exchange and adsorption processes in sodalite, and $\mathrm{Na}_{56} \mathrm{Y}$-zeolite, using for the first time ${ }^{23} \mathrm{Na}$ DOR as a structural probe. A general theoretical NMR background, which includes discussions of the relevant spin Hamiltonians, the concepts of "motional averaging" to remove anisotropic line-broadenings, and the double rotation technique, is given in Appendix 1. Practical aspects of DOR experiments are outlined in Appendix 2, and detailed technical drawings of the DOR apparatus are shown in Appendix 3. 


\section{Chapter 2}

\section{NMR Studies of Spin-Half}

\section{Quadrupolar Nuclei in Porous}

\section{Molecular Sieves}

\subsection{Introduction}

The birth of modern zeolite science has been coincidental with the discovery of nuclear magnetic resonance. The first synthetic zeolite was prepared in 1946 [3], the year in which the first NMR phenomena was observed. In the following decades, one witnessed a rapid progress in the synthesis, uses, and characterization of zeolite materials. The advent of NMR has been instrumental in understanding structures and chemical processes in zeolite molecular sieves. ${ }^{1} \mathrm{H}$ NMR reports on water adsorption in silica gel, for example, have appeared as early as 1956 [10]. Further developments like magic angle spinning (MAS) [11], and pulsed NMR [12], have significantly expanded the scope of NMR experiments on zeolites. Several 
books and articles provide thorough reviews of the applications of NMR in zeolite science and technology $[4,5,6]$.

Numerous NMR studies of zeolites have used spin- $-\frac{1}{2}$ nuclei, such as ${ }^{1} \mathrm{H}$ and ${ }^{29} \mathrm{Si}$. In general, NMR studies of spin- $\frac{1}{2}$ nuclei in solid materials have been particularly attractive because of the relatively high spectral resolution, obtained using modern techniques such as MAS. Thorough discussion of NMR studies which involve spinhalf nuclei in zeolites is beyond the scope of this work; several references, however, provide excellent reviews on this subject $[5,6]$. Zeolite structures and adsorbed species within the zeolite channels also contain quadrupolar nuclei [spin $>\frac{1}{2}$ ], such as ${ }^{27} \mathrm{Al},{ }^{23} \mathrm{Na}$, and ${ }^{7} \mathrm{Li}$, which play significant roles in determining the chemical and physical properties of the materials. The utility of solid state NMR experiments which involve quadrupolar nuclei has been limited, however, because of the retention of anisotropic broadening in the spectral lines, see detailed discussion in Appendix 1.

This chapter provides a general review of NMR studies involving non-integer quadrupolar nuclei in zeolites and aluminophosphate molecular sieves. Particular contributions of solid state NMR, as related to the main issues and challenges in zeolite science, are discussed. Specifically, I first examine the large number of NMR experiments which have been devoted to framework nuclei, mostly ${ }^{27} \mathrm{Al}$. Other studies have concentrated on extraframework charge-balancing cations, such as ${ }^{7} \mathrm{Li}$ and ${ }^{23} \mathrm{Na}$. Additional experimental work was carried out on other quadrupolar nuclei, and the structural and dynamical information which they provide is discussed as well.

The principle questions which have been addressed include ordering and site occupation within the framework of the molecular sieves, distinct chemical species 
which appear upon chemical and physical processes, and structural and dynamical aspects of adsorbed guest molecules within the porous host lattice. Certain limitations of the solid state NMR techniques are discussed, in particular the reduced spectral resolution, even with application of magic-angle spinning (MAS), due to the quadrupolar interaction affecting the nuclei in solid materials.

\subsection{Framework Nuclei}

\subsection{1 $\quad{ }^{27}$ Al Studies}

${ }^{27} \mathrm{Al}$ is a favorable nucleus for NMR measurements. It is $100 \%$ abundant, and its gyromagnetic ratio, 6.976 [13], is relatively high [130.31 $\mathrm{MHz}$ in an 11.7 Tesla magnetic field]. However, ${ }^{27} \mathrm{Al}$ has a nuclear spin of $\frac{5}{2}$ and its quadrupolar moment of $0.15 \times 10^{28} \mathrm{Q} / \mathrm{m}^{2}[13]$ often gives rise to significant quadrupolar couplings at sites of low symmetry. On the other hand, the quadrupolar interaction experienced by the ${ }^{27} \mathrm{Al}$ nuclei usually causes fast spin-lattice relaxation; thus very short repetition delays can be utilized in the NMR experiments. Extensive reviews on the application of ${ }^{27} \mathrm{Al}$ NMR to zeolites can be found in several references $[5,6]$. Most studies take advantage of the ${ }^{27} \mathrm{Al}$ chemical shift range $[\approx 450 \mathrm{ppm}[14]]$, and the high shape-sensitvity of the resonance, to obtain useful information on ${ }^{27} \mathrm{Al}$ environments within zeolite frameworks.

Wide-line ${ }^{27} \mathrm{Al}$ NMR experiments on faujasite-type zeolites were reported in the early 1970's [15]. A comprehensive review on the use of ${ }^{27} \mathrm{Al}$ NMR to monitor the synthesis and agglomeration of zeolites is given by Barrer [3]. Applications of MAS to the study of quadrupolar nuclei in solids first appeared in the literature in 
$1981[16,17]$, and the use of high magnetic field strengths [18] has further initiated an extensive research into the properties of ${ }^{27} \mathrm{Al}$ in frameworks of zeolite materials.

Porous aluminophosphate materials, first synthesized in 1982 [19], have attracted ${ }^{27} \mathrm{Al}$ NMR research from an early stage [20]. The short range ordering in these novel materials, due to the alternation of the $\mathrm{AlO}_{4}$ and $\mathrm{PO}_{4}$ structural units, offers a particular advantage for NMR studies. Aluminophosphate molecular sieves do not contain extraframework, charge-balancing, cations; this fact makes them particularly interesting for spectroscopic studies.

\section{Site Identification}

The observation of crystallographically inequivalent ${ }^{27} \mathrm{Al}$ sites, and the ability to distiguish between different chemical environments, have been among the major scientific issues since the onset of ${ }^{27} \mathrm{Al}$ NMR studies of zeolite materials. A thoroughly studied example is the coordination number of framework aluminum. Significantly different spectral positions were detected for four-coordinated and six-coordinated aluminum, respectively, in hydrated aluminosilicate zeolites $[18,25,26,27,28]$.

Aluminum atoms in zeolite frameworks are tetrahedrally coordinated to four oxygen atoms, and give rise to resonance frequencies at between $55 \mathrm{ppm}$ and $65 \mathrm{ppm}$, depending on the magnetic field strength, and the materials investigated $[5,28]$. Chemical modifications of the zeolite framework, such as dealumination $[18,26,29]$, and dehydroxylation $[28,30]$, cause more shielded nuclear environments, which are associated with 6-coordinated aluminum, located on the exterior of the zeolite framework. The observation of a distinct ${ }^{27} \mathrm{Al}$ signal associated with 6 -coordinated extraframework aluminum provides a highly sensitive analytical tool for intimate structural studies of the mechnisms of chemical modifications of the zeolite inner 
surface $[18,25,29,30,31]$.

The "extraframework" aluminum is believed to exist mostly in the form of the hydrated cation, $\mathrm{Al}\left(\mathrm{H}_{2} \mathrm{O}\right)_{6}^{3+}$, and located close to the negatively-charged aluminosilicate surface within the channels of zeolite $Y$ [18], and zeolite omega [26], for example. The formation of aluminum-hydroxides was also suggested [28]. Quantification of the extraframework aluminum, from the relative intensities of the NMR signals has been tried by some researchers $[28,29,32]$. Accurate intensity measurements, however, were difficult to accomplish, particularly in water evacuated samples $[28,29]$, because of the relatively large quadrupolar interaction at lowsymmetry sites.

Indeed, the use of higher magnetic fields, which reduces the magnitude of the quadrupolar coupling [see Appendix 1], enabled the detection of highly distorted extraframework aluminum species in hydrothermally treated faujasite and zeolite ZSM-5 $[29,33]$. Both studies have identified a distinct aluminum signal at around $30 \mathrm{ppm}$, roughly halfway between the four-coordinated aluminum signal, at around $60 \mathrm{ppm}$, and the six-coordinated ${ }^{27} \mathrm{Al}$ resonance, at $\approx 0 \mathrm{ppm}$. However, Samoson et al [29], using nutation-NMR analysis, claimed that the aluminum species in the highly asymmetric environment is extraframework four-coordinated aluminum, while Gilson et al [33] assigned the peak at around $30 \mathrm{ppm}$ to five-coordinated aluminum.

Five-coordinated aluminum was identified by ${ }^{27} \mathrm{Al}$ MAS in an 11.7 Tesla magnetic field in the mineral andalusite [34]. The ${ }^{27} \mathrm{Al}$ MAS resonance featured secondorder quadrupolar broadening, because of the low symmetry at the aluminum site. Five-coordinated aluminum, in the form of $\mathrm{AlO}_{4} \mathrm{OH}$, is also found in $\mathrm{AlPO}_{4}-21$, 


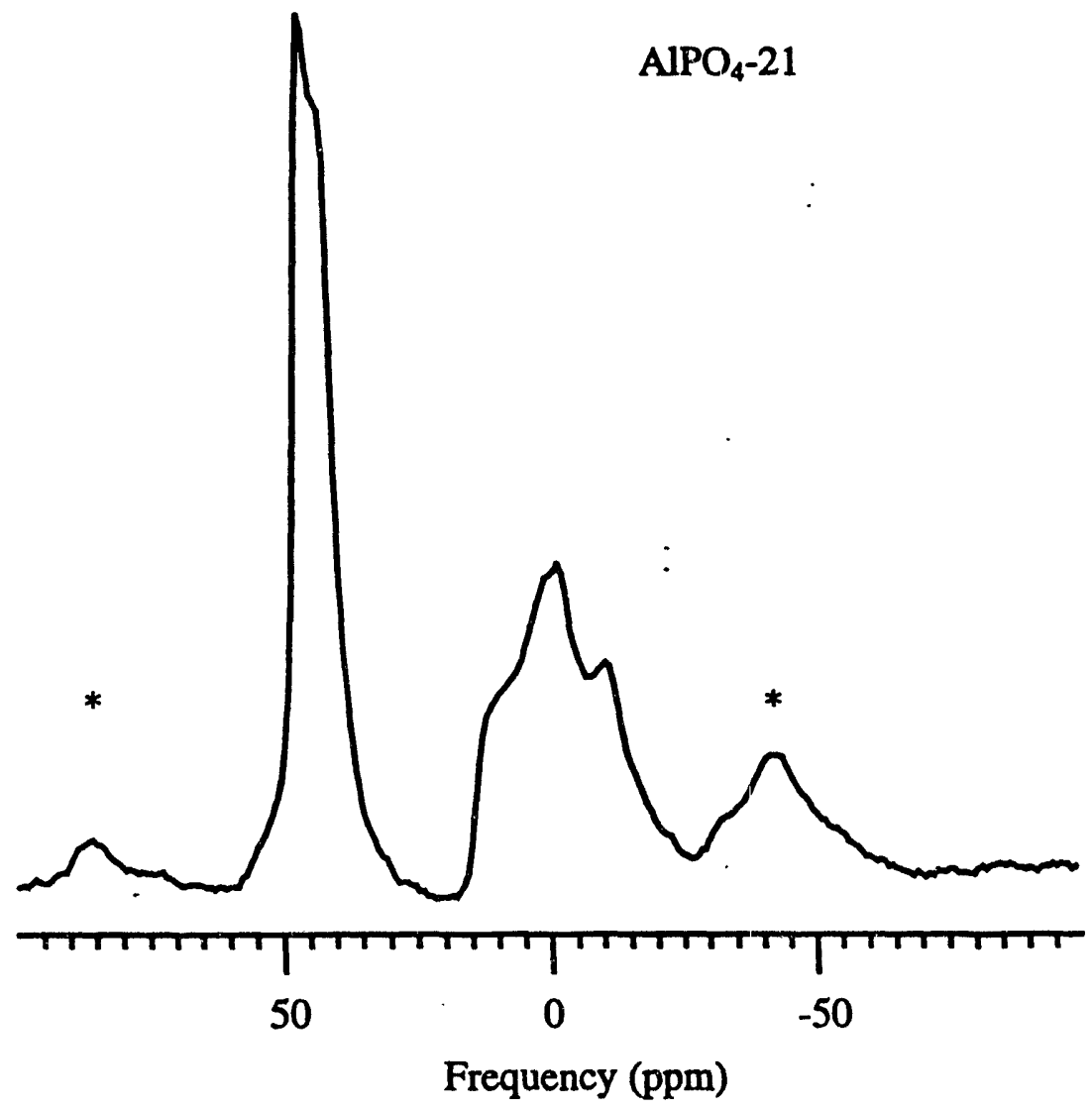

Figure 2.1: ${ }^{27} \mathrm{Al}$ MAS spectrum of the aluminophosphate molecular sieve precursor $\mathrm{AlPO}_{4}-21$, taken at $11.7 \mathrm{~T}$. The spinning speed was $5 \mathrm{kHz}$. The asterisks indicate spinning sidebands. 
an aluminophosphate precursor [35]. This material contains two highly distorted 5 -coordinated aluminum environments which exhibit relatively large quadrupolar interactions [36]. This is shown in Figure 2.1; the tetrahedral aluminum atoms give rise to a second-order powder pattern at around $40 \mathrm{ppm}$, while the two quadrupolar powder patterns associated with the 5-coordinated aluminum give rise to the broad and complicated feature at around $0 \mathrm{ppm}$.

\section{Aluminophosphate Molecular Sieves}

The appearance of intermediate aluminum coordination species in hydrated aluminophosphate molecular sieves was suggested in several studies $[20,37,38]$. This is demonstrated in the ${ }^{27} \mathrm{Al}$ MAS spectrum of hydrated $\mathrm{AlPO}_{4}-5$, Figure 2.2. Tetrahedral and octahedral aluminum give rise to the ${ }^{27} \mathrm{Al}$ peaks at around $35 \mathrm{ppm}$ and $-15 \mathrm{ppm}$, respectively. The signal at around $0 \mathrm{ppm}$ is probably associated with intermediate species, although it might contain contributions from second-order anisotropic quadrupolar broadening, not completely averaged by MAS.

Adsorption of water molecules within the channels of aluminophosphates is markedly different from the parallel process in aluminosilicate zeolites. Specifcally, the aluminophosphate framework does not have electric charge, as opposed to the negatively-charged framework of the silicon-containing zeolites. In the latter materials, adsorption processes critically depend on the charge balancing, extraframework cations, such as ${ }^{1} \mathrm{H}$ and ${ }^{23} \mathrm{Na}[1,3]$. In aluminophosphate molecular sieves, on the other hand, water molecules within the channels form secondary coordination with the framework aluminum and phosphorous atoms. The nature of the interaction between the aluminum and water molecules, as well as the structure and organization of the adsorbed water, is a primary question. This issue is discussed 


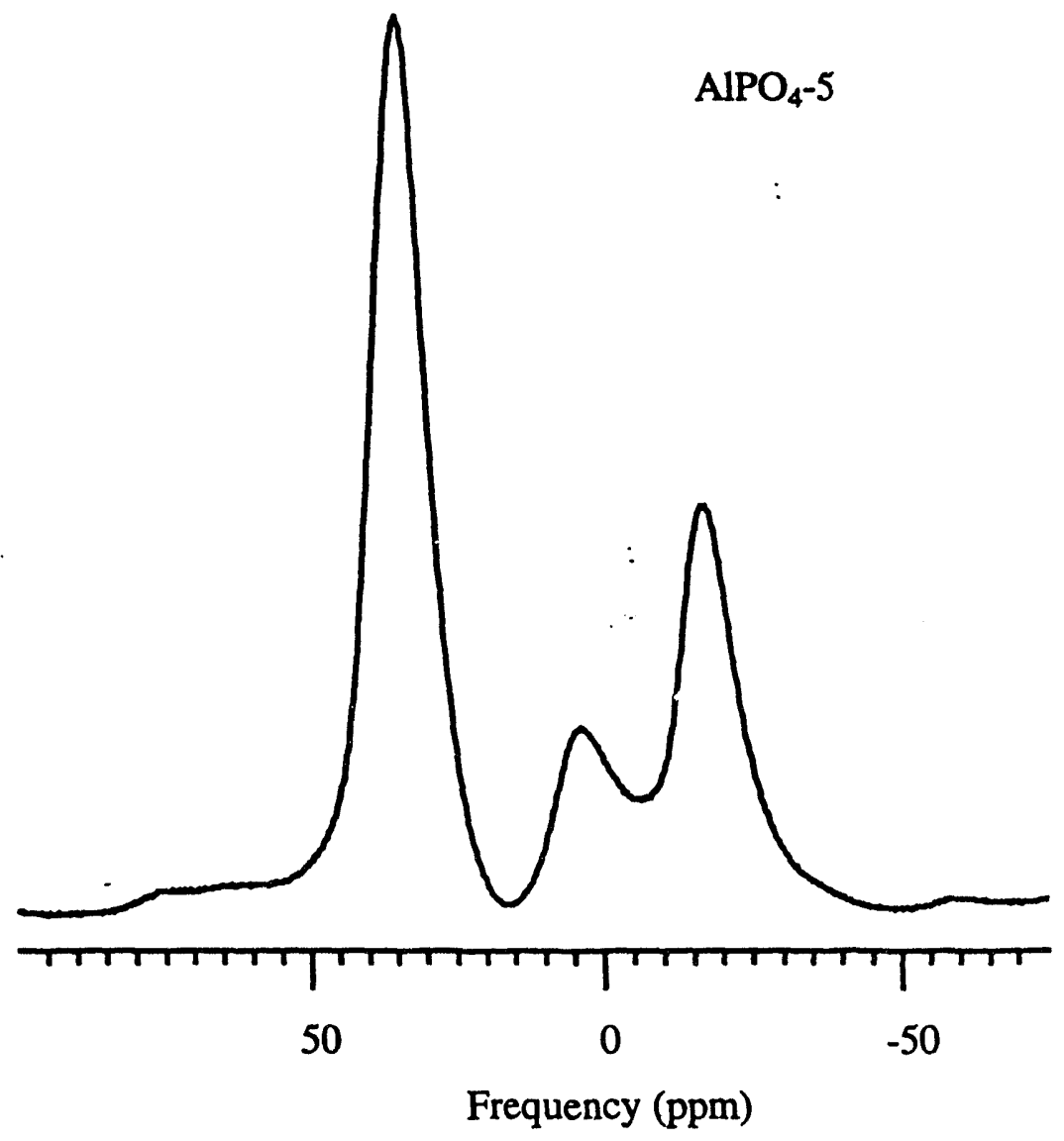

Figure 2:2: ${ }^{27} \mathrm{Al}$ MAS spectrum of hydrated $\mathrm{AlPO}_{4}-5$, taken at $11.7 \mathrm{~T}$. The spinning speed was $5 \mathrm{kHz}$. 
in several studies $[39,40,41,42]$.

Considerable attention has been devoted to water adsorption in VPI-5, the first aluminophosphate molecular sieve with 18-membered ring channels [43]. Several studies have utilized ${ }^{27} \mathrm{Al}$ NMR to investigate the structure, adsorption properties, and phase transitions of VPI-5 $[44,45,46,47,48]$. Extensive spectroscopic investigations have indicated the existence of a unique and reversible water arrangement within the wide channels of VPI-5 $[42,44,45,49]$.

${ }^{27} \mathrm{Al}$ MAS spectra of dehydrated and hydrated VPI-5, taken at $11.7 \mathrm{~T}$ are shown in Figure 2.3. Distinct ${ }^{27} \mathrm{Al}$ resonances ar $\approx$ ahserved between $35-40 \mathrm{ppm}$, and around $-15 \mathrm{ppm}$ in the hydrated material, and are associated with four-, and six-coordinated aluminum, respectively [45]. The two crystallographic aluminum sites in VPI-5 [44] are not resolved in the ${ }^{27} \mathrm{Al}$ MAS spectra, Figure 2.3, due to overlapping of second-order quadrupolar patterns of the two ${ }^{27} \mathrm{Al}$ sites [50]. The second-order quadrupolar powder pattern at around $-15 \mathrm{ppm}$, Figure 2.3(b), corresponds to the octahedral ${ }^{27} \mathrm{Al}$ in the framework of the hydrated material. This indicates an asymmetric charge distribution around the 6-coordinated aluminum, which produces a rather large electric field gradient at the ${ }^{27} \mathrm{Al}$ nuclei.

A correlation between the ${ }^{27} \mathrm{Al}$ isotropic chemical shift and the mean $\mathrm{Al}-\mathrm{O}-\mathrm{P}$ angle has been reported for $\mathrm{AlPO}_{4}$ polymorph and $\mathrm{AlPO}_{4}-5[51,52]$. These analyses take advantage of the alternation of the $\mathrm{AlO}_{4} / \mathrm{PO}_{4}$ tetrahedra in the framework of the aluminophosphate materials. An apparent limitation of the method is the need for an accurate estimation of the quadrupolar coupling constant of the ${ }^{27} \mathrm{Al}$ nuclei, in order to extract a reliable value of the isotropic chemical shifts. This might be difficult in low-resolution ${ }^{27} \mathrm{Al}$ spectra, and/or multiple aluminum sites in alu- 

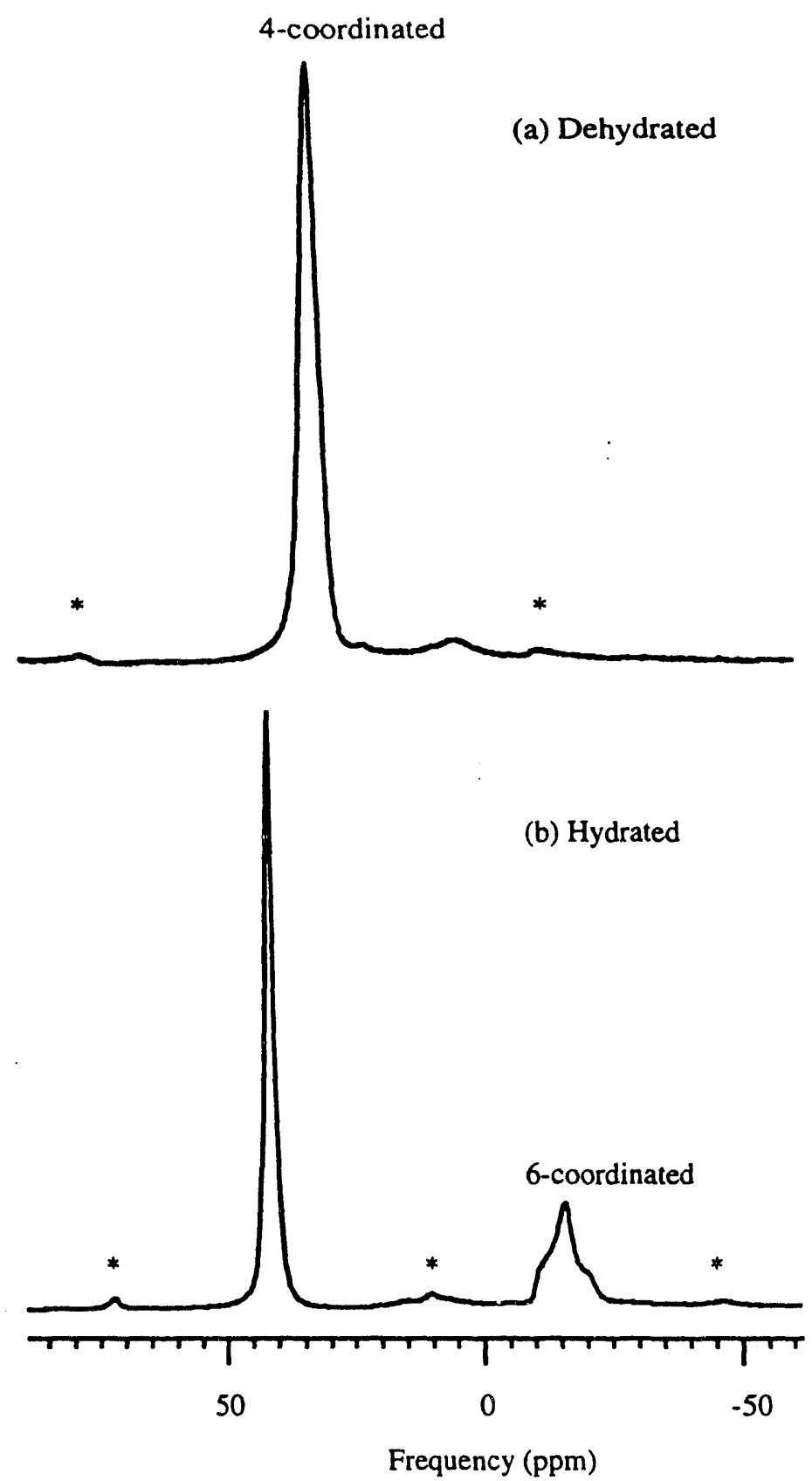

Figure 2.3: ${ }^{27} \mathrm{Al}$ MAS spectra of dehydrated and hydrated VPI-5, taken at 11.7 $\mathrm{T}$. The spinning speed was $5 \mathrm{kHz}$. The asterisks indicate spinning sidebands. For discussion of the spectral features see text. 
minophosphate with more complex channel systems.

\section{Aluminum Ordering and Correlations to Structural Parameters}

An attractive feature of aluminophosphate molecular sieves for NMR studies, is the strict $\mathrm{AlO}_{4}, \mathrm{PO}_{4}$ ordering in the framework. Similar ordering is not found in porous aluminosilicates, in general [1]. IIowever, a wealth of information on local structures in zeolite frameworks can still be obtained from ${ }^{27} \mathrm{Al}$ NMR experiments. Specifically, questions arise as to whether there is a correlation between spectral parameters of ${ }^{27} \mathrm{Al}$, such as chemical shifts and quadrupolar coupling constants, and structural parameters such as the distribution of the atoms in the framework, nearest neighbor effects, and the $\mathrm{Si}-\mathrm{O}-\mathrm{Al}$ bond angles.

The correlation between ${ }^{29} \mathrm{Si}$ chemical shifts and first tetrahedral nearest neighbour has long been a unique analytical tool for determining structures and chemical modifications of zeolites [53]. Such correlation is not available for aluminum nuclei becauce of the empirical "Loewenstein rule" [54], which rules out connectivity between two $\mathrm{AlO}_{4}$ tetrahedra in aluminosilicate frameworks. Nevertheless, several zeolite materials clearly violate Loewenstein rule [6].

The general question of distribution of silicon/aluminum nuclei in zeolite frameworks have attracted considerable interest, because of the strong relationship between the catalytic activity of the zeolite and the location of the silicon and aluminum atoms in the framework [1]. Again, the usefulness of ${ }^{29} \mathrm{Si}$ MAS spectra for statistical and structural models of $\mathrm{Si} / \mathrm{Al}$ distribution was immediately recognized [55]. The application of ${ }^{27} \mathrm{Al}$ NMR to this problem, however, is limited because of the low resolution spectra of zeolites with multiple aluminum environments.

A well known feature of ${ }^{29} \mathrm{Si}$ MAS experiments on zeolites is the correlation 
established between the ${ }^{29} \mathrm{Si}$ chemical shifts and the mean $\mathrm{Si}-\mathrm{O}-\mathrm{Al}(\mathrm{Si})$ bond angles [57]. A similar linear correlation between the isotropic chemical shifts of ${ }^{27} \mathrm{Al}$ and the mean bond angle $\mathrm{Si}-\mathrm{O}-\mathrm{Al}$ in framework silicates was reported [56]. Problems with this method arise, however, in materials where the ${ }^{27} \mathrm{Al}$ nuclei exhibit large quadrupolar couplings [58]

$\mathrm{SiO}_{4} / \mathrm{AlO}_{4}$ ordering exists in some porous aluminosilicates, such as sodalite and zeolite $\mathrm{A}[1,59]$. In these materials the ${ }^{27} \mathrm{Al}$ chemical shift is highly sensitive to the local environments within the cavities $[5,60,61]$. This enables one to establish correlations between the ${ }^{27} \mathrm{Al}$ shifts in the spectrum and geometric parameters [61]. The effect of water adsorption on ${ }^{27} \mathrm{Al}$ environments in a zeolite framework is shown in Figure 2.4. Figure 2.4 features ${ }^{27} \mathrm{Al}$ MAS spectra of partially-hydrated and hydrated $\mathrm{Na}_{8}(\mathrm{OH})_{2}-\mathrm{Al}_{6} \mathrm{Si}_{6} \mathrm{O}_{24} \cdot \mathrm{xH}_{2} \mathrm{O}$ (hydroxide-sodalite). The peaks observed in the spectra are associated with different water occupancies in the sodalite cages; the content of water molecules in each cage affects the $\mathrm{Si}-\mathrm{O}-\mathrm{Al}$ bond angles in the material [62], and consequently the shifts and shapes of the ${ }^{27} \mathrm{Al}$ resonances.

\section{Studies of Adsorption Processes}

A primary goal which underlies all NMR work in zeolite science, is to contribute to the understanding of adsorption and other chemical processes within the zeolite pores. A large number of ${ }^{27} \mathrm{Al}$ NMR studies have investigated chemical processes which result in modifications of the zeolite surface or composition $[5,6]$. Common catalytic treatments, such as dealumination and dehydroxylation, cause significant changes to the aluminum environments and contents. Indeed, chemical modifications of the aluminum environments are initiated specifically because of the close correlation between the aluminum content and positions in the zeolite lattice, and 

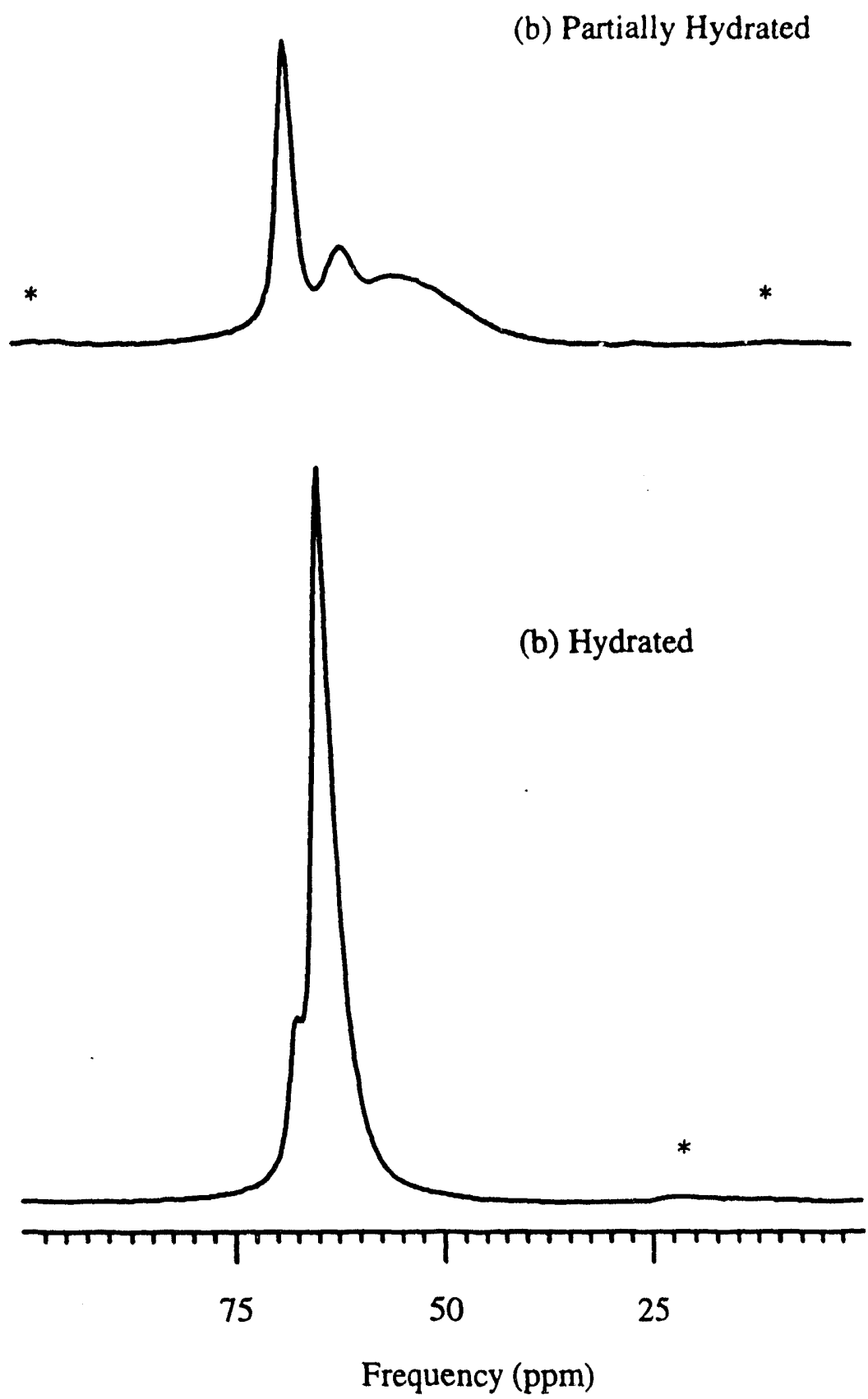

Figure 2.4: ${ }^{27} \mathrm{Al}$ MAS spectra of partially hydrated and completely hydrated $\mathrm{Na}_{8}(\mathrm{OH})_{2}-\mathrm{Al}_{6} \mathrm{Si}_{6} \mathrm{O}_{24} \cdot \mathrm{xH}_{2} \mathrm{O}$ (hydroxide-sodalite), taken at $11.7 \mathrm{~T}$. The spinning speed was $5 \mathrm{kHz}$, and the asterisks indicate spinning sidebands. The ${ }^{27} \mathrm{Al}$ peaks in the spectra probably correspond to cages with different number of water molecules [62], see text. 
the active acid sites on the zeolite surface $[31,63]$.

Fewer NMR studies have detected effects on ${ }^{27} \mathrm{Al}$ spectra, caused by direct interactions between adsorbed molecules within the zeolite cavities, and the framework aluminum. The limitation of NMR as an analytical tool in this case, is due primarily to the absence of aluminum ordering in zeolite frameworks, as discussed above. In addition, it should be emphasized that adsorption processes usually involve extraframework cations, such as $\mathrm{H}^{+}$and $\mathrm{Na}^{+}\{1]$, and only indirectly affect the framework nuclei. Thus, most NMR work on sorption processes in zeolites involve spectroscopic investigations of the guest atoms themselves, such as ${ }^{1} \mathrm{H}$ [64], ${ }^{13} \mathrm{C}[65],{ }^{129} \mathrm{Xe}[66]$ and others.

Water incorporation in zeolites is often investigated as a model system for chemical adsorption processes, similar to the aluminophosphate molecular sieves, discussed above. The effects of water molecules on the symmetry of aluminum environments, and the spectral shifts, have been reported by several groups $[67,68]$. A number of studies have examined the adsorption of molecules other than water, such as methanol [68], and Lewis-acid adducts [69]. A common observation in these studies is the increase of symmetry at the ${ }^{27} \mathrm{Al}$ nuclear sites upon adsorption of the guest molecules. This causes a reduction of the quadrupolar coupling constants experienced by the aluminum nuclei, and narrowing of the ${ }^{27} \mathrm{Al}$ resonances, following the adsorption process.

\subsubsection{Framework Nuclei Other Than ${ }^{27} \mathrm{Al}$}

A limited number of NMR reports on framework quadrupolar nuclei other than

${ }^{27} \mathrm{Al}$ have appeared in the literature. This is partly due to the fact that the frame- 
works of the vast majority of known zeolites contain only $\mathrm{AlO}_{4}$ and $\mathrm{SiO}_{4}$ units. Solid state ${ }^{17} \mathrm{O}$ NMR was used in some studies $[70,71,72]$. However, the application of ${ }^{17} \mathrm{O}$ NMR as a useful tool for zeolite charcterization is limited by the extremely low natural abundance of the isotope $(0.037 \%)$ - which requires expensive enriched samples, and the large quadrupolar coupling constants experienced by ${ }^{17} \mathrm{O}$.

There has recently been a growing interest in trying to improve the catalytic activity of zeolites by isomorphous substitution of the silicon and aluminum framework atoms $[73,74]$. Some NMR experiments were reported on ${ }^{11} \mathrm{~B}[75]$, and ${ }^{69} \mathrm{Ga}$ and ${ }^{71} \mathrm{Ga}[76,77]$, in boron, and gallium substituted zeolites, respectively. Changes in the gallium resonances, for example, were detected upon chemical modifications of gallium-substituted ZSM-5 zeolite [78].

The limitations of performing gallium NMR experiments are demonstrated in Figure 2.5. Figure 2.5 features a ${ }^{71} \mathrm{Ga}$ MAS spectrum of as-synthesized cloverite, a novel gallo-phosphate with 20-tetrahedral-atom channels [79]. Two peaks are observed in the spectrum, at around $200 \mathrm{ppm}$ and $0 \mathrm{ppm}$, which probably correspond to 4-coordinated and 6-coordinated gallium, respectively [77]. Both signals, however, particularly the peak at around $200 \mathrm{ppm}$, exhibit substantial broadening, mostly due to rather large quadrupolar interaction at the gallium nuclei.

\subsection{Extraframework Nuclei}

Essentially all aluminosilicate zeolites contain extraframework cations which compensate for the negative charge on the framework [1,3]. Extraframework cations play an important role in determining the adsorption properties and catalytic activity of zeolite sieves [1], and have consequently attracted NMR research $[5,6]$. Nu- 


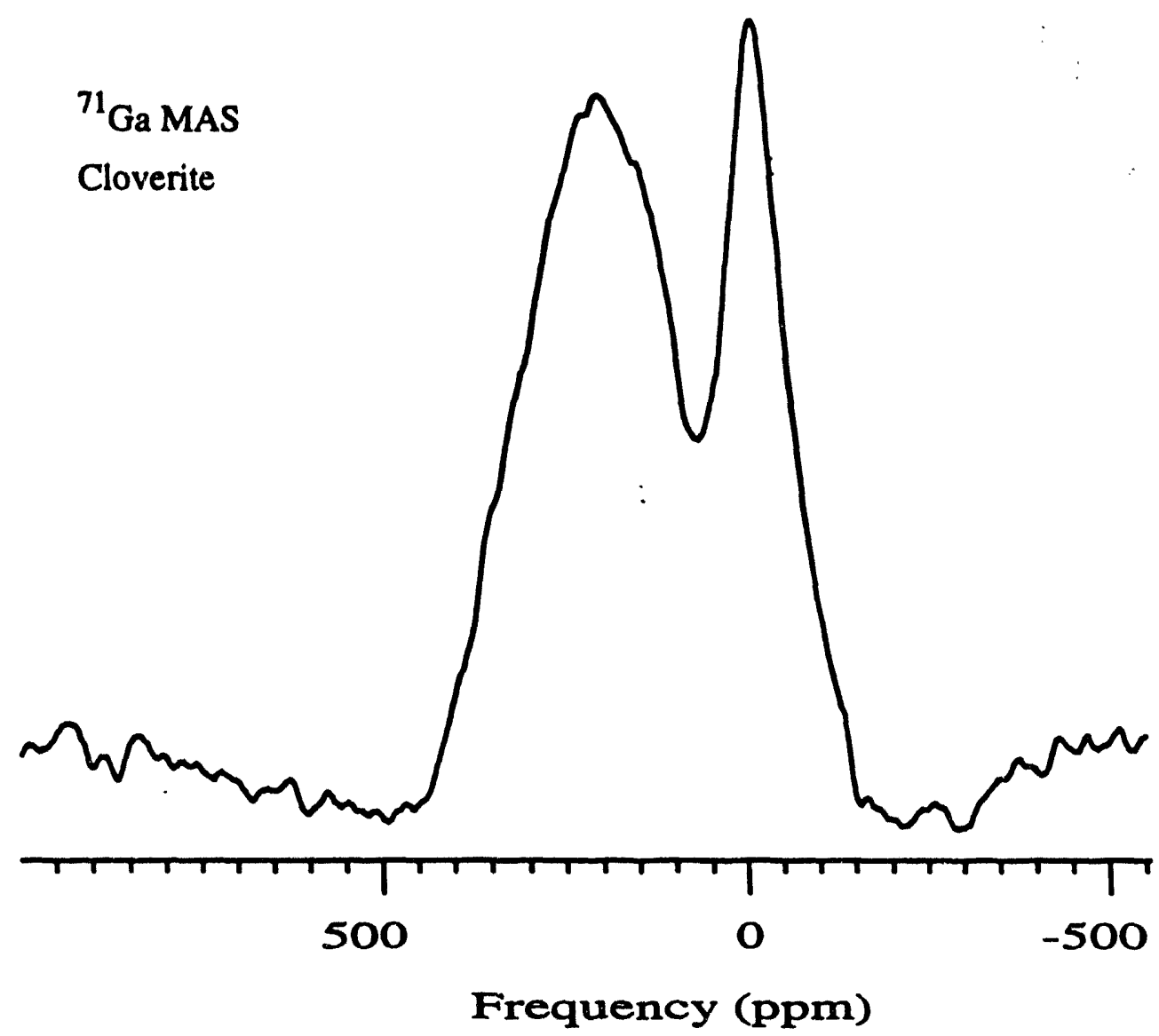

Figure 2.5: ${ }^{71} \mathrm{Ga}$ MAS Spectrum of as-synthesized cloverite, taken at $11.7 \mathrm{~T}$. The spinning speed was $5 \mathrm{kHz}$ 
merous studies have concentrated on characterization of acid sites using ${ }^{1} \mathrm{H}$ NMR techniques $[64,80]$. Other studies have utilized cation-exchanged nuclei, such as ${ }^{205} \mathrm{Tl}[81],{ }^{133} \mathrm{Cs}[82]$, and ${ }^{7} \mathrm{Li}[83,84,85]$.

\subsection{1 ${ }^{23} \mathrm{Na}$ Studies}

Most aluminosilicate zeolites contain $\mathrm{Na}^{+}$cations in the as-synthesized form $[1,3] . \mathrm{Na}^{+}$cations are involved in adsorption and chemical processes within the zeolite cavities $[1,86]$. Therefore, ${ }^{23} \mathrm{Na}$ NMR spectroscopy should provide insight into physical and chemical processes within the zeolite pores. ${ }^{23} \mathrm{Na}$ nuclei are, in principle, attractive to NMR experiments; the natural abundance of ${ }^{23} \mathrm{Na}$ is $100 \%$, and its high gyromagnetic ratio, 7.08 [13] (132.3 $\mathrm{MHz}$ in an 11.7 Tesla magnetic field) should give rise to high sensitivity spectra. ${ }^{23} \mathrm{Na}$ nuclei, however, exhibit quite large quadrupolar moment $\left[0.1 \times 10^{28} \mathrm{Q} / \mathrm{m}^{2}[13]\right]$. Thus, quadrupolarly broadened ${ }^{23} \mathrm{Na}$ resonances are often observed in ${ }^{23} \mathrm{Na}$ spectra of materials which contain lowsymmetry sodium sites $[87,88]$.

Multiple cation sites within the zeolite lattice, and a distribution of chemical environments, further decrease the resolution of NMR spectra of extraframework $\mathrm{Na}^{+}$cations, and limit the usefulness of ${ }^{23} \mathrm{Na}$ NMR as a probe of structures and chemical processes within zeolite cavities $[15,87,88,89] . \mathrm{Na}_{56} \mathrm{Y}$-zeolite provides an example to the challenges of applying ${ }^{23} \mathrm{Na}$ NMR to zeolites. A schematic Figure of the framework of $\mathrm{Na}_{56} \mathrm{Y}$-zeolite is shown in Figure 2.6. The locations of the extraframework cation sites within the zeolite cavities are indicated in the Figure. X-ray, and neutron diffraction measurements have indicated that $\mathrm{Na}_{56} \mathrm{Y}-$ zeolite exhibits four extraframework cation sites, however only three are populated 
in the dehydrated phase [90].

${ }^{23} \mathrm{Na}$ MAS spectra of dehydrated $\mathrm{Na}_{56} \mathrm{Y}$-zeolite, and $\mathrm{Na}_{56} \mathrm{Y}$-zeolite loaded with $\mathrm{Mo}(\mathrm{CO})_{6}$ guest molecules, are shown in Figure 2.7. The MAS spectrum of the dehydrated material, Figure 2.7(a), features a Gaussian signal at around 0 ppm, and a complex upfield pattern, which probably corresponds to overlapping quadrupolarlybroadened ${ }^{23} \mathrm{Na}$ signals. Distribution of the $\mathrm{Na}^{+}$environments within sites at $\mathrm{Na}_{56} \mathrm{Y}$-zeolite might additionally contribute to the: unresolved spectral features between $-15 \mathrm{ppm}$ and $-45 \mathrm{ppm}$.

Incorporation of $\mathrm{Mo}(\mathrm{CO})_{6}$ guest molecules evidently modifies the environments of the ${ }^{23} \mathrm{Na}$ nuclei, Figure 2.7(b). Specifically, a clear change is observed in the upfield features in the MAS spectrum. However, the quadrupolar broadening and/or distribution of the $\mathrm{Na}^{+}$cations again significantly reduces the spectral resolution; consequently, the information that can be obtained from the NMR experiment is limited.

Better ${ }^{23} \mathrm{Na}$ MAS spectral resolution is achieved in zeolite materials which contain single, or relatively few extraframework cation sites, such as sodalite or $\mathrm{NaA}$ zeolite (schematic drawings of which are shown in Figure 2.8) $\{29,81,91,92,93]$. Some studies have detected changes in the ${ }^{23} \mathrm{Na}$ chemical shifts and quadrupolar coupling constants upon incorporation of different anions into the cavities $[92,93]$. Sensitivities of ${ }^{23} \mathrm{Na}$ NMR spectra to the content of water molecules within sodalite cages [29], and to cation-exchange processes [81], were also detected.

\section{Dynamics of Extraframework $\mathrm{Na}^{+}$Cations}

An important feature of most extraframework cations in zeolites is their mobility within the zeolite cavities $[82,85,89,95,120]$. Since the extraframework cations 


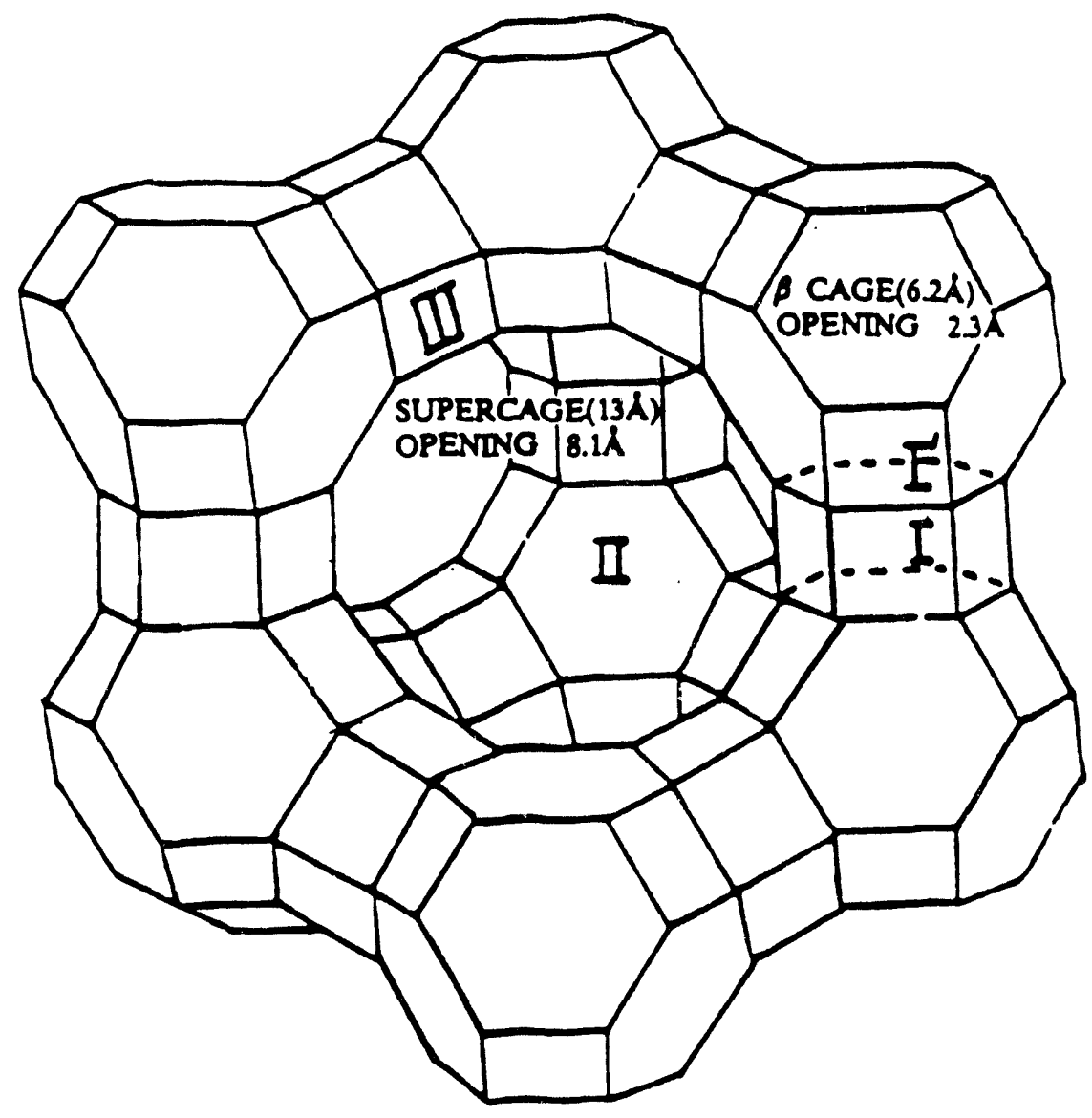

Figure 2.6: A schematic drawing of part of $\mathrm{Na}_{56} \mathrm{Y}$-zeolite unit cell. The drawing shows the $13 \AA$-wide supercage between the interconnected sodalite-cages and hexagonal prisms. The four extraframework cation sites are indicated: I inside the hexagonal prism, I' in the sodalite cage, and II and III within the supercage. 


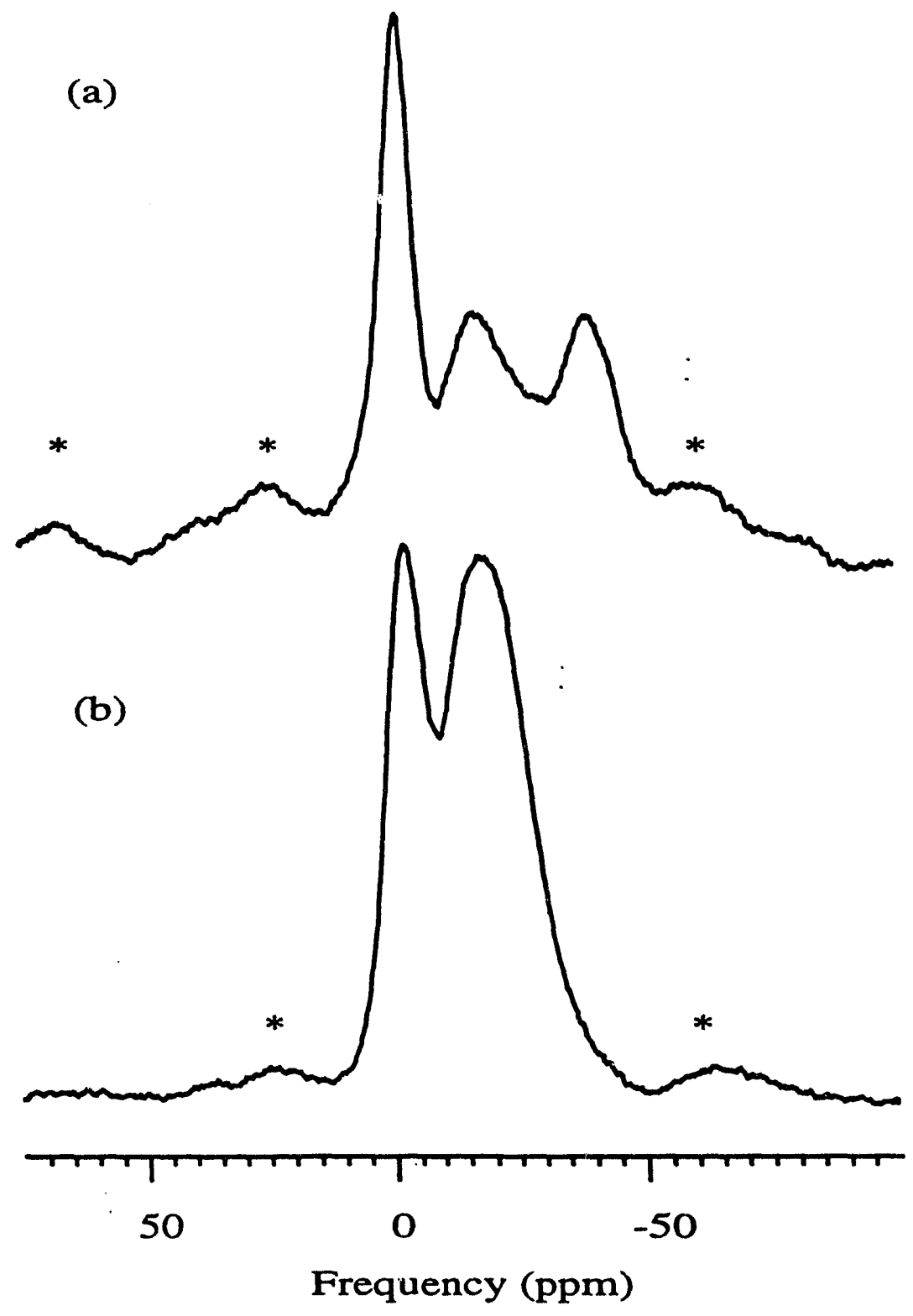

Figure 2.7: ${ }^{23} \mathrm{Na}$ MAS spectra, taken at $11.7 \mathrm{~T}$, of (a)dehydrated $\mathrm{Na}_{56} \mathrm{Y}-$ zeolite; and (b)dehydrated $\mathrm{Na}_{56} \mathrm{Y}$-zeolite loaded with $2 \mathrm{Mo}(\mathrm{CO})_{6}$ guest molecules in each supercage. The spinning speed was $\approx 5 \mathrm{kHz}$, the asterisks indicate spinning sidebands. 
SODALITE

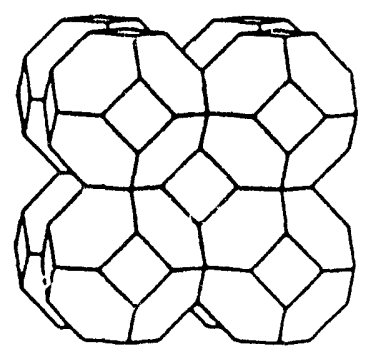

ZEOLITE A

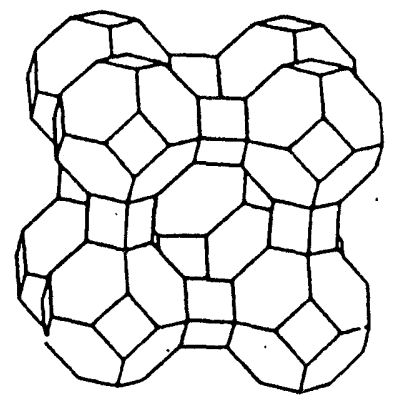

Figure 2.8: Schematic drawings of parts of the unit-cells of sodalite and zeolite $\mathrm{A}$

are actually not chemically-bonded to the framework, they exhibit a certain motion within the porous framework. Dynamical aspects of $\mathrm{Na}^{+}$cations have attracted increasing interest in recent years. Several NMR techniques have been applied to elucidate $\mathrm{Na}^{+}$mobility and migration within the zeolite pores, among them resonance-shape analyses $[15,81]$, variable-temperature nutation $\mathrm{NMR}[89,96]$, rotary-echo nutation spectroscopy $[91,92]$, and spin-lattice relaxation measurements $[89,97]$.

A general conclusion based on the NMR work, is the dependence of the environments and mobility of the $\mathrm{Na}^{+}$cations on the temperature and degree of hydration. Specifically, one observes broadening of ${ }^{23} \mathrm{Na}$ spectral lines and increased quadrupolar coupling constants of the sodium nuclei, upon decreasing the temperature, and/or reducing the number of water molecules within the zeolite cages $[15,88,89,91,96,97]$.

Higher temperature, and adsorbed water molecules, essentially permit increased 

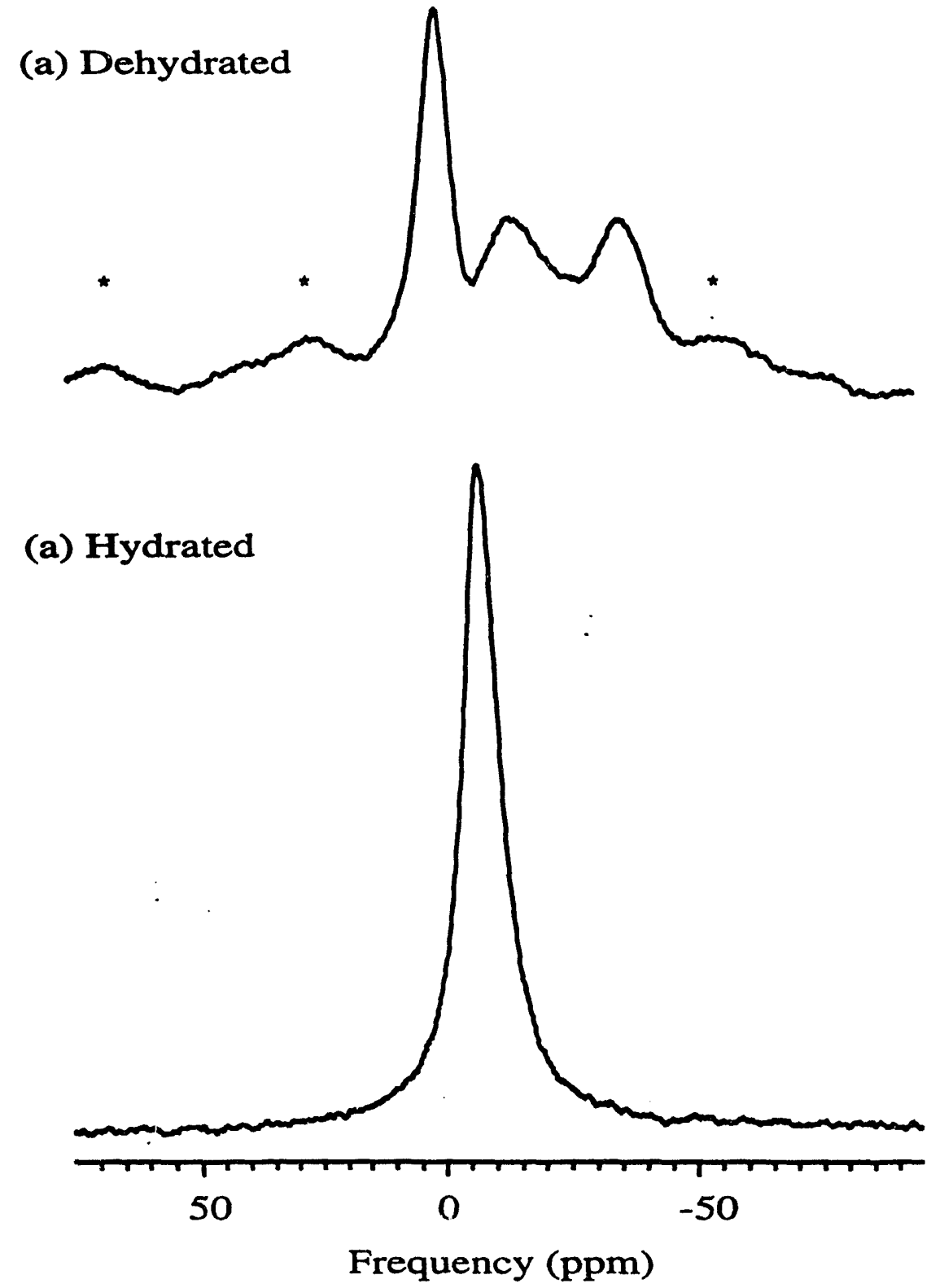

Figure 2.9: ${ }^{23} \mathrm{Na}$ MAS spectra of: (a) dehydrated; and (b) hydrated $\mathrm{Na}_{56} \mathrm{Y}-$ zeolite, taken at $11.7 \mathrm{~T}$. The spinning speed was $\approx 5 \mathrm{kHz}$, the asterisks indicate spinning side-bands. 
mobility of the $\mathrm{Na}^{+}$cations within the zeolite cages; thus creating for the ${ }^{23} \mathrm{Na}$ nuclei average, more symmetrical, environments. This is demonstrated in the case of $\mathrm{Na}_{56} \mathrm{Y}$-zeolite in Figure 2.9. The ${ }^{23} \mathrm{Na}$ MAS spectrum of hydrated $\mathrm{Na}_{56} \mathrm{Y}$-zeolite, Figure 2.9(b), features a single narrow Gaussian signal, indicating a symmetrical ${ }^{23} \mathrm{Na}$ environment. Indeed, the static ${ }^{23} \mathrm{Na}$ spectrum of hydrated $\mathrm{Na}_{56} \mathrm{Y}$-zeolite, is almost identical to the ${ }^{23} \mathrm{Na}$ MAS spectrum shown in Figure 2.9(b), which additionally points to a spatially averaged, highly symmetrical, ${ }^{23} \mathrm{Na}$ environment within the pores of $\mathrm{Na}_{56} \mathrm{Y}$-zeolite. 


\section{Chapter 3}

\section{Investigation of the}

\section{Aluminophosphates $\mathrm{AlPO}_{4}-\mathbf{2 1}$}

\section{and $\mathrm{AlPO}_{4}-25$ by ${ }^{27} \mathrm{Al}$ Double}

\section{Rotation}

\subsection{Abstract}

Aluminum-27 double-rotation in a magnetic field of 11.7 Tesla distinguishes the extremely distorted five-coordinated aluminum sites in the molecular sieve precursor $\mathrm{AlPO}_{4}$-21. Upon calcination, $\mathrm{AlPO}_{4}-21$ transforms to $\mathrm{AlPO}_{4}-25$, which has two tetrahedral aluminum sites with similar isotropic chemical shifts, that cannot be resolved in an 11.7 Tesla field. The two tetrahedral environments, however, have different quadrupolar coupling constants and are distinguished by ${ }^{27} \mathrm{Al} \mathrm{DOR}$ at 4.2 Tesla field. The quadrupolar coupling constants obtained for these sites indicate 
that the tetrahedral aluminum environments are less distorted in the hydrated material. The advantages of carrying out the DOR experiments at more than a single magnetic field are demonstrated.

\subsection{Introduction}

$\mathrm{AlPO}_{4}-21$ is one of a range of novel crystalline aluminophosphates first synthesized at Union Carbide Laboratories by hydrothermal treatment of gels containing organic templates [98]. This material is particularly interesting as it contains fivecoordinate aluminum in the framework. Calcination to remove the organic template produces molecular sieves of potential industrial importance. In the case of $\mathrm{AlPO}_{4}$ 21 there is also a structural transition to $\mathrm{AlPO}_{4}-25$ during the calcination process.

The structure of $\mathrm{AlPO}_{4}-21$ has been determined by single crystal X-ray diffraction and is shown in idealized form in Figure $3.1[100,101]$. There are three distinct crystallographic phosphorus sites, which are all regular $\mathrm{P}(\mathrm{OAl})_{4}$ tetrahedra. There are also three distinct aluminum sites: an $\mathrm{Al}(\mathrm{OP})_{4}$ tetrahedron, and two distorted five-coordinate $\mathrm{Al}(\mathrm{OP})_{4}(\mathrm{OH})$ environments. The asymmetric charge distributions at the five-coordinated aluminum sites result in large quadrupolar interactions, which cause severe line-broadening, making detection of such species particularly difficult using conventional MAS methods. It is interesting to note that $\mathrm{AlPO}_{4}-21$ contains $\mathrm{Al}-\mathrm{OH}-\mathrm{Al}$ groups, which are unusual for zeolite structures. As a consequence, $\mathrm{AlPO}_{4}-21$ comprises 3- and 5-membered rings, as well as the even-numbered rings usually observed in $\mathrm{AlPO}_{4}$ frameworks. It does not, however, violate the "Loewenstein rule" [54] which only forbids linkages between tetrahedral aluminum atoms. 


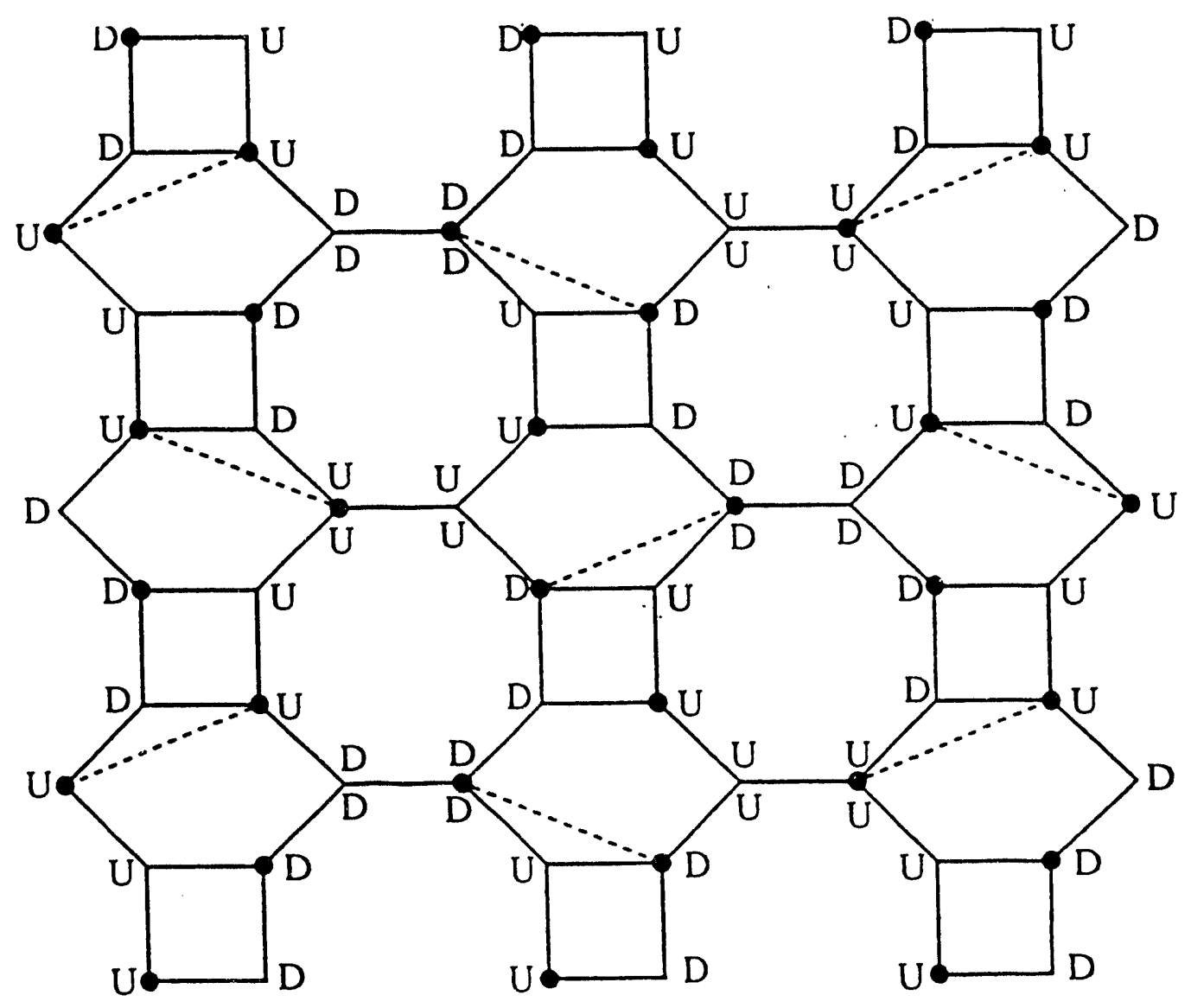

Figure 3.1: Idealized diagram of $\mathrm{AlPO}_{4}-21$ framework. Aluminum atoms are marked by the solid circles, and phosphorous atoms are located at the other vertices. $\mathrm{U}$ and $\mathrm{D}$ represent upward and downward pointing connections. There is a bridging oxygen in the midpoint of each solid line and a bridging $\mathrm{OH}$ group in the middle of the dashed lines, which result in two distinct five-coordinated aluminum sites. 


\subsection{Experimental Considerations}

$\mathrm{AlPO}_{4}-21$ was synthesized according to the general procedure described by Wilson et al [98], from a gel containing pyrrolidine as the organic template. The powder $\mathrm{XRD}$ pattern obtained for the material is shown in Figure 3.2 and verifies the high crystallinity and purity of the $\mathrm{AlPO}_{4}-21$ product. A portion of the $\mathrm{AlPO}_{4}-21$ sample was subsequently calcined in dry oxygen gas at $873 \mathrm{~K}$ for $24 \mathrm{~h}(2 \mathrm{~K} / \mathrm{min}$ heating rate) to form the molecular sieve $\mathrm{AlPO}_{4}-25$. For recording spectra of dehydrated $\mathrm{AlPO}_{4}-25$, the sample was heated overnight under vacuum at $623 \mathrm{~K}$ and transferred into the rotor in a dry nitrogen atmosphere.

Conventional ${ }^{31} \mathrm{P}$ and ${ }^{27} \mathrm{Al}$ MAS spectra were recorded in 4.2 and 11.7 Tesla magnetic fields, using spinning speeds of $5.5-6.5 \mathrm{kHz}$. The ${ }^{31} \mathrm{P}$ pulse-length was $4 \mu \mathrm{sec}\left[90^{\circ}\right.$ pulse], while the ${ }^{27} \mathrm{Al}$ data were collected using $3 \mu \mathrm{sec}$ pulses $\left[90^{\circ}\right.$ pulse in solution was $12 \mu \mathrm{sec}$, with $3 \mathrm{~s}$ recycle delays. DOR spectra, also recorded at 4.2 and $11.7 \mathrm{~T}$, were obtained using a home-built probe [99]. The inner DOR rotor was spun at about $5 \mathrm{kHz}$, and the outer rotor at $600-800 \mathrm{~Hz}$. In the DOR experiments, 1000-2000 acquisitions were obtained using 1s delays between $3 \mu$ sec pulses [solution $90^{\circ}$ time-18 $\mu \mathrm{sec}$ ]. All spectra were zero-filled to $4 \mathrm{~K}$ data points, with $100 \mathrm{~Hz}$ Gaussian broadening, and referenced to $85 \%$ aqueous $\mathrm{H}_{3} \mathrm{PO}_{4}$ for ${ }^{31} \mathrm{P}$, and to an aqueous solution of $\mathrm{Al}\left(\mathrm{NO}_{3}\right)_{3}$ for ${ }^{27} \mathrm{Al}$.

\section{$3.4 \mathrm{AlPO}_{4}-21$}

${ }^{31} \mathrm{P}$ and ${ }^{27} \mathrm{Al} \mathrm{MAS} \mathrm{spectra}$ of $\mathrm{AlPO}_{4}-21$ are shown in Figure 3.3 . The ${ }^{31} \mathrm{P}$ MAS spectrum in Figure 3.3(a) shows complete resolution of the three distinct 


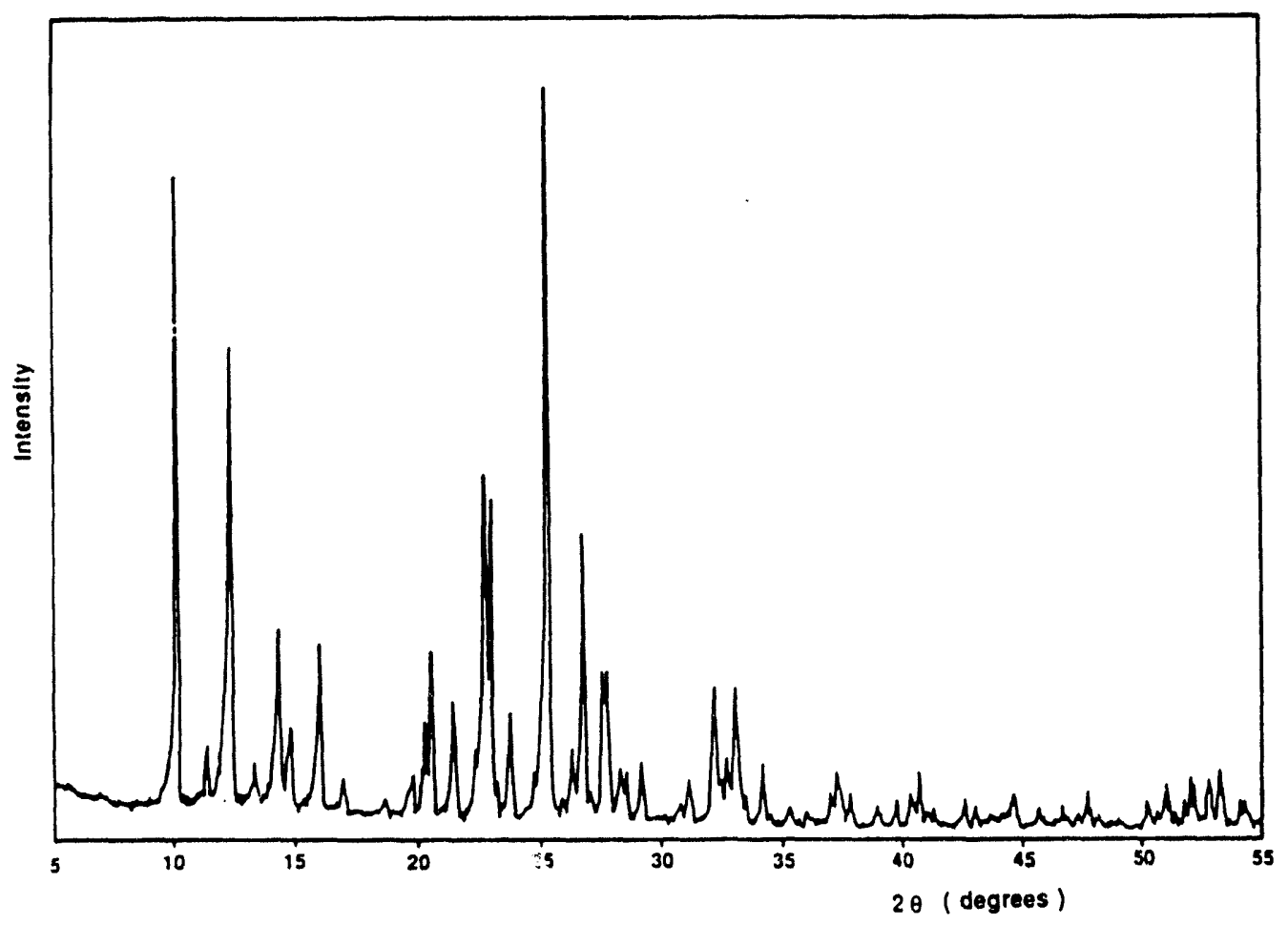

Figure 3.2: Powder $\mathrm{X}$ ray diffraction pattern of $\mathrm{AlPO}_{4}-21$. The sharp lines in the pattern indicate a pure and highly crystalline material. 
phosphorus sites in a population ratio of approximately 1:1:1. The narrow lines at $-13.3,-21.1$, and $-30.3 \mathrm{ppm}$ confirm the high crystallinity of the sample and cover a range of the frequency regime normally associated with $\mathrm{P}(\mathrm{OAl})_{4}$ species $[20,37]$. The correlation suggested by Müller et al. [51] between the ${ }^{31} \mathrm{P}$ chemical shift and the mean $\mathrm{P}-\mathrm{O}-\mathrm{Al}$ bond angle in $\mathrm{AlPO}_{4}$ polymorphs enables these peaks to be assigned to specific crystallographic sites.

The $\mathrm{P}-\mathrm{O}-\mathrm{Al}$ bond angles in pyrrolidine-containing $\mathrm{AlPO}_{4}-21$ were calculated from the data in ref. $[100]$ and the ${ }^{31} \mathrm{P}$ peaks were assigned as follows:

$$
\begin{array}{ll}
\delta=-13.3 \mathrm{ppm}, \mathrm{P} 3 \text { site } & \langle P 3-O-A l\rangle=137.4^{\circ} \\
\delta=-21.1 \mathrm{ppm}, \mathrm{P} 2 \text { site } & \langle P 2-O-A l\rangle=142.0^{\circ} \\
\delta=-30.3 \mathrm{ppm}, \mathrm{P} 1 \text { site } & \langle P 1-O-A l\rangle=148.8^{\circ}
\end{array}
$$

The ${ }^{27} \mathrm{Al}$ MAS spectrum shown in Figure $3.3(\mathrm{~b})$ features a prominent peak at $44 \mathrm{ppm}$ with a typical second-order quadrupolar broadened lineshape, corresponding to the single tetrahedral aluminum environment, and an additional broad signal at lower frequency associated with the two five-coordinated aluminum sites [36]. These resonance lines are broadened by anisotropic second-order quadrupolar effects which are not removed by MAS, even at higher spinning speeds [36].

Better resolution is obtained in the ${ }^{27} \mathrm{Al}$ spectrum of $\mathrm{AlPO}_{4}-21$ using double rotation NMR. Figure 3.4 shows the ${ }^{27} \mathrm{Al}$ DOR spectrum obtained at $11.7 \mathrm{~T}$. DOR averages the second-order quadrupolar interaction to its isotropic component, thus substantially narrowing the peaks. The spectrum shows a single symmetric peak at $42.2 \mathrm{ppm}$, while two resonances, at 0.4 and $-5.4 \mathrm{ppm}$, due to the five-coordinate sites can be distinguished from the spinning sidebands by varying the spinning speed of the outer rotor. The sideband manifold remains relatively broad, however, 

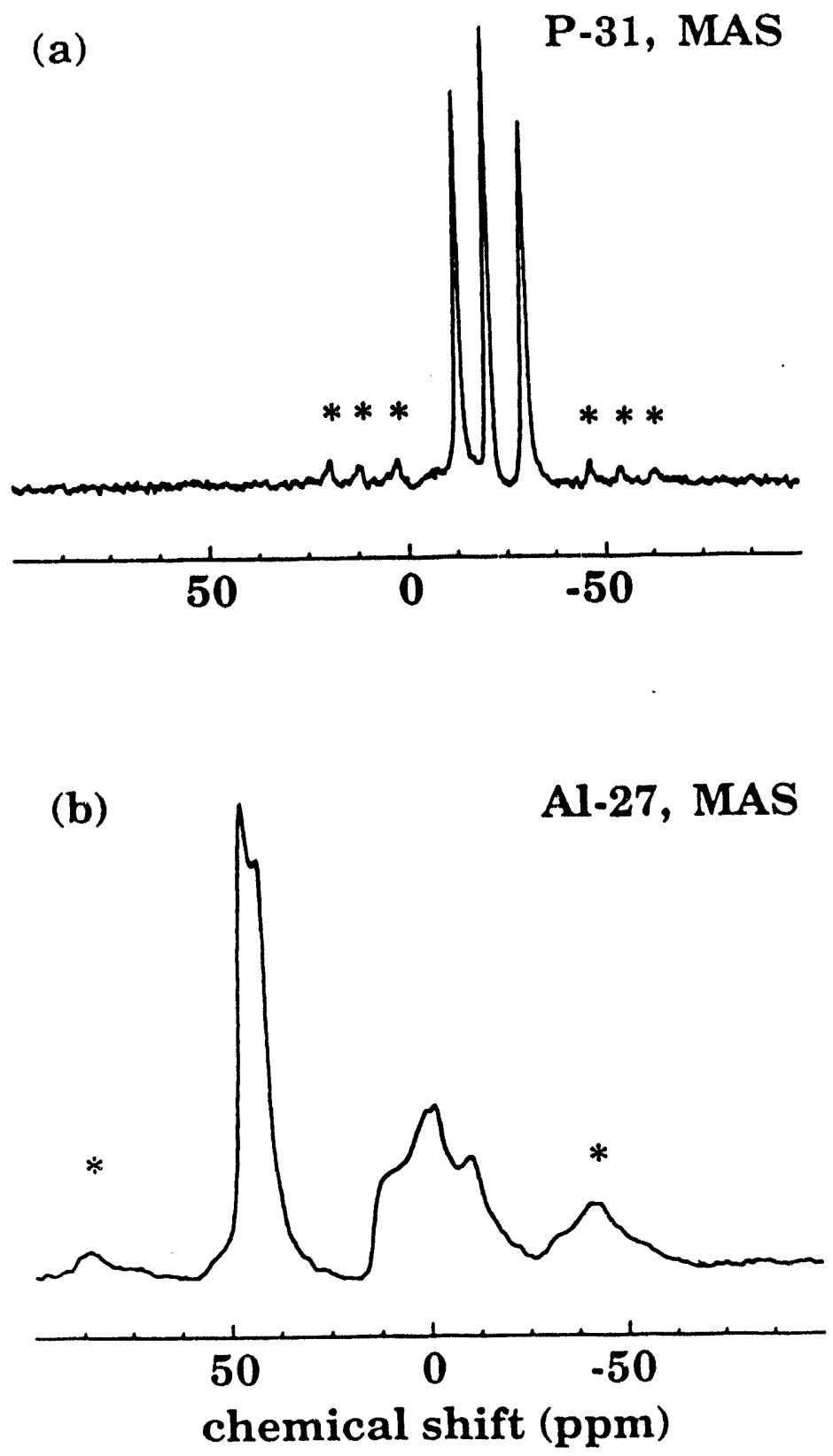

Figure 3.3: MAS spectra of $\mathrm{AlPO}_{4}-21$ acquired at $11.7 \mathrm{~T}$ : (a) ${ }^{31} \mathrm{P}$, and (b) ${ }^{27} \mathrm{Al}$. 


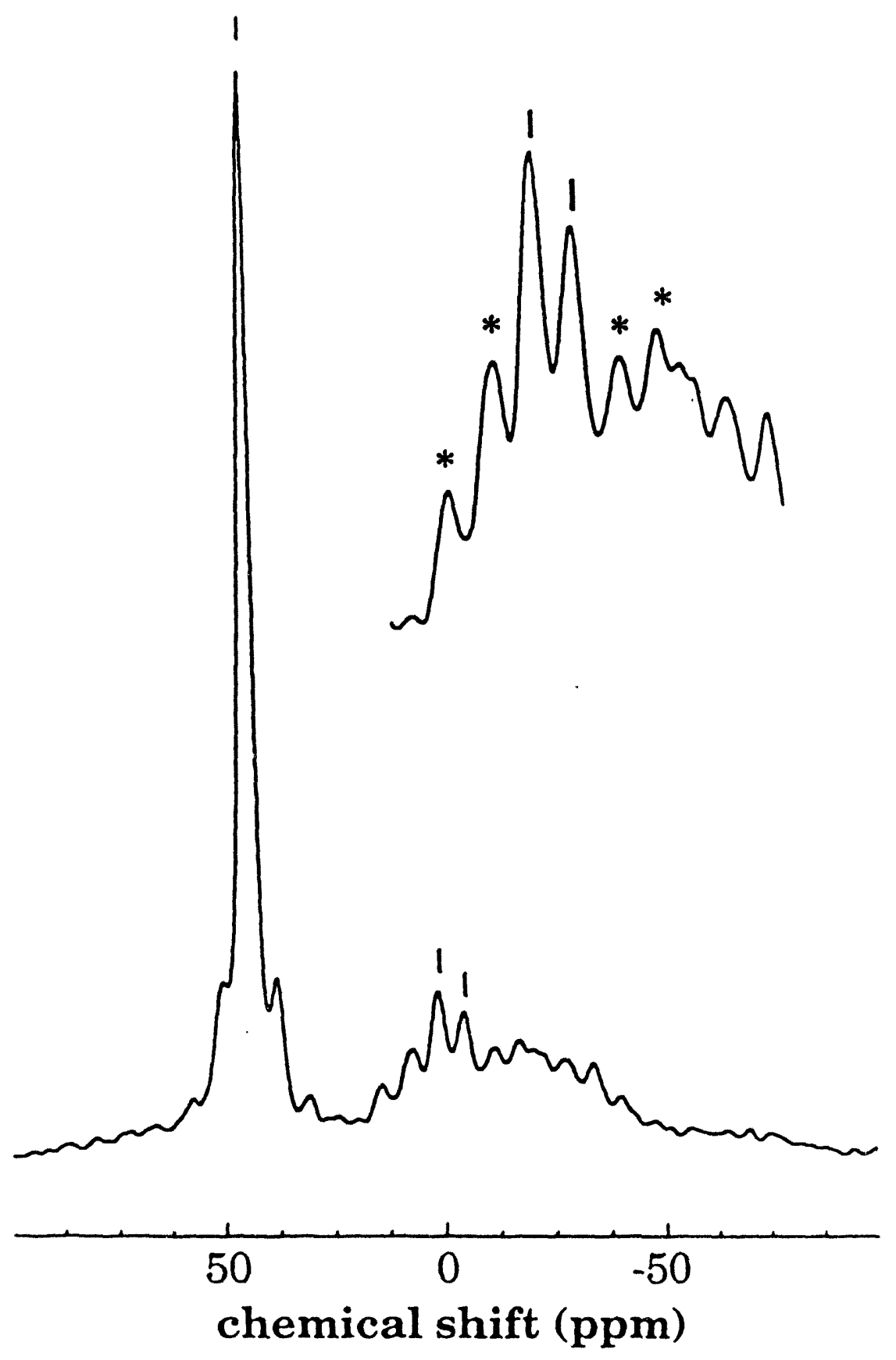

Figure 3.4: ${ }^{27} \mathrm{Al}$ DOR spectrum of $\mathrm{AlPO}_{4}-21$ acquired at $11.7 \mathrm{~T}$. The three distinct aluminum sites are indicated in the Figure, while the asterisks indicate spinning sidebands of the big rotor. 
making it difficult to quantify the relative amounts of aluminum at each site. The centerband peaks appear at their respective isotropic shifts, incorporating contributions from both the isotropic chemical shift, $\delta_{c s}$, and the isotropic second-order quadrupolar shift, $\delta_{Q, i s o}$, given by:

$$
\delta_{i s o, o b s}=\delta_{c s}+\delta_{Q, i s o}
$$

The isotropic quadrupolar shift $\delta_{Q, i s o}$ is related to the asymmetry parameter $\eta$, and the quadrupolar coupling constant $C_{Q} \equiv \frac{\mathrm{e}^{2} q Q}{h}$, by the equation:

$$
\delta_{Q, \text { iso }}(p p m)=-\frac{3\left[I(I+1)-\frac{3}{4}\right]}{40 I^{2}(2 I-1)^{2}}\left(1+\frac{\eta^{2}}{3}\right) \frac{C_{Q}^{2}}{\nu_{0}^{2}} \times 10^{6}
$$

where $I$ is the nuclear spin and $\nu_{0}$ is the resonance frequency.

The DOR results and spectral simulations of the MAS data, Figure 3.5, yield the quadrupolar parameters for the three sites shown in Table 3.1. It should be pointed out that the parameters obtained by Alemany et al. [36], upon fast spinning MAS, do not produce an acceptable fit to the experimental data here, Figure 3.5(c), although they fit rather well their experimental spectrum. In particular, the parameters obtained for the five-coordinated site $\mathrm{Al}(2)$ are significantly different from those reported previously, though there is good agreement for the other sites. This discrepancy may indicate greater sensitivity in one of the five-coordinate aluminum sites to the method of sample preparation.

The spectral simulation of the centerbands required an intensity ratio of $1: 0.3: 0.5$ for $\mathrm{Al}(1), \mathrm{Al}(2)$ and $\mathrm{Al}(3)$, respectively, which differs from the theoretical $1: 1: 1$ ratio. This difference occurs because of the relatively slow spinning speed achieved in the MAS experiment, resulting in a significant fraction of the signal from the five-coordinate aluminum to be contained in spinning sidebands. It is also possible 

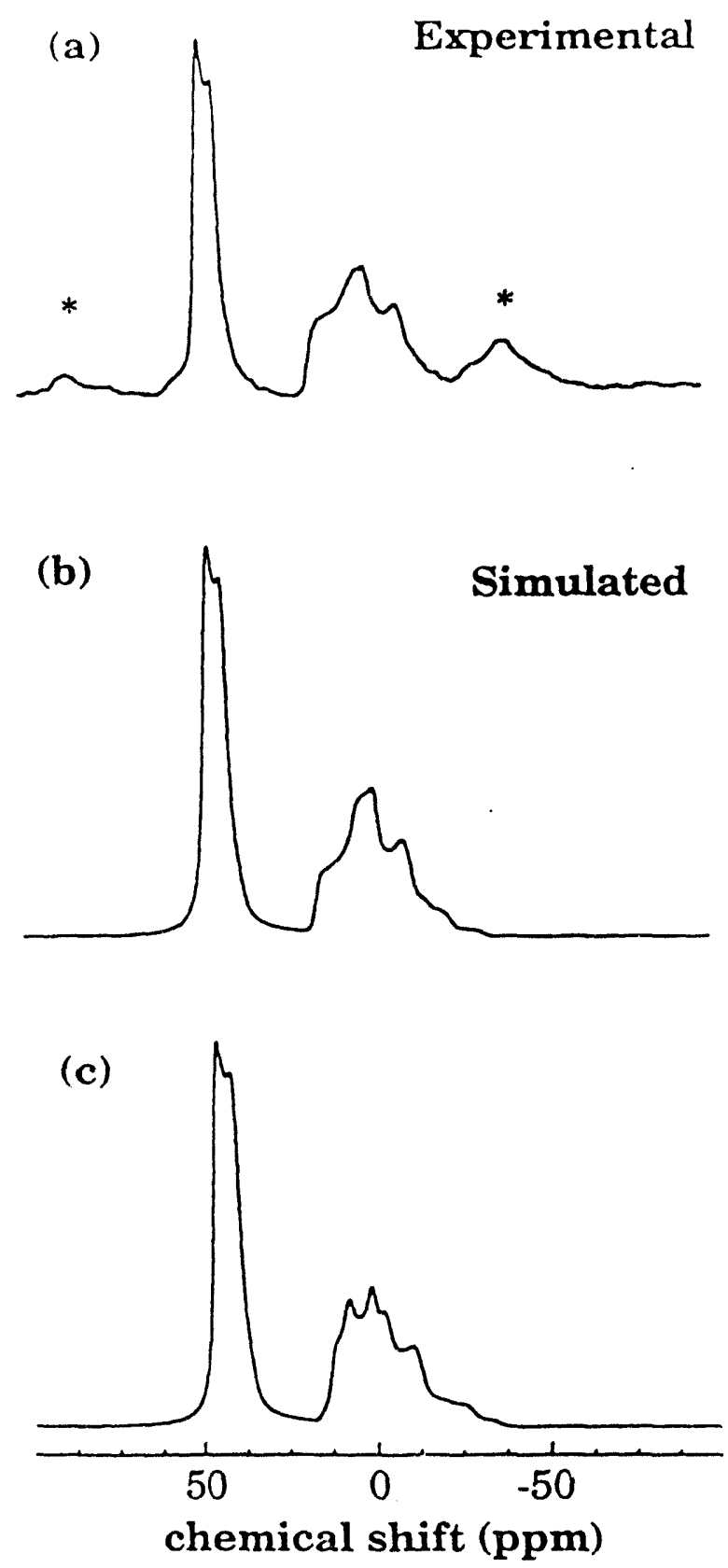

Figure 3.5: ${ }^{27} \mathrm{Al}$ MAS spectrum of $\mathrm{AlPO}_{4}-21$ acquired at $11.7 \mathrm{~T}$ and MAS computer simulations: (a) experimental; (b) spectral simulation using the parameters given in Table 3.1 with site intensity ratio of 1.0:0.3:0.5 $[\mathrm{Al}(1)$, $\mathrm{Al}(2)$, and $\mathrm{Al}(3)$, respectively; and (c) spectral simulation using the parameters given in ref. [36]. 
Table 3.1: Spectral and structural parameters, $\delta_{c s}, \eta, C_{Q} \equiv \frac{e^{2} q Q}{h}$, obtained from DOR results [using Equations 3.1 and 3.2] and simulations of ${ }^{27} \mathrm{Al}$ MAS spectra on $\mathrm{AlPO}_{4}-21$. Our values are compared with those of ref. [36].

\begin{tabular}{|c|c|c|c|c|c|c|c|c|}
\hline \multirow{2}{*}{\multicolumn{2}{|c|}{ site }} & \multirow{2}{*}{$\begin{array}{l}\delta_{i s o, o b s} \\
(\mathrm{ppm})\end{array}$} & \multicolumn{3}{|c|}{ Our MAS simulation } & \multicolumn{3}{|c|}{ Simulation of ref. [36] } \\
\hline & & & $\delta_{c s}(\mathrm{ppm})$ & $\eta$ & $C_{Q}(\mathrm{MHz})$ & $\delta_{c s}(\mathrm{ppm})$ & $\eta$ & $C_{Q}(\mathrm{MHz})$ \\
\hline $\mathrm{Al}(1)$ & $\mathrm{AlO}_{4}$ & 42.2 & 47.3 & 0.15 & 3.7 & 48 & 0.15 & 3.7 \\
\hline $\mathrm{Al}(2)$ & $\mathrm{AlO}_{5}$ & 0.4 & 14.6 & 0.68 & 5.9 & 14 & 0.4 & 5.1 \\
\hline $\mathrm{Al}(3)$ & $\mathrm{AlO}_{5}$ & -5.4 & 15.7 & 0.52 & 7.4 & 16 & 0.65 & 7.4 \\
\hline
\end{tabular}

that the excitation radio frequency $3 \mu \mathrm{sec}$ pulse was not sufficiently short for quantitative analysis of this system, in which the aluminum sites possers substantially different quadrupolar parameters. Further discussion on intensity aspects in DOR experiments is provided in Chapter 6 .

\section{$3.5 \quad \mathrm{AlPO}_{4}-25$}

The transformation of $\mathrm{AlPO}_{4}-21$ into $\mathrm{AlPO}_{4}-25$ is achieved upon removal of the organic template during calcination. The structure of dehydrated $\mathrm{AlPO}_{4}-25$ above $530 \mathrm{~K}$ has recently been solved by Rietveld refinement of neutron time-of-flight data [102], and is shown schematically in Figure 3.6. This high-temperature form of $\mathrm{AlPO}_{4}-25$ contains the same type of two-dimensional net as depicted in Figure 3.1 for $\mathrm{AlPO}_{4}-21$, but with an "up-down-up-down" chain of tetrahedra rather than the "up-up-down-down" arrangement in $\mathrm{AlPO}_{4}-21$. This produces two aluminum sites and two phosphnrus positions, both of which occur in population ratios of $2: 1$. At temperatures below $530 \mathrm{~K}$, dehydrated $\mathrm{AlPO}_{4}-25$ appears to adopt a lower symme- 


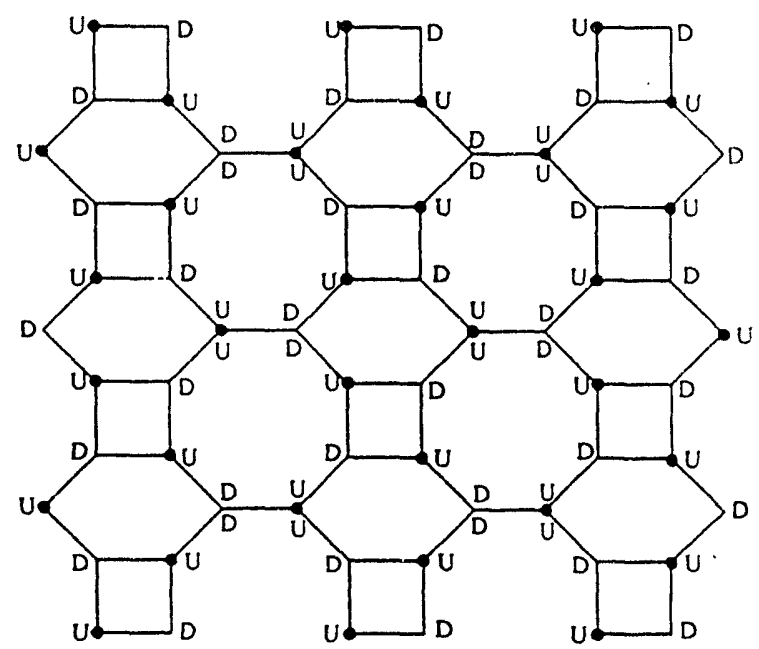

Figure 3.6: Idealized diagram of $\mathrm{AlPO}_{4}-25$ framework, using the same conventions as in Figure 3.1.

try structure [102]. The Rietveld structural refinement showed all aluminum and phosphorus atoms to be tetrahedrally coordinated, yet was unable to distinguish between the two.

Figure 3.7 features the ${ }^{31} \mathrm{P}$ and ${ }^{27} \mathrm{Al}$ MAS spectra of dehydrated $\mathrm{AlPO}_{4}-25$. The ${ }^{31} \mathrm{P}$ spectrum in Figure 3.7(a), acquired at $11.7 \mathrm{~T}$, contains a single broad peak at $-30.7 \mathrm{ppm}$, suggesting a range of similar $\mathrm{P}(\mathrm{OAI})_{4}$ environments. The ${ }^{27} \mathrm{Al}$ MAS spectra, obtained at 11.7 and $4.2 \mathrm{~T}$, Figures $3.7(\mathrm{~b})$ and (c), respectively, do not resolve the two aluminum sites in the material. In particular, the ${ }^{27} \mathrm{Al}$ MAS spectrum of dehydrated $\mathrm{AlPO}_{4}-25$ taken at $4.2 \mathrm{~T}$, Figure 3.7(c), features unresolved, quadrupolarly broadened ${ }^{27} \mathrm{Al}$ signals.

${ }^{27} \mathrm{Al}$ DOR spectra of dehydrated $\mathrm{AlPO}_{4}-25$ at two magnetic field strengths are shown in Figure 3.8. The two framework aluminum sites are not resolved in the ${ }^{27} \mathrm{Al}$ DOR spectrum of dehydrated $\mathrm{AlPO}_{4}-25$ recorded in an 11.7 Tesla field, Figure 3.8(a). They are clearly resolved, however, at 21.9 and $33.6 \mathrm{ppm}$, in the DOR 

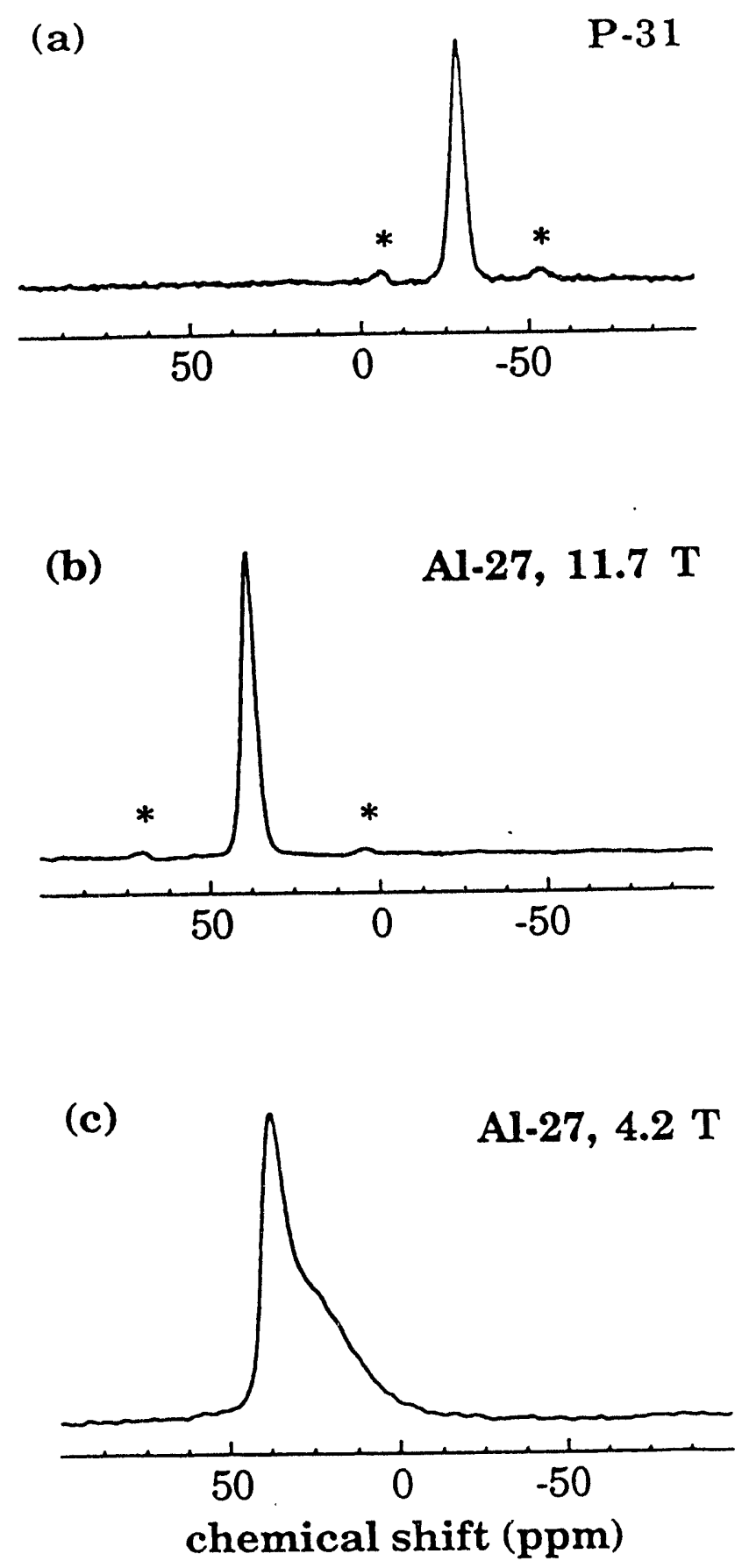

Figure 3.7: MAS Spectra of dehydrated $\mathrm{AlPO}_{4}-25:$ (a) ${ }^{31} \mathrm{P}$ acquired at $11.7 \mathrm{~T}$, (b) ${ }^{27} \mathrm{Al}$ acquired at $11.7 \mathrm{~T}$, and (c) ${ }^{27} \mathrm{Al}$ acquired at $4.2 \mathrm{~T}$. The spinning speed in the experiments was $5.5 \mathrm{kHz}$, and the asterisks indicate spinning sidebands. 

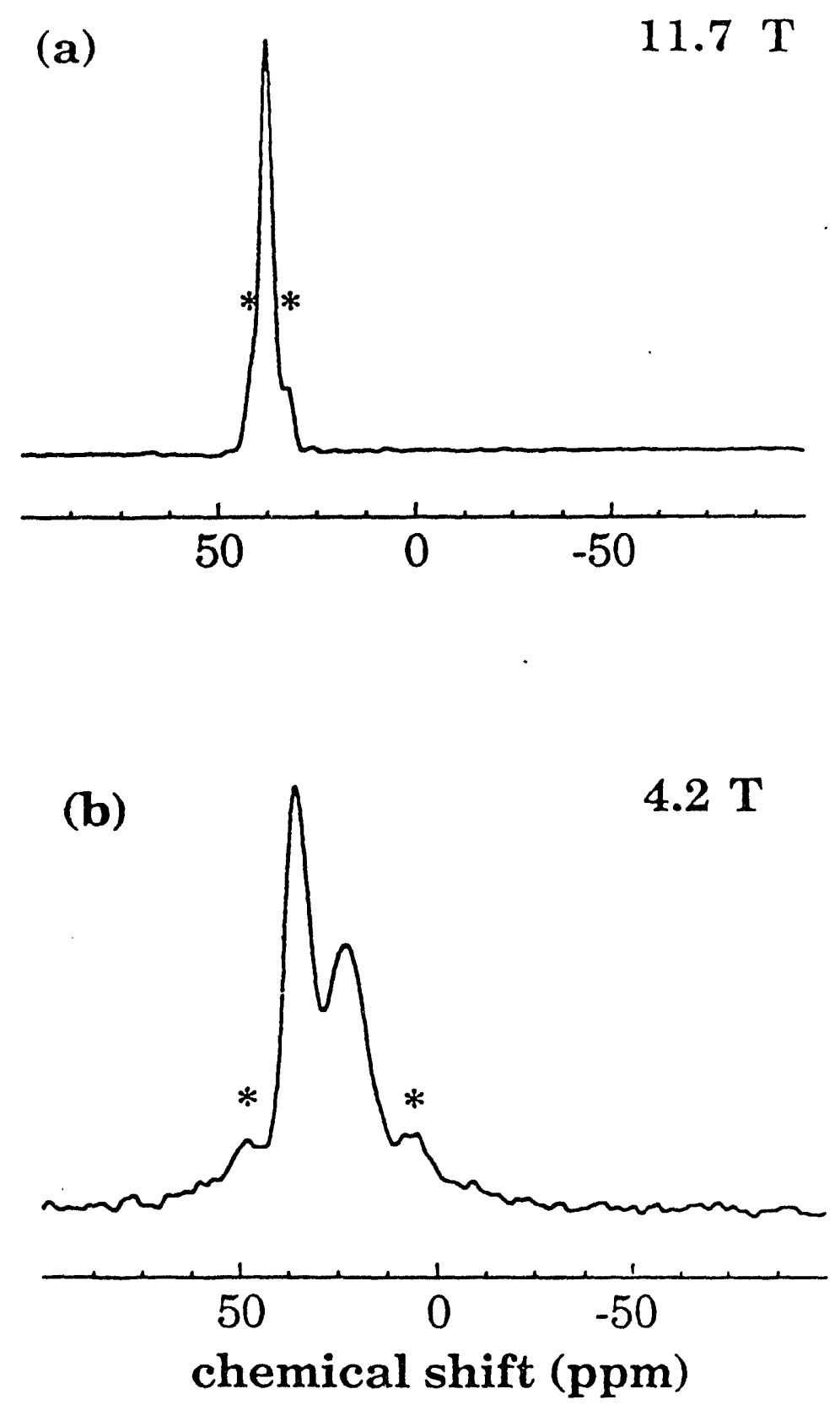

Figure 3.8: ${ }^{27} \mathrm{Al}$ DOR Spectra of dehydrated $\mathrm{AlPO}_{4}-25$ : (a) acquired at $11.7 \mathrm{~T}$, (b) acquired at $4.2 \mathrm{~T}$. Outer rotor spinning speed was $750 \mathrm{~Hz}$. The asterisks indicate spinning speed of the outer rotor. 
spectrum at 4.2 $\mathrm{T}$ shown in Figure 3.8(b). The two peaks correspond to the tetrahedral aluminum sites and have an intensity ratio of $2: 1$ as anticipated. The peaks overlap in the higher magnetic field since they have similar isotropic chemical shifts, and their isotropic quadrupolar shifts are comparatively small, see Equation 3.1.

The ${ }^{27} \mathrm{Al}$ DOR results shown in Figure 3.8 demonstrate that the use of lower magnetic fields might actually increase the resolution of NMR spectra of quadrupolar nuclei in some solid materials. DOR resonances associated with nuclei in structurally similar sites with small quadrupolar coupling constants might be distinguished in rather lower magnetic fields, at which greater isotropic quadrupolar shifts result [Equation 3.2]. On the other hand, high field DOR investigations facilitate the interpretation of spectra in cases where quadrupolar nuclei occupy distorted sites of low symmetry, for which the quadrupolar coupling constants may be large (>5 MHz). Indeed, the assignment of isotropic peak positions to the five-coordinated aluminum nuclei in $\mathrm{AlPO}_{4}-21$, Figure 3.4, is possible only at field strengths approaching $11.7 \mathrm{~T}$.

\subsubsection{Water Adsorption in $\mathrm{AlPO}_{4}-\mathbf{2 5}$}

Upon hydration, $\mathrm{AlPO}_{4}-25$ adsorbs approximately $0.145 \mathrm{~g}$ of water per $1 \mathrm{~g}$ of dehydrated material. The ${ }^{31} \mathrm{P}$ MAS spectrum of hydrated $\mathrm{AlPO}_{4}-25$ was almost identical to that of the dehydrated material, shown in Figure 3.7(a). ${ }^{27} \mathrm{Al}$ DOR spectra of the hydrated material are shown in Figure 3.9. At 11.7 T, Figure 3.9(a), the spectrum contains a main peak at $39.3 \mathrm{ppm}$, typical of tetrahedral $\mathrm{Al}(\mathrm{OP})_{4}$ species. This tetrahedral peak is broader than the corresponding resonance in dehydrated $\mathrm{AlPO}_{4}-25$, Figure 3.8(a), due to incomplete overlapping of the two 

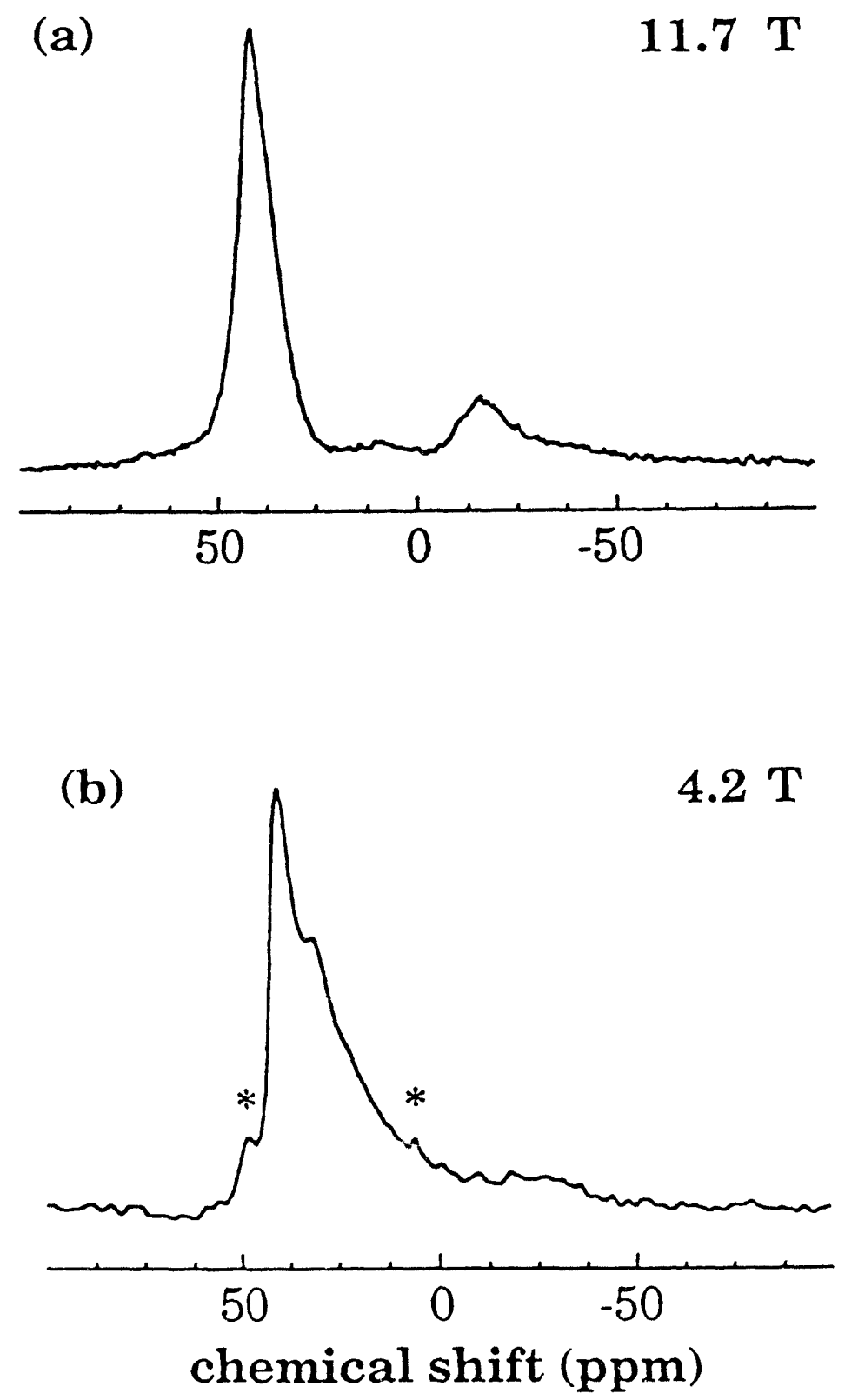

Figure 3.9: ${ }^{27} \mathrm{Al}$ DOR Spectra of hydrated $\mathrm{AlPO}_{4}-25$ : (a) acquired at $11.7 \mathrm{~T}$, (b) acquired at $4.2 \mathrm{~T}$. Outer rotor spinning speed was $650 \mathrm{~Hz}$. The asterisks indicate spinning sidebands of the outer rotor. 
tetrahedral sites, as well as embedded spinning sidebands.

The broad smaller feature near $-16 \mathrm{ppm}$ in Figure 3.9(a) reflects the existence of octahedrally coordinated framework aluminum bound to adsorbed water [44, 45]. Another broad signal can be observed between 0-10 ppm which indicates the presence of distorted aluminum environments and possibly extra-framework species. Distorted aluminum environments may arise from intermediate-hydration, 5-coordinated, aluminum nuclei which give rise to ${ }^{.27} \mathrm{Al}$ resonance in the range between tetrahedral and octahedral aluminum. This assignment is supported by the positions of the ${ }^{27} \mathrm{Al}$ DOR peaks from distorted 5-coordinated aluminum sites in $\mathrm{AlPO}_{4}-21$, Figure 3.4 .

The ${ }^{27} \mathrm{Al}$ DOR spectrum at $4.2 \mathrm{~T}$, Figure $3.9(\mathrm{~b})$, reveals the splitting between the two tetrahedral aluminum sites, as well as a broad signal at lower frequency. The positions of the two tetrahedral resonances in the hydrated and dehydrated materials, and their structural parameters, calculated using Equations 3.1 and 3.2, are shown in Table 3.2. The "qudrupolar product", $P_{Q}=\left(1+\frac{\eta^{2}}{3}\right) C_{Q}^{2}$, is calculated using Equation 3.2.

Examining Table 3.2 reveals that the quadrupolar shifts are smaller for the hydrated sample than the dehydrated material. This observation indicates that hydration confers a more symmetric environment to the tetrahedral aluminum sites. This result reflects as well the greater strain in the aluminophosphate framework of the dehydrated sample. It should be emphasized that the occurance of symmetry changes in the environments of the framework aluminum atoms is a strong indication that framework aluminum atoms are directly involved in the adsorption process. A detailed study of the structural changes undergone by framework 
Table 3.2: Isotropic quadrupolar shifts, $\delta_{Q, i s o}$, and chemical shifts, $\delta_{c s}$, calculated for the two tetrahedral aluminum sites in dehydrated and hydrated $\mathrm{AlPO}_{4}-25$. The quadrupolar product, $P_{Q}=\left(1+\frac{\eta^{2}}{3}\right) C_{Q}^{2}$, is calculated using Equation 3.2.

\begin{tabular}{|ll|l|l|}
\hline \hline & & Dehydrated $\mathrm{AlPO}_{4}-25$ & Hydrated $\mathrm{AlPO}_{4}-25$ \\
\hline Site A & & $\delta_{c s}=39.2 \mathrm{ppm}$ & $\delta_{c s}=40.8 \mathrm{ppm}$ \\
& $11.7 \mathrm{~T}$ & $\delta_{Q, \text { iso }}=-2.2 \mathrm{ppm}$ & $\delta_{Q, \text { iso }}=-1.5 \mathrm{ppm}$ \\
& $4.2 \mathrm{~T}$ & $\delta_{Q, \text { iso }}=-17.3 \mathrm{ppm}$ & $\delta_{Q, \text { iso }}=-11.7 \mathrm{ppm}$ \\
& & $P_{Q}=6.2 \mathrm{MHz}$ & $P_{Q}=4.3 \mathrm{MHz}$ \\
\hline \multirow{2}{*}{ Site B } & & $\delta_{c s}=37.5 \mathrm{ppm}$ & $\delta_{c s}=39.5 \mathrm{ppm}$ \\
& $11.7 \mathrm{~T}$ & $\delta_{Q, i s o}=-0.5 \mathrm{ppm}$ & $\delta_{Q, \text { iso }}=-0.3 \mathrm{ppm}$ \\
& $4.2 \mathrm{~T}$ & $\delta_{Q, i s o}=-3.9 \mathrm{ppm}$ & $\delta_{Q, \text { iso }}=-2.3 \mathrm{ppm}$ \\
& & $P_{Q}=1.4 \mathrm{MHz}$ & $P_{Q}=0.8 \mathrm{MHz}$ \\
\hline
\end{tabular}

aluminum atoms upon water adsorption is presented in Chapter 4 .

The fact that the two tetrahedral aluminum sites in $\mathrm{AlPO}_{4}-25$ experience different quadrupolar interactions provides further insight into the framework of the aluminophosphate material. In Table 3.2, site A corresponds to aluminum at the nodes sharing 6,8 and 8 rings of the framework [see Figure 3.6]. It is not possible for both the 6 rings and 8 rings to be regular in the $\mathrm{AlPO}_{4}-25$ structure, thus the tetrahedron at site $\mathrm{A}$ is expected to be quite distorted, accounting for its high quadrupolar product. Site B corresponds to aluminum sharing 4,6 and 8 rings, and will have a more symmetric environment.

The extremely broad resonance between zero and $-50 \mathrm{ppm}$, observed at $4.2 \mathrm{~T}$ for the hydrated sample, Figure $3.9(\mathrm{~b})$, is assigned primarily to octahedrallycoordinated framework aluminum and a range of distorted environments. It is 
difficult to determine population ratios of the various aluminum sites in hydrated $\mathrm{AlPO}_{4}-25$ owing to the broad linewidths. It seems, however, that both tetrahedral aluminum sites in the framework are affected by water to approximately the same extent; the change of the isotropic quadrupolar and chemical shift contributions upon hydration is nearly identical for both sites.

\subsection{Conclusions}

High resolution NMR data of aluminum nuclei in the framework of $\mathrm{AlPO}_{4}-21$ and $\mathrm{AlPO}_{4}-25$ is obtained using ${ }^{27} \mathrm{Al}$ DOR. The spectra of aluminum species display substantially narrower peaks compared with the second-order quadrupolar broadened lineshapes present under MAS conditions. For $\mathrm{AlPO}_{4}-21$, isotropic shifts are obtained for aluminum in one tetrahedral and two five-coordinated environments. The enhanced resolution provided by DOR, combined with MAS spectral simulations, yield quadrupolar parameters for the three sites.

During calcination, $\mathrm{AlPO}_{4}-21$ is structurally transformed to $\mathrm{AlPO}_{4}-25$, which contains two different tetrahedral aluminum sites which are resolved by DOR at 4.2 T. The tetrahedral aluminum environments conform to higher symmetry upon hydration, relieving the strain present in the framework of the dehydrated material. The water molecules adsorbed in the channels produce octahedral aluminum configurations and probably other distorted environments as well. The quadrupolar parameters of the ${ }^{27} \mathrm{Al}$ sites are obtained by carrying out the DOR experiments at two magnetic field strengths. 


\section{Chapter 4}

\section{Adsorption Effects in}

\section{Aluminophosphate Molecular}

\section{Sieves Studied by ${ }^{27} \mathrm{Al}$}

\section{Double-Rotation}

\subsection{Abstract}

${ }^{27} \mathrm{Al} \mathrm{DOR}$ is employed to investigate structural changes in the framework of several aluminophosphate molecular sieves upon adsorption of water. The shapes, widths, and positions of the spectral lines yield information on the aluminum environments, adsorption sites, and degree of structural disorder caused by water adsorption. 


\subsection{Introduction}

The absence of extraframework charge-balancing cations in aluminophosphate molecular sieves means that the phosphorus and aluminum atoms in the framework significantly determine the adsorption properties of the materials. It is important, therefore, to accurately characterize the environments of the tramework atums in these materials. The alternation of $\mathrm{AlO}_{4} / \mathrm{PO}_{4}$ tetrahedra in the framework provides a particular advantage for NMR investigations. As discussed in Chapter 2, a large number of studies have used ${ }^{31} \mathrm{P}$ and ${ }^{27} \mathrm{Al} \mathrm{NMR}$ to obtain structural information on the framework, adsorption processes, and interactions of guest molecules with the internal surface of aluminophosphate molecular sieves.

Hydration is by far the most widely studied adsorption phenomenon in aluminophosphate molecular sieves $[20,37,39,40,41,42,44,45,46,49,50,103,104]$. Characterization of the interactions between water molecules and the aluminophosphate framework is, in principle, a useful model system for the study of adsorption processes. Water molecules are smaller than the pore openings of most molecular sieves [dynamical diameter of $\mathrm{H}_{2} \mathrm{O}$ is $2.2 \AA$ [105]], which assures their incorporation within the channels. This property, as well as the polarity of the water molecules, might explain the interesting characteristics of hydrated aluminophosphates; several studies have proposed a secondary structure of adsorbed $\mathrm{H}_{2} \mathrm{O}$ upon the internal surface of some aluminophosphates $[42,45,49,50,104]$.

${ }^{27} \mathrm{Al}$ DOR spectra of several porous aluminophosphate molecular sieves are presented in this chapter, and the information they provide on the process of water adsorption within the channels is discussed. Specifically, the increased resolution obtained with the DOR technique facilitates reliable interpretation of spectral fea- 
tures. The NMR experiments provide insight on changes in the structures and ordering of the framework aluminum, which occur upon the adsorption of $\mathrm{H}_{2} \mathrm{O}$ molecules.

\subsection{Experimental Considerations}

${ }^{27} \mathrm{Al}$ DOR experiments were carried out in an 11.7 Tesla magnetic field, using a home-built DOR probe whose features are described elsewhere [99]. Spinning speeds of $5 \mathrm{kHz}$ for the inner rotor and $600-700 \mathrm{~Hz}$ for the outer one were used. Short, $30^{\circ}$, radio-frequency pulses were employed with $0.5 \mathrm{~s}$ recycle delays. All spectra are referenced to $0.1 \mathrm{M} \mathrm{Al}(\mathrm{NO})_{3}$, used as an external standard.

Dehydration of the materials was carried out at $\approx 10^{-4}$ torr according to the procedures described below: VPI-5 was evacuated at room temperature for $72 \mathrm{hrs}$; $\mathrm{AlPO}_{4}-5$ was evacuated at room temperature for $48 \mathrm{hrs}$, followed by $5 \mathrm{hrs}$ at $473 \mathrm{~K}$. The $\mathrm{AlPO}_{4}-8$ sample was initially prepared by thermal decomposition of nascent VPI -5 at $373 \mathrm{~K}$ for $4 \mathrm{hrs}[41,109]$, with subsequent dehydartion carried out by room temperature evacuation for $48 \mathrm{hrs}$. The samples were packed into the DOR rotor in a dry argon glove-box under rigorous anaerobic conditions. Water content of partially hydrated samples was determined by comparing the weight of the partially hydrated sample to the fully dehydrated material.

\subsection{VPI -5}

Figure 4.1 shows a schematic drawing of dehydrated VPI-5 structure, and the

${ }^{27}$ Al DOR spectra of the material in several hydration stages. This molecular sieve, 


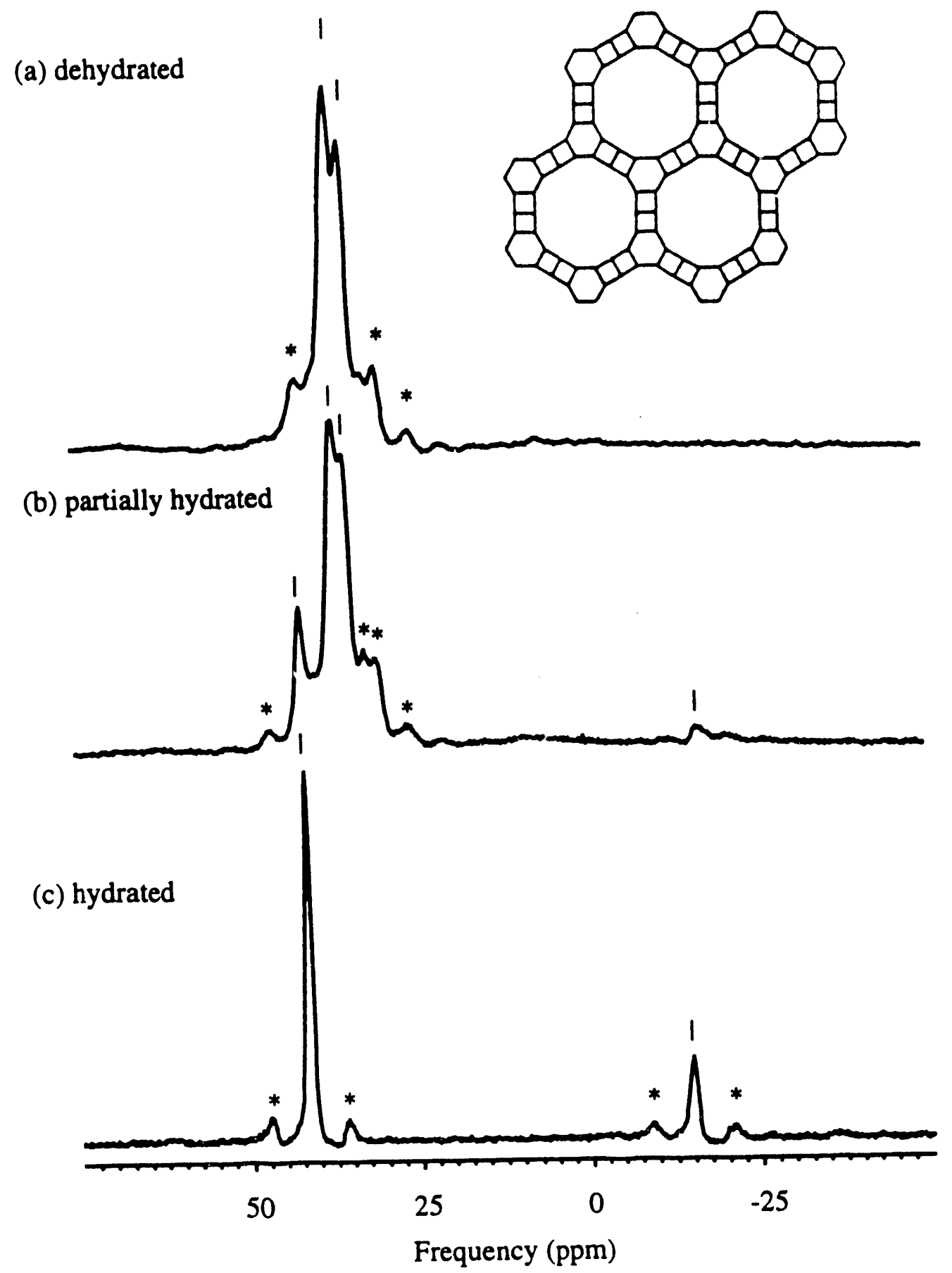

Figure 4.1: A schematic diagram of the dehydrated structure of VPI-5; and ${ }^{27} \mathrm{Al}$ DOR spectra of VPI-5, taken at $11.7 \mathrm{~T}$, of (a) dehydrated; (b) partially hydrated; (c) hydrated. The asterisks indicate spinning sidebands of the outer rotor. 
with 18-membered ring channels, has a large, $12 \AA$, pore diameter [43], and two aluminum and phosphorus crystallographic sites. Two tetrahedrally coordinated framework aluminum sites are resolved at $36.2 \mathrm{ppm}$ and $34.2 \mathrm{ppm}$, respectively, in the dehydrated sample, Figure 4.1(a), while the peaks overlap completely at $41.2 \mathrm{ppm}$ in the hydrated material, as shown in Figure $4.1(\mathrm{c})$. The two aluminum sites in the hydrated sample are not resolved at $11.7 \mathrm{~T}$, because they have similar isotropic chemical shift values. The aluminum sites, however, exhibit quite different quadrupolar parameters which enable the two ${ }^{27} \mathrm{Al}$ DOR resonances to be resolved in hydrated VPI-5 in a lower magnetic field strength $[50,106]$.

In an intermediate hydration stage, Figure $4.1(\mathrm{~b})$, one observes changes in the spectral region associated with the tetrahedral aluminum environments, at around $35 \mathrm{ppm}$. A distinct ${ }^{27} \mathrm{Al}$ environment appears at $39 \mathrm{ppm}$, as well as a small upfield signal at around $-16 \mathrm{ppm}$. Thus, the ${ }^{27} \mathrm{Al}$ DOR spectra indicate that water adsorption clearly affects the tetrahedral aluminum sites in the framework of VPI-5, and gives rise to different aluminum environments in the framework. The upfield ${ }^{27} \mathrm{Al}$ resonance, at $-16 \mathrm{ppm}$, is assigned to octahedral aluminum species formed upon sorption of two water molecules onto the framework tetrahedral ${ }^{27} \mathrm{Al}$. The DOR spectra are reproduced upon successive hydration/dehydration treatments, indicating that the water adsorption process is fully reversible, and the six-coordinated aluminum is essentially part of the framework.

The positions of the two tetrahedral ${ }^{27} \mathrm{Al}$ peaks in VPI-5 shift upon water adsorption, as shown in Figure 4.1. This observation indicates that both the aluminum site located between the four-, and six-membered rings in the VPI-5 framework [which corresponds to the signal at $36.2 \mathrm{ppm}$ ], as well as the aluminum site between 
the two four-membered rings [which gives rise to the ${ }^{27} \mathrm{Al}$ DOR signal at $34.2 \mathrm{ppm}$ ], experience structural changes upon adsorption of water.

The widths of the resonance lines observed in DOR experiments can provide additional information on the systems investigated. In principle, the DOR technique completely averages out the anisotropic components of the NMR resonances, such as the dipole-dipole coupling, and the anisotropic quadrupolar interaction [8]. Thus, the DOR linewidths are essentially determined by the distribution of chemical environments at a given crystallographic site. In the case of VPI-5, Figure 4.1, the widths of the signals do not change appreciably upon the addition of water, indicating that the short-range ordering of the aluminum environments is retained throughout the adsorption process.

Ordering is also evident in the six-coordinated aluminum environments, since the width of the resonance at around $-16 \mathrm{ppm}$, Figure 4.1(c), is comparable to the peaks ascribed to the tetrahedral aluminum species. The sharp ${ }^{27} \mathrm{Al}$ resonance at $-16 \mathrm{ppm}$ stands in contrast to the rather broad upfield feature associated with octahedral aluminum in hydrated $\mathrm{AlPO}_{4}-25$, see Chapter 3 , Figure 3.9. This result provides additional support for a model of secondary structure of water molecules in the channels of VPI-5, which war proposed by previous diffraction and NMR studies $[42,49,104]$.

\section{5 $\mathrm{AlPO}_{4}-5$}

Different results are obtained for $\mathrm{AlPO}_{4}-5$. This aluminophosphate molecular sieve exhibits significantly narrower channels, $7 \AA$-diameter, which are formed by 12-membered rings [107]. Figure 4.2 shows a schematic drawing of the dehydrated 

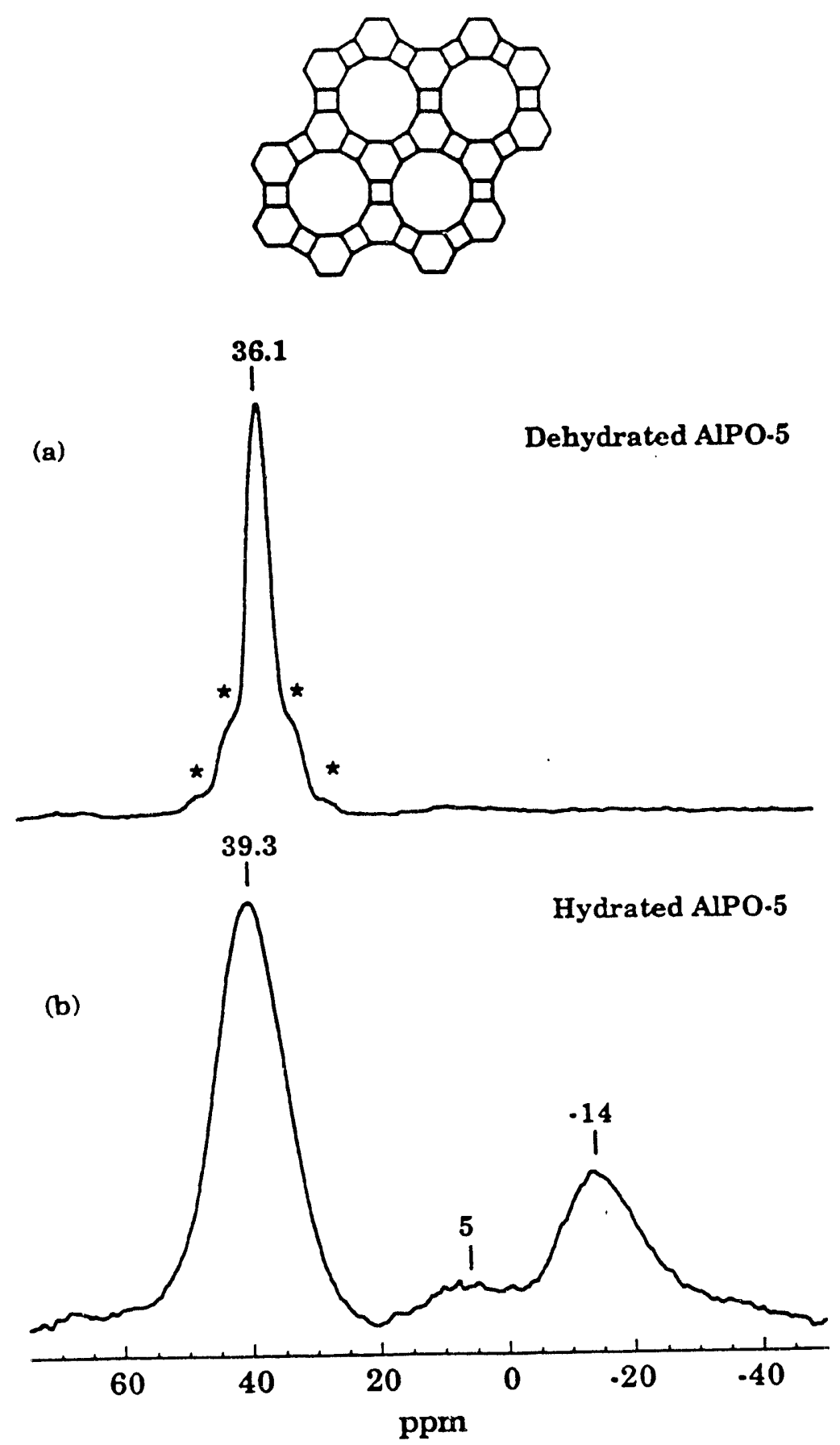

Figure 4.2: A schematic diagram of the dehydrated structure of $\mathrm{AlPO}_{4}-5$; and ${ }^{27} \mathrm{Al}$ DOR spectra of (a) dehydrated $\mathrm{AlPO}_{4}-5$; (b) hydrated $\mathrm{AlPO}_{4}-5$. The asterisks indicate spinning sidebands of the outer rotor. 
structure of $\mathrm{AlPO}_{4}-5$, and the ${ }^{27} \mathrm{Al}$ DOR spectra of the dehydrated and hydrated samples. The framework of dehydrated $\mathrm{AlPO}_{4}-5$ contains a single tetrahedral aluminum environment [107], which gives rise to the single sharp Gaussian peak at $36.1 \mathrm{ppm}$ in Figure 4.2(a).

The spectrum of the hydrated material, shown in Figure 4.2(b), features two prominent signals, at around $39 \mathrm{ppm}$ and $-14 \mathrm{ppm}$, respectively. Both are substantially broader than the resonance observed in the ${ }^{27} \mathrm{Al} \mathrm{DOR}$ spectrum of the dehydrated material in Figure 4.2(a). The downfield peak, at around $39 \mathrm{ppm}$, is ascribed to tetrahedrally coordinated aluminum species, while the peak at around $-15 \mathrm{ppm}$ corresponds to six-coordinated environments. The small hump which is observed in the vicinity of $0 \mathrm{ppm}$ probably arises from aluminum sites with intermediate coordinations, most likely (nominally) five-coordinated ${ }^{27} \mathrm{Al}$ species, which have been observed to produce DOR resonances in this spectral region $[34,108]$.

The broad spectral lines in the ${ }^{27} \mathrm{Al}$ DOR spectrum of hydrated $\mathrm{AlPO}_{4}-5$, Figure 4.2 (b), indicate diminished structural ordering, particularly compared to the highly ordered hydrated VPI-5 framework, which yields the narrow peaks in Figure 4.1(c). Previous studies have proposed the formation of hydroxide defect sites within the framework of $\mathrm{AlPO}_{4}-5$ upon water adsorption [103], which might lead to broadening of the spectral lines. In addition, adsorption of water molecules nonselectively within the relatively narrow channels of $\mathrm{AlPO}_{4}-5$ may also contribute to the broad, featureless signals in the hydrated material, Figure 4.2(b). Non-selective adsorption might consequently produce a large distribution of ${ }^{27} \mathrm{Al}$ environments which would spread the NMR frequencies over a comparatively large spectral range. 


\section{6 $\mathrm{AlPO}_{4}-8$}

As discussed above, the channel sizes of aluminophosphate molecular sieves might influence their adsorption properties. In order to check this possibility, water adsorption in $\mathrm{AlPO}_{4}-8$ was examined. The framework of this aluminophosphate, which is produced upon structural transformation of VPI-5 under thermal treatment [109], contains 14-membered ring channels with $8.7 \AA$ diameters [110]. $\mathrm{AlPO}_{4}-8$ exhibits five distinct aluminum crystallographic sites in its dehydrated framework $[109,110]$, and has been a challenging material for solid state ${ }^{27} \mathrm{Al}$ NMR studies $[41,111]$.

The ${ }^{27} \mathrm{Al}$ DOR spectra of $\mathrm{AlPO}_{4}-8$ containing different amounts of adsorbed water are shown in Figure 4.3. The DOR spectrum of dehydrated $\mathrm{AlPO}_{4}-8$, Figure 4.3(a), is not resolved into specific ${ }^{27} \mathrm{Al}$ sites, probably because of overlapping signals from the five distinct aluminum sites in the dehydrated material. In addition, a relatively high degree of aluminum disorder most likely accounts for the unresolved ${ }^{27} \mathrm{Al}$ signals, though $\mathrm{X}$-ray diffraction experiments show the material to be highly crystalline [110].

Figure $4.3(\mathrm{~b})-(\mathrm{e})$ features ${ }^{27} \mathrm{Al}$ DOR spectra of partially hydrated $\mathrm{AlPO}_{4}-8$. The weight percentage of the adsorbed water was determined after exposing the dehydrated material in the DOR rotor to atmospheric conditions for short time periods. From Figure 4.3, it is apparent that structural changes occur both in the tetrahedral aluminum sites, detected in the NMR spectra at around $40 \mathrm{ppm}$, as well as in the six-coordinated environments, which appear further upfield at around -15 ppm. Specifically, one can detect narrowing of the two downfield peaks, at $40 \mathrm{ppm}$ and $43.5 \mathrm{ppm}$, as greater amount of water is adsorbed onto $\mathrm{AlPO}_{4}-8$ 


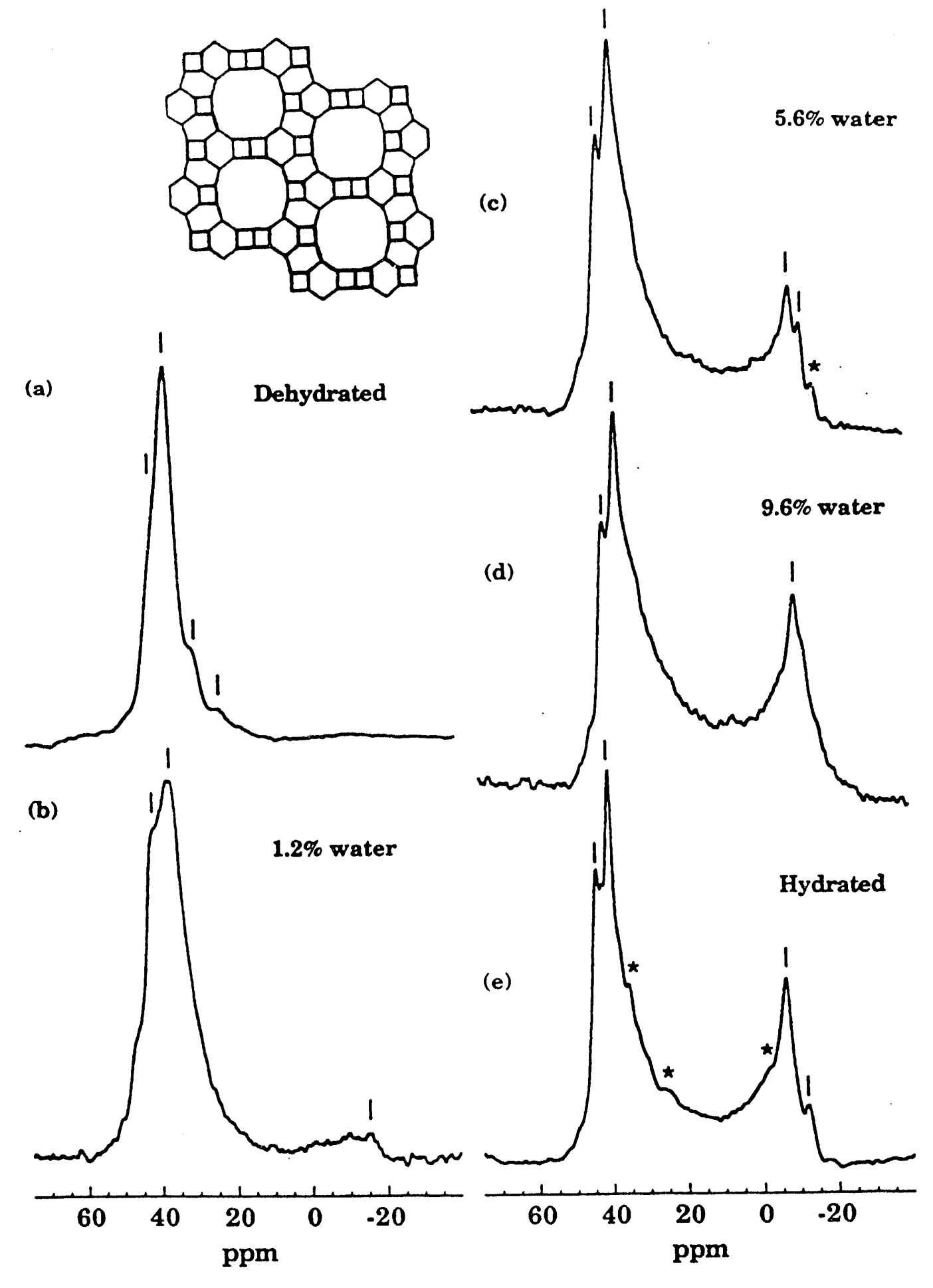

Figure 4.s: $\dot{A}$ schematic diagram of the dehydrated structure of $\mathrm{AlPO}_{4}-8$; and ${ }^{27} \mathrm{Al}$ DOR spectra for various water loadings: (a) dehydrated $\mathrm{AlPO}_{4}-8$; (b) 1.2 wt\% water; (c) $5.6 \mathrm{wt} \%$ water; (d) $9.6 \mathrm{wt} \%$ water; (e) fully hydrated $\mathrm{AlPO}_{4}-8$. The asterisks indicate spinning sidebands of the outer rotor. 
framework. Similarly, the octahedral aluminum environments exhibit significant sensitvity to water adsorption; one detects at least two sites at around $-15 \mathrm{ppm}$, with the positions shifting somewhat as the water content is increased.

The ${ }^{27} \mathrm{Al} \mathrm{DOR}$ results obtained for $\mathrm{AlPO}_{4}-8$ indicate that distinct hydration sites most likely exist within the framework. These adsorption sites give rise to the sharp tetrahedral and octahedral ${ }^{27} \mathrm{Al}$ peaks that emerge in the spectra upon incorporation of water. ${ }^{27} \mathrm{Al}$ quadrupolar nutation analysis, combined with ${ }^{1} \mathrm{H}-$ ${ }^{27} \mathrm{Al}$ cross-polarization (CP) experiments [111], have also detected the appearance of specific hydration sites within $\mathrm{AlPO}_{4}-8$ framerwork. Similar interpretation is apparent in recent CP-DOR results [112].

The broad ${ }^{27} \mathrm{Al}$ signal observed between the regions of the two prominent resonances in the spectra of the partially-, and fully-hydrated materials, Figure 4.3(b)(e), indicates a continuous distribution of ${ }^{27} \mathrm{Al}$ environments, between the relatively ordered four- and six-coordinated species. This result stands in contrast to the ${ }^{27} \mathrm{Al}$ DOR spectra of VPI-5, Figure 4.1 , which indicate that hydration does not conform intermediate aluminum coordination in the latter material. The distinct and sharp ${ }^{27} \mathrm{Al}$ resonances observed in the ${ }^{27} \mathrm{Al}$ DOR spectra of VPI-5, Figure 4.1, compared with both $\mathrm{AlPO}_{4}-5$, and $\mathrm{AlPO}_{4}-8$, might again point to a relationship between the channel size and ordering in the aluminophosphate framework upon adsorption of water.

High resolution transmission electron microscopy (HRTEM) experiments were conducted to determine the extent of structural ordering of $\mathrm{AlPO}_{4}-8$ [113]. The TEM image of $\mathrm{AlPO}_{4}-8$, shown in Figure 4.4, indicates an abundance of stacking faults perpendicular to the long axis of the crystalline $\mathrm{AlPO}_{4}-8$. This observation is 


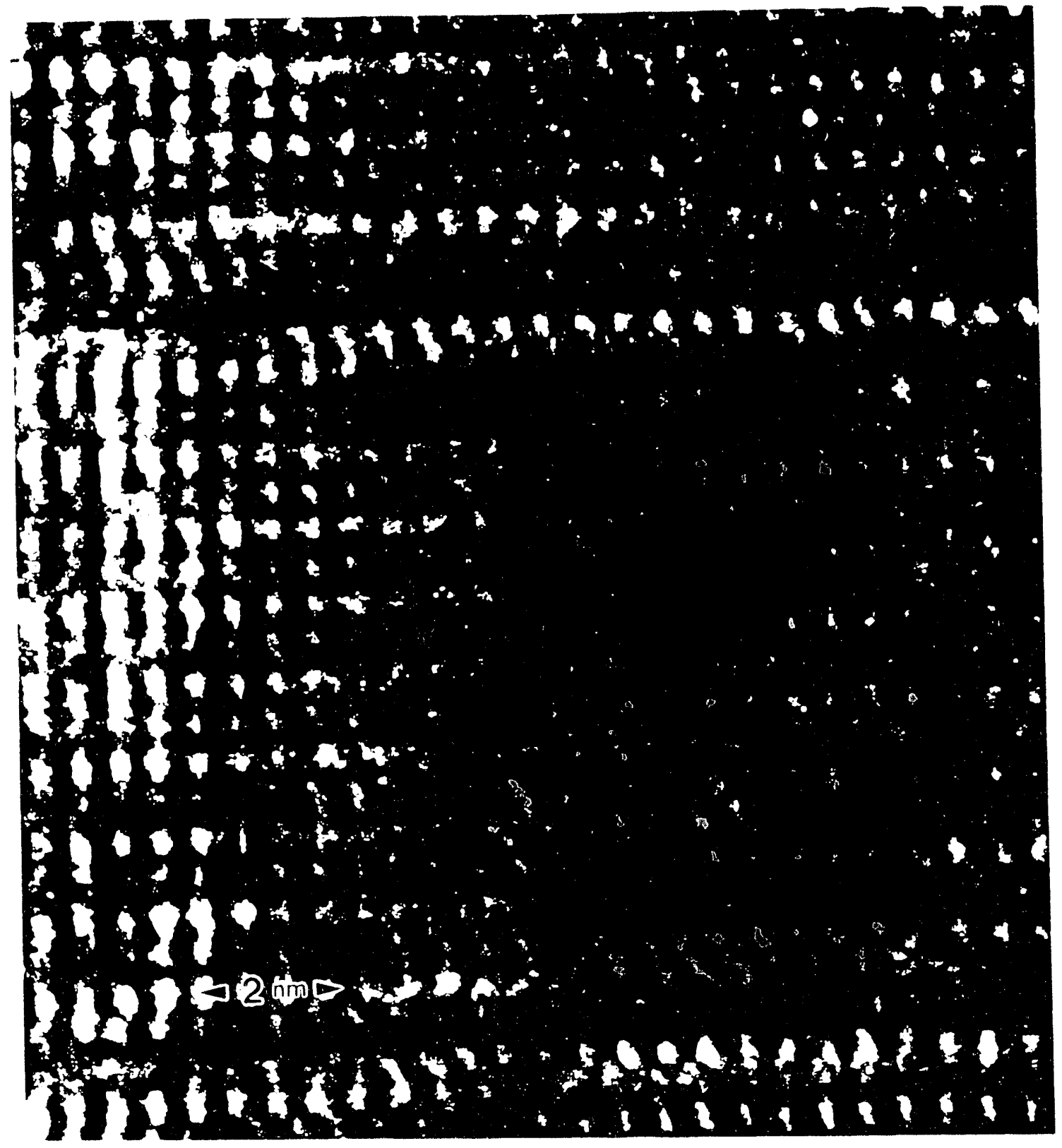

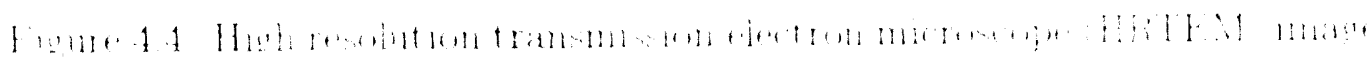

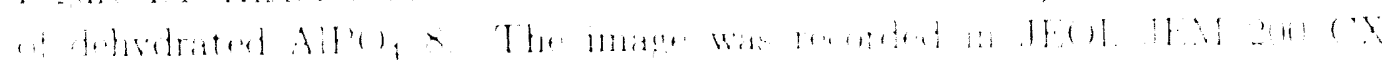

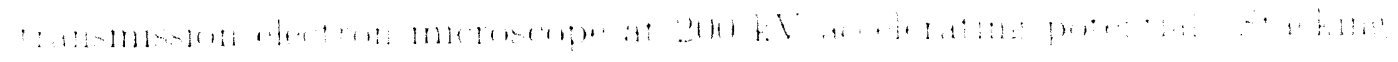


consistent with the local aluminum disorder in dehydrated $\mathrm{AlPO}_{4}-8$, manifested by the broad lines in the ${ }^{27} \mathrm{Al}$ DOR spectrum shown in Figure 4.3(a). The appearance of stacking disorder throughout the aluminophosohate material could produce a large distribution of aluminum environments, that would broaden the ${ }^{27} \mathrm{Al}$ spectral lines observed for dehydrated $\mathrm{AlPO}_{4}-8$, as well as for $\mathrm{AlPO}_{4}-8$ in a state of incipient hydration, Figure 4.3(b). These stacking disorders may additionally contribute to the broad distribution of the aluminum environments between $0 \mathrm{ppm}$ and $20 \mathrm{ppm}$, Figure 4.3(c)-(e).

\subsection{Conclusions}

${ }^{27} \mathrm{Al}$ DOR provides useful information on water adsorption processes in aluminophosphate molecular sieves. The sensitivity of different sites to the addition of water molecules is examined through the positions of the ${ }^{27} \mathrm{Al}$ resonances, with the shapes and widths of the peaks providing additional insight on local ordering of framework aluminum sites. Different adsorption properties are detected at a molecular level for VPI-5, $\mathrm{AlPO}_{4}-5$, and $\mathrm{AlPO}_{4}-8$, reflecting a probable connection between sieve channel dimensions and both local and macroscopic adsorption characteristics. 


\section{Chapter 5}

\section{Multinuclear NMR Study of the}

\section{Synthesis and Assembly of a}

\section{Sodalite Semiconductor}

\section{Superlattice}

\subsection{Abstract}

${ }^{23} \mathrm{Na}$ and ${ }^{27} \mathrm{Al}$ DOR and MAS, combined with ${ }^{29} \mathrm{Si}$ and ${ }^{81} \mathrm{Br}$ MAS experiments, $\mathrm{X}$ ray diffraction and infra-red measurements, provide structural and electronic details for the newly developed sodalite semiconductor superlattices. The evolution of the nucleation and crystallization processes of sodium-halide sodalites is monitored, and the appearance of anion-empty sodalite cages is detected. Subtle changes in the electronic and quadrupolar interactions of sodium and aluminum nuclei occur upon loading chloride, bromide and iodide into the sodalite cages. The NMR results 
indicate a significantly different electronic charge distribution within the sodalite cavities in chemically-synthesized mixed chloride-iodide sodalite.

A preference for silver exchange of sodium cations in halide-containing cages, over hydroxide-containing and anion-empty sodalite cavities, is detected. Extraction of the isotropic chemical shift and quadrupolar contributions to the sodium resonances is achieved by performing the DOR experiments at two magnetic field strengths. The parameters obtained indicate a change in the charge distribution around the sodium nuclei upon exchanging approximately one-quarter of the extraframework $\mathrm{Na}^{+}$cations with $\mathrm{Ag}^{+} \cdot{ }^{81} \mathrm{Br}$ MAS data provide additional evidence for a significant change of the charge distribution within the sodalite cavities, which occur upon $\mathrm{Ag}^{+}$cation-exchange of sodium,bromo-sodalites.

\subsection{Introduction}

The Federovian cuboctahedral structure of sodalites [1] enables them to host insulator, semiconductor or metal cluster guests of uniform size and shape [114]. This unique quality confers upon this class of microporous solids potential uses as advanced materials, which may include semiconductor quantum "dots" [115], expanded metal or superconducting arrays [116], or optically active zeolite electrodes and thin films [117]. Figure 5.1 features a schematic picture of sodalite structure, and the sodium-halide cluster inside the cavity.

Single crystal and Rietveld powder X-ray diffraction methods have been pivotal in providing precise structural details of zeolite-type materials, which exhibit longrange ordering $[4,6]$. Solid-state NMR, on the other hand, can address structural questions of a more proximate nature, yielding invaluable information on the en- 


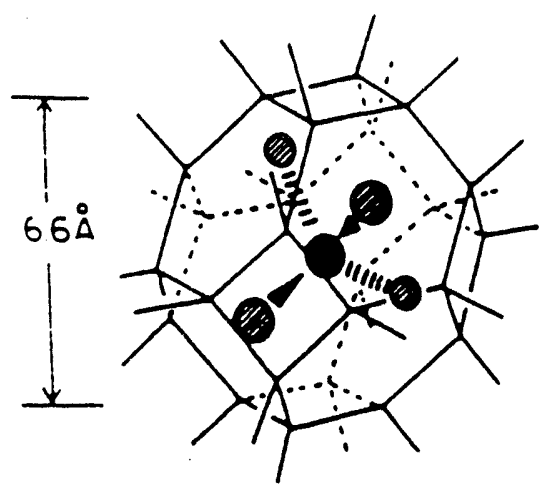

(A) Sodalite Coge

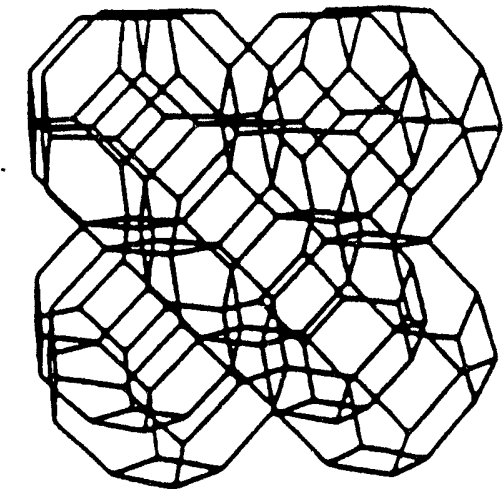

(B) Sodolite

Figure 5.1: (A) A schematic picture of $\mathrm{Na}_{4} \mathrm{X}\left(\mathrm{X}=\mathrm{Cl}^{-}, \mathrm{Br}^{-}, \mathrm{I}^{-}\right)$arrangement within a sodalite cage; (B) Sodalite framework, emphasizing the close packing of cages. 
vironments of atomic species in powder materials, having short-range order. The use of high magnetic fields, combined with spatial-averaging sample reorientation NMR techriques like magic-angle spinning (MAS), enables one to obtain structural information on open-framework materials. As discussed and demonstrated in previous chapters, the double rotation (DOR) technique further increases the spectral resolution of quadrupolar nuclei, and yields valuable insight into structural arrangements and chemical processes within zeolite materials.

This work concentrates on the application of ${ }^{27} \mathrm{Al}$ and ${ }^{23} \mathrm{Na} \mathrm{MAS}$ and DOR, complemented by ${ }^{29} \mathrm{Si}$ and ${ }^{81} \mathrm{Br}$ NMR, X-ray diffraction and mid- and far-infrared (IR) measurements, in probing intimate structural details of the sodium-halosodalite system [unit cell composition $\mathrm{Na}_{8} \mathrm{X}_{2}\left(\mathrm{Al}_{6} \mathrm{Si}_{6} \mathrm{O}_{12}\right)$, where $\left.\mathrm{X}=\mathrm{Cl}, \mathrm{Br}, \mathrm{I}\right]$. Additional experiments are carried out on the silver-exchanged samples $\mathrm{Na}_{8-p} \mathrm{Ag}_{p} \mathrm{X}_{2}\left(\mathrm{Al}_{6} \mathrm{Si}_{6} \mathrm{O}_{12}\right)$, sodalite-encapsulated semiconductor superlattices $[118,119]$. Optical spectroscopic studies of the materials have detected size-effects in the energy band-structure of the encapsulated silver-bromide clusters, which might be associated with "quantum confinement" of the semiconductor components $[117,118,119]$. Previous works have also investigated the structural and electronic properties of sodium,silver, halosodalites, anion and cation distributions in the materials, and motion inside the cages, using X-ray diffraction and optical spectroscopy [119]. Far-IR studies on sodalite structures were conducted as well [120].

Issues addressed in this study include the process of nucleation and crystallization of the parent sodium-sodalite materials, cation and anion arrangements throughout the framework, and the transformation of the sodium parent materials into a semiconductor-component superlattice upon silver ion-exchange. Quantita- 
tive results are obtained for the cation and anion occupation of the sodalite cavities. In addition, the experimental results might indicate an electronic coupling between the contents of adjacent sodalite cages. This is a highly important concept when considering further technological and scientific applications of these materials, such as in electronic devices and non-linear optics.

\subsection{Experimental Considerations}

The sodium-halosodalite precursors were prepared by a low-temperature hydrothermal synthesis, similar to the method described by Barrer [3], from aqueous mixtures of $\mathrm{Al}(\mathrm{OH})_{3}, \mathrm{SiO}_{2}$ gels, and $\mathrm{NaX}$ salts $[\mathrm{X}=\mathrm{Cl}, \mathrm{Br}, \mathrm{I}$ in chloro-, bromo-, and iodo-sodalites, respectively]. Silver-containing sodalites were prepared by a melt ion-exchange of a mixture containing the quantitative amounts of the parent sodium sodalite and $\mathrm{AgNO}_{3}$ crystals. The powders were grained thoroughly in a porcelain mortar, and heated to $230^{\circ} \mathrm{C}$ in the dark for 24 hours. The products were filtered in the dark by de-ionized water, and dried in air. Because of their light sensitivity, the white-to-yellow dry powders were stored in dark sample vials. A detailed description of the synthetic procedures is provided elsewhere $[118,122]$.

Room temperature, high resolution powder X-ray data were collected on a Philips PW 1051 diffractometer using Ni-filtered $\mathrm{CuK}_{\alpha}$ radiation $(\lambda=1.54178 \AA$, $\mathrm{K}_{\alpha 2}$ stripped, $40 \mathrm{~mA}, 45 \mathrm{kV}$ ) with a liquid nitrogen cooled solid state Ge detector. Infrared measurements were carried out on a Nicolet 5DX or a Nicolet 20SXB FTIR spectrometer with far-IR capability $\left(650-30 \mathrm{~cm}^{-1}\right)$. All spectra were obtained with $4 \mathrm{~cm}^{-1}$ resolution by coadding 250-500 interferograms (far-IR range) or 100 interferograms (mid-IR range). The spectra were baseline corrected by subtracting 
Table 5.1: Experimental parameters used in the NMR measurements. For ${ }^{27} \mathrm{Al}$ and ${ }^{23} \mathrm{Na}$, DOR pulse widths are indicated.

\begin{tabular}{|c|c|c|c|}
\hline \hline Nucleus & Resonance Frequency & Reference Material & $90^{\circ}$ Pulse Length \\
\hline Si-29 & 99.35 & TMS & $11 \mu \mathrm{sec}$ \\
$\mathrm{Al}-27$ & 130.31 & Dilute aqueous Al(NO) & $15 \mu \mathrm{sec}$ \\
$\mathrm{Na}-23$ & 132.28 & $0.1 \mathrm{M} \mathrm{NaCl}$ & $11 \mu \mathrm{sec}$ \\
$\mathrm{Br}-81$ & 135.05 & $0.1 \mathrm{M} \mathrm{NaBr}$ & $10 \mu \mathrm{sec}$ \\
\hline
\end{tabular}

a linear ramp from the observed results.

NMR measurements were carried out at 11.7 Tesla magnetic field, using a Chemagnetics CMX-500 spectrometer and MAS probehead. Additional experiments were carried out in a 9.4 Tesla field using a Bruker AM-400 spectrometer. DOR spectra in both fields were obtained using a home-built probe [99]; the spinning speed was $5 \mathrm{kHz}$ for the inner rotor and $500-700 \mathrm{~Hz}$ for the outer one. In the MAS measurements the samples were spun at 5-6 kHz. Experimental parameters used in the NMR measurements are given in Table 5.1. The accuracy of peak positions relative to the external reference was $\pm 0.3 \mathrm{ppm}$. 500-1000 acquisitions were averaged at room temperature, in the ${ }^{27} \mathrm{Al}$ and ${ }^{23} \mathrm{Na}$ MAS and DOR experiments, using $0.5 \mathrm{sec}$ delays between short, $\approx 30^{\circ}$, pulses. For quantitative NMR measurements, identical sample-quantities were used, and the same number of transients acquired. All spectra were zero-filled to $2 \mathrm{~K}$ data points, with $50 \mathrm{~Hz}$ Lorentzian broadening. 


\subsection{Crystallization of Sodium,bromo-Sodalite}

The crystallization process of sodalite involves the intermediate formation of a NaA zeolite phase [3]. Several studies, however, conclude that zeolite $\mathrm{A}$ is not formed in the presence of chloride salts [1]. We investigated the evolution of the $\mathrm{Na}_{8} \mathrm{Br}_{2}$-sodalite crystallization [sodalite $\equiv\left(\mathrm{Al}_{6} \mathrm{Si}_{6} \mathrm{O}_{12}\right)$ ], and the possible appearance of different species during the synthesis. The bromo-sodalite synthesis was interrupted at different times and the structural details of the materials synthesized were examined.

Selected powder XRD patterns are shown in Figure 5.2, for reaction products recovered after 0.5 to 153 hours. Within 0.5 hour, Figure $5.2(\mathrm{a})$, all sodalite reflections are already observed, but they are still very weak and broad. The 0.5 hour XRD pattern also featu sad background attributed to an amorphous phase, as well as additional $\mathrm{re}_{2} \quad$ is due to zeolite $\mathrm{A}$ as the major crystalline phase. The NaA zeolite reflections decrease with time, Figure 5.2(b-d), and disappear completely within four hours; the amorphous background is also no loriger apparent by this time. The sodalite pattern continues to sharpen with further reaction time and, as shown in Figure 5.2(d-g), reaches its final form within 4-8 hours.

The NMR data support a rucleation mechanism involving $\mathrm{NaA}$ zeolite as a chemical intermediate and provide further structural and quantitative information. The ${ }^{29} \mathrm{Si}$ MAS spectrum of the material extracted after $1 / 2$ hour synthesis time, Figure 5.3, displays two partially resolved resonances. The lowest intensity peak, at -86.1 ppm, corresponds to the $\mathrm{Na}_{8} \mathrm{Br}_{2}$-sodalite structure [123], while the resonance at $-89.2 \mathrm{ppm}$ is assigned to the $\mathrm{Si}(\mathrm{OAl})_{4}$ tetrahedra in $\mathrm{NaA}$ zeolite [6].

More information is provided by ${ }^{27} \mathrm{Al}$ MAS experiments shown in Figure 5.4. 


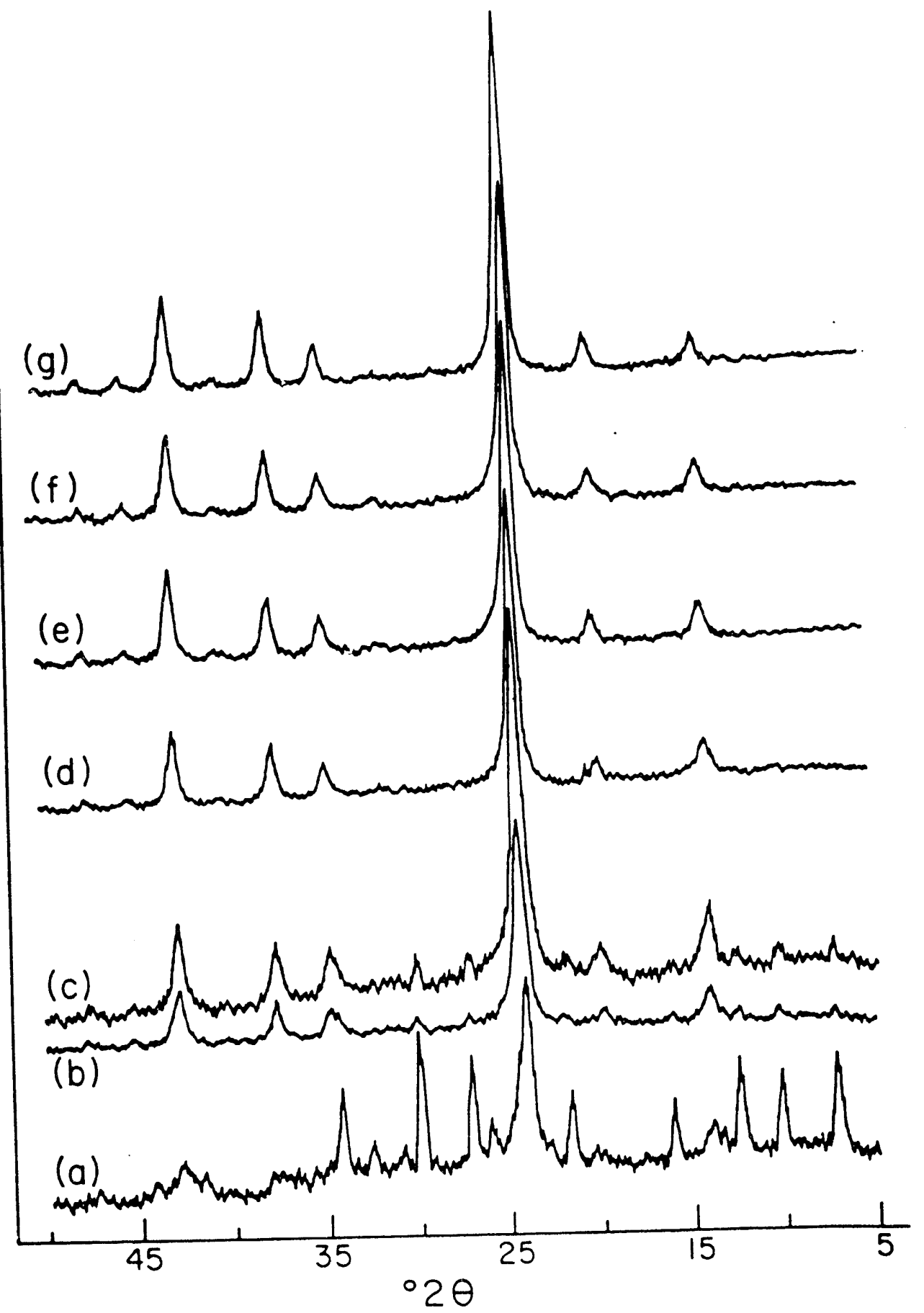

Figure 5.2: Powder $\mathrm{X}$ ray diffraction patterns of products from $\mathrm{Na}_{8} \mathrm{Br}_{2}-$ sodalite synthesis, sampled after: (a) $0.5 \mathrm{hr},(\mathrm{b}) 1 \mathrm{hr},(\mathrm{c}) 2 \mathrm{hr},(\mathrm{d}) 4 \mathrm{hr},(\mathrm{e}) 7.8 \mathrm{hr}$, (f) $13 \mathrm{hr},(\mathrm{g}) 153 \mathrm{hr}$. 


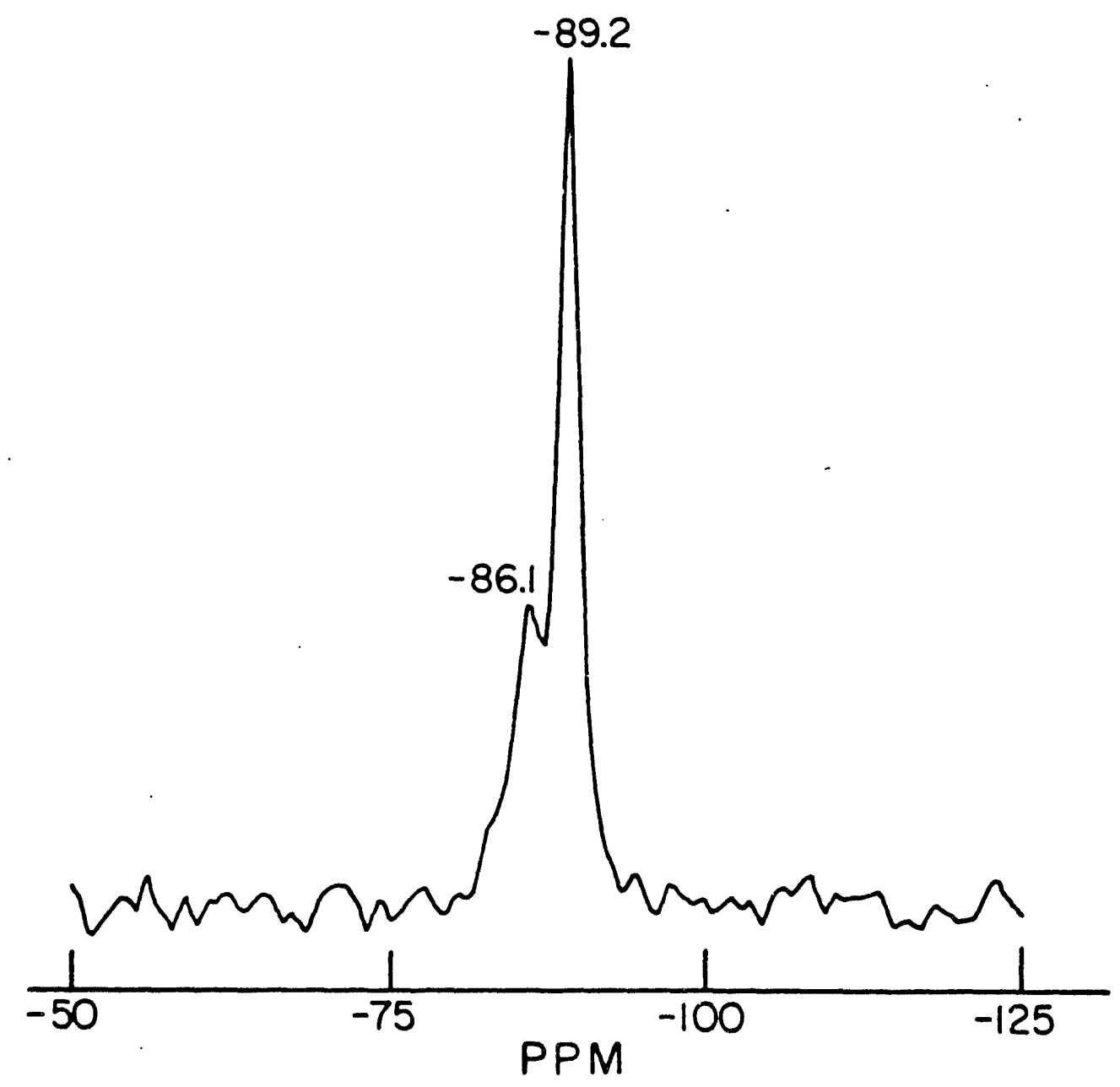

Figure 5.3: ${ }^{29} \mathrm{Si}$ MAS spectrum of $\mathrm{Na}_{8} \mathrm{Br}_{2}$-sodalite sampled after $0.5 \mathrm{~h} .200$ transients were accumulated in the experiment, with $20 \mathrm{sec}$ recycle delays. 

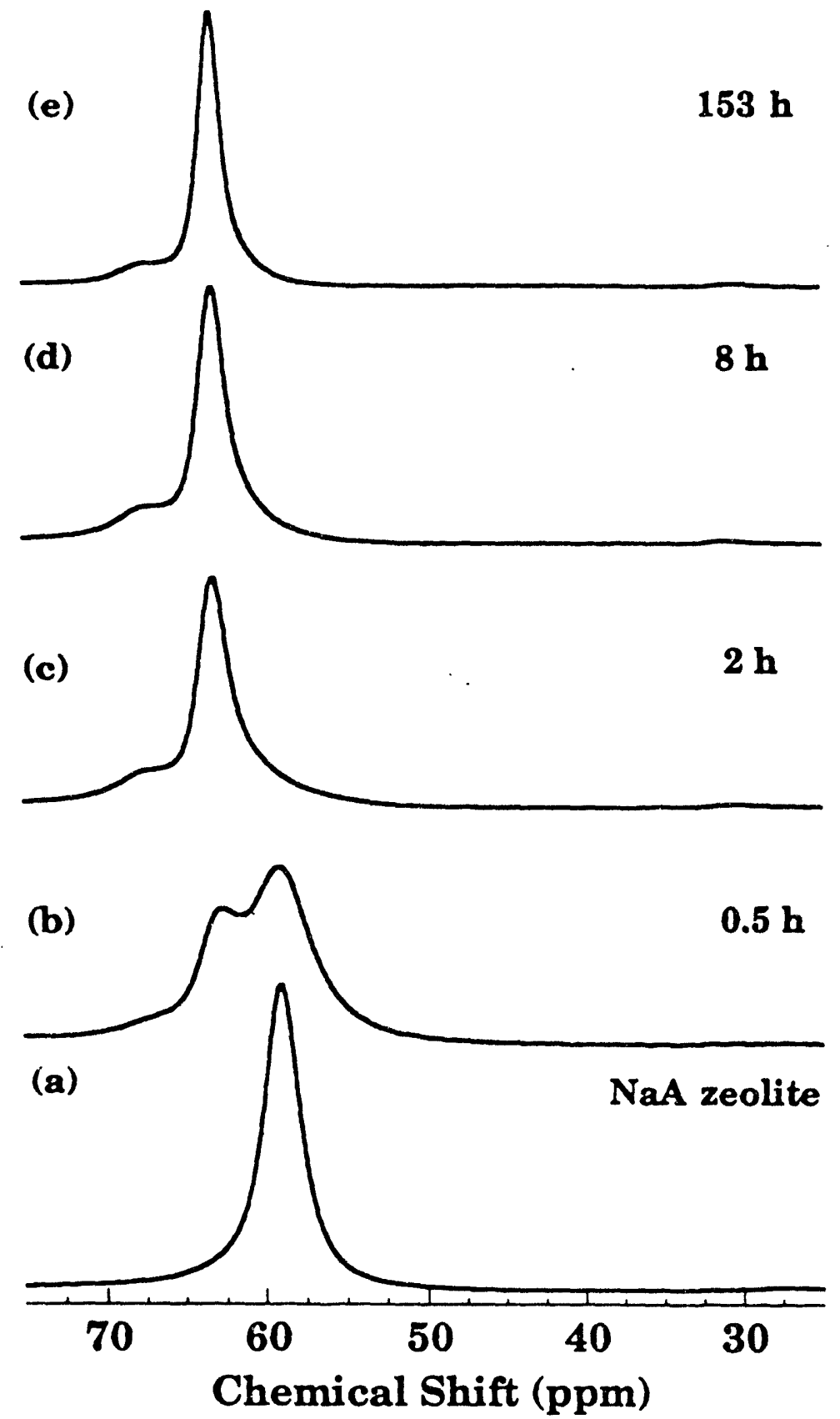

Figure 5.4: ${ }^{27} \mathrm{Al}$ MAS spectra of (a) $\mathrm{NaA}$-zeolite, and products from $\mathrm{Na}_{8} \mathrm{Br}_{2}-$ sodalite synthesis sampled after:(b) $0.5 \mathrm{hr}$, (c) $2 \mathrm{hr}$, (d) $8 \mathrm{hr}$, (e)153 hr. 
Upon comparison with the fully crystalline material, the prominent down-field peak at $62.2 \mathrm{ppm}$ in Figure $5.4(\mathrm{~b}-\mathrm{e})$ is assigned to $\mathrm{Al}(\mathrm{OSi})_{4}$ species in the $\mathrm{Na}_{8} \mathrm{Br}_{2}-$ sodalite framework. This shift is close to the reported value of $61.0 \mathrm{ppm}$ for ${ }^{27} \mathrm{Al}$ in sodalite-hydrate and $65.0 \mathrm{ppm}$ for $\mathrm{Na}_{8} \mathrm{Cl}_{2}$-sodalite [18]; the difference can be traced to structural and electronic sensitivity of the framework towards the encapsulated anion [see discussion in the following section]. The upfield peak at $58.7 \mathrm{ppm}$ coincides with the known position for four-coordinated aluminum in $\mathrm{NaA}$ zeolite [18], whose ${ }^{27} \mathrm{Al}$ MAS spectrum is shown in Figure 5.4(a). The quantitative transformation of the NaA phase into sodalite is followed as a function of the synthesis time: after two hours, the downfield powder pattern predominates, Figure 5.4(c), as $\mathrm{Na}_{8} \mathrm{Br}_{2}$-sodalite becomes the major component. A weak $\mathrm{NaA}$-zeolite remnant is still observed in the ${ }^{27} \mathrm{Al}$ spectrum at this time, but disappears completely thereafter.

The ${ }^{23} \mathrm{Na}$ results, shown in Figure 5.5, feature a noticeable difference from the ${ }^{27} \mathrm{Al}$ MAS data. The intensity of an upfield resonance around $-2.5 \mathrm{ppm}$ decreases with time in the early stages of the reaction, Figure $5.5(b-c)$, but in contrast to the ${ }^{27} \mathrm{Al}$ MAS data, this peak does not disappear later. DOR experiments conducted on the series confirmed that the signal at around $-2.5 \mathrm{ppm}$ is not a residual quadrupolar-broadened MAS peak, but rather a resonance from a distinct ${ }^{23} \mathrm{Na}$ site. As shown in Figure 5.5(e), the upfield peak is still present even after more than 100 hours, at which time both the XRD and ${ }^{27} \mathrm{Al}$ measurements indicate a final $\mathrm{Na}_{8} \mathrm{Br}_{2}$-sodalite product. The ${ }^{23} \mathrm{Na}$ resonance which is detected at $-1.8 \mathrm{ppm}$ in pure NaA zeolite, shown in Figure 5.5(a), is clearly further downfield from the $-2.5 \mathrm{ppm}$ resonance observed throughout the synthesis series. This appears to reflect that 


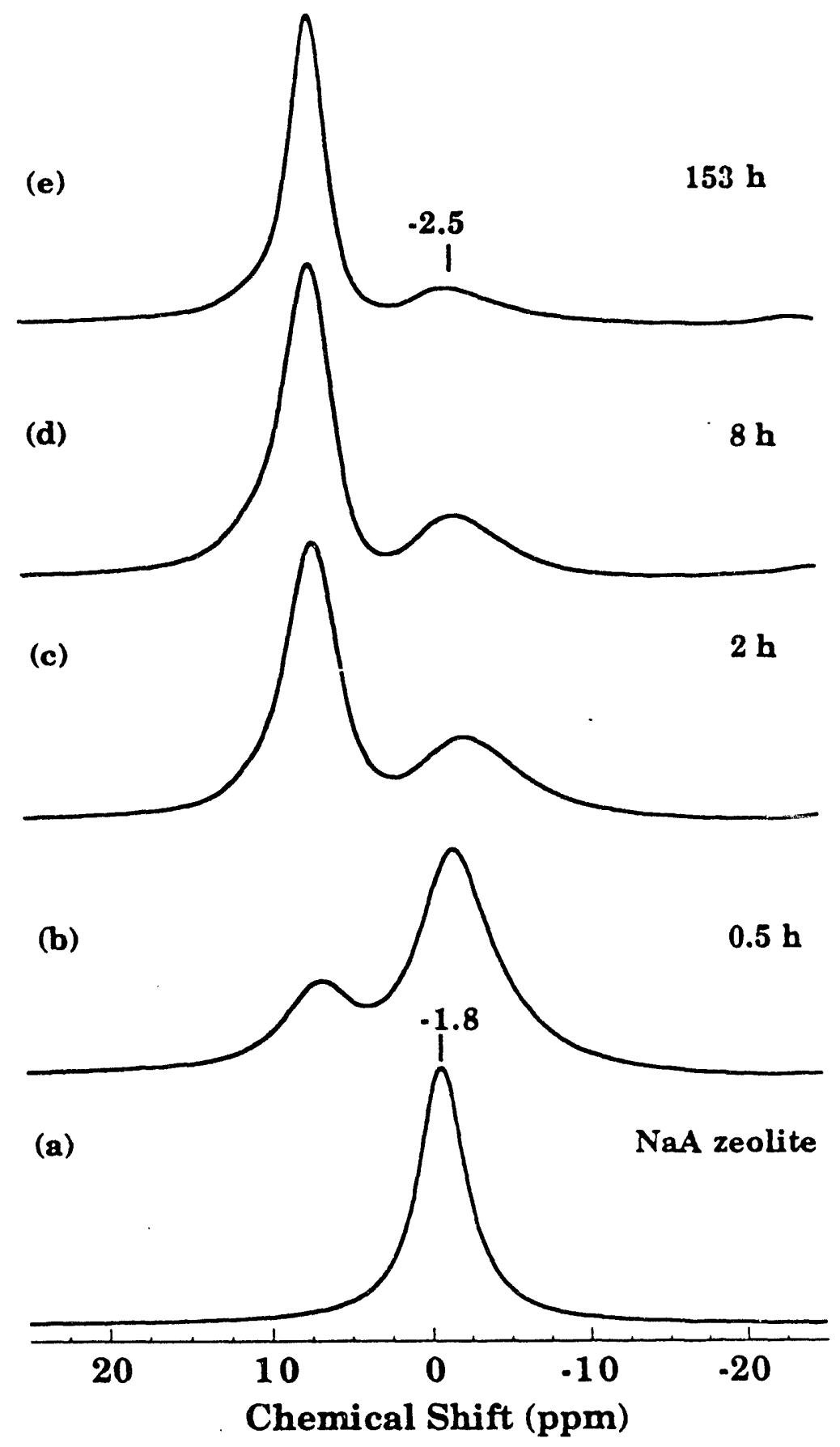

Figure 5.5: ${ }^{23} \mathrm{Na}$ MAS spectra of (a)NaA-zeolite, and products from $\mathrm{Na}_{8} \mathrm{Br}_{2}-$ sodalite synthesis sampled after:(b) $0.5 \mathrm{hr},(\mathrm{c}) 2 \mathrm{hr},(\mathrm{d}) 8 \mathrm{hr}$, (e) $153 \mathrm{hr}$. 
the peak at around $-2.5 \mathrm{ppm}$ in Figure 5.5 corresponds to a sodium environment in sodalite, which is different than that in $\mathrm{NaA}-$ zeolite.

The peak at $-2.5 \mathrm{ppm}$ disappears upon vacuum dehydration $\left[4\right.$ hours at $110^{\circ} \mathrm{C}$ ], as shown in Figure 5.6. A similar result is observed for $\mathrm{Na}_{6} \cdot \mathrm{nH}_{2} \mathrm{O}$-sodalite, Figure 5.7, where the ${ }^{23} \mathrm{Na}$ MAS signal associated with $\mathrm{Na}_{3} \cdot \mathrm{nH}_{2} \mathrm{O}$ cavities almost disappears completely upon dehydration of the sample. The sodium signal from the anion-free cages in dehydrated $\mathrm{Na}_{6} \cdot \mathrm{nH}_{2} \mathrm{O}$-sodalite, Figure $5.7(\mathrm{~b})$, is spread over a large frequency range, thus is not observed in the spectral window used. This effect is probably due to an increase in the electric field gradients around the ${ }^{23} \mathrm{Na}$ nuclei [16] in the absence of anions or water molecules in the cavity. In addition, dehydration might cause a large distribution of the $\mathrm{Na}^{+}$environments at available loccitions within the anion-empty sodalite cage. In the presence of water molecules, however, the sodium ions exhibit fast motion, so that the ${ }^{23} \mathrm{Na}$ NMR signal is motionally narrowed and appears as a rather sharp Gaussian peak, Figure 5.7(a).

The upfield ${ }^{23} \mathrm{Na}$ peak at around $-2.5 \mathrm{ppm}$, in the synthesis products series, Figure 5.5(a), is therefore assigned to $\mathrm{Na}^{+}$cations in $\mathrm{Na}_{3} \cdot \mathrm{nH}_{2} \mathrm{O}$ cages, while the peak at around $7 \mathrm{ppm}$ is associated with $\mathrm{Na}^{+}$cations in $\mathrm{Na}_{4} \mathrm{Br}$ cavities. Thus, the ${ }^{23} \mathrm{Na}$ MAS results leads to the conclusions that a certain number of "defect"-cages, which do not contain anions, are produced during the synthetic procedure. These cages give rise to the ${ }^{23} \mathrm{Na}$ resonance at $-2.5 \mathrm{ppm}$. Based on this assignment, the ${ }^{23} \mathrm{Na}$ MAS signal from the arion-containing cages in $\mathrm{Na}_{8} \cdot \mathrm{Br}_{2}$-sodalite seems to be unaffected by dehydration, Figure 5.6(b). This observation indicates a more symmetrical environment of the $\mathrm{Na}^{+}$cation in the cavities which contain $\mathrm{Br}^{-}$anion at their center. In addition, the $\mathrm{Na}^{+}$cations are probably confined to distinct 

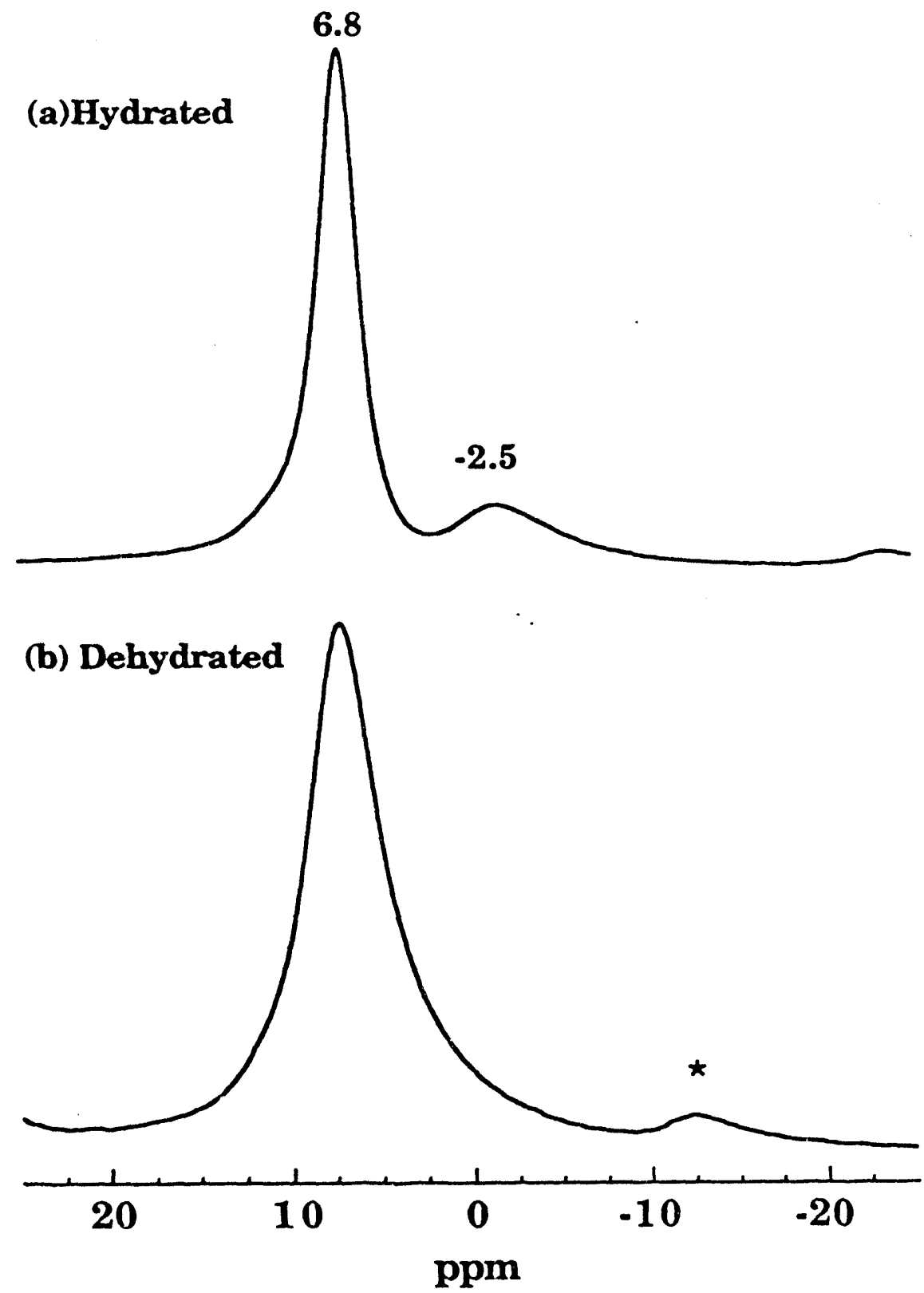

Figure 5.6: ${ }^{23} \mathrm{Na}$ MAS spectra of (a)hydrated $\mathrm{Na}_{8} \mathrm{Br}_{2}$-sodalite; (b)dehydrated $\mathrm{Na}_{8} \mathrm{Br}_{2}$-sodalite. 


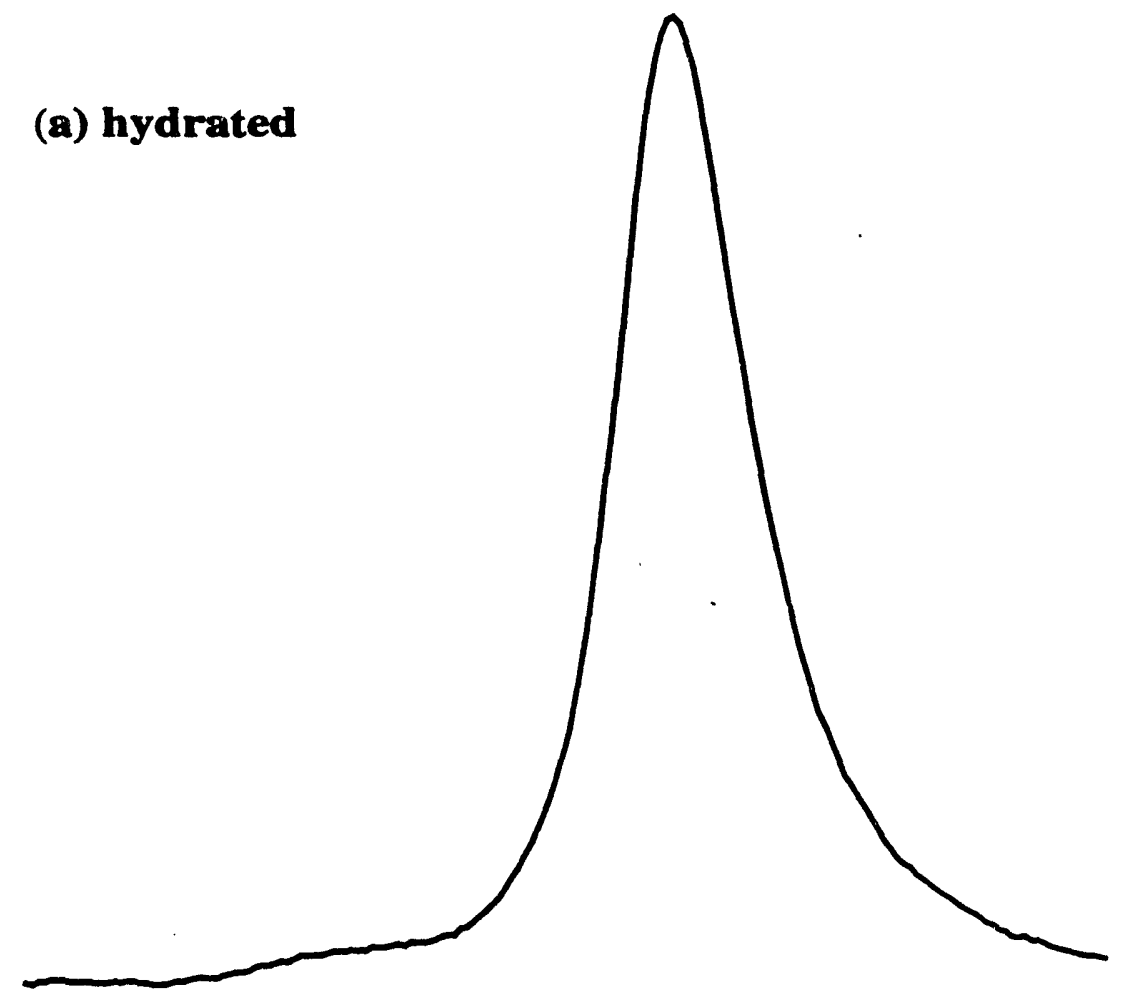

(b) denydrated

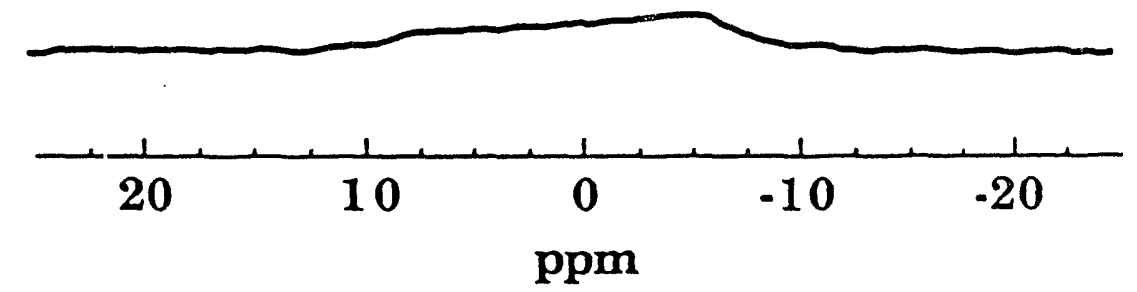

Figure 5.7: ${ }^{23} \mathrm{Nd}$ MAS spectra of (a)hydrated; (b) dehydrated $\mathrm{Na}_{6} \cdot \mathrm{nH}_{2} \mathrm{O}-$ s'jdalite. 
extraframework sites within the $\mathrm{Br}^{-}$-containing cavities in $\mathrm{Na}_{8} \mathrm{Br}_{2}$-sodalite. The observation of two separate sodium resonances in hydrated $\mathrm{Na}_{8} \mathrm{Br}_{2}$-sodalite indicates the absence of fast $\mathrm{Na}^{+}$exchange between sodalite cages at room temperature.

Integration of the peak intensities in the ${ }^{23} \mathrm{Na}$ MAS spectrum of the synthesized material in Figure 5.5(e) indicates that $\approx 10 \%$ anion-free cages are produced. This side-product in hydrothermally prepared sodalites is not detected by XRD and may have been overlooked in previous studies. Șmeulders et al [124] have hypothesized that halide anions diffuse out of the sodalite cages leaving behind $\mathrm{Na}_{4}^{3+}$ clusters, whereas this study suggests that the cages containing $\mathrm{Na}_{3} \cdot \mathrm{nH}_{2} \mathrm{O}$ are apparently already present after the initial synthetic route. A later report conducted by nutation analysis found evidence for water molecules inside the sodalite cages [92]. Water molecules, however, do not fit into cages occupied by halide ions due to spatial restrictions [3], but are rather present in the halide-free cavities. This finding further supports the production of sodalite cages which do not contain halide anions throughout the synthesis of halo-sodalites. Incidentally, it has recently been reported that anion-free cages in sodium-sodalites are formed upon extraction of $\mathrm{NaOH}$ following washing of the crude product with water, from defect hydroxide anion-containing cages produced in the as-synthesized materials [62].

\subsection{Halo-Sodalites}

Inspection of the schematic drawing of halo-sodalites, Figure 5.1, reveals that the monovalent sodium cations are tetrahedrally arranged around the anion, which is located at the center of the cavity. The halogen ions encapsulated within the sodalite framework in this study, namely $\mathrm{I}^{-}, \mathrm{Br}^{-}$, and $\mathrm{Cl}^{-}$, have different radii $[2.06 \AA$, 
$1.8 \AA, 1.67 \AA$, respectively [125]], and Pauling electronegativity values. These properties can be invoked to explain perturbations in the structure of the aluminosilicate framework and the electronic properties of the charge balancing $\mathrm{Na}^{+}$cations. Previous ${ }^{29} \mathrm{Si}$ MAS studies, for example, have correlated ${ }^{29} \mathrm{Si}$ chemical shifts with $\mathrm{Si}-\mathrm{O}-\mathrm{Al}$ angles in sodalites $[u .5,123,126]$, reflecting structural and electronic differences due to the presence of the various anions.

${ }^{27} \mathrm{Al}$ DOR spectra of the anion-loaded samples are shown in Figure 5.8. The DOR technique averages out the anisotropic contributions to the ${ }^{27} \mathrm{Al}$ resonances and makes it possible to obtain the exact isotropic shifts of the peaks. The positions of the ${ }^{27} \mathrm{Al}$ DOR resonances clearly exhibit sensitivity to structural features of the sodalite framework upon loading various anions. As expected, one observes further shielding of the framework aluminum atoms as the Pauling electronegativity [i.e. the capacity for electronic "charge-pulling"] of the anions, decreases, and the size of the anion increases. NaI-sodalite, for example, gives rise to an aluminum resonance at $61.2 \mathrm{ppm}$, Figure $5.8(\mathrm{c})$, while $\mathrm{Na}_{8} \mathrm{Cl}_{2}$-sodalite, which contains the smallest and most electronegative anion among the three anions examined, produces a peak at $64.5 \mathrm{ppm}$, Figure 5.8(a). The trend toward a more shielded ${ }^{27} \mathrm{Al}$ environment also reflects the widening of the $\mathrm{Si}-\mathrm{O}-\mathrm{Al}$ bond angle [5], which may be attributed to the larger size of the $\mathrm{I}^{-}$ion compared to $\mathrm{Cl}^{-}$.

The $\mathrm{Na}^{+}$cations exhibit high sensitivity towards the anionic species, as shown in Figure 5.9. $\mathrm{Cl}^{-}$and $\mathrm{Br}^{-}$-containing samples feature single Gaussian-shaped ${ }^{23} \mathrm{Na}$ MAS peaks, Figure 5.9(a,b), while the MAS spectrum of $\mathrm{Na}_{8} \mathrm{I}_{2}$-sodalite shows a substantially broader pattern, Figure 5.9(c). Application of DOR averages out the anisotropic quadrupolar broadening and yields the isotropic ${ }^{23} \mathrm{Na}$ shifts for 

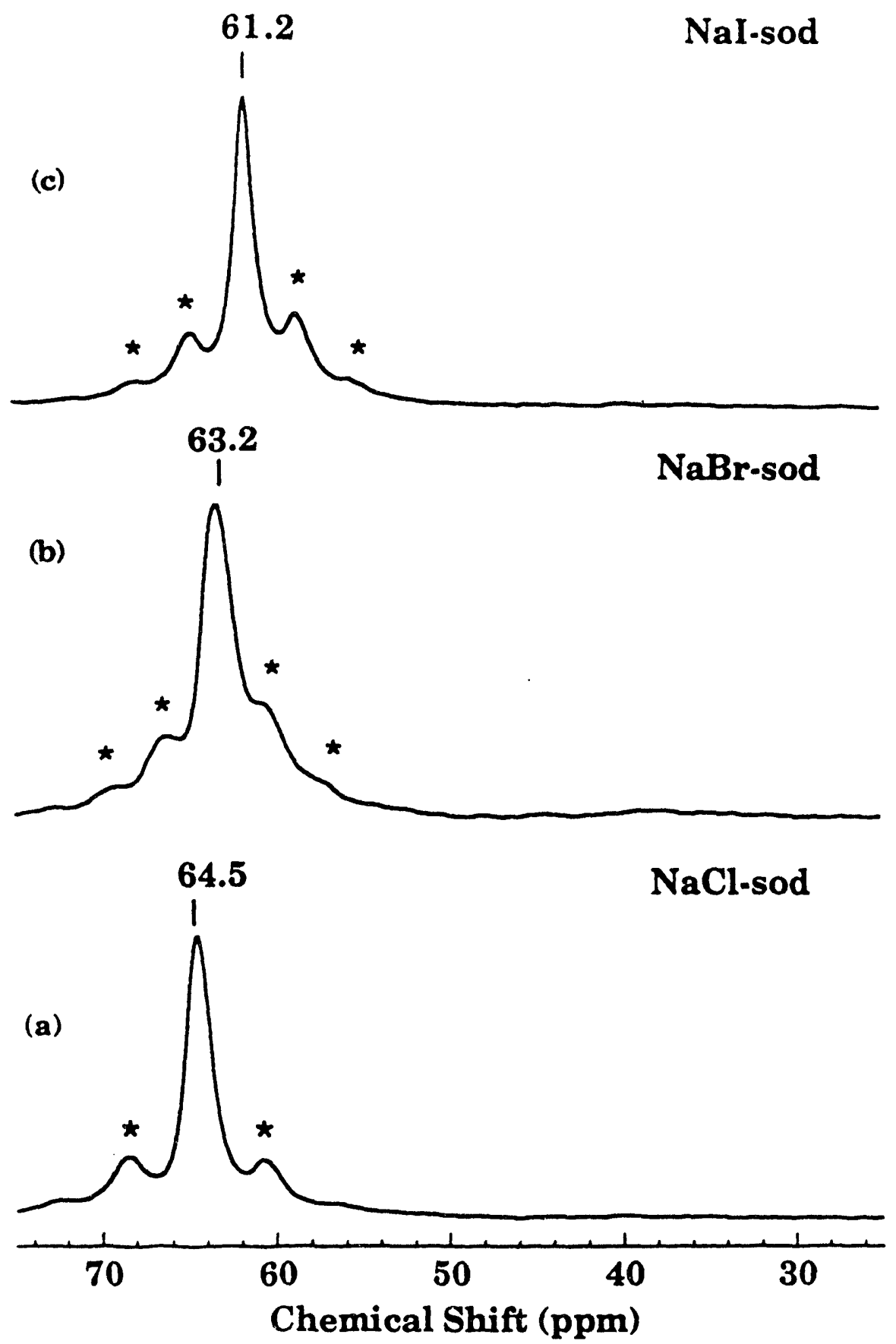

Figure 5.8: ${ }^{27} \mathrm{Al}$ DOR spectra of (a) $\mathrm{Na}_{8} \mathrm{Cl}_{2}$-sodalite; (b) $\mathrm{Na}_{8} \mathrm{Br}_{2}$-sodalite; (c) $\mathrm{Na}_{8} \mathrm{I}_{2}$-sodalite. The asterisks indicate spinning sidebands. 

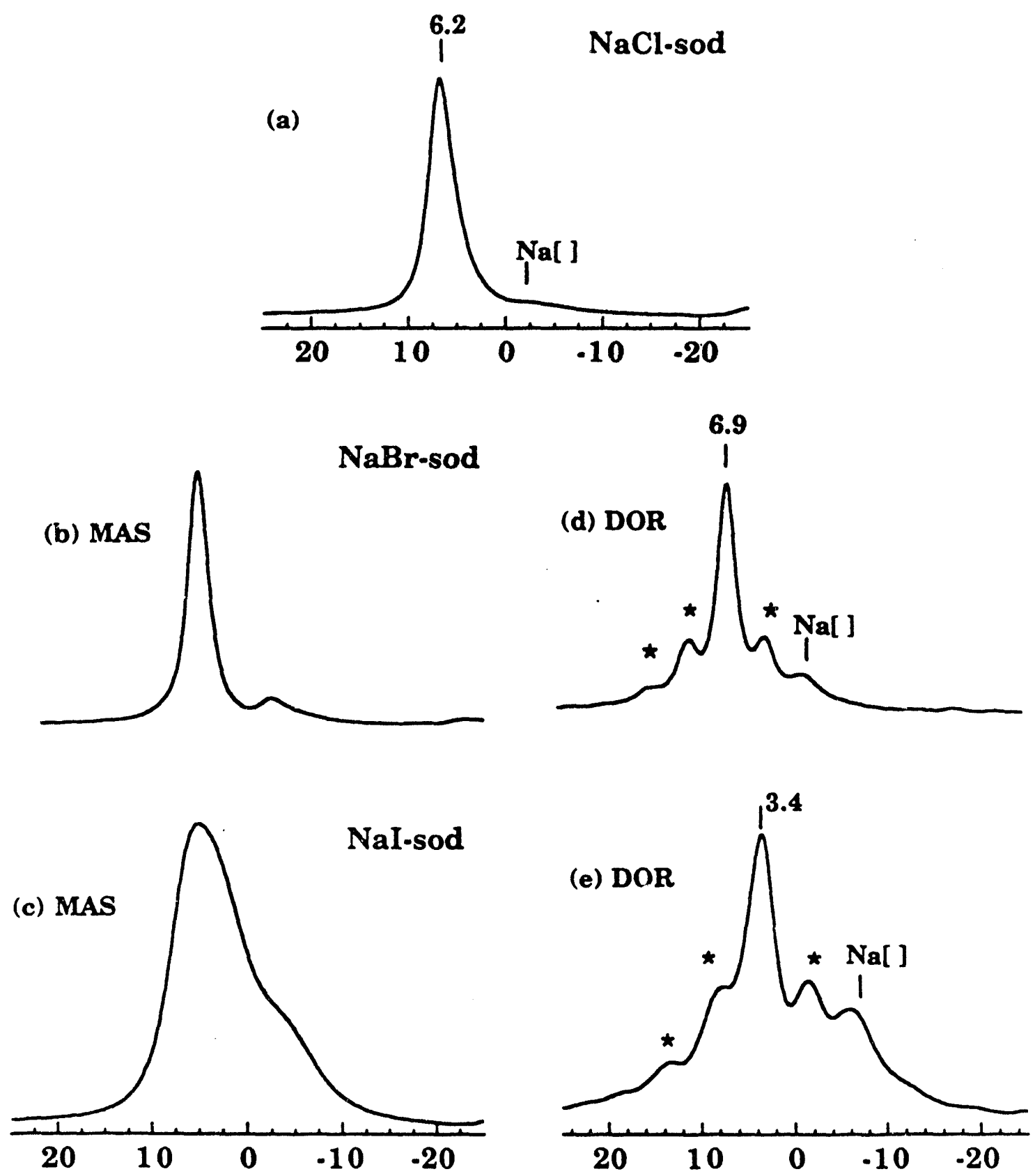

Figure 5.9: ${ }^{23} \mathrm{Na} \mathrm{NMR}$ spectra of sodium, halo-sodalites: (a) $\mathrm{Na}_{8} \mathrm{Cl}_{2}$-sodalite, MAS; (b) $\mathrm{Na}_{8} \mathrm{Br}_{2}$-sodalite, MAS; (c) $\mathrm{Na}_{8} \mathrm{I}_{2}$-sodalite, MAS; (d; $\mathrm{Na}_{8} \mathrm{Br}_{2}$-sodalite, DOR; (e) $\mathrm{Na}_{8} \mathrm{I}_{2}$-sodalite, DOR. The asterisks indicate spinning sidebands. 
$\mathrm{Na}_{8} \mathrm{Br}_{2}$-sodalite and $\mathrm{Na}_{8} \mathrm{I}_{2}$-sodalite, as shown in Figure 5.9(d) and (e), respectively. No apparent difference in the linewidths and positions was observed between the ${ }^{23} \mathrm{Na}$ MAS and DOR spectra of $\mathrm{Na}_{8} \mathrm{Cl}_{2}$-sodalite, Figure 5.9(a).

The $\mathrm{Na}^{+}$cations are four-fold coordinated, and positioned within bonding distance from the halide ion and three framework oxygens, Figure 5.1. Thus, the electronegativity difference between the framework oxygens and the anion probably has i significant effect in determining the charge distribution surrounding the encapsulated sodium. The calculated values are $\Delta(\chi$ [oxygen] $-\chi X)=0.28,0.48$, 0.78 for $X=\mathrm{Cl}, \mathrm{Br}, \mathrm{I}$, respectively, where $\chi$ is the Pauling electronegativity. Under these circumstances, an asymmetric distribution of charge is expected in the iodide cavities, consistent with the quadrupolar broadening in Figure 5.9(c), as more negative charge is drawn towards the framework oxygens. On the other hand, a more symmetric sodium environment is expected in the $\mathrm{Cl}^{-}$cages, as electron density would be located most likely on the highly electronegative chloride atom, and less on the aluminosilicate framework.

Further experiments in a lower, $9.4 \mathrm{~T}$, magnetic field, enable one to extract the isotropic chemical shifts and quadrupolar products using Equations 3.1 and 3.2. The calculated parameters are presented in Table 5.2. Recen published quadrupolar coupling constants [93], obtained through analysis of ${ }^{23} \mathrm{Na}$ MAS spectra of satellite transitions, are in close proximity to the values reported here.

The isotropic shifts and quadrupolar products in Table 5.2 indeed indicate more shielding, and less distortion, of the sodium electronic environment, as the electronegativity of the anion increases. The size of the halide may additionally have an effect on the sodium cations. A smaller halide, for example, might produce a de- 


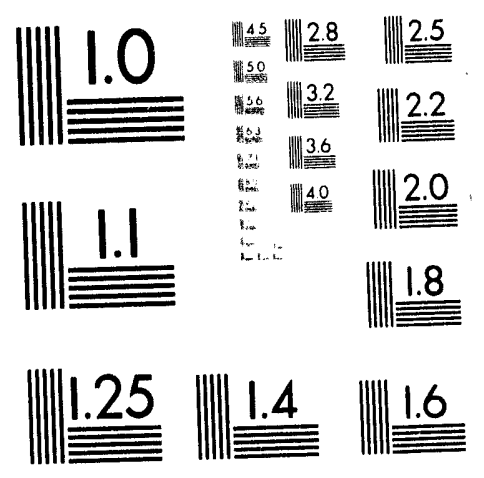



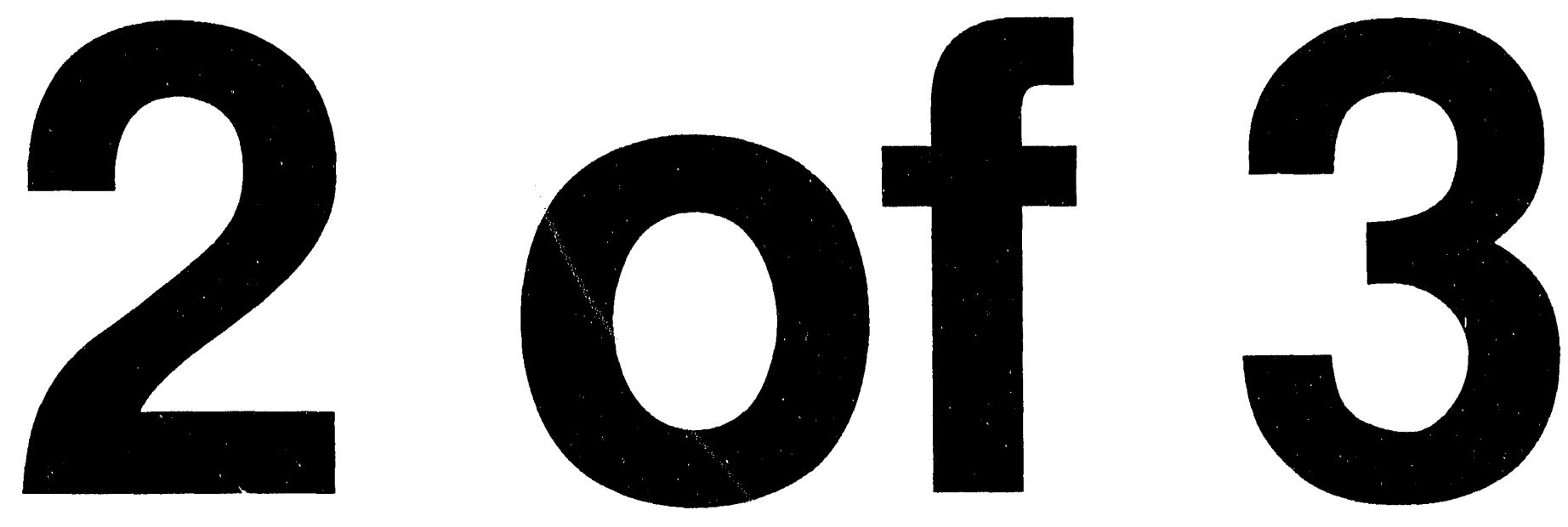
Table 5.2: ${ }^{23} \mathrm{Na}$ DOR resonance positions at $11.7 \mathrm{~T}$ and $9.4 \mathrm{~T}$, and calculated NMR parameters for different halo-sodalites. The isotropic chemical shift, $\delta_{c s, i s o}$, and quadrupolar product, $P_{Q}=\left(1+\frac{\eta^{2}}{3}\right) C_{Q}^{2}$, were calculated using Equations 3.1 and 3.2.

\begin{tabular}{|c|c|c|c|c|}
\hline & $\delta_{\text {obs }}(11.7 \mathrm{~T})$ & $\delta_{o b s}(9.4 \mathrm{~T})$ & $\delta_{c s, i s o}$ & $P_{Q}$ \\
\hline $\mathrm{NaCl}-\mathrm{sod}$ & $6.2 \mathrm{ppm}$ & $6.1 \mathrm{ppm}$ & $6.3 \mathrm{ppm}$ & $\approx 0 \mathrm{MHz}$ \\
$\mathrm{NaBr}-\mathrm{sod}$ & $6.9 \mathrm{ppm}$ & $6.0 \mathrm{ppm}$ & $8.5 \mathrm{ppm}$ & $1.1 \mathrm{MHz}$ \\
$\mathrm{NaI}-\mathrm{sod}$ & $3.4 \mathrm{ppm}$ & $0.1 \mathrm{ppm}$ & $9.3 \mathrm{ppm}$ & $3.7 \mathrm{MHz}$ \\
\hline
\end{tabular}

crease in the $\mathrm{Al}-\mathrm{O}-\mathrm{Si}$ angle. Consistent with the above arguments, the deshielding observed for the aluminum nuclei in this study appears related to higher electron densities around the framework atoms, and consequently to more shielded $\mathrm{Na}^{+}$ cations.

\subsection{Mixed-Halide Sodalites}

An interesting and closely related class of materials are the mixed-halide sodalites, $\mathrm{Na}_{8} \mathrm{Cl}_{2-p} \mathrm{I}_{\mathrm{p}}$-sodalite. It is important to assess the organization of the anions within the sodalite lattice, since this affects the electronic band structure of the material. Models of mixed anion distribution include: (1) an ordered array, in which a higher-order unit cell would be created (manifested by extra diffraction lines in the powder XRD pattern); (2) a solid solution of anions within the lattice; (3) a segregated physical mixture of chloro- and iodo-sodalite microcrystallites (de- 
tected as a superposition of pure $\mathrm{Na}_{8} \mathrm{Cl}_{2}$-sodalite and $\mathrm{Na}_{8} \mathrm{I}_{2}$-sodalite spectra using the spectroscopic methods in this study); and (4) a mixture of chloride and iodide domains smaller than $\approx 50 \AA$, which is below the detection limit of $\mathrm{X}$ ray diffraction.

Figures 5.10 and 5.11 show powder XRD patterns, mid-IR and far-IR spectra of pure chloro and iodo-sodalites, chemically prepared $\mathrm{NaICl}$-sodalites, and physical mixtures of the pure materials. The PXRD pattern of the chemically synthesized material in Figure 5.10(b) shows no extra diffraction lines corresponding to integer multiples of the urit cell edge, thus eliminating the ordered-array model from consideration. This observation differs from electron microscopy results obtained for the mineral nosean [127], a sodalite in which $\mathrm{Na}_{4} \cdot \mathrm{H}_{2} \mathrm{O}$ and $\mathrm{Na}_{4} \cdot \mathrm{SO}_{4}$ units form an incommensurate superlattice structure. The PXRD pattern of the physical mixture, Figure 5.10(a), stands in contrast to the single phase, narrow peak, pattern of the chemically prepared sample, Figure 5.10(b). The pattern of the physically mixed sample features broad peaks composed of the corresponding separate chloroand iodo-sodalite signals.

A similar interpretation is apparent from the mid-IR spectra in Figure 5.10(c), where the results seem to exclude the formation of separate $\mathrm{Na}_{8} \mathrm{Cl}_{2}$-sodalite and $\mathrm{Na}_{8} \mathrm{I}_{2}$-sodalite microcrystallites. Three distinct framework, $\nu_{s}(\mathrm{~T}-\mathrm{O})$, vibrational modes are observed for pure $\mathrm{Na}_{8} \mathrm{Cl}_{2}$-sodalite and $\mathrm{Na}_{8} \mathrm{I}_{2}$-sodalite shown in Figure $5.10(\mathrm{c})$, i and ii, respectively. $\nu_{s}(\mathrm{~T}-\mathrm{O})$ modes of the chemically prepared sample, Figure 5.10 (c) iv, give rise to three sharp bands in the $650-740 \mathrm{~cm}^{-1}$ region, while a clear superposition of $\mathrm{Na}_{8} \mathrm{Cl}_{2}-$ sodalite and $\mathrm{Na}_{8} \mathrm{I}_{2}$-sodalite bands is observed in the spectrum of the physical mixture, Figure 5.10 (c) iii.

Intriguingly, the far-IR spectra of a series of chemically synthesized $\mathrm{NaICl}-$ 

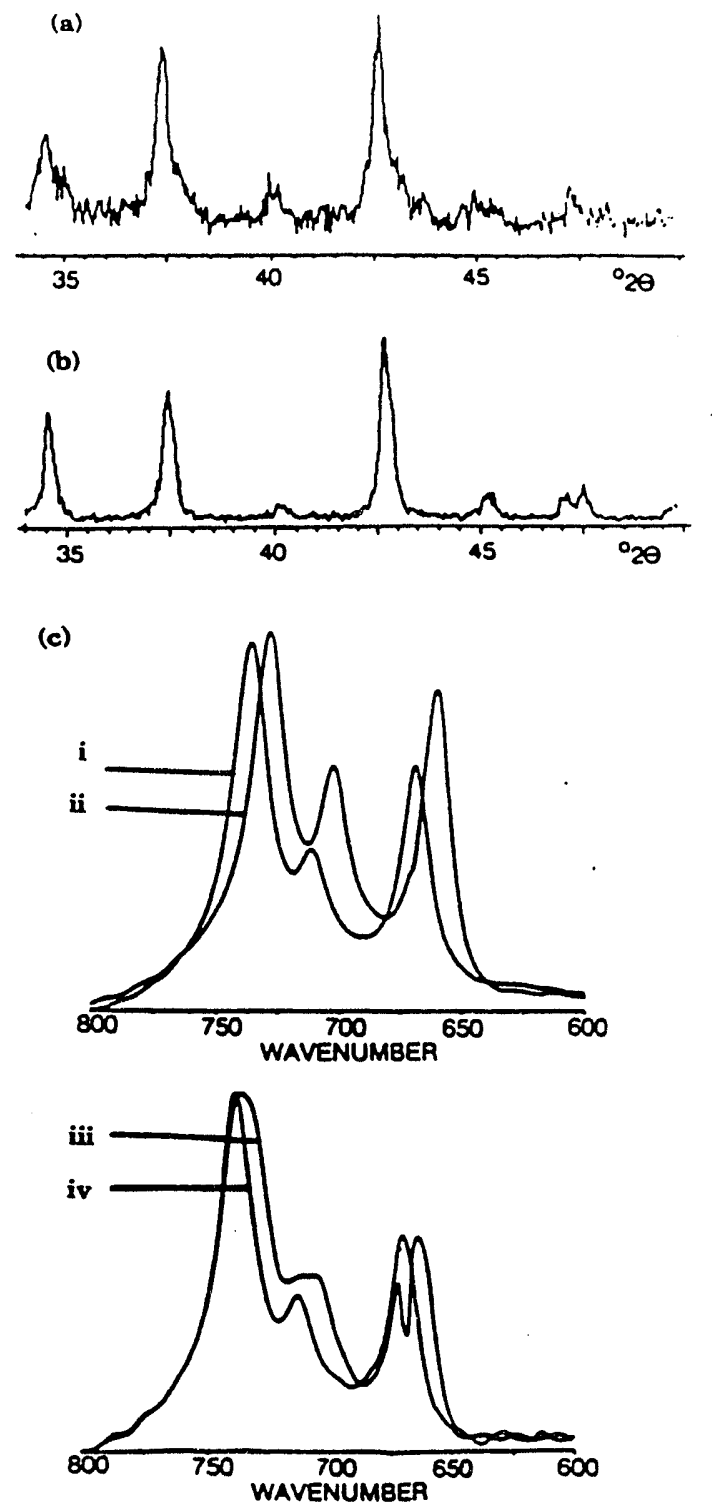

Figure 5.10: Powder X-ray diffaction patterns of: (a) 1:4 physical mixture of $\mathrm{Na}_{8} \mathrm{Cl}_{2}$-sodalite, and $\mathrm{Na}_{8} \mathrm{I}_{2}$-sodalite, respectively; (b) $\mathrm{Na}_{8} \mathrm{Cl}_{1.1} \mathrm{I}_{0.9}-$ sodalite, chemically synthesized, and (c) Mid-IR spectra of: (i) $\mathrm{Na}_{8} \mathrm{Cl}_{2}-$ sodalite; (ii) $\mathrm{Na}_{8} \mathrm{I}_{2}$-sodalite; (iii) 1:1 physical mixture of $\mathrm{Na}_{8} \mathrm{Cl}_{2}$-sodalite and $\mathrm{Na}_{8} \mathrm{I}_{2}$-sodalite; (iv) chemically synthesized $\mathrm{Na}_{8} \mathrm{Cl}_{1.86} \mathrm{I}_{0.14}$-sodalite. 
(A)

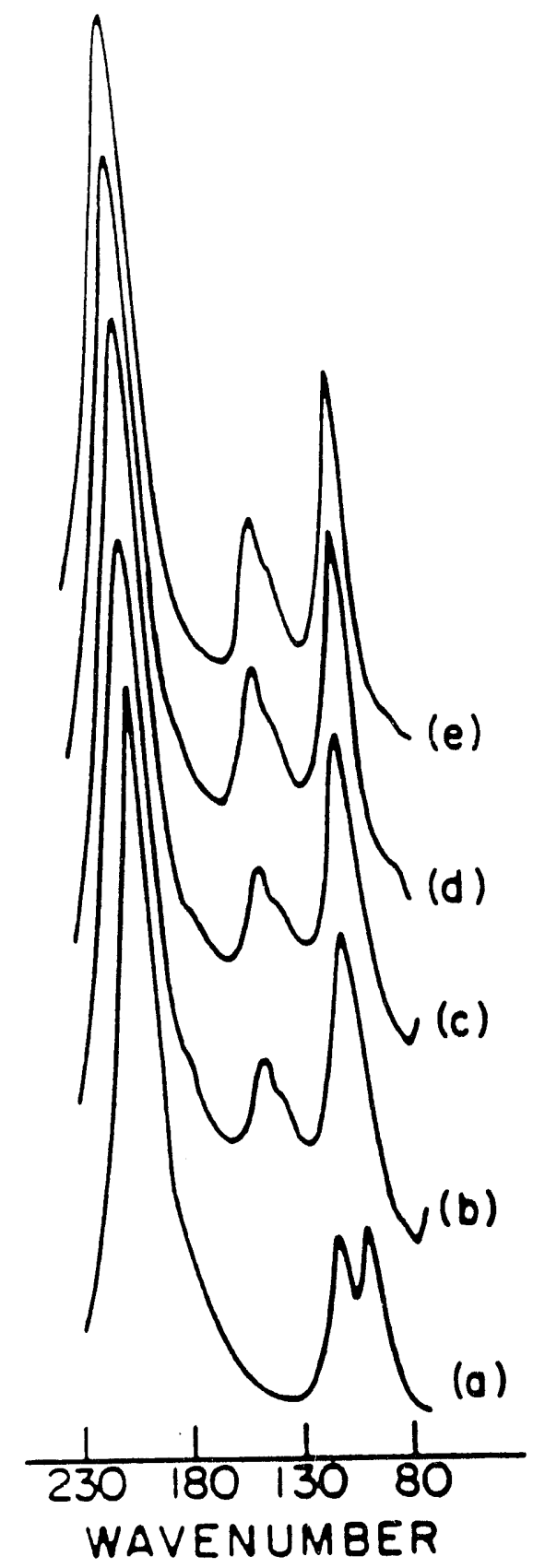

(B)

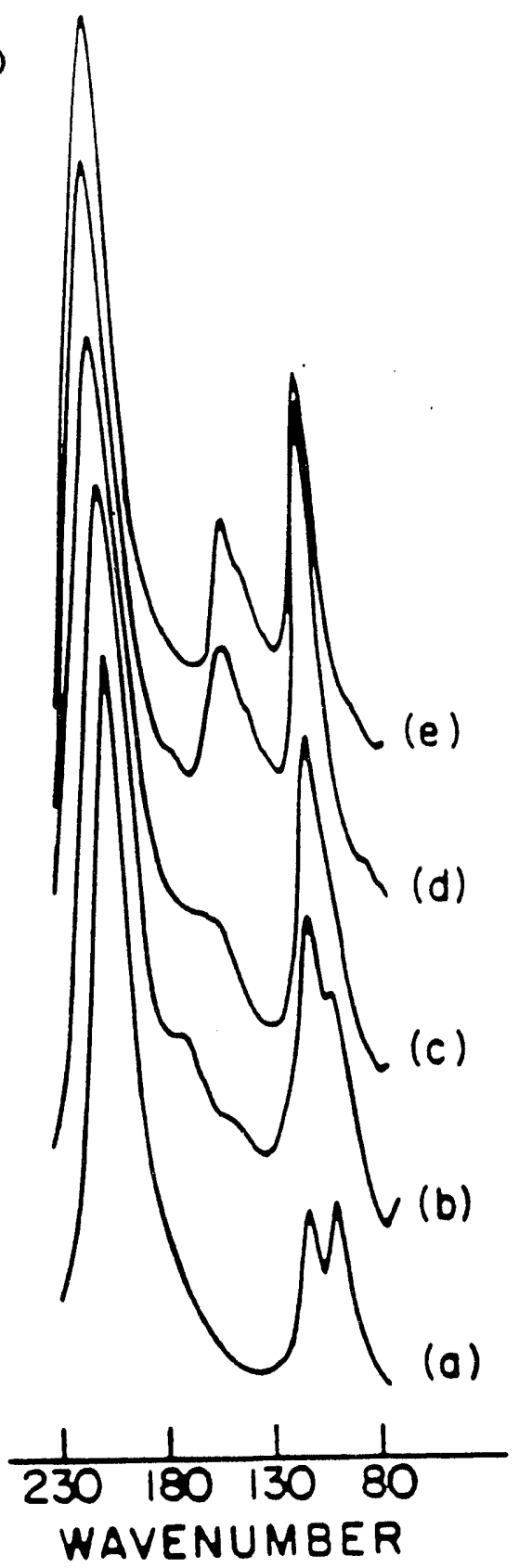

Figure 5.11: (A) Series of far-IR spectra of physical mixtures of $\mathrm{Na}_{8} \mathrm{Cl}_{2}$ sodalite: $\mathrm{Na}_{8} \mathrm{I}_{2}$-sodalite in the following ratios: (a) $1: 0$; (b) $10: 1$; (c) $1: 1$; (d) $3: 7$; (e) $0: 1$. (B) Series of far-IR spectra of the chemically synthesized materials:

(a) $\mathrm{Na}_{8} \mathrm{Cl}_{2}$-sodalite; (b) $\mathrm{Na}_{8} \mathrm{Cl}_{1.96} \mathrm{I}_{0.04}$-sodalite; (c) $\mathrm{Na}_{8} \mathrm{Cl}_{1.9} \mathrm{I}_{0.1}$-sodalite;

(d) $\mathrm{Na}_{8} \mathrm{Cl}_{1.1} \mathrm{I}_{0.9}$-sodalite; (e) $\mathrm{Na}_{8} \mathrm{I}_{2}$-sodalite 
sodalites shown in Figure 5.11(B), feature new cation/anion-coupled translational modes $\left[200-50 \mathrm{~cm}^{-1}\right]$ which are different from the cation and anion modes detected in the physically prepared samples, shown in Figure 5.11(A). This observation is explained in terms of coupling between the $\mathrm{Na}_{4} \mathrm{I}$ and $\mathrm{Na}_{4} \mathrm{Cl}$ clusters formed in the chemically synthesized materials $[119,120]$.

${ }^{27} \mathrm{Al}$ and ${ }^{23} \mathrm{Na}$ DOR spectra of mixed-halide sodalites are shown in Figure 5.12. Physically mixed samples of $\mathrm{NaCl}$-sodalite and $\mathrm{NaI}$-sodalite, shown in Figure 5.12(a), feature two distinct resonances, at 6.3 and $3.2 \mathrm{ppm}$, respectively, for ${ }^{23} \mathrm{Na}$, and at 64.2 and $61.2 \mathrm{ppm}$, respectively, for ${ }^{27} \mathrm{Al}$, in the anticipated positions for separate $\mathrm{Na}_{4} \mathrm{I}$ and $\mathrm{Na}_{4} \mathrm{Cl}$ cages. Chemically prepared mixed-halide samples, on the other hand, exhibit peaks at different positions from the physical mixture. When small amounts of chloride are displaced by iodide in the $\mathrm{Na}_{8} \mathrm{Cl}_{2}$-sodalite lattice, yielding $\mathrm{Na}_{8} \mathrm{Cl}_{1.9} \mathrm{I}_{0.1}$-sodalite, Figure 5.12(b), both aluminum and sodium resonances are shifted in the direction of the ${ }^{23} \mathrm{Na}$ position in $\mathrm{Na}_{8} \mathrm{I}_{2}$-sodalite. The same effect is observed for the ${ }^{23} \mathrm{Na}$ and ${ }^{27} \mathrm{Al}$ resonances of $\mathrm{Na}_{8} \mathrm{I}_{2}$-sodalite upon chemical incorporation of $\mathrm{Cl}^{-}$into the cavities, as shown for $\mathrm{Na}_{8} \mathrm{Cl}_{0.5} \mathrm{I}_{1.5}$-sodalite, Figure $5.12(\mathrm{c})$. Overall, the ${ }^{27} \mathrm{Al}$ and ${ }^{23} \mathrm{Na}$ resonance positions in the chemically-synthesized samples can be considered as a weighted-average of the anion content in the sodalite. Indeed, extended Hückel molecular orbital [EHMO] calculations on two adjacent sodalite cages containing $\mathrm{Na}_{4} \mathrm{X}$ clusters $[\mathrm{X}=\mathrm{Cl}$ and $\mathrm{I}]$ indicate that the charge on $\mathrm{Na}^{+}$increases as iodide replaces chloride in neighboring cavities [122]. As mentioned previously, an additional contribution to the shielding of the sodium nuclei upon incorporation of $\mathrm{I}^{-}$anions may arise from an increase in the size of the unit cell. 

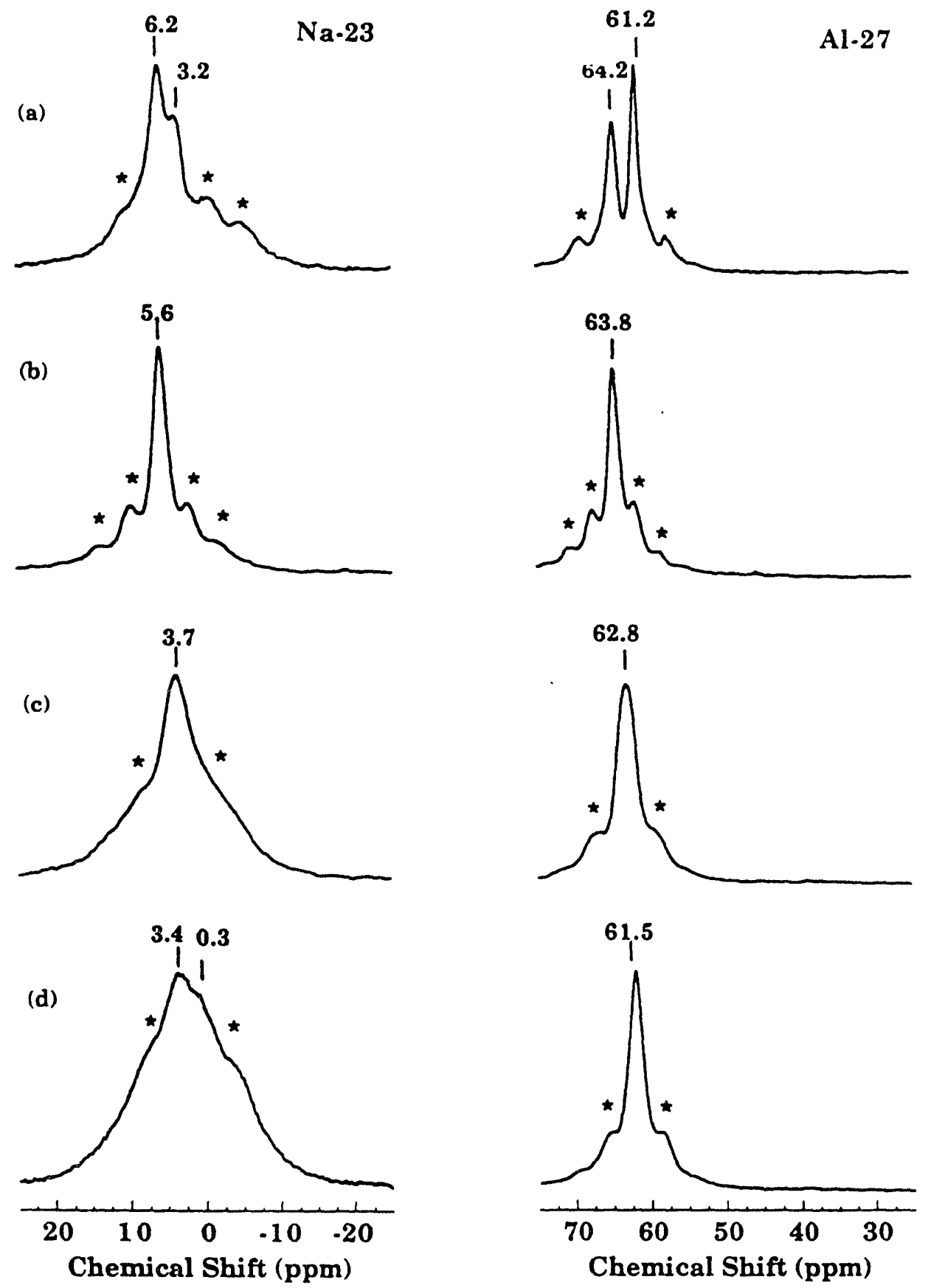

Figure 5.12: ${ }^{23} \mathrm{Na}$ and ${ }^{27} \mathrm{Al}$ DOR spectra of mixed halide sodalites: (a) 5:4 physical mixture of $\mathrm{Na}_{8} \mathrm{Cl}_{2}$-sodalite and $\mathrm{Na}_{8} \mathrm{I}_{2}$-sodalite, respectively; (b) $\mathrm{Na}_{8} \mathrm{Cl}_{1.9} \mathrm{I}_{0.1}$-sodalite; (c) $\mathrm{Na}_{8} \mathrm{Cl}_{0.5} \mathrm{I}_{1.5}$-sodalite; (d) $\mathrm{Na}_{8} \mathrm{Cl}_{1.1} \mathrm{I}_{0.9}$-sodalite. The asterisks indicate spinning sidebands. 
Significantly different results are obtained for $\mathrm{Na}_{8} \mathrm{Cl}_{1.1} \mathrm{I}_{0.9}$-sodalite, chemically synthesized. The ${ }^{27} \mathrm{Al}$ DOR resonance at $61.5 \mathrm{ppm}$, Figure $5.12(\mathrm{~d})$, indicates a shielded aluminum environment, farther upfield than what would be expected from a sample with roughly equivalent chloride and iodide compositions. The corresponding ${ }^{23} \mathrm{Na}$ spectrum features a peak at around $3 \mathrm{ppm}$ and a distinguishable shoulder at around $0 \mathrm{ppm}$. The two signals can be assigned to ${ }^{23} \mathrm{Na}$ in chloride and iodide cages, respectively, though both resonances are shifted noticeably upfield. This shielding effect cannot be entirely traced to a change in the framework dimensions to accomodate chloride and iodide, since this fails to explain the upfield shift of the ${ }^{23} \mathrm{Na}$ resonances from sodium cations in both cavities. This result might indicate electronic coupling between clusters throughout the aluminosilicate framework. Intracavity coupling may alter the electron density within the cages, placing higher average charge around the sodium nuclei.

\section{7 $\mathrm{Ag}^{+}$Exchange of Sodium,bromo-Sodalites}

\subsubsection{Cation Distribution}

$\mathrm{Ag}^{+}$Ion-exchanging sodium,bromo-sodalite produces semiconductor-component superlattice structures [118]. For the present study, progressive silver-exchange with sodium, bromo-sodalites was carried out, yielding $\mathrm{Na}_{8-p} \mathrm{Ag}_{p} \mathrm{Br}_{2}$-sodalite. The sodium environments, as well as framework structural properties, are examined at various stages of the cation exchange.

First, the exchange process is examined in sodalite materials which contain known amounts of "defects", specifically $\mathrm{OH}^{-}$or anion-empty cages. The $\mathrm{Ag}^{+}$ 


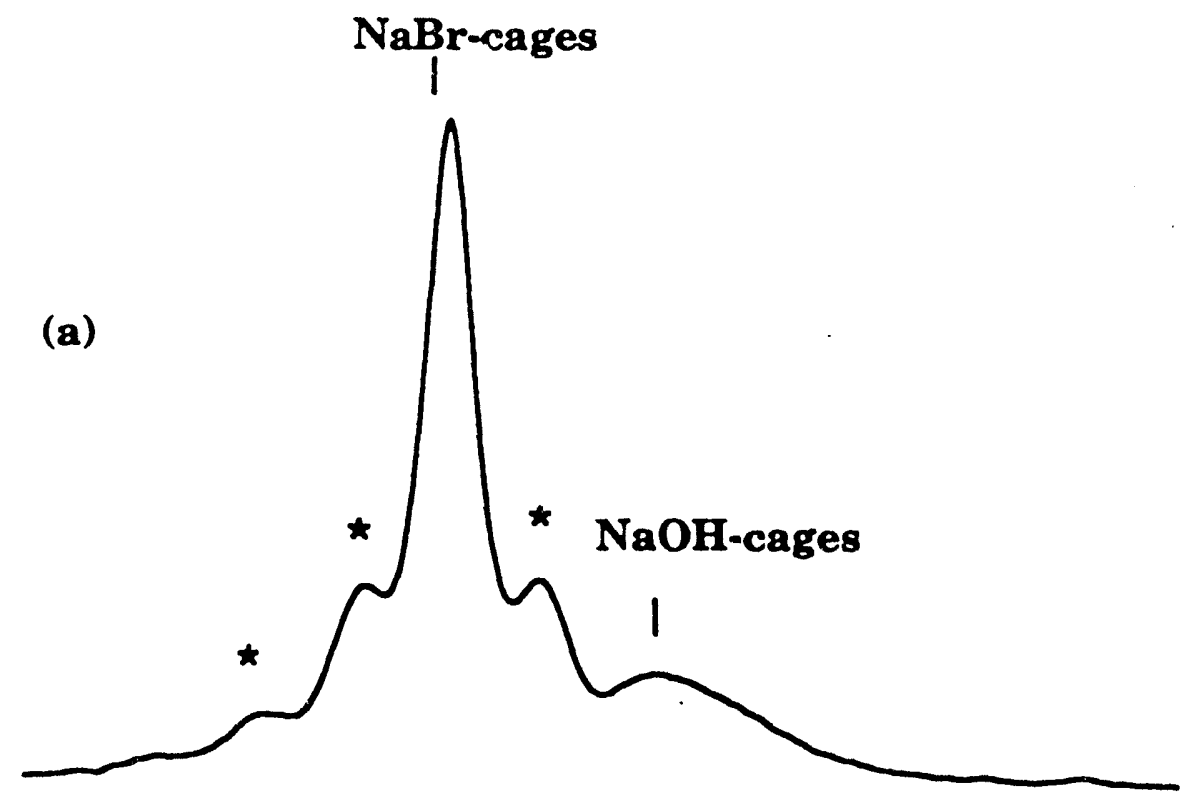

(b)

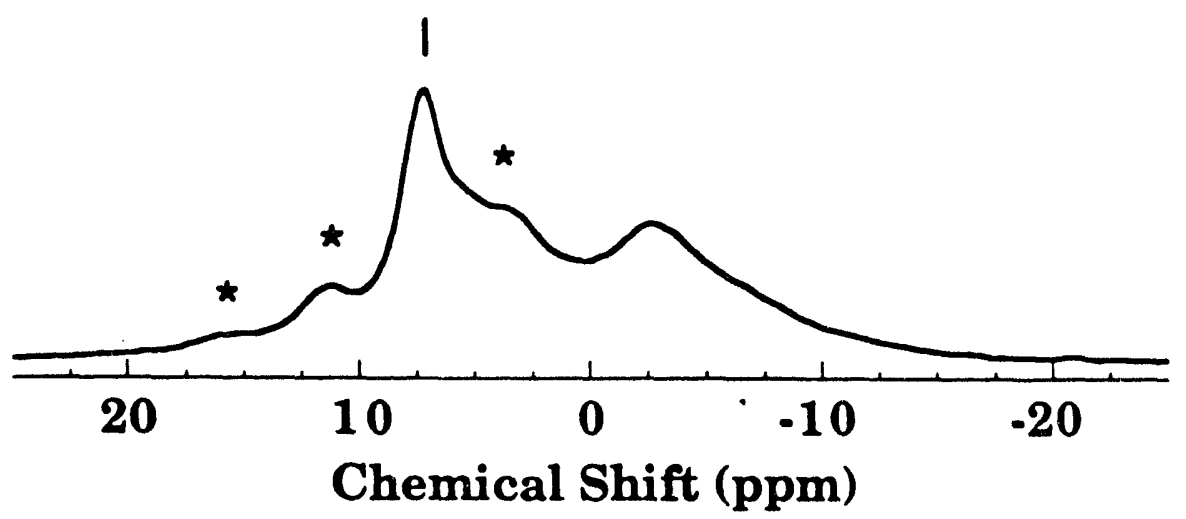

Figure 5.13: ${ }^{23} \mathrm{Na}$ DOR spectra of sodium,bromo-hydroxy-sodalite before and after silver exchange: (a) $\mathrm{Na}_{8} \mathrm{Br}_{1.2}(\mathrm{OH})_{0.8}$-sodalite; (b) $\mathrm{Na}_{6} \mathrm{Ag}_{2} \mathrm{Br}_{1.2}(\mathrm{OH})_{0.8}$ sodalite. The asterisks indicate spinning sidebands of the outer rotor. 

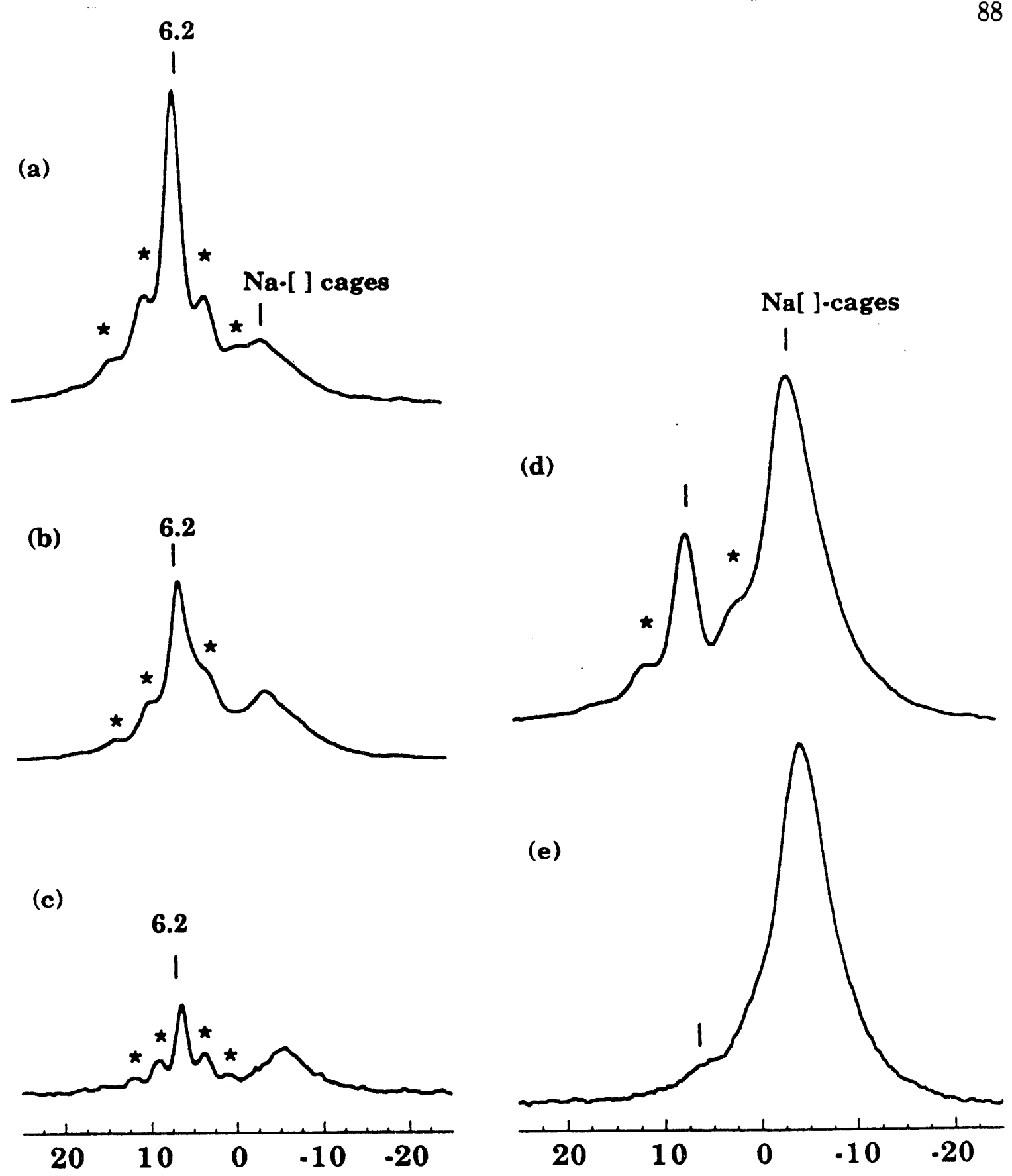

Figure 5.14: ${ }^{23} \mathrm{Na}$ DOR spectra of sodium,bromo-sodalites, which contain halide-free cages, before and after silver exchange ([ ]=empty cage): (a) $\mathrm{Na}_{7.25} \mathrm{Br}_{1.25}[]_{0.75}$-sodalite; (b) $\mathrm{Na}_{6.25} \mathrm{Ag}_{1} \mathrm{Br}_{1.25}[]_{0.75}$-sodalite; (c) $\mathrm{Na}_{1} \mathrm{Ag}_{6.25} \mathrm{Br}_{1.25}[]_{0.75}$-sodalite. (d) $\mathrm{Na}_{6.2} \mathrm{Br}_{0.2}[]_{1.8}$-sodalite; (e) $\mathrm{Na}_{4.2} \mathrm{Ag}_{2} \mathrm{Br}_{0.2}[]_{1.8}$-sodalite. The asterisks indicate spinning sidebands of the outer rotor. 
exchange reaction yields $\mathrm{Na}_{8-p} \mathrm{Ag}_{p}(\mathrm{OH})_{n} \mathrm{Br}_{2-n}$-sodalite for the $\mathrm{OH}^{-}$-containing material, and $\mathrm{Na}_{8-p-n} \mathrm{Ag}_{p}[]_{n} \mathrm{Br}_{2-n}$-sodalite (where [ ] denotes anion-empty cages), respectively. In these two classes of compounds one detects a clear preference for silver exchange into halide-containing cages, and into neither hydroxide-containing, nor halide-free cavities, Figures 5.13 and 5.14, respectively. As shown in Figure 5.13 , the ${ }^{23} \mathrm{Na}$ resonance associated with the sodium, bromide cavities diminishes upon $\mathrm{Ag}^{+}$exchange, while the intensity of the sodium resonance in hydroxidecontaining cages essentially remains constant.

Similarly, this observation holds true for anion-empty sodalite cavities. Figure $5.14(\mathrm{a}-\mathrm{c})$ clearly shows significantly fewer sodium cations in halide-containing cages, relative to those in anion-free environments, for higher silver loadings. Such preferential $\mathrm{Ag}^{+}$exchange into cavities with halide anions, and not into cages containing $\mathrm{Na}_{3} \cdot \mathrm{H}_{2} \mathrm{O}$, persists even when there is a low concentration of $\mathrm{Br}^{-}$-containing cages, Figure 5.14(d,e).

Preferred silver exchange into halide-containing cavities is manifested even at samples with already high silver loading, Figure 5.14. This observation is important because powder XRD measurements [119] have indicated that the $\mathrm{Ag} \cdot \mathrm{Br}$ internuclear distance in the $\mathrm{Na}_{4-p} \mathrm{Ag}_{p} \mathrm{Br}$ clusters lengthens when the number of $\mathrm{Ag}^{+}$cations increase. The lengthening of the $\mathrm{Ag} \cdots \mathrm{Br}$ distance is associated with a decrease in the covalency of the $\mathrm{Ag}-\mathrm{Br}$ bond. Thus, the silver preference cannot be assigned solely to a stronger covalent bond which forms between the silver and halides; a bond which in principle is stronger than the respective silver-hydroxide bond [105].

A possible explanation to account for the low affinity of $\mathrm{Ag}^{+}$cation for exchanging $\mathrm{Na}^{+}$at the anion-empty and hydroxide-containing cages, is the higher hydration 
energy of $\mathrm{Na}^{+}$compared to $\mathrm{Ag}^{+}[-406 \mathrm{~kJ} / \mathrm{mol}[105]$ and $-339 \mathrm{~kJ} / \mathrm{mol}$ [128], respectively], which induces more effective complexation between $\mathrm{Na}^{+}$, rather than $\mathrm{Ag}^{+}$, and hydroxide or water. Thus, $\mathrm{Na}^{+}$cations may experience more favorable "solvation" in the halide-free and $\mathrm{OH}^{-}$-containing cages than $\mathrm{Ag}^{+}$cations, as the two types of cavities host imbibed water molecules.

\subsubsection{Siructural and Electronic Effects of $\mathrm{Ag}^{+}$Cation- Exchange}

Previous studies of $\mathrm{Na}_{8-p} \mathrm{Ag}_{p} \mathrm{Br}_{2}$-sodalite indicate a statistical distribution of silver atoms within the sodalite lattice, rather than creation of aggregates distributed inhomogenously throughout the material $[118,119]$. The ${ }^{23} \mathrm{Na}$ resonances associated with the bromide cages are affected by silver loading in a manner which is consistent with the above description, Figure 5.15. One observes, for example, symmetrical peaks in the DOR spectra, whose centers-of-mass move upfield with silver loading. This indicates a different average chemical environment rather than a superposition of mixed phases. Further information can be extracted from the peak positions: Whereas the halide-cage sodium peak is shifted slightly downfield as the silver content is increased from 0 to 2.7 atoms per unit cell, Figure 5.15(a-d), a somewhat abrupt jump, from $\approx 7 \mathrm{ppm}$ to $5.7 \mathrm{ppm}$, is observed when four and more $\mathrm{Ag}^{+}$cations are loaded per unit cell, Figure 5.15(e,f). In addition, broadening of the peaks is observed.

Application of DOR at $11.7 \mathrm{~T}$ enables one, using Equations 3.1 and 3.2 , to estimate the isotropic chemical shift and quadrupolar contributions to the observed

${ }^{23} \mathrm{Na}$ resonance position, and the results are shown in Table 5.3 and Figure 5.16. 


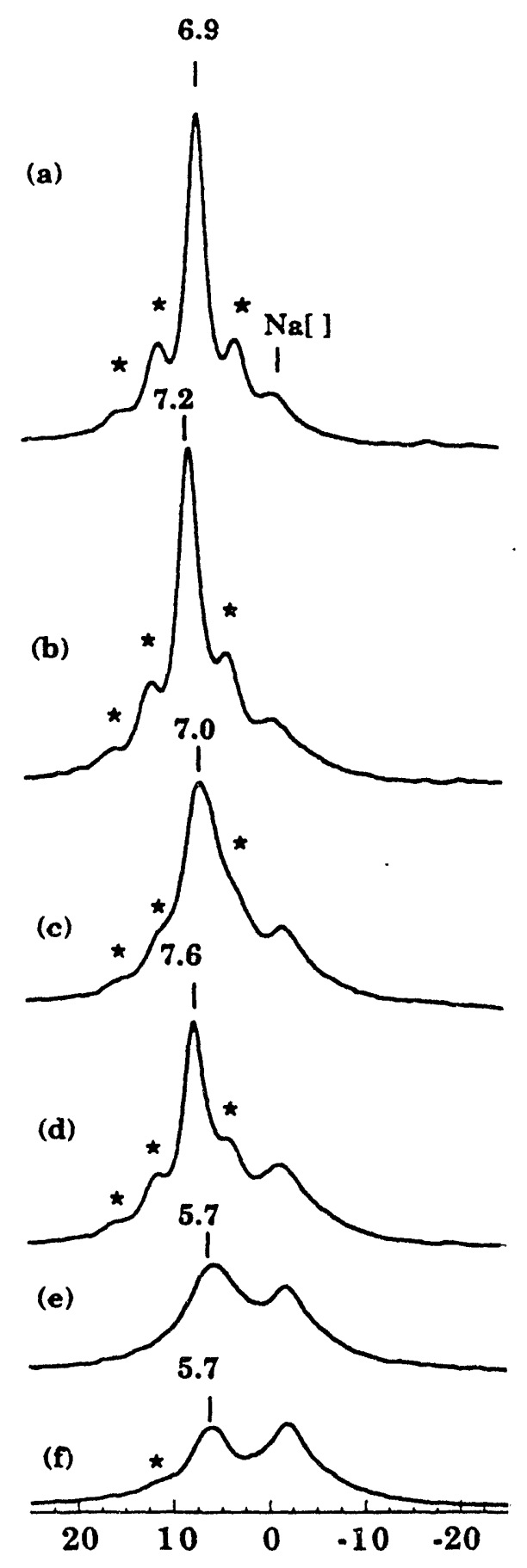

Figure 5.15: ${ }^{23} \mathrm{Na}$ DOR spectra of sodium,bromo-sodalite at different stages of $\mathrm{Ag}^{+}$cation-exchange: (a) $\mathrm{Na}_{8} \mathrm{Br}_{2}$-sodalite; (b) $\mathrm{Na}_{7.2} \mathrm{Ag}_{0.8} \mathrm{Br}_{2}$-sodalite; (c) $\mathrm{Na}_{6.1} \mathrm{Ag}_{1.9} \mathrm{Br}_{2}$-sodalite; (d) $\mathrm{Na}_{5.3} \mathrm{Ag}_{2.7} \mathrm{Br}_{2}$-sodalite; (e) $\mathrm{Na}_{4} \mathrm{Ag}_{4} \mathrm{Br}_{2}$-sodalite; (f) $\mathrm{Na}_{2.8} \mathrm{Ag}_{5.2} \mathrm{Br}_{2}$-sodalite. The halide-free defect cages present in the sodalite framework, see text, are not accounted for in the notation. The asterisks indicate spinning sidebands of the outer rotor. 
Table 5.3: ${ }^{23} \mathrm{Na}$ resonance positions at $11.7 \mathrm{~T}$ and $9.4 \mathrm{~T}$, and calculated NMR parameters for various silver-exchanged $\mathrm{Na}_{8} \mathrm{Br}_{2}$-sodalites. The isotropic chemical shifts, $\delta_{c s, i s o}$, and quadrupolar products, $P_{Q}$, were calculated using Equations 3.1 and 3.2 .

\begin{tabular}{|c|c|c|c|c|}
\hline \hline $\mathrm{Ag}^{+}$per u.c. & $\delta_{\text {obs }}(11.7 \mathrm{~T})$ & $\delta_{\text {obs }}(9.4 \mathrm{~T})$ & $\delta_{c s, \text { iso }}$ & $P_{Q}$ \\
\hline 0 & $6.9 \mathrm{ppm}$ & $6.0 \mathrm{ppm}$ & $8.5 \mathrm{ppm}$ & $1.1 \mathrm{MHz}$ \\
0.8 & $7.2 \mathrm{ppm}$ & $6.0 \mathrm{ppm}$ & $.9 .3 \mathrm{ppm}$ & $1.5 \mathrm{MHz}$ \\
1.9 & $7.0 \mathrm{ppm}$ & $6.1 \mathrm{ppm}$ & $8.6 \mathrm{ppm}$ & $1.1 \mathrm{MHz}$ \\
2.7 & $7.6 \mathrm{ppm}$ & $6.2 \mathrm{ppm}$ & $10.1 \mathrm{ppm}$ & $1.7 \mathrm{MHz}$ \\
4 & $5.7 \mathrm{ppm}$ & $3.6 \mathrm{ppm}$ & $9.5 \mathrm{ppm}$ & $2.6 \mathrm{MHz}$ \\
5.2 & $5.7 \mathrm{ppm}$ & $3.6 \mathrm{ppm}$ & $9.5 \mathrm{ppm}$ & $2.6 \mathrm{MHz}$ \\
\hline \hline
\end{tabular}

While the isotropic chemical shifts of the ${ }^{23} \mathrm{Na}$ nuclei hardly change, Figure $5.16(\mathrm{~b})$, the quadrupolar interaction seems to increase when the silver loading is raised to beyond two atoms per unit cell, Figure 5.16(c).

In this context, a more asymmetric distribution of charge around the $\mathrm{Na}^{+}$nuclei is consistent with greater electron density on the framework oxygens upon silver loading. This effect most likely originates from the localization of electron density in covalent $\mathrm{Ag}-\mathrm{Br}$ bonds of $\mathrm{Na}_{4-n} \mathrm{Ag}_{n} \mathrm{Br}$ clusters, which is known to diminish with $\mathrm{Ag}^{+}$loading $[118,119]$. Consequently, the "effective" electronegativity of the $\mathrm{Br}^{-}$decreases with $\mathrm{Ag}^{+}$loading, causing a more asymmetric electronic environment around the remaining $\mathrm{Na}^{+}$cations. It seems, however, that the change in the quadrupolar interaction experienced by the $\mathrm{Na}^{+}$is not gradual, but rather abrupt beyond the one-silver-per-cavity loading threshold, Figure 5.16(c). This 


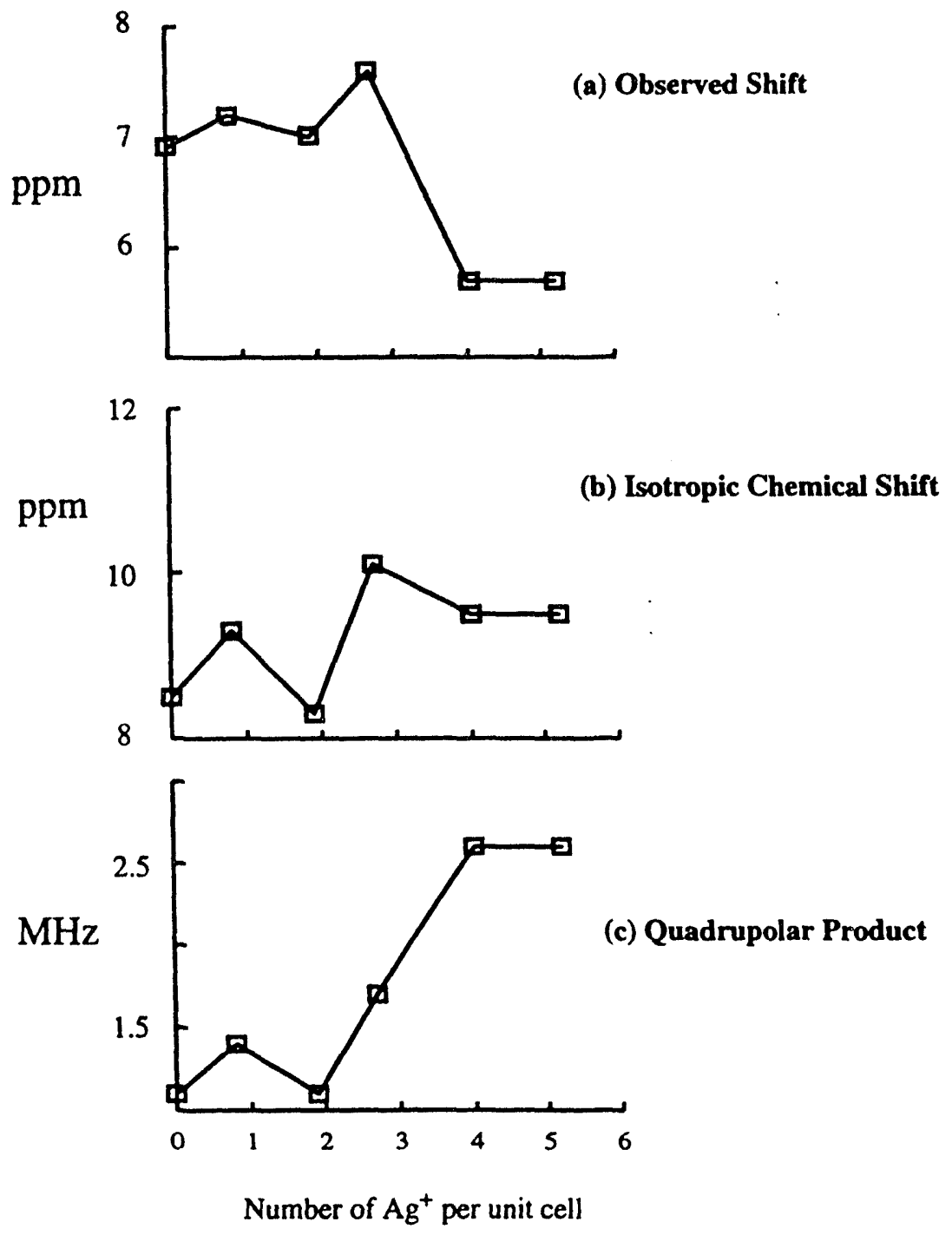

Figure 5.16: (a) Observed ${ }^{23} \mathrm{Na}$ DOR resonance positions in $11.7 \mathrm{~T}$, (b) isotropic chemical shifts, and (c) quadrupolar products as a function of the amount of silver exchanged in a unit cell of $\mathrm{Na}_{8} \mathrm{Br}_{2}$-sodalite. The isotropic chemical shifts were calculated from Equation 3.1 using results from DOR experiments at two magnetic field strengths; the quadrupolar products were calculated using Equation 3.2. 
"step" might signal the development of intercavity electronic coupling between $\mathrm{Ag}^{+}$-exchanged sodium, bromide clusters.

Indeec, previous optical reflectance, $\mathrm{X}$-ray diffraction and infrared results have indicated the possible formation of an expanded $\mathrm{AgBr}$ supralattice throughout the sodalite structure when silver and bromide loadings are sufficiently high [118, 119, 122]. Moreover, it should be noted that no change in the ${ }^{23} \mathrm{Na}$ DOR resonance positions is observed in the $\mathrm{Na}_{8-x} \mathrm{Ag}_{x} \mathrm{Br}_{2-y}[]_{y}$-sodalite series, Figure $5.14(\mathrm{a}-\mathrm{c})$. These are materials for which electronic coupling between the halide cages might not occur, since they contain high abundance of anion-empty cavities. The positions of the ${ }^{23} \mathrm{Na}$ resonances for sodium in halide cages in those samples remain identical even upon high degree of $\mathrm{Ag}^{+}$cation-exchange.

${ }^{81} \mathrm{Br}$ MAS results, [129], shown in Figures 5.17 and 5.18, yield further evidence of a change in the charge distribution in $\mathrm{Ag}^{+}$-exchanged sodium,bromo-sodalite. Figure 5.17 features ${ }^{81} \mathrm{Br}$ MAS spectra of a series of $\mathrm{Ag}^{+}$-exchanged $\mathrm{Na}_{8} \mathrm{Br}_{2}$-sodalite. The ${ }^{81} \mathrm{Br}$ MAS results demonstrate a profound upfield shift of the ${ }^{81} \mathrm{Br}$ signal, at around $-550 \mathrm{ppm}$, which is associated with encpsulated $\mathrm{Ag}_{4} \mathrm{Br}$ clusters in $\mathrm{Ag}_{8} \mathrm{Br}_{2}-$ : sodalite [129]. The upfield shift is quite unexpected, since one anticipates a rather deshielded ${ }^{81} \mathrm{Br}$ environment in the more covalent-bonded $\mathrm{Ag}_{4} \mathrm{Br}$ clusters, compared with the encpsulated $\mathrm{Na}_{4} \mathrm{Br}$ tetrahedra [which give rise to the ${ }^{81} \mathrm{Br}$ peak at around -220 ppm, Figure 5.17 [129]]. Moreover, no upfield ${ }^{81} \mathrm{Br}$ signal is observed in $\mathrm{Ag}^{+}$-exchanged sodium,bromo-sodalite sample which contains a high abundance of anion-empty cavities, Figure 5.18. The high concentration of bromide-free cavities essentially prevents any electronic "communication", or coupling, between the encapsulated $\mathrm{Ag}_{4} \mathrm{Br}$ clusters in this material. 


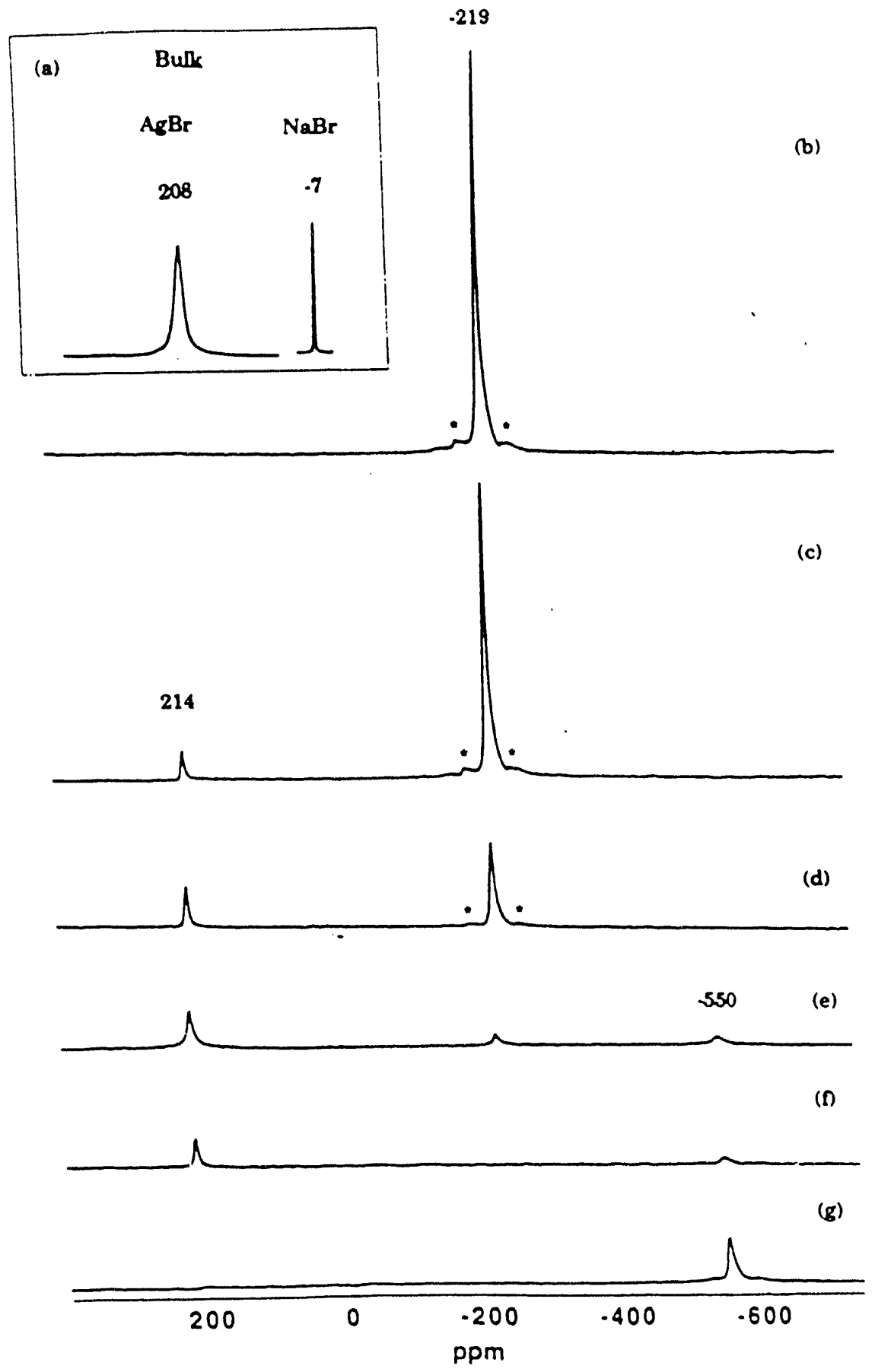

Figure 5.17: ${ }^{81} \mathrm{Br}$ MAS spectra of (a)bulk $\mathrm{NaBr}$ and $\mathrm{AgBr}$; and $\mathrm{Ag}^{+}$exchange products of $\mathrm{Na}_{8} \mathrm{Br}_{2}$-sodalite: (b) $\mathrm{Na}_{8} \mathrm{Br}_{2}$-sodalite (c) $\mathrm{Na}_{7.2} \mathrm{Ag}_{0.8} \mathrm{Br}_{2}-$ sodalite; (d) $\mathrm{Na}_{6} \mathrm{Ag}_{2} \mathrm{Br}_{2}$-sodalite; (e) $\mathrm{Na}_{4} \mathrm{Ag}_{4} \mathrm{Br}_{2}$-sodalite; (f) $\mathrm{Na}_{2.8} \mathrm{Ag}_{5.2} \mathrm{Br}_{2}$ sodalite; ( $\mathrm{g}$ ) $\mathrm{Ag}_{8} \mathrm{Br}_{2}$-sodalite. The asterisks indicate spinning sidebands. 

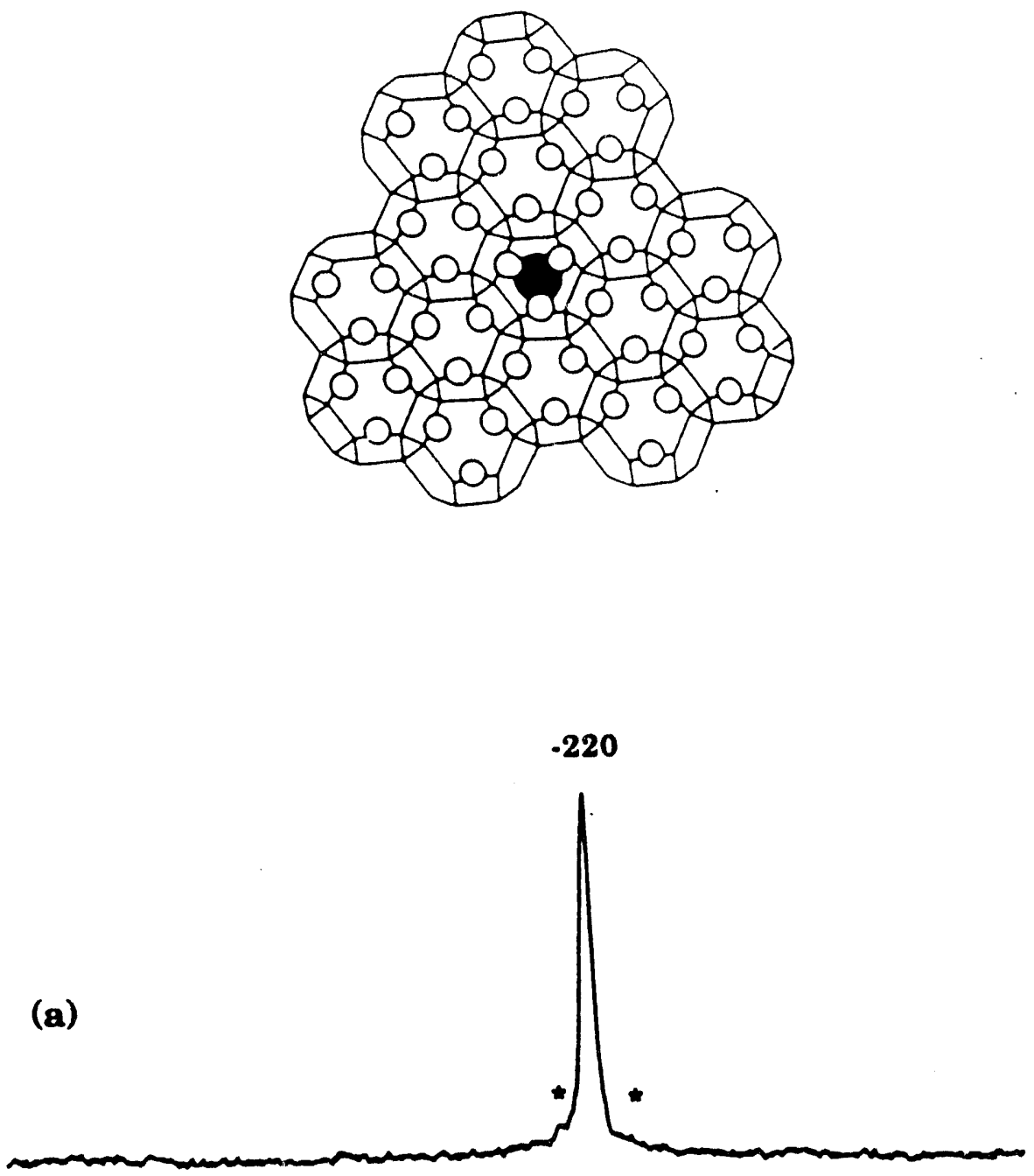

(b)

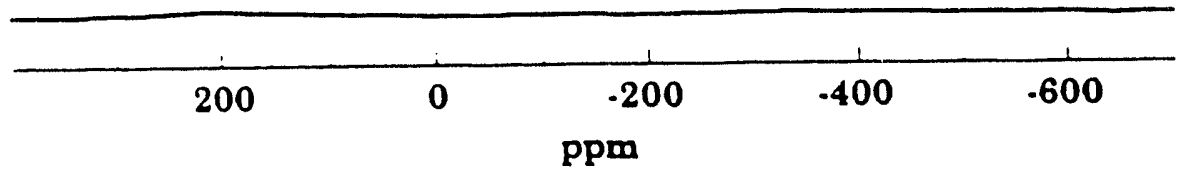

Figure 5.18: A schematic representation of the sodalite framework showing bromide-containing and bromide-free cavities in approximately 1:9 ratio, the black circle represents a $\mathrm{Br}^{-}$anion inside a cavity; ${ }^{81} \mathrm{Br}$ MAS spectra of the corresponding materials: (a) $\mathrm{Na}_{6.2} \mathrm{Br}_{0.2}[]_{1.8}$-sodalite; and (b) fully $\mathrm{Ag}^{+}$exchanged product, $\mathrm{Ag}_{6.2} \mathrm{Br}_{0.2}[]_{1.8}$-sodalite. The asterisks indicate spinning sidebands. 
${ }^{29} \mathrm{Si}$ and ${ }^{27} \mathrm{Al}$ NMR experiments did not detect any structural differences in the framework of the sodalites as a function of silver loading. This result stands in contrast to the sensitivity of ${ }^{27} \mathrm{Al}$ NMR to the different anions inside the sodalite cavities, Figure 5.8. Stronger space-filling effects are probably present for the different anions, as compared to the $\mathrm{Na}^{+}$and $\mathrm{Ag}^{+}$cations which possess almost identical ionic radii, $1.13 \AA$ and $1.14 \AA$, respectively [125]. The lack of apparent change in the NMR spectra of the framework nuclei also suggests that a relatively weak interaction exists between the silver and the framework atoms, consistent with the notion of a stronger interaction between the $\mathrm{Ag}^{+}$cations and the anions encapsulated within the cavities.

\subsection{Conclusions}

This study demonstrates the usefulness of double rotation NMR, complemented by MAS studies, in addressing structural and electronic questions concerning the preparation and assembly of sodalite supralattices. Information about cation-anion distributions, effects of defect cavities, and intercavity electronic coupling is obtained by performing MAS and DOR experiments on the ${ }^{29} \mathrm{Si}$ and ${ }^{27} \mathrm{Al}$ framework atoms, extraframework ${ }^{23} \mathrm{Na}$ cations, and ${ }^{81} \mathrm{Br}$ anions in the sodalite cages. The additional use of two magnetic fields provides accurate estimations of the isotropic chemical shifts and quadrupolar contributions to the DOR resonances.

Following insertion of various halide anions into the sodalite cages, ${ }^{27} \mathrm{Al}$ and, particularly, ${ }^{23} \mathrm{Na}$ NMR experiments yield subtle information on the distribution of electronic charge inside the cavities. The quadrupolar interactions and electronic shielding of the ${ }^{23} \mathrm{Na}$ nuclei increase as the charge polarity between the halide and 
framework oxygen increases, and the framework $\mathrm{Si}-\mathrm{O}-\mathrm{Al}$ bond angle increases. Examination of mixed-anion sodalites indicates that structural and electronic modifications occur within the framework. A unique shielding effect is observed for sodium nuclei in a sodalite lattice which hosts almost equal amounts of chloride and iodide, indicating a different electronic charge distribution within the cavities of the material.

Useful chemical information is also provided concerning the process of $\mathrm{Ag}^{+}$ cation-exchange into the sodalite cavities. A preference is detected for silver exchange of sodium cations in halide-containing cages, compared to $\mathrm{OH}^{-}$-containing or halide-free cavities. Changes in the electronic environment of the ${ }^{23} \mathrm{Na}$ nuclei are observed throughout the silver-exchange process. An increase in the quadrupolar interaction of the ${ }^{23} \mathrm{Na}$ nuclei is detected upon loading about two $\mathrm{Ag}^{+}$cations per unit cell. This result, combined with an extraordinary upfield shift of the ${ }^{81} \mathrm{Br}$ MAS resonance in $\mathrm{Ag}_{8} \mathrm{Br}_{2}$-sodalite, corroborates other data pointing to the onset of a semiconductor superlattice within the sodalite matrix. These are fundamental issues in understanding the compositional dependence of the band structures in this interesting class of advanced materials. 


\section{Chapter 6}

\section{${ }^{23} \mathrm{Na}$ DOR Studies of Cation}

\section{Exchange and Molecular}

\section{Adsorption in $\mathrm{Na}_{56} \mathrm{Y}$-zeolite}

\subsection{Abstract}

${ }^{23} \mathrm{Na}$ double rotation NMR for the first time distinguishes the three extraframework $\mathrm{Na}^{+}$cation sites in $\mathrm{Na}_{56} \mathrm{Y}$-zeolite. A combination of site-specific $\mathrm{Mo}(\mathrm{CO})_{6}$ adsorption, and $\mathrm{Tl}^{+}$and $\mathrm{Ca}^{2+}$ cation exchange, enables the assignment of the DOR resonances to the specific extraframework sites within the zeolite pores. Cationexchange pathways of monovalent and divalent cations are investigated, and the progressive depletion of $\mathrm{Na}^{+}$cations from distinct sites is observed. ${ }^{23} \mathrm{Na} \mathrm{DOR}$ experiments provide information on the adsorption of $\mathrm{Mo}(\mathrm{CO})_{6}, \mathrm{H}_{2} \mathrm{O}$ and $\mathrm{P}\left(\mathrm{CH}_{3}\right)_{3}$ guest-molecules in $\mathrm{Na}_{56} \mathrm{Y}$-zeolite. 


\subsection{Introduction}

The most common extraframework charge-balancing cation found in as - synthesized zeolites is sodium [1]. $\mathrm{Na}^{+}$cations, located at specific sites within the zeolite lattice, play an important role in determining adsorption, chemical and catalytic properties of the materials. Consequently, it is of great interest to understand the interactions of the $\mathrm{Na}^{+}$cations with the zeolite framework and the guest species, their coordination and chemical characteristics. Direct methods for elucidating details concerning structural and chemical aspects of the extraframework sodium cations, however, are usually neither straightforward nor unequivocal. In particular, as descibed in detail in Chapter 2, conventional solid state NMR studies of ${ }^{23} \mathrm{Na}$ nuclei in zeolites have had limited applicability due to the large quadrupolar broadening present in the NMR spectra. The DOR technique, however, dramatically alters the situation for quadrupolar nuclei like ${ }^{23} \mathrm{Na}\left(I=\frac{3}{2}\right)$. By removing anisotropic line broadening contributions, DOR becomes a high resolution spectral probe of structures, bonding, and dynamical aspects of quadrupolar nuclei in zeolites.

In this chapter, ${ }^{23} \mathrm{Na}$ DOR is employed to study cation-exchange and adsorption processes in $\mathrm{Na}_{56} \mathrm{Y}$-zeolite. Specifically, progressive adsorptions of $\mathrm{Mo}(\mathrm{CO})_{6}, \mathrm{H}_{2} \mathrm{O}$, and trimethylphosphine $\left[\mathrm{P}\left(\mathrm{CH}_{3}\right)_{3}\right.$, denoted $\left.\mathrm{PMe}_{3}\right]$, within the porous framework of $\mathrm{Na}_{56} \mathrm{Y}$-zeolite is examined. In addition, ${ }^{23} \mathrm{Na}$ DOR results enable one to investigate cation exchange processes in $\mathrm{Na}_{56} \mathrm{Y}$-zeolite by replacing the $\mathrm{Na}^{+}$cations with $\mathrm{Tl}^{+}$ and $\mathrm{Ca}^{2+}$. The results indicate that the $\mathrm{Na}^{+}$cations are exchanged at distinct sites within the unit cell of $\mathrm{Na}_{56} \mathrm{Y}$-zeolite. 


\subsection{Experimental Considerations}

High purity, crystalline zeolite $\mathrm{Y}$, with $\mathrm{Na}_{56}\left(\mathrm{AlO}_{2}\right)_{56}\left(\mathrm{SiO}_{2}\right)_{136} \cdot \mathrm{xH}_{2} \mathrm{O}$ unit cell composition, was obtained from UOP Corporation. In order to remove cation defect sites, thermally dehydrated/calcined $\mathrm{Na}_{56} \mathrm{Y}$ was slurried with $0.01 \mathrm{M} \mathrm{NaCl}, 0.01 \mathrm{M}$ $\mathrm{NaOH}$ solution and washed until free of $\mathrm{Cl}^{-}$. All zeolite samples were stored over saturated $\mathrm{NH}_{4} \mathrm{Cl}$ solution to ensure constant humidity until use. The thermal dehydration of $\mathrm{Na}_{56} \mathrm{Y}$ was carried out under dynamic vacuum [approximately $10^{-5} \mathrm{Torr}$ ], using an Omega Series model no. CN-2010 programmable temperature controller. The dehydration followed a preset temperature schedule: $25 \mathrm{C}-100 \mathrm{C}$ over $1 \mathrm{hr}, 1 \mathrm{hr}$ at $100 \mathrm{C}, 100 \mathrm{C}-450 \mathrm{C}$ over $3 \mathrm{hrs}$, and $5 \mathrm{hr}$ at $450 \mathrm{C}$. Calcination of the materials for $1 \mathrm{hr}$ in a static $\mathrm{O}_{2}$ atmosphere of 300 Torr at $450 \mathrm{C}$, followed by vacuum pumping at this temperature, ensured homogeneity of the samples. The degree of dehydration was judged by the flatness of the baseline in the mid-IR $\nu-\mathrm{OH}$ and $\delta-\mathrm{OH}$ deformation regions, $3400-3700 \mathrm{~cm}^{-1}$ and $1600-1650 \mathrm{~cm}^{-1}$, respectively. Quantitative adsorption of $\mathrm{H}_{2} \mathrm{O}$ and $\mathrm{PMe}_{3}$ was achieved by exposing $\mathrm{Na}_{56} \mathrm{Y}$ to the gaseous materials, respectively. The $\mathrm{n}\left\{\mathrm{Mo}(\mathrm{CO})_{6}\right\}-\mathrm{Na}_{56} \mathrm{Y}$ samples were prepared using quantitative vapor adsorption of the organometallic compound into the dehydrated zeolite. The preparation methods are described in detail elsewhere $[130,131]$.

${ }^{23} \mathrm{Na}$ DOR experiments were carried out at 11.7 Tesla on a Chemagnetics CMX500 spectrometer using a home-built DOR probe whose features are described in Appendix 1 [99]. The spinning speed was $5 \mathrm{kHz}$ for the inner rotor and $600-800 \mathrm{~Hz}$ for the outer one. All samples were loaded into the air-tight sample spinners in a dry argon glove box. 1000-3000 acquisitions were accumulated in each experiment using pulse length of $4 \mu \sec \left(25^{\circ}\right)$. For quantitative NMR measurements, identical 
sample-quantities were used, and the same number of transients acquired. The spectra were zero-filled to $2 \mathrm{~K}$ data points, with application of $200 \mathrm{~Hz}$ Lorentzian broadening. The external reference was $0.1 \mathrm{M} \mathrm{NaCl}$ solution.

\subsection{Adsorption of $\mathrm{Mo}(\mathrm{CO})_{6}$ in $\mathrm{Na}_{56} \mathrm{Y}$-zeolite}

A portion of $\mathrm{Na}_{56} \mathrm{Y}$-zeolite framework is shown in Figure 6.1. The framework of $\mathrm{Na}_{56} \mathrm{Y}$ consists of $\mathrm{AlO}_{4}$ and $\mathrm{SiO}_{4}$ tetrahedra which form a face-centered cubic

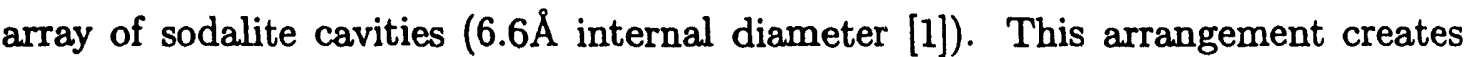
a diamond network of larger $13 \AA$ diameter supercages, of which there are eight in the cubic unit cell. Four distinct extraframework sites are located within the zeolite framework as indicated in the figure [1]: site I inside the hexagonal prism (located between two six-membered rings), site $\mathrm{I}^{\prime}$ within the sodalite cage (located above one six-ring), and two sites, II and III, inside the supercage (above six-, and four-rings, respectively).

${ }^{23} \mathrm{Na}$ NMR spectra of dehydrated $\mathrm{Na}_{56} \mathrm{Y}-$ zeolite are shown in Figure 6.2. The MAS spectrum, Figure 6.2(a), displays a peak around $-4 \mathrm{ppm}$, while features upfield are composed of quadrupolar broadened signals, and overlapping spinning sidebands. The ${ }^{23} \mathrm{Na}$ DOR spectrum, Figure $6.2(\mathrm{~b})$, yields higher resolution. The anisotropic quadrupolar broadening is averaged out in the DOR experiment and three distinct peaks appear in the spectrum: a prominent Gaussian around -4 ppm, and two weaker peaks, on top of a broad background signal and a sideband manifold, at $-29 \mathrm{ppm}$ and $-40 \mathrm{ppm}$, respectively.

In order to assign the ${ }^{23} \mathrm{Na}$ DOR signals to specific $\mathrm{Na}^{+}$cation sites, $\mathrm{Na}_{56} \mathrm{Y}-$ zeolite samples containing adsorbed $\mathrm{Mo}(\mathrm{CO})_{6}$ guest molecules were examined. 


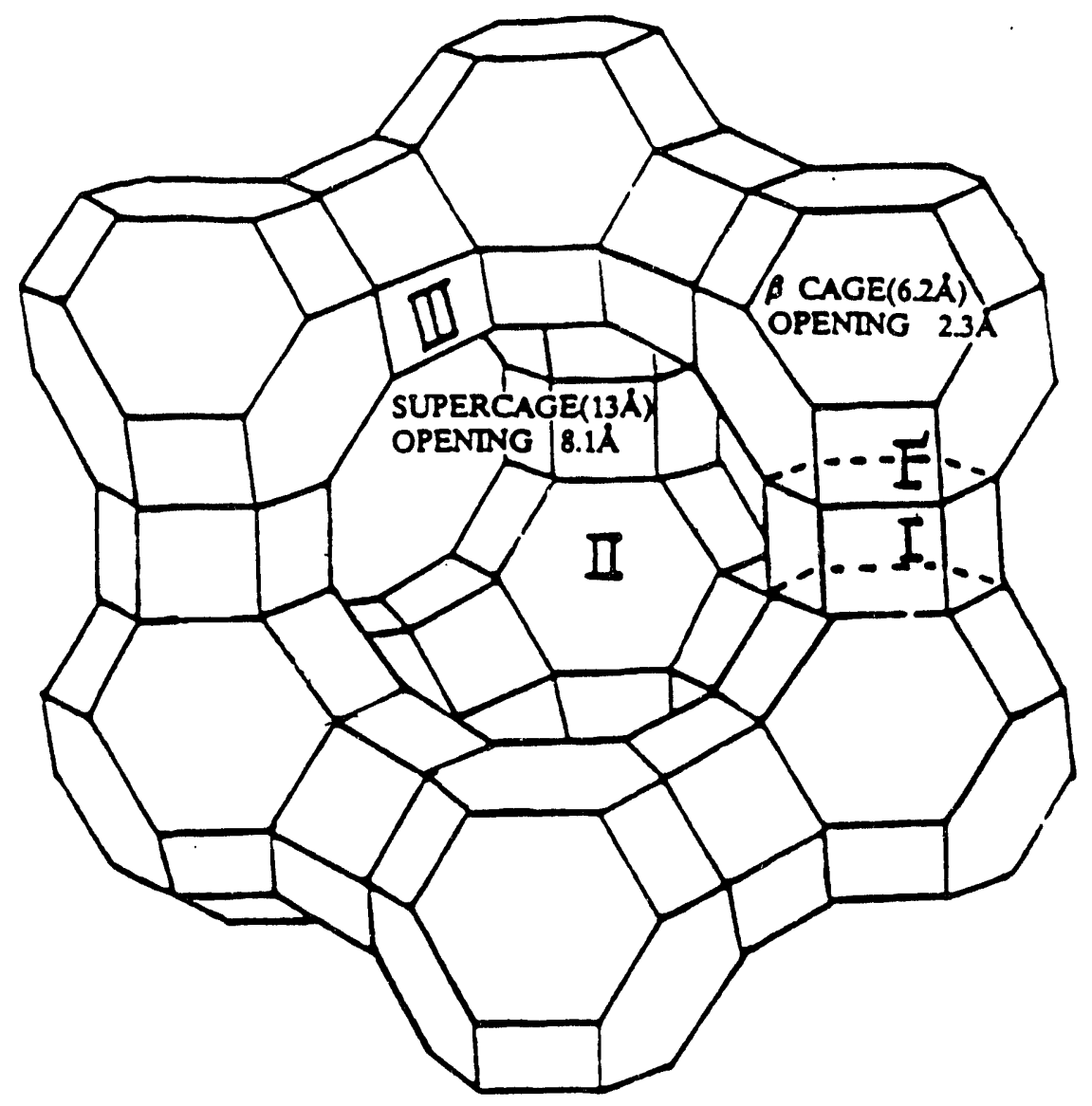

Figure 6.1: An illustration of part of the unit cell of $\mathrm{Na}_{56} \mathrm{Y}$-zeolite. Extraframework cation sites I, I', II, III are indicated. 


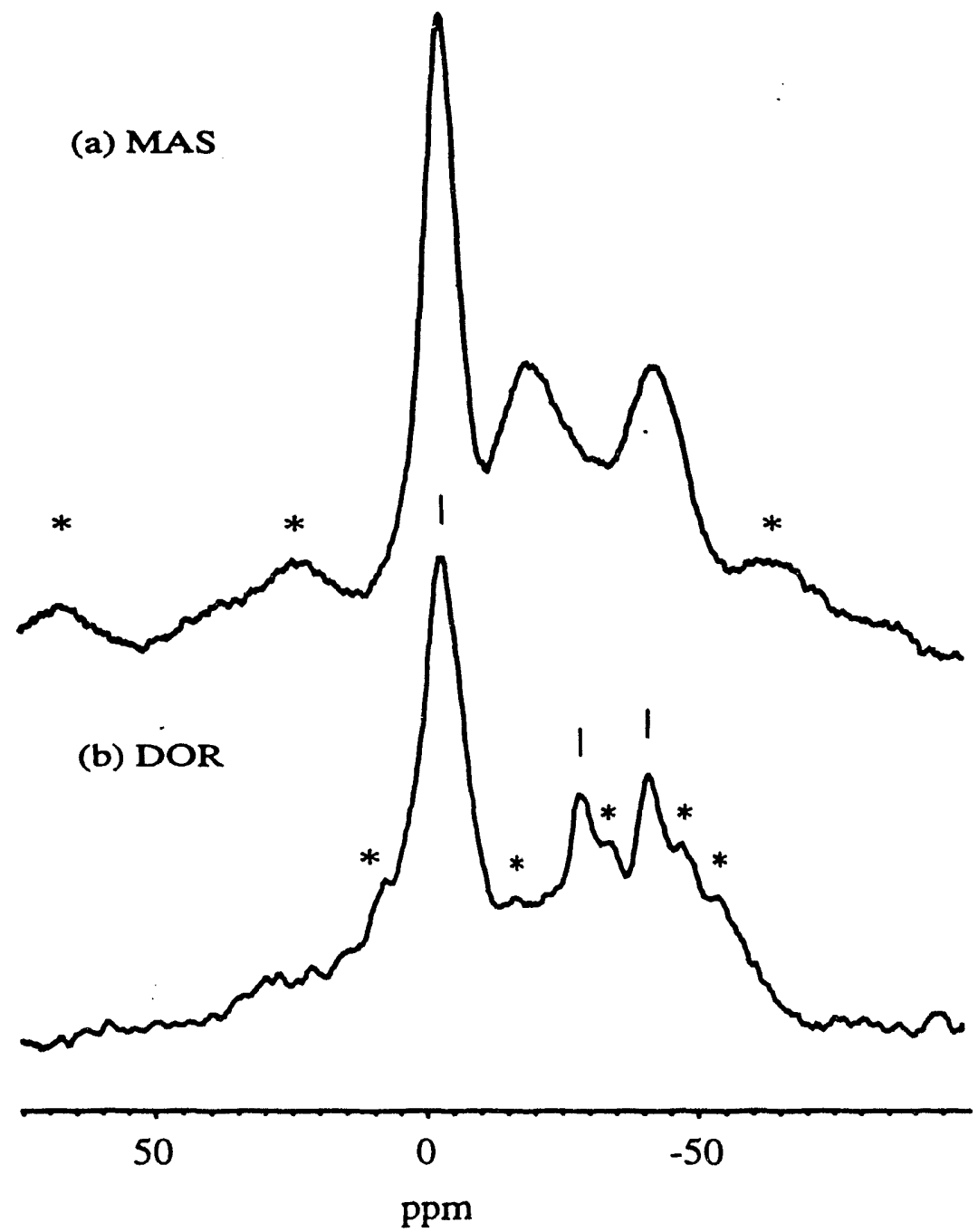

Figure 6.2: ${ }^{23} \mathrm{Na}$ NMR spectra of dehydrated $\mathrm{Na}_{56} \mathrm{Y}$-zeolite: (a) MAS; (b) DOR. The isotropic peak positions in the DOR experiment are indicated, and the asterisks indicate spinning sidebands of the outer rotor. 
This adsorption process has been thoroughly investigared using several analytical and spectroscopic techniques $[132,133,134]$. Previous studies have determined that the $\mathrm{Mo}(\mathrm{CO})_{6}$ guest molecules are encapsulated only within the supercages of $\mathrm{Na}_{56} \mathrm{Y}$-zeolite, and strongly interact with the extraframework $\mathrm{Na}^{+}$cations at site II within the supercage (see Figure 6.1) [130, 131, 135].

${ }^{23} \mathrm{Na}$ DOR spectra of dehydrated $\mathrm{Na}_{56} \mathrm{Y}$-zeolite loaded with various quantities of $\mathrm{Mo}(\mathrm{CO})_{6}$ guest molecules are shown in Figure 6.3. The effect of higher $\mathrm{Mo}(\mathrm{CO})_{6}$ loading on the NMR spectra is essentially a substantial enhancement of the intensity of the ${ }^{23} \mathrm{Na}$ resonance at around $-25 \mathrm{ppm}$. This peak is therefore ascribed to the anchoring $\mathrm{Na}^{+}$cations at site II, within the supercages. The intensity of the ${ }^{23} \mathrm{Na}$ signals at $-5 \mathrm{ppm}$ and $-41 \mathrm{ppm}$ seems to be unaffected by the $\mathrm{Mo}(\mathrm{CO})_{6}$ adsorption. From examining Figure 6.3, one essentially "discovers" the ${ }^{23} \mathrm{Na}$ DOR signal from site II through the selective anchoring of the $\mathrm{Na}^{+}$cations to $\mathrm{Mo}(\mathrm{CO})_{6}$ moieties.

$\mathrm{X}$ ray diffraction [136] and neutron diffraction measurements [137] have established that approximately $55 \%$ of the extraframework $\mathrm{Na}^{+}$cations in dehydrated $\mathrm{Na}_{56} \mathrm{Y}$ are located inside the supercage at site II, around $30 \%$ in the sodalite-cage at site $\mathrm{I}^{\prime}, 7-8 \%$ at side $\mathrm{I}$, with the remainder at site III or unlocated. The ${ }^{23} \mathrm{Na}$ DOR spectrum of the bare $\mathrm{Na}_{56} \mathrm{Y}$, Figure $6.3(\mathrm{a})$, features a different intensity ratio between the $\mathrm{Na}^{+}$sites, in particular the relatively low intensity of the ${ }^{23} \mathrm{Na}$ peak around $-99 \mathrm{ppm}$, which is ascribed to $\mathrm{Na}^{+}$cations at site II. The rather small DOR signal from the $\mathrm{Na}^{+}$cations at site II, Figure 6.3(a), might originate from a large distribution of chemical environments of the sodium ions at this site. This hypothesis might also explain the broad background signal around $-30 \mathrm{ppm}$. In addition, 


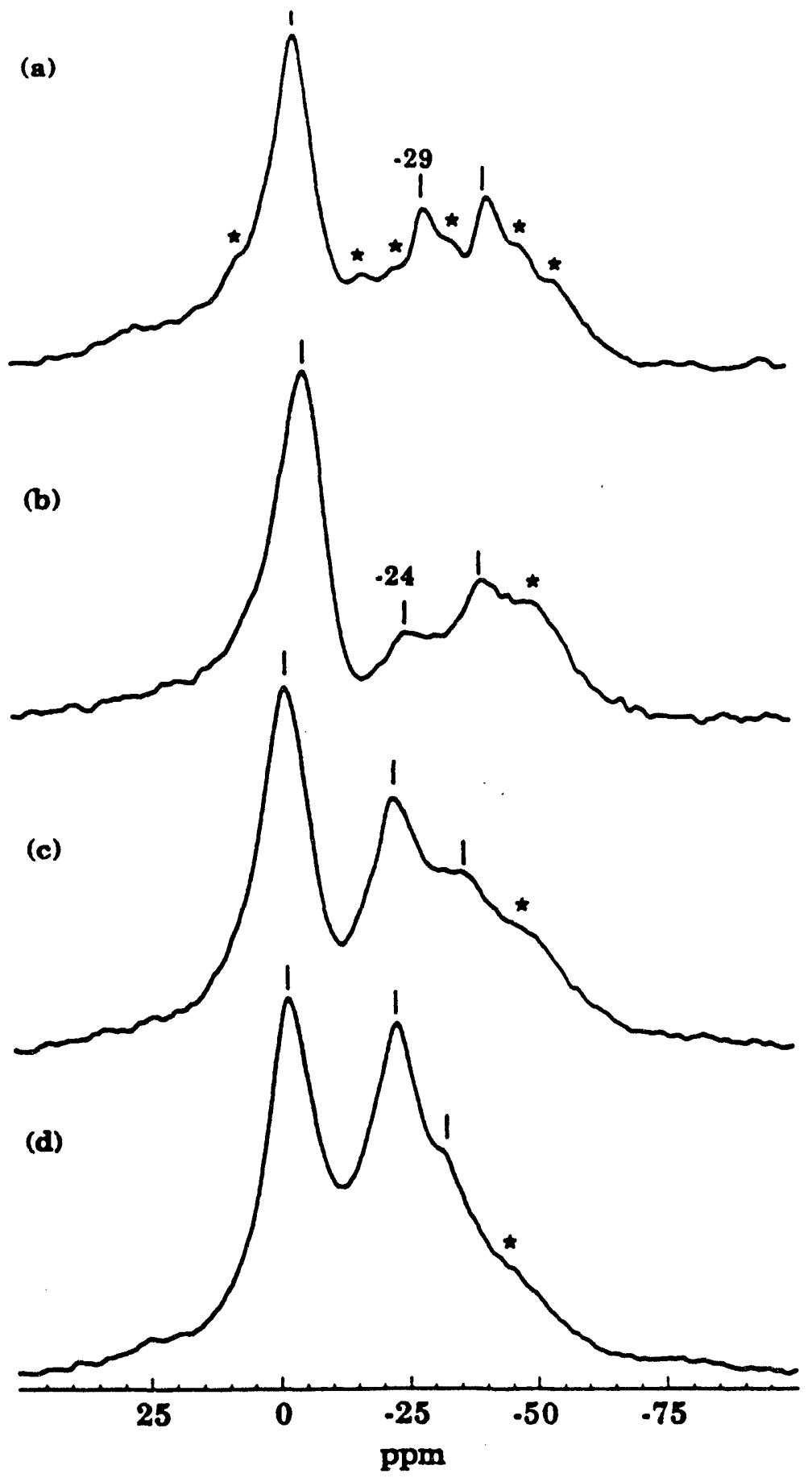

Figure 6.3: ${ }^{23} \mathrm{Na}$ DOR spectra of (a) dehydrated $\mathrm{Na}_{56} \mathrm{Y}$-zeolite, and $\mathrm{Na}_{56} \mathrm{Y}$-zeolite loaded with: (b) $4 \mathrm{Mo}(\mathrm{CO})_{6}$ guest molecules per unit cell; (c) $8 \mathrm{Mo}(\mathrm{CO})_{6}$ guest molecules per unit cell; $(\mathrm{d}) 16 \mathrm{Mo}(\mathrm{CO})_{6}$ guest molecules per unit cell. The asterisks indicate spinning sidebands of the outer rotor. 
broadening of the ${ }^{23} \mathrm{Na}$ DOR signal might be brought about through motion, on the time scale of the NMR experiment, of the $\mathrm{Na}^{+}$cations inside the supercage between accessible sites in the spacious cavity.

A further contribution to the broadening of the ${ }^{23} \mathrm{Na}$ signal from site II might be a relatively large charge asymmetry at this sodium site. Overall, very broad spectral features, which in this case are probably associated with ${ }^{23} \mathrm{Na}$ nuclei at site II within the supercages, might be lost in the baseline fluctuations, as well as in the spectrometer "deadtime", prior to data acquisition. A similar effect has been discussed in the previous chapter for sodalite containing $\mathrm{Na}_{3}^{3+}$ cluster guests in the cages. In this material, a distinct ${ }^{23} \mathrm{Na}$ resonance from $\mathrm{Na}_{3}^{3+}$ clusters is observed in the hydrated sample but is broadened considerably, essentially "disappearing", upon removal of the water molecules, see Figure 5.7.

In this sense, the transformation of "half-naked" $\mathrm{ZO}-\mathrm{Na}^{+}$in the dehydrated material [where $\mathrm{Z}$ indicates silicon or aluminum framework atoms] into coordinated $\mathrm{ZONa}^{+} \ldots \mathrm{OC}$ in $\mathrm{n}\left\{\mathrm{Mo}(\mathrm{CO})_{6}\right\}-\mathrm{Na}_{56} \mathrm{Y}$, increases the symmetry around the ${ }^{23} \mathrm{Na}$ nuclei at site II, and/or reduces the $\mathrm{Na}^{+}$motion within the supercage to the extent * that the "missing" ${ }^{23} \mathrm{Na}$ signal is recovered. Thus, the intensity of the signal ascribed to the $\mathrm{Na}^{+}$cations at site II progressively increases as more $\mathrm{Mo}(\mathrm{CO})_{6}$ guest molecules are adsorbed within the supercages, as shown in Figure 6.3(b-d).

Other factors might also determine the relative intensities in DOR experiments, and account for the population ratio observed in the NMR spectra. It should be emphasized that in the NMR experiments carried out in this study, as well as in other systems which involve quadrupolar nuclei in non-spherically symmetric environments, what is observed, and mostly excited, is the "central transition" $\left[\frac{1}{2} \leftrightarrow-\frac{1}{2}\right]$. 
However, a certain amount of the excitation and resonance energies might account for "satellite transitions" of the quadrupolar nuclei $\left[-\frac{1}{2} \leftrightarrow-\frac{3}{2}\right.$ and $\frac{3}{2} \leftrightarrow \frac{1}{2}$ for ${ }^{23} \mathrm{Na}$ nuclei], a situation which is denoted a "non-selective" excitation $[138,139]$. In multi-site materials, where some environments experience small quadrupolar interactions [such as the $\mathrm{Na}^{+}$cation at site $\mathrm{I}$, in the hexagonal prisms of $\mathrm{Na}_{56} \mathrm{Y}$ zeolite], while others exhibit greater quadrupolar effects $\left[\mathrm{Na}^{+}\right.$cations at site II in the supercages, for example], the radio-frequency [rf] pulses might act differently on the nuclei. Specifically, nuclei that experience smaller quadrupolar interaction would exhibit greater spectral intensities than sites with high quadrupolar interaction, due to the effects of non-selective excitation of the nuclei [139]. This would produce spectra where the relative intensities would not correspond to an accurate population ratio of the sites. This is demonstrated, for example, in the ${ }^{27} \mathrm{Al}$ NMR experiments on $\mathrm{AlPO}_{4}-21$, Chapter 3 .

Another important issue to be considered in this context is the distribution of the NMR signal between the observed centerband and the spinning sidebands. The intensity incorporated in spinning sidebands in motional averaging experiments : like MAS and DOR, is determined by the spinning speed, and also substantially by the anisotropic interactions present at the nuclei, such as the quadrupolar and anisotropic chemical shift [140]. In general, more signal will appear in spinning sidebands, rather than the centerband, for nuclei which exhibit greater quadrupolar interactions [140]. These effects might account for the spectral features of dehydrated $\mathrm{Na}_{56} \mathrm{Y}$-zeolite, Figure 6.3(a). The peak ascribed to $\mathrm{Na}^{+}$cations at site II, around $-30 \mathrm{ppm}$, is located within a broad sideband manifold. This stands in contrast to the ${ }^{23} \mathrm{Na}$ nuclei at site I, which give rise to the sharp peak at around 
$-4 \mathrm{ppm}$ [see below]. The $\mathrm{Na}^{+}$cations at site I are positioned in a rather symmetrical environment between two six-membered rings in the hexagonal prisms. Indeed, the

${ }^{23} \mathrm{Na}$ DOR signal at around $-4 \mathrm{ppm}$ has almost no associated spinning sidebands. In conclusion, the effects described above contribute to the broad background signal and sideband manifold around $-30 \mathrm{ppm}$ in the ${ }^{23} \mathrm{Na}$ DOR spectrum of dehydrated $\mathrm{Na}_{56} \mathrm{Y}$, Figure 6.3(a), and limit the available information on population ratios which can be extracted from the signal intensities.

\section{5 $\mathrm{Tl}^{+}$and $\mathrm{Ca}^{2+}$ Cation Exchange}

\subsection{1 $\mathrm{TI}^{+}$Ion Exchange}

${ }^{23} \mathrm{Na}$ DOR spectra of $\mathrm{Tl}^{+}$-exchanged $\mathrm{Na}_{56} \mathrm{Y}$ samples are shown in Figure 6.4. The $\mathrm{Tl}^{+}$ion is quite large compared to the $\mathrm{Na}^{+}$cation (ionic radii $1.47 \AA$ and $0.97 \AA$, respectively [105]). With reference to $\mathrm{Cs}^{+}$cation locations in $\mathrm{Cs}_{56} \mathrm{Y}$ [141] one expects more than $90 \%$ of the $\mathrm{Tl}^{+}$cations in $\mathrm{Tl}_{56} \mathrm{Y}$ to reside inside the supercage. Far-IR spectroscopic studies of $\mathrm{Na}^{+}$and $\mathrm{Tl}^{+}$translatory modes in $\mathrm{Tl}_{n} \mathrm{Na}_{56-n} \mathrm{Y}$ also favor preferential depletion of the $\mathrm{Na}^{+}$cations from the supercages. Slight depletion of $\mathrm{Na}^{+}$at site $\mathrm{I}^{\prime}$ in the sodalite cages, and site $\mathrm{I}$ in the hexagonal prisms, occurs during the initial exchange process as well.

The quantitative ${ }^{23} \mathrm{Na}$ DOR data shown in Figure 6.4 provide additional insight into the cation exchange process. The intensity of the ${ }^{23} \mathrm{Na}$ peak at $-30 \mathrm{ppm}$ decreases after around $15 \%$ of the $\mathrm{Na}^{+}$cations are exchanged, Figure $6.4(\mathrm{~b})$. The total background signal in the ${ }^{23} \mathrm{Na}$ DOR spectrum, Figure $6.4(\mathrm{~b})$, seems to diminish as well. When approximately $30 \%$ of the sodium cations are exchanged, the peak 


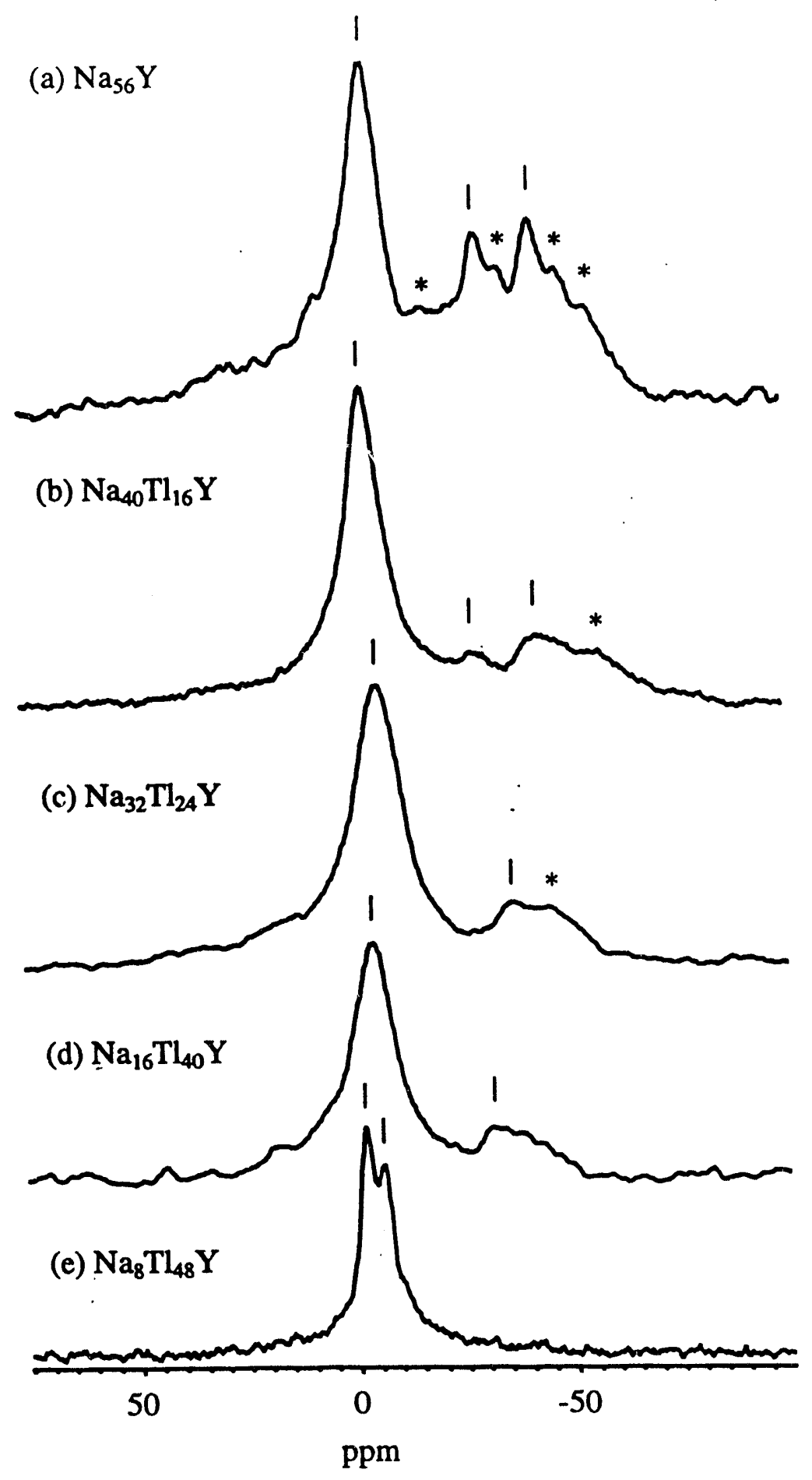

Figure 6.4: ${ }^{23} \mathrm{Na}-\mathrm{DOR}$ spectra of dehydrated $\mathrm{Na}_{56} \mathrm{Y}$ at various stages of $\mathrm{Tl}^{+}$ion exchange: (a) $\mathrm{Na}_{56} \mathrm{Y}$; (b) $\mathrm{Tl}_{8} \mathrm{Na}_{48} \mathrm{Y} ;$ (c) $\mathrm{Tl}_{16} \mathrm{Na}_{40} \mathrm{Y} ;$ (d) $\mathrm{Tl}_{40} \mathrm{Na}_{16} \mathrm{Y}$; (e) $\mathrm{Tl}_{48} \mathrm{Na}_{8} \mathrm{Y}$. The asterisks indicate spinning sidebands of the outer rotor. 
observed at around $-30 \mathrm{ppm}$, which is ascribed to the $\mathrm{Na}^{+}$cations at site II, is greatly diminished, as shown in Figure 6.4(c). In addition, the furthermost upfield peak seems to shift to a higher frequency, Figure $6.4(\mathrm{c})$, and its intensity decreases somewhat upon progressively loading more $\mathrm{Tl}^{+}$cations, Figure 6.4(b-d).

The ${ }^{23} \mathrm{Na}$ DOR spectrum of $\mathrm{Na}_{8} \mathrm{Tl}_{48} \mathrm{Y}$, shown in Figure 6.4(e), displays a very small remnant of the signal at around $-40 \mathrm{ppm}$, while the prominent down-field resonance is split into two signals at $-2 \mathrm{ppm}$ and $-6 \mathrm{ppm}$, respectively. The diminishing signal intensity of the peak at $-40 \mathrm{ppm}$ implies that this peak is probably associated with $\mathrm{Na}^{+}$cations at site $\mathrm{I}^{\prime}$, because in the final stages of the cation exchange process the $\mathrm{Tl}^{+}$cations may displace $\mathrm{Na}^{+}$in the sodalite-cages.

The Gaussian peak at around $-5 \mathrm{ppm}$; Figure 6.4 , is therefore assigned to $\mathrm{Na}^{+}$cations at site I within the hexagonal prisms of $\mathrm{Na}_{56} \mathrm{Y}$-zeolite. The intense and narrow DOR resonance associated with the $\mathrm{Na}^{+}$cations at site $\mathrm{I}$, observed throughout the entire exchange series, is probably due to the highly symmetrical octahedral environment of the $\mathrm{Na}^{+}$cations inside the hexagonal prism, Fig. 6.1. In addition, one anticipates a more restricted motion of the $\mathrm{Na}^{+}$ions at this site, " compared with the more spacious sodalite cavities and supercages of $\mathrm{Na}_{56} \mathrm{Y}$-zeolite. Thus, although the population of site $\mathrm{I} \mathrm{Na}^{+}$cations is quite low compared to sites II and I' $[90,136,137]$, the small electric field gradient at the site, as well as the "pinning down" of the $\mathrm{Na}^{+}$cations in the hexagonal prism, lead to the relatively higher intensity and narrow appearance of the DOR resonance associated with the ${ }^{23} \mathrm{Na}$ cations at site I. The observation of a well resolved splitting of the ${ }^{23} \mathrm{Na}$ signal in the spectrum of $\mathrm{Tl}_{48} \mathrm{Na}_{8} \mathrm{Y}$, Figure 6.4(e), indicates the existence of at least two distinct local symmetries of the $\mathrm{Na}^{+}$cations at site I. Since at this stage of 
the cation-exchange process $\mathrm{Tl}^{+}$ions start replacing $\mathrm{Na}^{+}$in the sodalite-cages, this splitting might be related to a nearest-neighbor effect of the $\mathrm{Tl}^{+}$present in sodalite-cavities adjacent to the hexagonal prisms.

\subsection{2 $\mathrm{Ca}^{2+}$ Ion Exchange}

Figure 6.5 shows ${ }^{23} \mathrm{Na}$ synchronized DOR spectra of $\mathrm{Ca}^{2+}$ cation-exchanged $\mathrm{Na}_{56} \mathrm{Y}$-zeolite. In synchronized DOR experiments, transients are acquired at the $0^{\circ}$ and $180^{\circ}$ positions of the inner rotor [relative to the magnetic field], thus achieving an effective spinning of twice the outer rotor speed. This provides better spectral resolution than ordinary DOR experiments. The results shown in Figure 6.5 provide additional support for the assignment of the sharp downfield ${ }^{23} \mathrm{Na}$ DOR Gaussian peak to the $\mathrm{Na}^{+}$cations at site I inside the hexagonal prisms. $\mathrm{Ca}^{2+}$ cations in dehydrated $\mathrm{Ca}^{2+}$-exchanged $\mathrm{Na}_{56} \mathrm{Y}$-zeolite are preferably located within the hexagonal prisms, rather than the supercages [1]. This is indeed dernonstrated in Figure 6.5. The intensity of the ${ }^{23} \mathrm{Na}$ DOR peak at around $-4 \mathrm{ppm}$, which is ascribed to the $\mathrm{Na}^{+}$cations at site $\mathrm{I}$ in the hexagonal prisms, substantially decreases upon replacing $\mathrm{Na}^{+}$cations with $\mathrm{Ca}^{2+}$ ions. This result stands in contrast to the essentially unperturbed ${ }^{23} \mathrm{Na}$ DOR resonance at around $-4 \mathrm{ppm}$ in the $\mathrm{Tl}^{+}$exchange series, Figure 6.4. The intensity of the upfield feature, ascribed to the $\mathrm{Na}^{+}$cations at site $\mathrm{I}^{\prime}$, changes only a little by the $\mathrm{Ca}^{2+}$ cation-exchange process, Figure 6.5. A very interesting result is the appearance of a distinct ${ }^{23} \mathrm{Na}$ signal at around $-95 \mathrm{ppm}$, Figure $6.5(b-c)$. This peak might be attributed to a sodium environmet in the supercages, affected by the exchanged $\mathrm{Ca}^{2+}$ cations. 


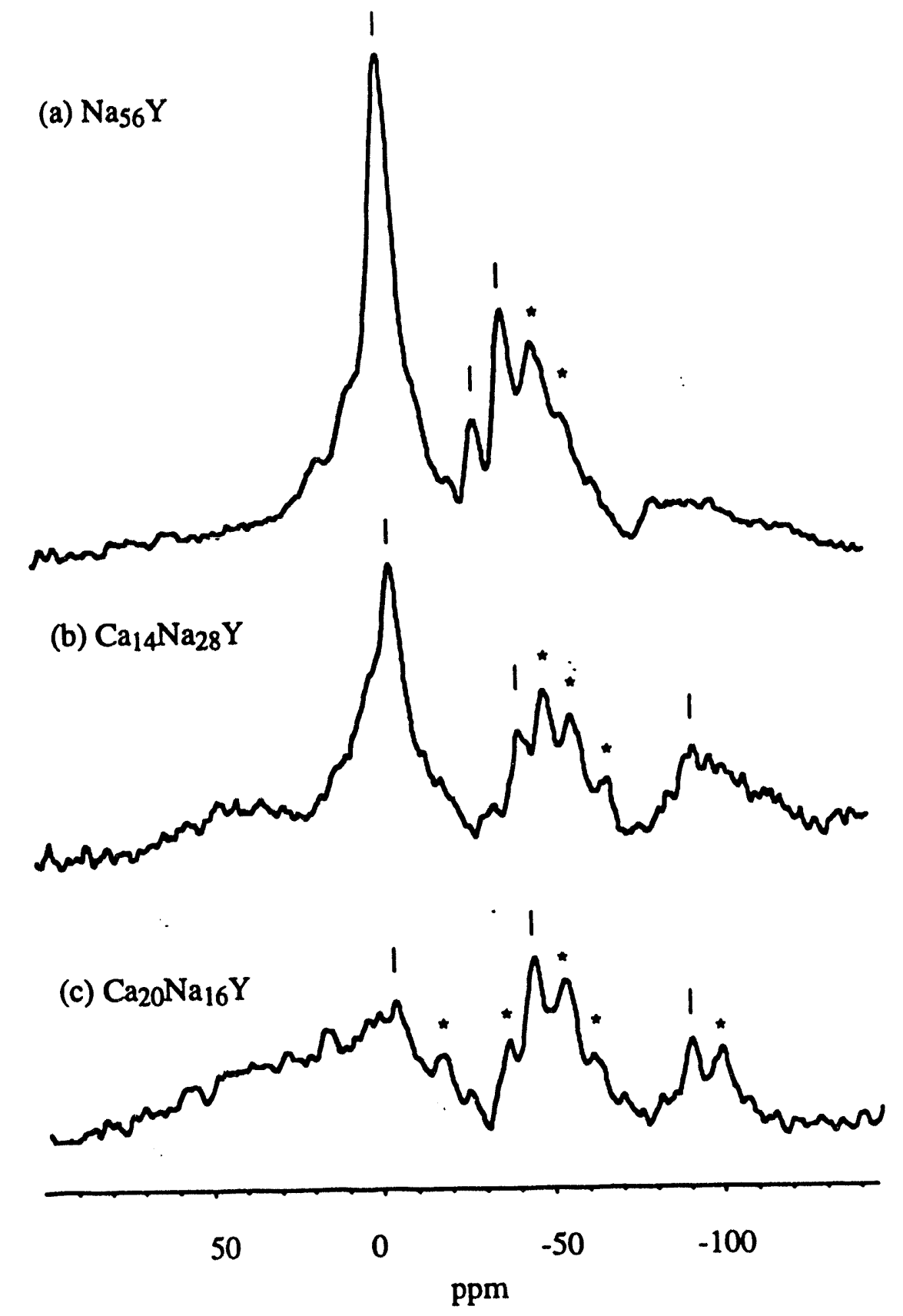

Figure 6.5: ${ }^{23} \mathrm{Na}$ Synchronized DOR spectra of dehydrated $\mathrm{Na}_{56} \mathrm{Y}$ at various stages of $\mathrm{Ca}^{2+}$ exchange: (a) $\mathrm{Na}_{56} \mathrm{Y}$; (b) $\mathrm{Ca}_{14} \mathrm{Na}_{28} \mathrm{Y}$; (c) $\mathrm{Ca}_{20} \mathrm{Na}_{16} \mathrm{Y}$. The asterisks indicate spinning sidebands of the outer rotor (twice the actual speed, see text). 


\subsection{Molecular Adsorption in $\mathrm{Na}_{56} \mathrm{Y}$-zeolite}

As demonstrated above, adsorption of $\mathrm{Mo}(\mathrm{CO})_{6}$, and cation-exchange experiments enable one to identify specific ${ }^{23} \mathrm{Na}$ DOR resonances associated with the $\mathrm{Na}^{+}$cation sites in $\mathrm{Na}_{56} \mathrm{Y}$-zeolite. Thus, ${ }^{23} \mathrm{Na}$ DOR experiments could in principle provide information on adsorption processes, interactions, and environments of the extraframework $\mathrm{Na}^{+}$cations. ${ }^{23} \mathrm{Na}$ DOR experiments which involve two adsorption processes in $\mathrm{Na}_{56} \mathrm{Y}$-zeolite are described below: They include $\mathrm{H}_{2} \mathrm{O}$ adsorption, and the incorporation of $\mathrm{PMe}_{3}$ within the porous framework of the zeolite.

\subsection{1 $\mathrm{H}_{2} \mathrm{O}$ Adsorption}

${ }^{23} \mathrm{Na}$ DOR spectra of dehydrated, and partially hydrated $\mathrm{Na}_{56} \mathrm{Y}$ are shown in Figure 6.6. As water molecules progressively adsorb onto $\mathrm{Na}_{56} \mathrm{Y}$-zeolite, a clear effect is detected on $\mathrm{Na}^{+}$cations at sites $\mathrm{II}$ and $\mathrm{I}^{\prime}$. The signals at $-30 \mathrm{ppm}$ and $-42 \mathrm{ppm}$, ascribed to $\mathrm{Na}^{+}$cations at sites II and $\mathrm{I}^{\prime}$, respectively, shift downfield, as

more $\mathrm{H}_{2} \mathrm{O}$ molecules are loaded, while the position of the peak at around $-4 \mathrm{ppm}$, which is ascribed to $\mathrm{Na}^{+}$cations at site I, does not change upon water adsorption. Sites I' and II are located in the sodalite-cages and supercages, respectively (Figure 6.1), which are more spacious than the hexagonal prisms and accessible to the water molecules. Thus, adsorbed $\mathrm{H}_{2} \mathrm{O}$ guest molecules might penetrate the larger cages within the zeolite framework, causing the observed shifts in the resonance positions of the $\mathrm{Na}^{+}$cations at sites $\mathrm{I}^{\prime}$ and II, Figure 6.6(b)-(e).

Previous studies have indicated that extraframework cations exhibit increased mobility in fully hydrated zeolite systems $[96,143]$. The NMR results shown in Figure 6.6 are consistent with, and expand upon, this description. The quantitative 

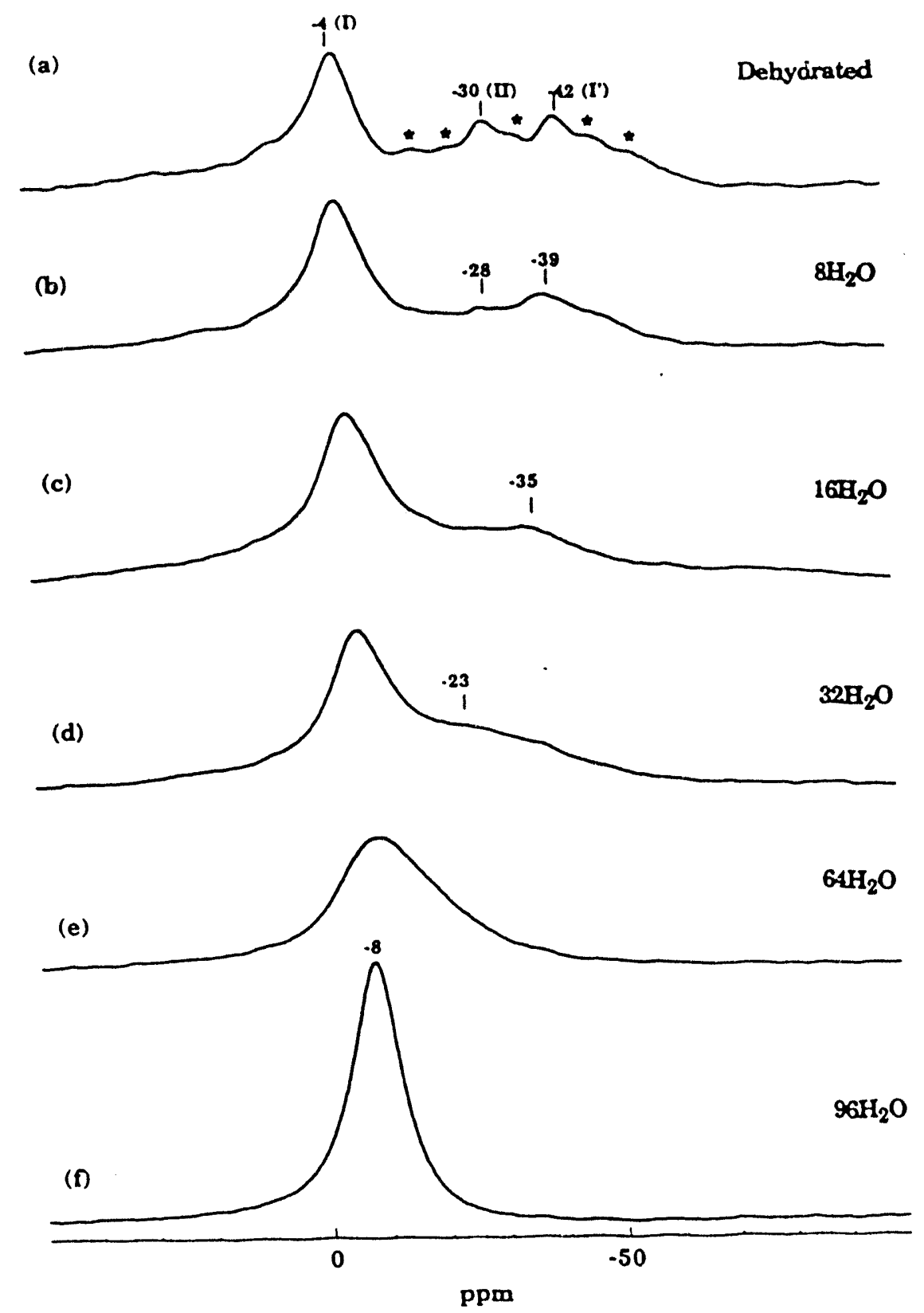

Figure 6.6: ${ }^{23} \mathrm{Na}$ DOR spectra of (a)dehydrated $\mathrm{Na}_{56} \mathrm{Y}$, and $\mathrm{Na}_{56} \mathrm{Y}$ progressively loaded with $\mathrm{H}_{2} \mathrm{O}$ guest molecules: (b) $8 \mathrm{H}_{2} \mathrm{O}$ per unit cell; (c) $16 \mathrm{H}_{2} \mathrm{O}$ per unit cell; (d) $32 \mathrm{H}_{2} \mathrm{O}$ per unit cell; (e) $64 \mathrm{H}_{2} \mathrm{O}$ per unit cell; (f) $96 \mathrm{H}_{2} \mathrm{O}$ per unit cell. The asterisks indicate spinning sidebands of the outer rotor. 
adsorption of $\mathrm{H}_{2} \mathrm{O}$ molecules in dehydrated $\mathrm{Na}_{56} \mathrm{Y}$ causes a progressive deshielding of the ${ }^{23} \mathrm{Na}$ nuclei at sites II and I', Figure 6.6, which most likely arises from the combined effects of diminishing interactions with the framework oxygens, and faster motion of the $\mathrm{Na}^{+}$cations. An interesting result is obtained for $\mathrm{Na}_{56} \mathrm{Y}$ zeolite which contains $32 \mathrm{H}_{2} \mathrm{O}$ molecules in the unit cell, Figure 6.6(d). The profound downfield shift of ihe ${ }^{23} \mathrm{Na}$ peak ascribed to site $\mathrm{I}^{\prime}$, from $-42 \mathrm{ppm}$ to approximately $-23 \mathrm{ppm}$, probably indicates a change of the interaction of site $\mathrm{I}^{\prime} \mathrm{Na}^{+}$cations with the zeolite framework. Migration of $\mathrm{Na}^{+}$cations from the sodalite cages to adjacent supercage sites might also contribute to this resonance shift; exchange of sodium cations between a sodalite-cavity and the supercage is possible because the ionic diameter of $\mathrm{Na}^{+}[2.3 \AA[125]]$ is smaller than the six-ring opening between the two types of cavities $[2.7 \AA[1]]$.

The sample containing $96 \mathrm{H}_{2} \mathrm{O}$ molecules per unit cell features a narrower Gaussian signal at around $-8 \mathrm{ppm}$, Figure 6.6(f). This spectrum is essentially identical to a ${ }^{23} \mathrm{Na}$ DOR spectrum of the fully hydrated material $\left\{240 \mathrm{H}_{2} \mathrm{O}\right\}-\mathrm{Na}_{56} \mathrm{Y}$, and indicates a single average environment for the $\mathrm{Na}^{+}$cations within the zeolite $\mathrm{Y}$ framework. The $\mathrm{Na}^{+}$cations are probably "solvated" by the water molecules at this stage, and exhibit a very fast motion within the zeolite pores, on the time scale of the NMR experiments. Indeed, several studies have determined that hydrated zeolites incorporate highly mobile species within the cavities $[96,97,143]$. The position of the ${ }^{23} \mathrm{Na}$ signal at around $-8 \mathrm{ppm}$, Figure $6.6(\mathrm{f})$, is close to the resonance ascribed to $\mathrm{Na}^{+}$cations at site I inside the hexagonal prism at $-4 \mathrm{ppm}$, Figure 6.6(a), which further indicates a highly symmetrical electronic environment for the hydrated $\mathrm{Na}^{+}$cations. 


\subsection{2 $\mathrm{P}\left(\mathrm{CH}_{3}\right)_{3}$ Adsorption}

The observed mobilization of the extraframework $\mathrm{Na}^{+}$cations with progressive additions of $\mathrm{H}_{2} \mathrm{O}$ molecules to $\mathrm{Na}_{56} \mathrm{Y}$-zeolite, most likely originates from Lewis base $\left\{\mathrm{H}_{2} \mathrm{O}\right\} \cdots \mathrm{Na}^{+} \mathrm{OZ}$ interactions. To test this proposal, the adsorption effects of trimethylphosphine $\left(\mathrm{PMe}_{3}\right)$ in $\mathrm{Na}_{56} \mathrm{Y}$-zeolite were examined. $\mathrm{PMe}_{3}$ is a sterically large, soft (class B) Lewis base, compared to $\mathrm{H}_{2} \mathrm{O}$, a small, hard (class A) Lewis base molecule [128]. Binding of $\mathrm{PMe}_{3}$ to Brønsted and Lewis acid sites in zeolite $\mathrm{Y}$ has been probed in several studies using ${ }^{31} \mathrm{P}$ MAS $[69,144,145,146]$. Figure 6.7 features the ${ }^{23} \mathrm{Na}$ DOR spectra of $\mathrm{Na}_{56} \mathrm{Y}$ zeolite, loaded with quantitative amounts of $\mathrm{PMe}_{3}$ guest molecules. The adsorbed $\mathrm{PMe}_{3}$ molecules clearly affect the environments of the sodium nuclei, causing profound changes in the positions and shapes of the ${ }^{23} \mathrm{Na}$ signals, as shown in Figure 6.7.

Previous ${ }^{31} \mathrm{P}$ results indicate the occurrence of electronic interaction between the phosphorus atom of $\mathrm{PMe}_{3}$, and $\mathrm{Na}^{+}$cations in the supercages of $\mathrm{Na}_{56} \mathrm{Y}$ [145]. Indeed, the ${ }^{23} \mathrm{Na}$ DOR signal ascribed to $\mathrm{Na}^{+}$cations at site II is shifted downfield, from $-30 \mathrm{ppm}$ in dehydrated $\mathrm{Na}_{56} \mathrm{Y}$, Figure $6.7(\mathrm{a})$, to around $-24 \mathrm{ppm}$ and $-15 \mathrm{ppm}$, upon loading $8 \mathrm{PMe}_{3}$ and $16 \mathrm{PMe}_{3}$ guest molecules, respectively, Figure 6.7(b) and (c). A relevant observation is the apparent effect of adsorbed $\mathrm{PMe}_{3}$ molecules on $\mathrm{Na}^{+}$cations at site $\mathrm{I}^{\prime}$, located inside the smaller sodalite cage, Figure 6.1 ; the ${ }^{23} \mathrm{Na}$ DOR peak at $-42 \mathrm{ppm}$, Figure $6.7(\mathrm{a})$, ascribed to $\mathrm{Na}^{+}$cations at site $\mathrm{I}^{\prime}$, shifts downfield to around $-30 \mathrm{ppm}$ upon $\mathrm{PMe}_{3}$ loading. The kinetic diame-

ter of $\mathrm{PMe}_{3}$ is $5.5 \AA$ [146], significantly larger than the $2.7 \AA$-wide six-ring window between the sodalite cage and the supercage [1]. This does not permit incorporation of $\mathrm{PMe}_{3}$ within the sodalite cavities of $\mathrm{Na}_{56} \mathrm{Y}$-zeolite, at room temperature. This 

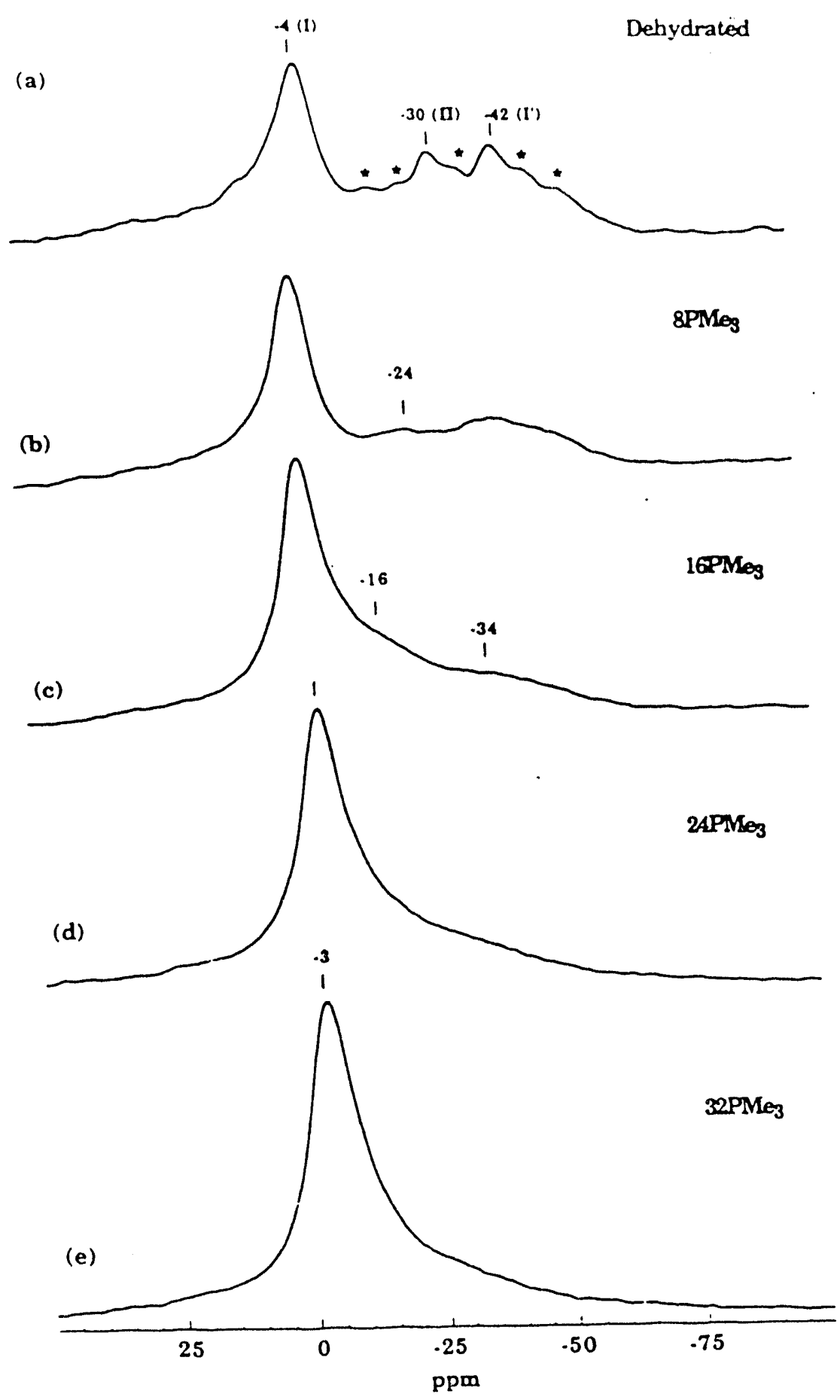

Figure 6.7: ${ }^{23} \mathrm{Na}$ DOR spectra of (a)dehydrated $\mathrm{Na}_{56} \mathrm{Y}$, and $\mathrm{Na}_{56} \mathrm{Y}$ progressively loaded with $\mathrm{PMe}_{3}$ guest molecules: (b) $8 \mathrm{PMe}_{3}$ per unit cell; (c) $16 \mathrm{PMe}_{3}$ per unit cell; (d) $24 \mathrm{PMe}_{3}$ per unit cell; (e)32PMe $\mathrm{PM}_{3}$ per unit cell. The asterisks indicate spinning sidebands of the outer rotor. 
situation is significantly different from that encountered in hydrated $\mathrm{Na}_{56} \mathrm{Y}$-zeolite, where the $\mathrm{H}_{2} \mathrm{O}$ guest molecules can move between the sodalite and supercages, as discussed above.

The NMR results, shown in Figure 6.7(b)-(e), show clearly that $\mathrm{PMe}_{3}$ molecules, encapsulated only within the supercages, do exhibit an indirect electronic (cooperative) effect on the smaller adjacent sodalite cavities. The downfield shift, as well as the broadening of the ${ }^{23} \mathrm{Na}$ signal from site $\mathrm{I}^{\prime}$, indicates a significant change in the environments of the $\mathrm{Na}^{+}$cations inside the sodalite cavities. This might arise from an increased mobility of the $\mathrm{Na}^{+}$cations, as discussed above in the $\mathrm{H}_{2} \mathrm{O}$-loaded samples.

The highest $\mathrm{PMe}_{3}$-loaded $\mathrm{Na}_{56} \mathrm{Y}$ sample contains $4 \mathrm{PMe}_{3}$ guest molecules in each supercage within the zeolite framework. The ${ }^{23} \mathrm{Na}$ DOR spectrum of this material, Figure 6.7(e), features a pronounced Gaussian peak at around $-3 \mathrm{ppm}$, which again indicates an average ${ }^{23} \mathrm{Na}$ environment. This observation favors a model of $\mathrm{Na}^{+}$cations coordinated by the mobile $\mathrm{PMe}_{3}$ molecules, similar to the one proposed above for $\mathrm{Na}_{56} \mathrm{Y}$ containing adsorbed $\mathrm{H}_{2} \mathrm{O}$. The position of the ${ }^{23} \mathrm{Na}$ peak in the highest-loaded $\mathrm{PMe}_{3}$ sample, at $-3 \mathrm{ppm}$ [Figure 6.7(e)], is further downfield from the analogous resonance, at $-8 \mathrm{ppm}$, ascribed to the $\mathrm{Na}^{+}$cations in the high $\mathrm{H}_{2} \mathrm{O}$-loaded material [Figure 6.6(f)]. This shift probably reflects differences in the nature of the interactions of the $\mathrm{PMe}_{3}$ and $\mathrm{H}_{2} \mathrm{O}$ guests, respectively, with the zeolite framework and the $\mathrm{Na}^{+}$cations.

Note the broad background signal observed at around $-25 \mathrm{ppm}$ for $\left\{32 \mathrm{PMe}_{3}\right\}-$ $\mathrm{Na}_{56} \mathrm{Y}$, Figure 6.7(e). This feature is not detected in the ${ }^{23} \mathrm{Na}$ DOR spectrum of $\left\{96 \mathrm{H}_{2} \mathrm{O}\right\}-\mathrm{Na}_{56} \mathrm{Y}$, Figure 6.6(f). This observation is consistent with the expectation 
of different interactions between the $\mathrm{Na}^{+}$cations, and the $\mathrm{H}_{2} \mathrm{O}$ and $\mathrm{PMe}_{3}$ guest molecules, and probably indicates a more restricted motion of the $\mathrm{Na}^{+}$cations in the $\mathrm{PMe}_{3}$-containing material. Steric limitations might exist within the "crowded" supercages in $\left\{32 \mathrm{PMe}_{3}\right\}-\mathrm{Na}_{56} \mathrm{Y}$, and would cause broadening of the ${ }^{23} \mathrm{Na}$ signal. 


\section{Chapter 7}

\section{Intrazeolitic Reactions in}

\section{$\mathrm{Na}_{56} \mathrm{Y}$-Zeolite Studied by}

\section{${ }^{23} \mathrm{Na}$ DOR}

\subsection{Abstract}

${ }^{23} \mathrm{Na}$ DOR provides site-specific structural and dynamical information on the substitution of $\mathrm{CO}$ ligands by $\mathrm{P}\left(\mathrm{CH}_{3}\right)_{3}$ in $\left\{\mathrm{Mo}(\mathrm{CO})_{6}\right\}-\mathrm{Na}_{56} \mathrm{Y}$, and photooxidation of $\mathrm{Mo}(\mathrm{CO})_{6}$ and $\mathrm{W}(\mathrm{CO})_{6}$, carried out inside the pores of $\mathrm{Na}_{56} \mathrm{Y}$-zeolite. The positions, shapes, and intensities of the ${ }^{23} \mathrm{Na}$ DOR resonances depend on the anchoring interactions and the environments of the extraframework cations, as well as on the molecular guests which are involved in the intrazeolitic reactions. Additional dynamical information on the extraframework cations and guest species is obtained by estimation of the spin-lattice relaxation of the ${ }^{23} \mathrm{Na}$ nuclei. 


\subsection{Introduction}

Traditional uses of zeolite materials have included catalytic and electrochemical transformations based on atomic and molecular adsorption processes [1]. There is a growing interest in recent years in using zeolites as templates for metal [147] and semiconductor nanoclusters [2]. The unique properties of zeolites, such as the uniform, molecular-dimension pores, the size and shape selectivity of the channels, and the chemical reactivity of the zeolite lattice, offer distinct advantages in using chemical routes for fabrication of semiconductor nanoparticle assemblies. For example, encapsulation of $\mathrm{CdS}$ and $\mathrm{PbS}$ clusters in zeolite $\mathrm{Y}$ has been shown to affect the optical properties of the semiconductor clusters [148]. Ordered intrazeolitic guest assemblies were synthesized and characterized $[149,150,151]$. Other studies have demonstrated practical technological applications of guest/host zeolite materials $[117,121,152]$.

The successful synthesis of organized, well defined, zeolite inclusion systems requires a thorough understanding of the effects of topology and reactivity of the zeolite' internal surface. These factors are pivotal in determining the location, population and distribution of the guest species inside the zeolite host lattice. Extraframework cations, located at specific sites within the zeolite lattice, play an important role in determining the reactivity of the zeolite, as well as structural and dynamical properties of the guest species. In this chapter, ${ }^{23} \mathrm{Na}$ DOR experiments are utilized to characterize the environments and distribution of extraframework $\mathrm{Na}^{+}$cations, and the changes which occur throughout various intrazeolite reactions are discussed. Specifically, the intrazeolitic reactions investigated in this chapter include the substitution of the $\mathrm{CO}$ ligands of $\mathrm{Mo}(\mathrm{CO})_{6}$ by $\mathrm{P}\left(\mathrm{CH}_{3}\right)_{3}$, yielding 
zeolite-encpsulated $\mathrm{Mo}(\mathrm{CO})_{4}\left(\mathrm{PMe}_{3}\right)_{2}$, and the photooxidation, followed by thermal reduction, of intrazeolite $\mathrm{Mo}(\mathrm{CO})_{6}$ and $\mathrm{W}(\mathrm{CO})_{6}$, yielding $\left\{\mathrm{MoO}_{x}\right\}-\mathrm{Na}_{56} \mathrm{Y}(\mathrm{x}=2,3)$ and $\left\{\mathrm{WO}_{x}\right\}-\mathrm{Na}_{56} \mathrm{Y}(\mathrm{x}=2,2.5,3)$, respectively. Details regarding the arrangements and motion of the guest molecules are also provided by carrying out the DOR experiments at two magnetic field strengths, and estimating the spin-lattice relaxation rates of the ${ }^{23} \mathrm{Na}$ nuclei.

\subsection{Experimental Considerations}

The quantitative adsorption of $\mathrm{Mo}(\mathrm{CO})_{6}$ and $\mathrm{W}(\mathrm{CO})_{6}$ was achieved using vapor deposition of the organometallic compounds into dehydrated $\mathrm{Na}_{56} \mathrm{Y}$-zeolite, see previous chapter. Ligand substitution of the encapsulated $\mathrm{Mo}(\mathrm{CO})_{6}$ with $\mathrm{PMe}_{3}$ was performed by heating the co-adsorbed guests to $70^{\circ}[130,131]$, according to the following reaction stoichiometry:

$$
\begin{aligned}
& 8\left\{\mathrm{M}(\mathrm{CO})_{6}\right\}-\mathrm{Na}_{56} \mathrm{Y}+16 \mathrm{PMe}_{3} \stackrel{30^{\circ}}{\longrightarrow} 8\left\{\mathrm{M}(\mathrm{CO})_{6}\right\}, 16\left\{\mathrm{PMe}_{3}\right\}-\mathrm{Na}_{56} \mathrm{Y} \\
& \stackrel{70^{\circ}}{\longrightarrow} 8\left\{\mathrm{Mo}(\mathrm{CO})_{4}\left(\mathrm{PMe}_{3}\right)_{2}\right\}-\mathrm{Na}_{56} \mathrm{Y}+16 \mathrm{CO}
\end{aligned}
$$

Photooxidation of the encapsulated $\mathrm{M}(\mathrm{CO})_{6}(\mathrm{M}=\mathrm{Mo}, \mathrm{W})$ moieties, yielding intrazeolite $\mathrm{MO}_{3}$ clusters, was achieved by irradiating the dehydrated samples in the presence of $\mathrm{O}_{2}$ gas using $\lambda>240 \mathrm{~nm}$ light $[115,153,154]$ :

$$
\mathrm{m}\left\{\mathrm{M}(\mathrm{CO})_{6}\right\}-\mathrm{Na}_{56} \mathrm{Y}+\frac{9}{2} \mathrm{nO}_{2} \stackrel{h \nu}{\longrightarrow} \mathrm{m}\left\{\mathrm{MO}_{3}\right\}-\mathrm{Na}_{56} \mathrm{Y}+6 \mathrm{nCO}_{2}
$$

where $0 \leq \mathrm{m} \leq 16$

Further reduction of the molybdenum and tungsten trioxides was achieved through vacuum, thermal reductive-elimination of $\mathrm{O}_{2}[154,155,156]$, described by the fol- 
lowing reaction stoichiometries:

$$
\mathrm{n}\left\{\mathrm{WO}_{3}\right\}-\mathrm{Na}_{56} \mathrm{Y} \stackrel{300^{\circ} \mathrm{C}}{\longrightarrow} \mathrm{n}\left\{\mathrm{WO}_{2.5}\right\}-\mathrm{Na}_{56} \mathrm{Y} \stackrel{400^{\circ} \mathrm{C}}{\longrightarrow} \mathrm{n}\left\{\mathrm{WO}_{2}\right\}-\mathrm{Na}_{56} \mathrm{Y}
$$

and

$$
\mathrm{n}\left\{\mathrm{MoO}_{3}\right\}-\mathrm{Na}_{56} \mathrm{Y} \stackrel{400^{\circ} \mathrm{C}}{\longrightarrow} \mathrm{n}\left\{\mathrm{MoO}_{2}\right\}-\mathrm{Na}_{56} \mathrm{Y}
$$

These processes can be quantitatively reversed by exposing the reduced samples to $\mathrm{O}_{2}$ gas at $400^{\circ} \mathrm{C}$ and $300^{\circ} \mathrm{C}$, respectively. Detailed descriptions of the preparation procedures are provided in the literature $[115,153,154,155,156]$.

${ }^{23} \mathrm{Na}$ DOR experiments were carried out at $9.6 \mathrm{~T}$ and $11.7 \mathrm{~T}$. The spinning speed was $5 \mathrm{kHz}$ for the inner rotor and $600-800$ for the outer one. All samples were loaded into the air-tight sample spinners in a dry argon glove box. $1000-3000$ acquisitions were accumulated in each experiment. $4 \mu \mathrm{sec}\left(25^{\circ}\right)$ pulses were used in the 1-pulse NMR experiments, while the inversion-recovery pulse sequence [157] was used for measuring spin-lattice relaxation times, using soft pulses $\left[90^{\circ}=19 \mu \mathrm{sec}\right.$ in solution]. For quantitative NMR measurements, identical sample-quantities were used, and the same number of transients acquired. All spectra were zero-filled to 2K data points, with application of $200 \mathrm{~Hz}$ Lorentzian broadening. The external reference was $0.1 \mathrm{M} \mathrm{NaCl}$ solution.

\subsection{Ligand Substitution of $\mathrm{CO}$ by $\mathrm{P}\left(\mathrm{CH}_{3}\right)_{3}$ in $8\left\{\mathrm{Mo}(\mathrm{CO})_{6}\right\}-\mathrm{Na}_{56} \mathrm{Y}$}

Recently, the first quantitative kinetic study of an archetypical substitution reaction of $\mathrm{CO}$ by $\mathrm{PMe}_{3}$ in the well defined system $\mathrm{n}\left\{\mathrm{Mo}(\mathrm{CO})_{6}\right\}-\mathrm{Na}_{56} \mathrm{Y}$ has been reported [131]. The results indicated a transition state which consists of an activated 
$\left\{\mathrm{Mo}(\mathrm{CO})_{6}-\mathrm{Na}_{56} \mathrm{Y}\right\}$, with $\mathrm{PMe}_{3}$ anchored to $\mathrm{Na}^{+}$cations in the supercages of the $\mathrm{Na}_{56} \mathrm{Y}$ host lattice. Generally, an increase in $\mathrm{PMe}_{3}$ loading produces a decrease in the activating ability of the host lattice and was attributed to deanchoring of the encapsulated complex, caused by $\mathrm{Me}_{3} \mathrm{P} \cdots \mathrm{Na}^{+} \mathrm{OZ}(\mathrm{Z} \equiv \mathrm{Si}, \mathrm{Al}), \mathrm{Me}_{3} \mathrm{P} \cdots \mathrm{OZ}$, and/or $\mathrm{Me}_{3} \mathrm{P} \cdots \mathrm{Me}_{3} \mathrm{P}$ interactions.

${ }^{23} \mathrm{Na}$ DOR was used to examine the kinetics and mechanism of this intrazeolitic ligand substitution reaction. The technique was employed to investigate the reactant $8\left\{\mathrm{Mo}(\mathrm{CO})_{6}\right\}-\mathrm{Na}_{56} \mathrm{Y}$, the reactant-pair produced upon adsorption of $\mathrm{PMe}_{3}$, $8\left\{\mathrm{Mo}(\mathrm{CO})_{6}\right\}, 16\left\{\mathrm{PMe}_{3}\right\}-\mathrm{Na}_{56} \mathrm{Y}$, and the kinetic product, $8\left\{\right.$ cis- $\left.\mathrm{Mo}(\mathrm{CO})_{4}\left(\mathrm{PMe}_{3}\right)_{2}\right\}-$ $\mathrm{Na}_{56} \mathrm{Y}$, all of which play key roles in the $\mathrm{CO}$ substitution of $\mathrm{Na}_{56} \mathrm{Y}$-encapsulated $\mathrm{Mo}(\mathrm{CO})_{6}$ by $\mathrm{PMe}_{3}[131]$.

The ${ }^{23} \mathrm{Na}$ DOR results, shown in Figure 7.1, provide insight into the loading dependent anchoring interactions between the extraframework $\mathrm{Na}^{+}$cations and the adsorbed guest molecules. Introducing $\mathrm{Mo}(\mathrm{CO})_{6}$ guests into the pores of $\mathrm{Na}_{56} \mathrm{Y}$ causes a downfield shift of the ${ }^{23} \mathrm{Na}$ signal ascribed to the site II $\mathrm{Na}^{+}$cations, from $-30 \mathrm{ppm}$ in dehydrated $\mathrm{Na}_{56} \mathrm{Y}$, Figure 7.1(a), to around $-24 \mathrm{ppm}$ for $8\left\{\mathrm{Mo}(\mathrm{CO})_{6}\right\}-$ $\mathrm{Na}_{56} \mathrm{Y}$, Figure 7.1(b). In addition, a significant increase of the intensity of the signal from the $\mathrm{Na}^{+}$cations at site II is detected. These observations indicate a strong anchoring interaction between the $\mathrm{Mo}(\mathrm{CO})_{6}$ guests and the $\mathrm{Na}^{+}$cations at site II in the supercages, through the oxygen-end of the carbonyl ligands. A detailed discussion concerning intensity aspects in the ${ }^{23} \mathrm{Na}$ DOR spectra of $\mathrm{M}(\mathrm{CO})_{6}$ adsorbed within $\mathrm{Na}_{56} \mathrm{Y}$ is provided in the previous chapter.

A further change in the environments of the $\mathrm{Na}^{+}$cations is detected in the ${ }^{23} \mathrm{Na}$ DOR spectrum of the intrazeolite reactant-pair, $8\left\{\mathrm{Mo}(\mathrm{CO})_{6}\right\}, 16\left\{\mathrm{PMe}_{3}\right\}-\mathrm{Na}_{56} \mathrm{Y}$, 


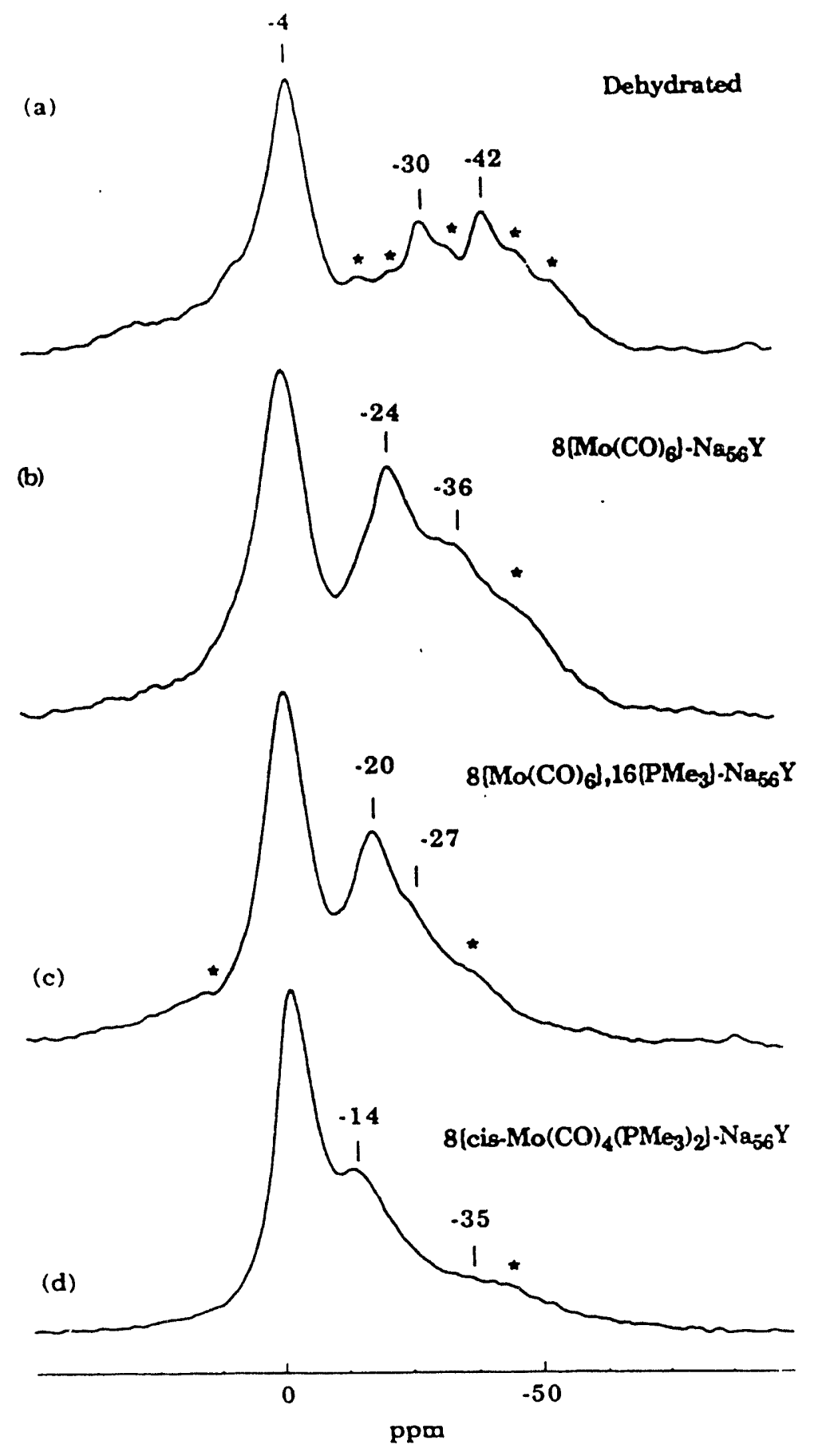

Figure 7.1: ${ }^{23} \mathrm{Na}$ DOR spectra at 11.7 Tesla of (a)dehydrated $\mathrm{Na}_{56} \mathrm{Y}$, and materials produced in the intrazeolite $\mathrm{PMe}_{3}$ reactions of $8\left\{\mathrm{Mo}(\mathrm{CO})_{6}\right\}-$ $\mathrm{Na}_{56} \mathrm{Y}$ : (b) reactant material, $8\left\{\mathrm{Mo}(\mathrm{CO})_{6}\right\}-\mathrm{Na}_{56} \mathrm{Y}$; (c) reactant-pair, $8\left\{\mathrm{Mo}(\mathrm{CO})_{6}\right\}, 16\left\{\mathrm{PMe}_{3}\right\}-\mathrm{Na}_{56} \mathrm{Y} ;$ (d) kinetic product, $8\left\{\mathrm{Mo}(\mathrm{CO})_{4}\left(\mathrm{PMe}_{3}\right)_{2}\right\}-$ $\mathrm{Na}_{56} \mathrm{Y}$. The asterisks denote spinning sidebands of the outer rotor. 
Figure 7.1(c). Here, the addition of two $\mathrm{PMe}_{3}$ guest molecules into a supercage containing one $\mathrm{Mo}(\mathrm{CO})_{6}$ reactant molecule, causes a downfield shift of the ${ }^{23} \mathrm{Na}$ signals associated with both the $\mathrm{Na}^{+}$cations at site $\mathrm{II}$ in the supercage and site $\mathrm{I}^{\prime}$, located in the adjacent sodalite cavities. The positions of the two resonances in the spectrum of $8\left\{\mathrm{Mo}(\mathrm{CO})_{6}\right\}, 16\left\{\mathrm{PMe}_{3}\right\}-\mathrm{Na}_{56} \mathrm{Y}$ are shifted to $-20 \mathrm{ppm}$ and $-27 \mathrm{ppm}$, respectively, which is further downfield from both the dehydrated $\mathrm{Na}_{56} \mathrm{Y}$ sample, Figure 7.1(a), as well as the reactant $8\left\{\mathrm{Mo}(\mathrm{CO})_{6}\right\}-\mathrm{Na}_{56} \mathrm{Y}$, Figure 7.1(b). These results might provide evidence for a direct electronic effect of the $\mathrm{PMe}_{3}$ guests on the $\mathrm{Na}^{+}$cations at site II, anchored to the adsorbed $\mathrm{Mo}(\mathrm{CO})_{6}$ molecules. The ${ }^{23} \mathrm{Na}$ DOR spectrum shown in Figure 7.1(c) also indicates an indirect negative cooperative effect exerted by the $\mathrm{PMe}_{3}$ guests on the $\mathrm{Na}^{+}$cations inside the sodalite cages. The smaller sodalite cavity is inaccessible to the $\mathrm{PMe}_{3}$ molecules. Nevertheless, a downfield shift is observed for the ${ }^{23} \mathrm{Na}$ DOR resonance associated with site $\mathrm{I}^{\prime} \mathrm{Na}^{+}$ cations, inside the sodalite cage, from around $-36 \mathrm{ppm}$ for $8\left\{\mathrm{Mo}(\mathrm{CO})_{6}\right\}-\mathrm{Na}_{56} \mathrm{Y}$, Figure 7.1(b), to $-27 \mathrm{ppm}$ for $8\left\{\mathrm{Mo}(\mathrm{CO})_{6}\right\}, 16\left\{\mathrm{PMe}_{3}\right\}-\mathrm{Na}_{56} \mathrm{Y}$, Figure $7.1(\mathrm{c})$.

The ${ }^{23} \mathrm{Na}$ DOR spectrum of the kinetic product, $8\left\{\mathrm{Mo}(\mathrm{CO})_{4}\left(\mathrm{PMe}_{3}\right)_{2}\right\}-\mathrm{Na}_{56} \mathrm{Y}$, Figure 7.1(d), features a noticeable difference from both the reactant, Figure 7.1(b), and the reactant-pair, Figure 7.1(c). The peak at -14 ppm in Figure 4(d) most likely corresponds to $\mathrm{Na}^{+}$cations at site II inside the supercages. The ${ }^{23} \mathrm{Na}$ DOR signal from site II shifts significantly downfield, reflecting a different interaction between the encapsulated kinetic product cis- $\mathrm{Mo}(\mathrm{CO})_{4}\left(\mathrm{PMe}_{3}\right)_{2}$, and the extraframework $\mathrm{Na}^{+}$cations in the supercage, compared with the analogous interaction of the reactant $\mathrm{Mo}(\mathrm{CO})_{6}$ molecules and the sodium cations. This is consistent with the expectation that the oxygen-end of the anchoring trans-carbonyl ligands in 
$8\left\{\right.$ cis-Mo $\left.(\mathrm{CO})_{4}\left(\mathrm{PMie}_{3}\right)_{2}\right\}-\mathrm{Na}_{56} \mathrm{Y}$ should exhibit a higher Lewis basicity than in the reactant $8\left\{\mathrm{Mo}(\mathrm{CO})_{6}\right\}-\mathrm{Na}_{56} \mathrm{Y}$, due to the substitution of two $\mathrm{CO}$ ligands by $\mathrm{PMe}_{3}$. The broad feature at around $-35 \mathrm{ppm}$, Figure $7.1(\mathrm{~d})$, may arise from other ${ }^{23} \mathrm{Na}$ environments in zeolite $\mathrm{Y}$, probably $\mathrm{Na}^{+}$cations within the sodalite cavities.

It should be noted that the ${ }^{23} \mathrm{Na}$ DOR resonance at around $-4 \mathrm{ppm}$, ascribed to $\mathrm{Na}^{+}$cations at site I inside the hexagonal prism [see previous chapter], is not affected by the reactant, reactant-pair or kinetic product contained in the supercages of $\mathrm{Na}_{56} \mathrm{Y}$, Figure 7.1(a)-(d). $\mathrm{Na}^{+}$cations at site $\mathrm{I}$ are spatially constrained between the two six-rings comprising the hexagonal prism [see Figure 6.1]; therefore, their interactions with the guest species inside the supercages are limited. Clearly, cooperative effects involving $\mathrm{Na}^{+}$cations at site I are negligible in these samples, as shown in Figure 7.1.

Further insight into the environments and interactions involving $\mathrm{Na}^{+}$cations in the supercages of $\mathrm{Na}_{56} \mathrm{Y}$ is provided by determining the chemical shift and quadrupolar contributions to the DOR lines. As described in Chapter 3, the centerband resonances that appear in DOR experiments, $\delta_{o b s}$, incorporate contributions from both the isotropic chemical shift, $\delta_{c s}$, related to the charge density around the nuclei, and the isotropic second-order quadrupolar shift, $\delta_{Q, i s o}$, which depends on the magnetic field and the quadrupolar parameters, see Equations 3.1 and 3.2. Thus, as demonstrated in Chapters 3 and 5, application of the DOR experiments at two magnetic field strengths enables one to independently determine the isotropic quadrupolar and chemical shift components of the resonances.

Table 7.1 shows the positions of the ${ }^{23} \mathrm{Na}$ DOR resonance ascribed to $\mathrm{Na}^{+}$cations at site $\mathrm{II}$, at $11.7 \mathrm{~T}$ and $9.6 \mathrm{~T}$, and the calculated values of the isotropic chemical 
Table 7.1: Observed positions of the ${ }^{23} \mathrm{Na}$ DOR peak ascribed to $\mathrm{Na}^{+}$cations at site II in the supercage of $\mathrm{Na}_{56} \mathrm{Y}, \delta_{\text {obs }}$, at 11.7 Tesla and 9.6 Tesla, and calculated values for the isotropic chemical shift, $\delta_{c s}$, and the quadrupolar product, $P_{Q}=$ $\left(1+\frac{\eta^{2}}{3}\right) C_{Q}^{2}$, determined by using Equations 3.1 and 3.2, see text. The uncertainty in the peak positions was $\pm 0.3 \mathrm{ppm}$.

\begin{tabular}{|c|c|c|c|}
\hline & $8\left\{\mathrm{Mo}(\mathrm{CO})_{6}\right\}-\mathrm{Na66} \mathrm{Y}$ & $8\left\{\mathrm{Mo}(\mathrm{CO})_{6}\right\}, 16\left\{\mathrm{PM}_{3}\right\}-\mathrm{Na}_{6} \mathrm{Y}$ & $8\left\{\mathrm{Mo}(\mathrm{CO})_{4}\left(\mathrm{PMe}_{3}\right)_{2}\right\}-\mathrm{Nas6}_{6} \mathrm{Y}$ \\
\hline$\delta_{\text {oba, }}, 11.7 \mathrm{~T}$ & -24 ppm & $-20 \mathrm{ppm}$ & -14 ppm \\
\hline$\delta_{o b o,}, 9.6 \mathrm{~T}$ & $-28 \mathrm{ppm}$ & $-24 \mathrm{ppm}$ & $-20 \mathrm{ppm}$ \\
\hline$\delta_{c o}$ & $-16.9 \mathrm{ppm}$ & $-12.9 \mathrm{ppm}$ & $-3.3 \mathrm{ppm}$ \\
\hline$P_{Q}$ & $2.2 \mathrm{MHz}$ & $2.2 \mathrm{MHz}$ & $2.7 \mathrm{MHz}$ \\
\hline
\end{tabular}

shift, $\delta_{c s}$, and the quadrupolar product $P_{Q}=\left(1+\frac{\eta^{2}}{3}\right) C_{Q}^{2}$, using Equations 3.1 and 3.2, respectively. These results reveal that on passing from the reactant $8\left\{\mathrm{Mo}(\mathrm{CO})_{6}\right\}-\mathrm{Na}_{56} \mathrm{Y}$, to the reactant-pair $8\left\{\mathrm{Mo}(\mathrm{CO})_{6}\right\}, 16\left\{\mathrm{PMe}_{3}\right\}-\mathrm{Na}_{56} \mathrm{Y}$, to the kinetic product, $8\left\{\right.$ cis- $\left.\mathrm{Mo}(\mathrm{CO})_{4}\left(\mathrm{PMe}_{3}\right)_{2}\right\}-\mathrm{Na}_{56} \mathrm{Y}$, the primary effect is deshielding of the anchoring $\mathrm{Na}^{+}$cations at site II. This is entirely consistent with the notions of negative cooperative effects exerted by the $\mathrm{PMe}_{3}$ guests in the reactant-pair, $8\left\{\mathrm{Mo}(\mathrm{CO})_{6}\right\}, 16\left\{\mathrm{PMe}_{3}\right\}-\mathrm{Na}_{56} \mathrm{Y}$, as well as the higher Lewis basicity of the oxygenend of the carbonyl ligands in the kinetic product, $8\left\{\right.$ cis- $\left.\mathrm{Mo}(\mathrm{CO})_{4}\left(\mathrm{PMe}_{3}\right)_{2}\right\}-\mathrm{Na}_{56} \mathrm{Y}$, both effects modifying the interaction and/or positioning of the $\mathrm{Na}^{+}$cations at their respective framework-oxygen six-ring sites.

The calculations presented in Table 7.1 show that the quadrupolar product remains virtually unchanged at $2.2 \mathrm{MHz}$ upon addition of $\mathrm{PMe}_{3}$ to the reactant, $8\left\{\mathrm{Mo}(\mathrm{CO})_{6}\right\}-\mathrm{Na}_{56} \mathrm{Y}$. This indicates a very small change in the electric field gradient around the ${ }^{23} \mathrm{Na}$ nuclei for the reactant pair. The quadrupolar product of the ${ }^{23} \mathrm{Na}$ nuclei at site II increases to $2.7 \mathrm{MHz}$ on formation of the kinetic product 
in the intrazeolitic reaction, 8 cis- $\left.\mathrm{Mo}(\mathrm{CO})_{4}\left(\mathrm{PMe}_{3}\right)_{2}\right\}-\mathrm{Na}_{56} \mathrm{Y}$, although this change might be experimentally insignificant. This result, combined with the substantial deshielding of the ${ }^{23} \mathrm{Na}$ nuclei in the kinetic product, Table 7.1, probably reflects stronger anchoring of the cis- $\mathrm{Mo}(\mathrm{CO})_{4}\left(\mathrm{PMe}_{3}\right)_{2}$ molecules with the $\mathrm{Na}^{+}$cation inside the supercages of $\mathrm{Na}_{56} \mathrm{Y}$.

\subsubsection{Spin-Lattice Relaxation Measurements}

Valuable information on dynamical aspects concerning the motion of extraframework $\mathrm{Na}^{+}$cations, as well as on the encapsulated guest species within the cavity spaces of sodium zeolite $Y$, can be obtained by estimating the spin-lattice relaxation of the ${ }^{23} \mathrm{Na}$ nuclei. The determination of site-specific spin-lattice relaxation rates in these materials is made possible by the increased spectral resolution obtained in the ${ }^{23} \mathrm{Na}$ DOR experiments.

Relaxation of quadrupolar nuclei, such as ${ }^{23} \mathrm{Na}\left(I=\frac{3}{2}\right)$, is dominated in diamagnetic systems by the interaction of the quadrupole moments with fluctuating electric field gradients $[97,158,159,160]$. In principle, the longitudinal relaxation of $I=\frac{3}{2}$ nuclei, due to the quadrupolar interactions, exhibits a nonexponential decay, due to a superposition of two exponentially decaying components [159]. Thus, as opposed to the common situation encountered in NMR experiments of $I=\frac{1}{2}$ nuclei, one cannot actually refer to a single relaxation rate in quadrupolar systems $[159,161]$. However, in the "extreme narrowing" case, which is the situation attained upon fast fluctuations of the electric field gradient, the quadrupolar spin-lattice relaxation rate, $\left(T_{1, Q}\right)^{-1}$, is given by [158]:

$$
\left(T_{1, Q}\right)^{-1}=\frac{3 \pi^{2}}{10}\left[\frac{2 I+3}{I^{2}(2 I-1)}\right]\left(\frac{e^{2} q Q}{h}\right)^{2}\left(1+\frac{\eta^{2}}{3}\right) \tau_{c}
$$


where $\tau_{c}$ is the correlation time characterizing the time dependence of the electric field gradient.

The following discussion assumes that the approximation of extreme narrowing, or fast motion within the zeolite pores in the $\mathrm{Na}_{56} \mathrm{Y}$-zeolite system, is valid. This hypothesis is supported by the observation in this study of similar spin-lattice relaxation rates at different magnetic field strengths $[13,158]$. In addition, previous studies have related the time dependent fluctuations of the electric field gradient around quadrupolar nuclei in fully hydrated zeolites, to motion of the highly mobile water guest molecules and extraframework cations $[97,160]$. These studies have shown that the high mobility of the adsorbed species within the zeolite pores at room temperature renders accurate the approximation that the spin-lattice relaxation of ${ }^{23} \mathrm{Na}$ nuclei in zeolite $\mathrm{Y}$ is in the fast motion regime.

Figure 7.2 shows room temperature ${ }^{23} \mathrm{Na}$ DOR results of $8\left\{\mathrm{Mo}(\mathrm{CO})_{6}\right\}-\mathrm{Na}_{56} \mathrm{Y}$, for various values of delay time, $\tau$, used in the inversion-recovery experiments $\left[\pi-\tau-\frac{\pi}{2}-\right.$ detection]. Additional spin-lattice relaxation experiments at variable temperatures are not yet feasible with the DOR apparatus used in this work. Inspection of the spectra in Figure 7.2 reveals that the ${ }^{23} \mathrm{Na}$ nuclei located at site I inside the hexagonal prism, which are associated with the peak at around $-3 \mathrm{ppm}$, exhibit longer spin-lattice relaxation than the $\mathrm{Na}^{+}$cations at site II in the supercages, which give rise to the upfield signal at around $-24 \mathrm{ppm}$. The apparent slower spin-lattice relaxation of the ${ }^{23} \mathrm{Na}$ nuclei at site I might reflect the substantially smaller quadrupolar interaction experienced by the sodium nuclei between the two six-rings inside the hexagonal prisms [see Figure 6.1]. Indeed, DOR experiments that were carried out at two magnetic field strengths yield a value of 


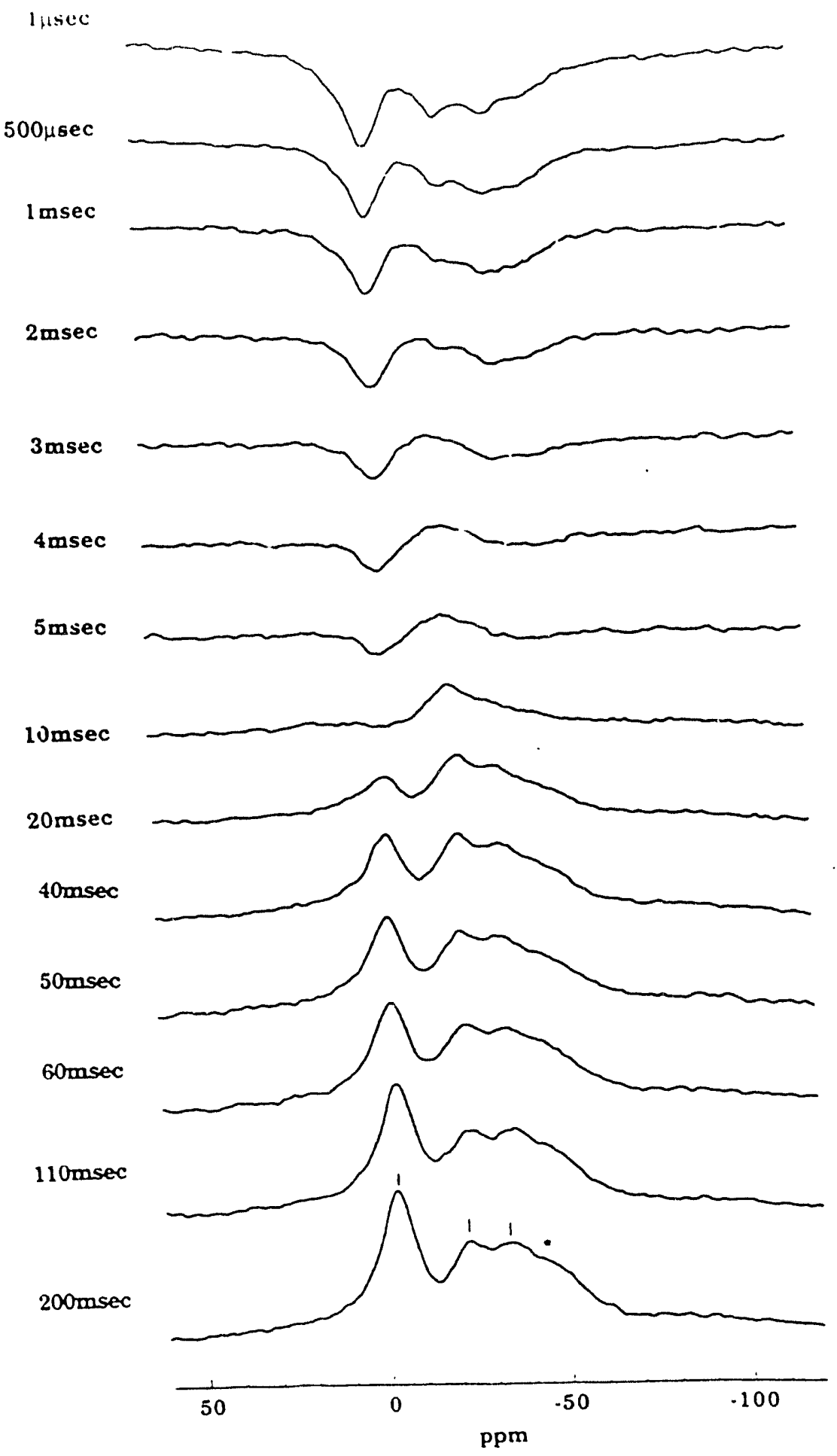

Figure 7.2: ${ }^{23} \mathrm{Na}$ DOR spectra of $8\left\{\mathrm{Mo}(\mathrm{CO})_{6}\right\}-\mathrm{Na}_{56} \mathrm{Y}$ acquired at 11.7 Tesla, using the inversion-recovery pulse sequence, $\pi-\tau-\frac{\pi}{2}-$ detection. The delay time $\tau$ is indicated. 
approximately $P_{Q}=0.4 \mathrm{MHz}$ for the quadrupolar product of ${ }^{23} \mathrm{Na}$ at site $\mathrm{I}$, as compared to $P_{Q}=2.2 \mathrm{MHz}$ for the ${ }^{23} \mathrm{Na}$ nuclei at site II, Table 7.1.

Plots featuring the magnetization decays of the ${ }^{23} \mathrm{Na}$ nuclei at site II, in the reactant sample, $8\left\{\mathrm{Mo}(\mathrm{CO})_{6}\right\}-\mathrm{Na}_{56} \mathrm{Y}$, and the reactant-pair, $8\left\{\mathrm{Mo}(\mathrm{CO})_{6}\right\}, 16\left\{\mathrm{PMe}_{3}\right\}-$ $\mathrm{Na}_{56} \mathrm{Y}$, are shown in Figure 7.3. The results indicate a significant increase in the longitudinal relaxation of the anchoring $\mathrm{Na}^{+}$cations at site II, upon addition of $\mathrm{PMe}_{3}$. The $\mathrm{T}_{1}$ of the $\mathrm{Na}^{+}$cations at site II increases from around $15 \mathrm{msec}$, in the reac$\operatorname{tant} 8\left\{\mathrm{Mo}(\mathrm{CO})_{6}\right\}-\mathrm{Na}_{56} \mathrm{Y}$, to $80 \mathrm{msec}$ in the reactant-pair, $8\left\{\mathrm{Mo}(\mathrm{CO})_{6}\right\}, 16\left\{\mathrm{PMe}_{3}\right\}-$ $\mathrm{Na}_{56} \mathrm{Y}$, Figure 7.3. Slight deviations from exponential relaxation of the ${ }^{23} \mathrm{Na}$ nuclei are observed in Figure 7.3. The nonexponential behaviour probably arises from non-selective excitation $[139,162]$, as well as from transitions within energy levels in the quadrupolar manifold. Although the reported $T_{1}$ values in Figure 7.3 are essentially average values, they reflect a significant difference between the spin-lattice relaxation rates of the ${ }^{23} \mathrm{Na}$ nuclei in the two samples.

The quadrupolar products $P_{Q}$ of the ${ }^{23} \mathrm{Na}$ nuclei at site II, in the reactant and reactant-pair materials, are equal, Table 7.1; therefore, the increase of $T_{1}$ in the reactant-pair is most likely related to a decrease in the quadrupolar correlation time, $\tau_{c}$, Equation 7.5. This result is again consistent with the description of increased motion of the anchoring $\mathrm{Na}^{+}$cations, and/or the $\mathrm{Mo}(\mathrm{CO})_{6}$ guest species, brought about by $\mathrm{Me}_{3} \mathrm{P} \cdots \mathrm{Na}^{+} \mathrm{OZ}(\mathrm{Z} \equiv \mathrm{Si}, \mathrm{Al}), \mathrm{Me}_{3} \mathrm{P} \cdots \mathrm{OZ}$ and/or $\mathrm{Me}_{3} \mathrm{P} \cdots \mathrm{Mo}(\mathrm{CO})_{6}$ interactions in the supecages of $\mathrm{Na}_{56} \mathrm{Y}$. The increased mobility might produce faster fluctuations of the electric field gradients at the ${ }^{23} \mathrm{Na}$ nuclei, which will bring about the slower spin-lattice relaxation observed after adsorption of the $\mathrm{PMe}_{3}$ guest molecules. 


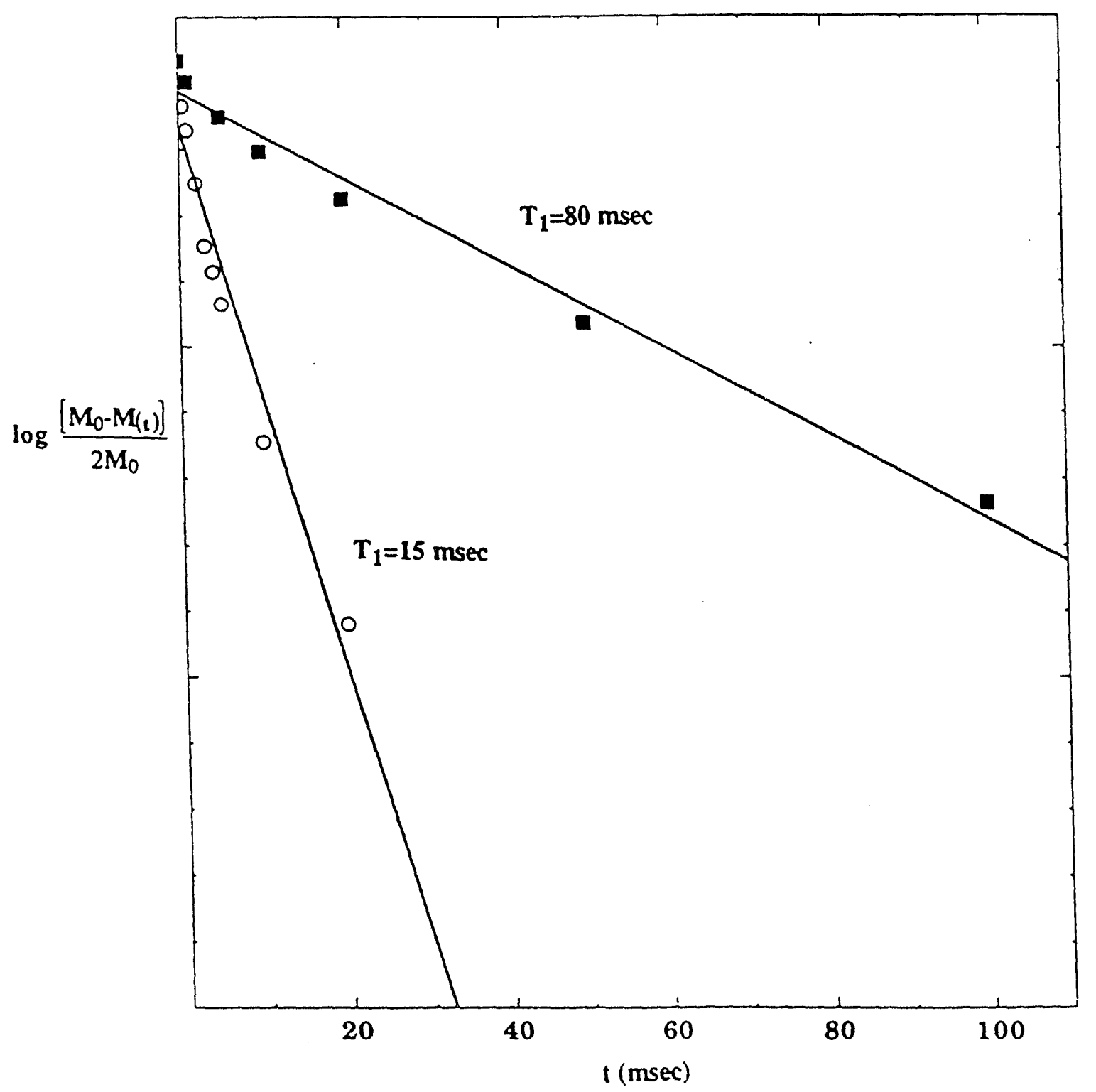

Figure 7.3: A semilogarithmic plot of the magnetization decays of the ${ }^{23} \mathrm{Na}$ nuclei at site II in the reactart material, $8\left\{\mathrm{Mo}(\mathrm{CO})_{6}\right\}-\mathrm{Na}_{56} \mathrm{Y}$ (open circles), and the reactant-pair, $8\left\{\mathrm{Mo}(\mathrm{CO})_{6}\right\}, 16\left\{\mathrm{PMe}_{3}\right\}-\mathrm{Na}_{56} \mathrm{Y}$ (shaded squares). $\mathrm{M}_{0}$ is the peak intensity measured after more than $5 \mathrm{~T}_{1}$ delay time, $\mathrm{M}_{(t)}$ is the intensity measured in the inversion-recovery experiments at a particular delay time, $t$. The lines are the polynomial fittings of the experimental results, and the $T_{1}$ values are the inverse of the respective slopes. 


\subsection{Photooxidation of $\mathrm{Mo}(\mathrm{CO})_{6}$ and $\mathrm{W}(\mathrm{CO})_{6}$ En-}

\section{capsulated in $\mathrm{Na}_{56} \mathrm{Y}$}

Photooxidation of hexacarbonylmetal $(0)$ complexes with dioxygen, Reaction 7.2 , is a prototypical "topotactic" intrazeolitic reaction, which results in a production of semiconductor nanoclusters within the zeolite pores. A particularly noteworthy feature of the synthesized intrazeolite metal oxides, is the ability to control their oxygen stoichiometries through vacuum, thermal reductive-elimination process, reactions 7.3 and 7.4. The reduction process is somewhat analogous to a "doping" process of semiconductor materials, as the energy band-gaps of the metal-oxides are modified by the reduction process $[153,155]$. A multiprong approach, including diffraction, spectroscopy, microscopy, thermal and chemical analyses, has been applied to the intrazeolite metal $(0)$ heaxcarbonyl precursors, $n\left\{M(C O)_{6}\right\}-\mathrm{Na}_{56} \mathrm{Y}$, and oxidation products, $\mathrm{n}\left\{\mathrm{MO}_{3-x}\right\}-\mathrm{Na}{ }_{56} \mathrm{Y}$, in order to probe their structures and properties $[153,154,155,156,163,164]$.

The proposed organizations of the guests for the special case of half-loading $(\mathrm{n}=16)$ samples in $\mathrm{Na}_{56} \mathrm{Y}$ are illustrated schematically in Figure 7.4 [molybdenumoxides] and Figure 7.5 [tungsten-oxides]. In all cases, bond lengths and coordination numbers were estimated from Mo K-edge and W LIII-edge EXAFS structure analyses $[130,154,155,156,163]$. As shown in Figures 7.4 and 7.5 , a ubiquitous feature for all intrazeolite $\mathrm{M}(\mathrm{CO})_{6}$ precursors and $\mathrm{MO}_{3-x}$ products, is the proposed existence of anchoring interactions between the oxygen-end of the carbonyl ligands [of the carbonyl precursors], or the oxometal bonds [of the metal oxides], and the extraframework charge balancing $\mathrm{Na}^{+}$cations located within the supercages. The 


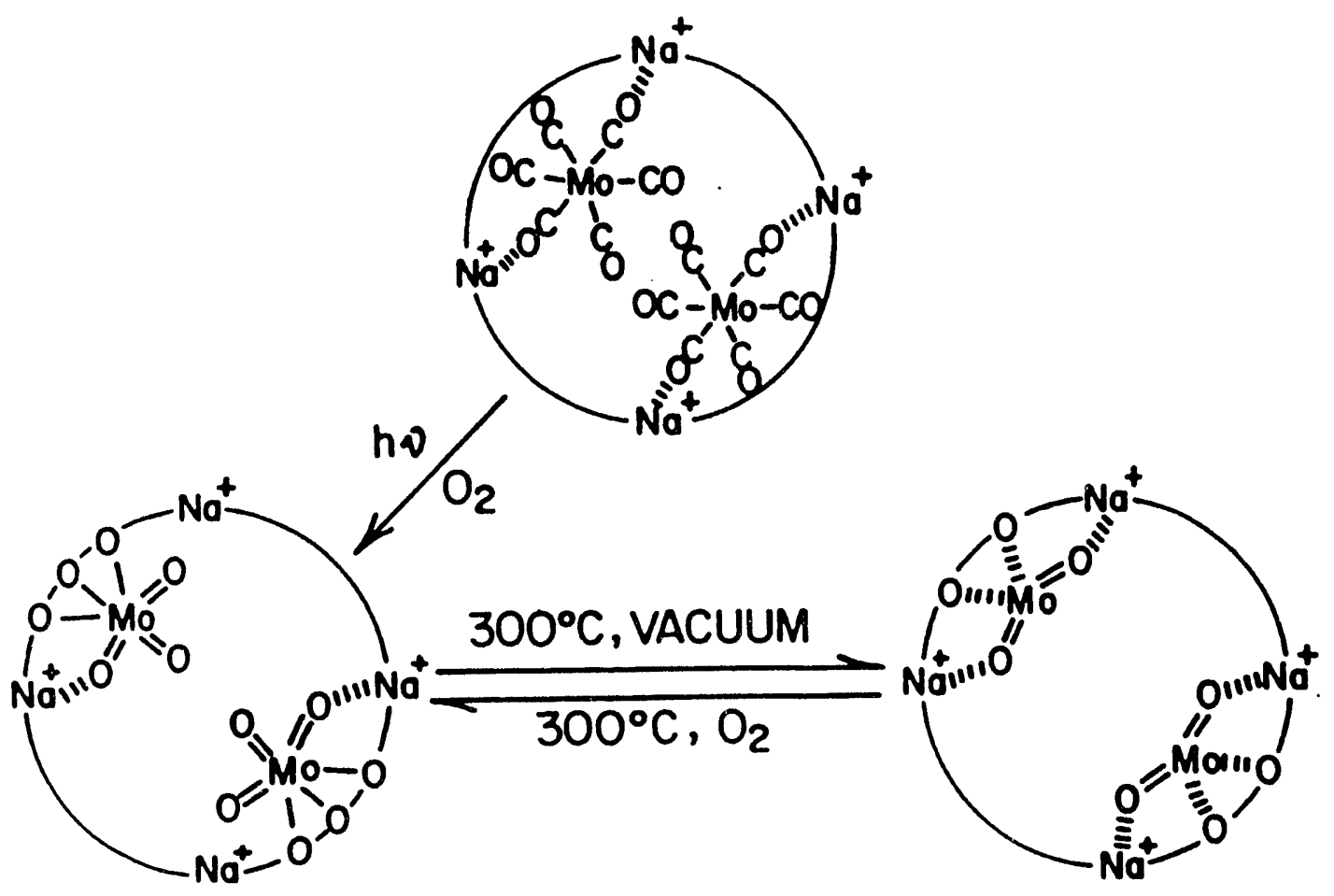

Figure 7.4: Schematic drawing of the intrazeolite structures and anchoring geometries of: $16\left\{\mathrm{Mo}(\mathrm{CO})_{6}\right\}-\mathrm{Na}_{56} \mathrm{Y}, 16\left\{\mathrm{MoO}_{3}\right\}-\mathrm{Na}_{56} \mathrm{Y}$ and $16\left\{\mathrm{MoO}_{2}\right\}-\mathrm{Na}_{56} \mathrm{Y}$ (ref. $[130,154])$. 


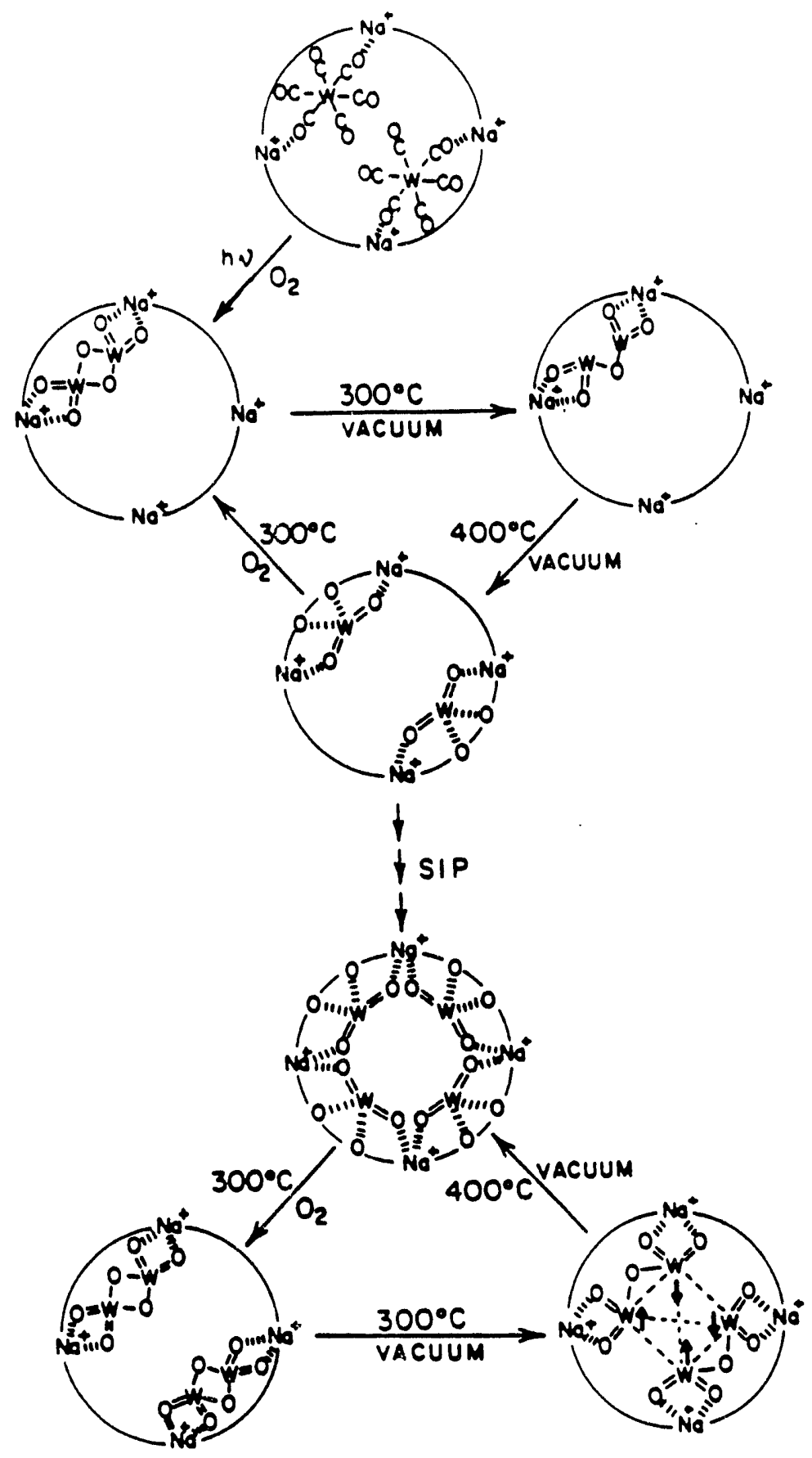

Figure 7.5: Schematic drawing of the intrazeolite structures and anchoring geometries of: $16\left\{\mathrm{~W}(\mathrm{CO})_{6}\right\}-\mathrm{Na}_{56} \mathrm{Y}, 16\left\{\mathrm{WO}_{3}\right\}-\mathrm{Na}_{56} \mathrm{Y}, 16\left\{\mathrm{WO}_{2.5}\right\}-\mathrm{Na}_{56} \mathrm{Y}$ and $16\left\{\mathrm{WO}_{2}\right\}-\mathrm{Na}_{56} \mathrm{Y}$ (ref. $\left.[155,156,163]\right)$. 
majority $\mathrm{Na}^{+}$cations in the supercages under these circumstances are arranged in a tetrahedral array of four $\mathrm{Na}^{+}$cations at site II, with each sodium ion being located above the center of an oxygen six-ring [137].

The existence of such $\mathrm{ZONa}^{+} \ldots \mathrm{O}$ interactions $(\mathrm{Z} \equiv \mathrm{Si}, \mathrm{Al})$ has been deduced in earlier studies from a combination of site-specific frequency shifts in the $\mathrm{Na}^{+}$ cation far-IR translatory modes, as well as line shifts and intensity alterations in the ${ }^{23} \mathrm{Na}$ MAS-NMR spectra, induced by the introduction of $\mathrm{M}(\mathrm{CO})_{6}$ and $\mathrm{MO}_{3-x}$ into the supercages of bare $\mathrm{Na}_{56} \mathrm{Y}[165,166]$. In addition, $\mathrm{Rb} \mathrm{K}$-edge EXAFS structure analysis has been employed to evaluate $\mathrm{ZORb}^{+} \ldots \mathrm{O}$ anchoring interactions in some of these systems [130]. Taken together, the results of the above studies provide compelling evidence for the existence of anchoring interactions of the type illustrated in Figures 7.4 and 7.5. However, each method has particular interpretive difficulties that might not produce unequivocal results. Specifically, the far-IR adsorption induced frequency shifts are usually only of the order of $2-5 \mathrm{~cm}^{-1}$, and might be blue, or red-shifted depending on the alterations in bonding and geometry around the $\mathrm{Na}^{+}$cation anchoring site $[165,166]$. The ${ }^{23} \mathrm{Na}$ MAS spectra of $\mathrm{Na}_{56} \mathrm{Y}$ and its guest-loaded derivatives are essentially convolutions of poorly resolved quadrupolar-broadened resonances from the various $\mathrm{Na}^{+}$sites, and the EXAFS derived adsorption induced changes in the $\mathrm{Rb}-\mathrm{O}$ coordination numbers are the same order of magnitude as the experimental precision $(20 \%)$. The ${ }^{23} \mathrm{Na}$ DOR results, however, provide a sensitive and direct probe of $\mathrm{ZONa}^{+} \ldots \mathrm{O}$ anchoring interactions in the supercages, which more completely define the structures and properties of $\mathrm{M}(\mathrm{CO})_{6}$ and $\mathrm{MO}_{3-x}$ guests in zeolite $\mathrm{Y}$. 


\subsubsection{Intrazeolite Oxidation of $\mathrm{Mo}(\mathrm{CO})_{6}$}

${ }^{23} \mathrm{Na}$ DOR spectra of oxidized $16\left\{\mathrm{Mo}(\mathrm{CO})_{6}\right\}-\mathrm{Na}_{56} \mathrm{Y}$ species, Reactions 7.2 and 7.4, are shown in Figure 7.6. The NMR results of both the photooxidized product, $16\left\{\mathrm{MoO}_{3}\right\}-\mathrm{Na}_{56} \mathrm{Y}$, Figure $7.6(\mathrm{c})$, and the further thermally reduced $16\left\{\mathrm{MoO}_{2}\right\}-$ $\mathrm{Na}_{56} \mathrm{Y}$, Figure 7.6(d), feature significant changes in the intensity of the signal ascribed to $\mathrm{Na}^{+}$cations at site II. $\mathrm{MoO}_{3}$ is a monomer, considered to exhibit a trigonal pyramidal structure, and anchored to three framework oxygens through the metal vertice [154], as illustrated in Figure 7.4. The disposition of the oxometal bonds in the trigonal pyramid is such that only a single oxygen-end can interact with an adjacent $\mathrm{Na}^{+}$cation at site II. Therefore, whereas two $\mathrm{Mo}(\mathrm{CO})_{6}$ molecules are anchored to four $\mathrm{Na}^{+}$cations at site II in the supercage, as shown in Figure 7.4, only two site II $\mathrm{Na}^{+}$cations will interact with the two $2 \mathrm{MoO}_{3}$ photooxidation products. Indeed, the ${ }^{23} \mathrm{Na}$ DOR spectrum of $16\left\{\mathrm{MoO}_{3}\right\}-\mathrm{Na}_{56} \mathrm{Y}$, Figure $7.6(\mathrm{c})$, shows a substantially reduced intensity of the peak associated with site II, as essentially only half of the anchored $\mathrm{Na}^{+}$cations in the precursor sample, Figure 7.6(b), are still bound in the photooxidized sample. As discussed in the previous chapter, the NMR signal from unanchored $\mathrm{Na}^{+}$cations is extremely broad, and is mostly buried in the fluctuations of the baseline and the experimental "deadtime".

Following the thermal reductive-elimination of $\mathrm{O}_{2}$, reaction 7.4, encapsulated $\mathrm{MoO}_{2}$ molecular guests are produced inside the supercages, as illustrated in Figure 7.4. The $\mathrm{MoO}_{2}$ molecule, similar to the $\mathrm{Mo}(\mathrm{CO})_{6}$ complex, exhibits a geometry that facilitates anchoring interactions to two $\mathrm{Na}^{+}$cations. Accordingly, the intensity of the signal at $-19 \mathrm{ppm}$, associated with $\mathrm{Na}^{+}$cations at site II in the supercages of $16\left\{\mathrm{MoO}_{2}\right\}-\mathrm{Na} a_{56} \mathrm{Y}$, Figure 7.6(d), increases significantly, compared to 

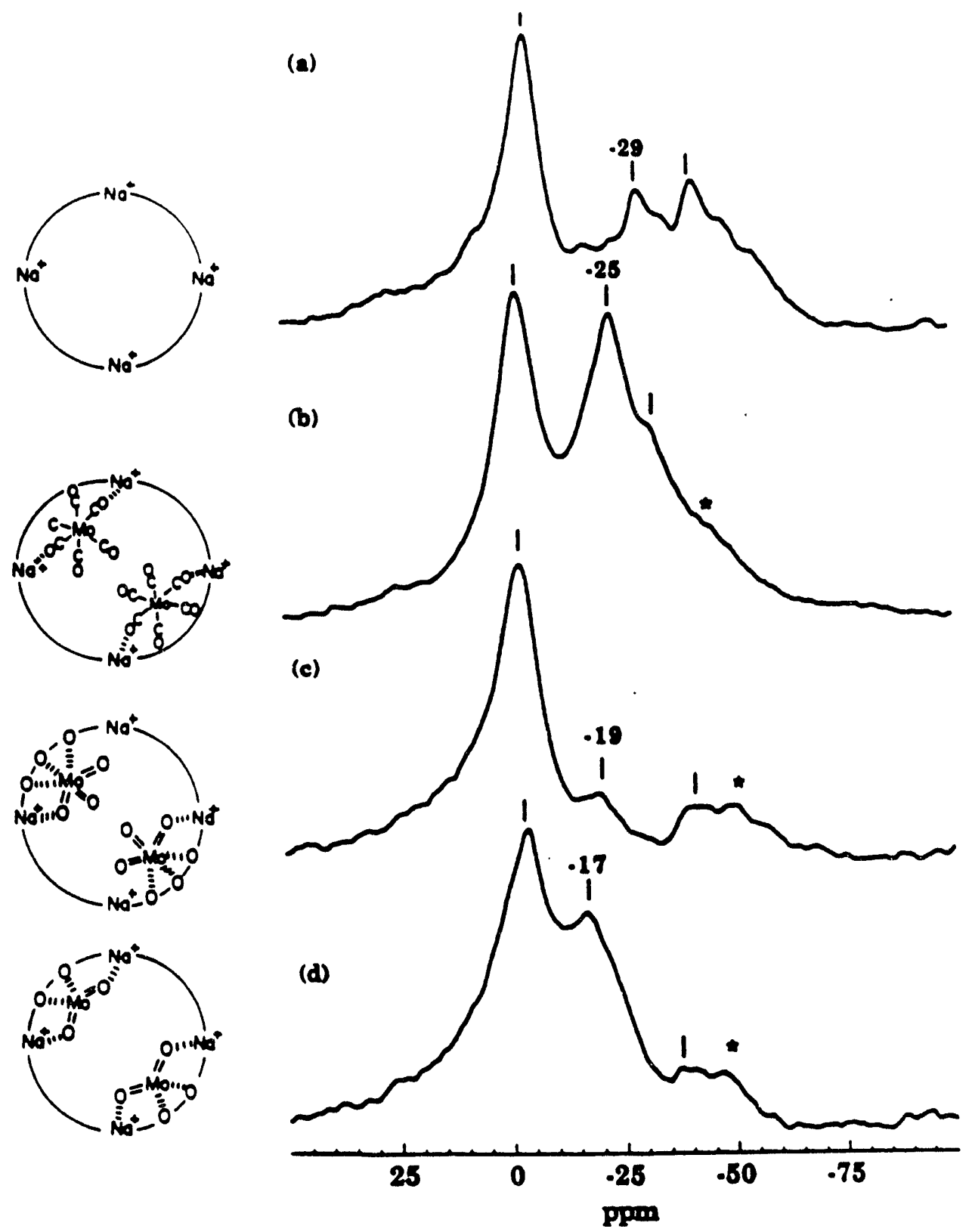

Figure 7.6: ${ }^{23} \mathrm{Na}$ DOR spectra of (a) dehydrated $\mathrm{Na}_{56} \mathrm{Y}$; (b) $16\left\{\mathrm{Mo}(\mathrm{CO})_{6}\right\}-$ $\mathrm{Na}_{56} \mathrm{Y}$; and oxidation products: (c) $16\left\{\mathrm{MoO}_{3}\right\}-\mathrm{Na}_{56} \mathrm{Y}$; (d) $16\left\{\mathrm{MoO}_{2}\right\}-\mathrm{Na}_{56} \mathrm{Y}$. The asterisks indicate spinning sidebands of the outer rotor. Schematic illustrations of the strucrural arrangement of the guest molecules in the supercage are shown on the left of each spectrum. 
the respective ${ }^{23} \mathrm{Na}$ signal at around $-18 \mathrm{ppm}$ in $16\left\{\mathrm{MoO}_{3}\right\}-\mathrm{Na}_{56} \mathrm{Y}$. Figure $7.6(\mathrm{c})$. Incidentally, one observes a shift in the ${ }^{23} \mathrm{Na}$ resonance ascribed to site II, from $-25 \mathrm{ppm}$ in $16\left\{\mathrm{Mo}(\mathrm{CO})_{6}\right\}-\mathrm{Na}_{56} \mathrm{Y}$, Figure $7.6(\mathrm{~b})$, to around $-18 \mathrm{ppm}$ in the $\mathrm{MoO}_{3}$ and $\mathrm{MoO}_{2}$-loaded samples, Figure 7.6(c) and (d), respectively. This shift might indicate a different interaction between the extraframework $\mathrm{Na}^{+}$cations and the oxygen-ends of the carbonyl and oxo-molybdenum bonds, respectively.

\subsubsection{Intrazeolite Oxidation of $\mathrm{W}(\mathrm{CO})_{6}$}

Figure 7.7 features the ${ }^{23} \mathrm{Na}$ DOR spectra of the intrazeolite tungsten hexacarbonyl and oxide series, Reactions 7.2 and 7.3. The proposed structural arrangements are shown schematically in Figure 7.5 . The DOR spectrum of $16\left\{\mathrm{~W}(\mathrm{CO})_{6}\right\}-$ $\mathrm{Na}_{56} \mathrm{Y}$, Figure 7.7(b), is almost identical to the respective molybdenum precursor, $16\left\{\mathrm{Mo}(\mathrm{CO})_{6}\right\}-\mathrm{Na}_{56} \mathrm{Y}$, shown in Figure $7.6(\mathrm{~b})$. The similarity between the NMR spectra indicates that the anchoring interactions and guest arrangements in both tungsten and molybdenum precursor carbonyl materials are probably identical.

Photooxidation of the parєnt material $16\left\{\mathrm{~W}(\mathrm{CO})_{6}\right\}-\mathrm{Na}_{56} \mathrm{Y}$ produces $16\left\{\mathrm{WO}_{3}\right\}-$ $\mathrm{Na}_{56} \mathrm{Y}$, Reaction 7.2 , which is viewed is a supralattice of $\mathrm{W}_{2} \mathrm{O}_{6} \operatorname{dimers}\left(\mathrm{W}^{6+} / \mathrm{W}^{6+}\right)$ within the zeolite framework $[155,163]$. As shown in Figure 7.5 , this configuration produces anchoring interactions of each $\mathrm{W}_{2} \mathrm{O}_{6}$ dimer with only two $\mathrm{Na}^{+}$ cations at site II, through the oxygen-end of the terminal oxo-tungsten bonds of the molecule. Accordingly, one observes a significant decrease in the intensity of the ${ }^{23} \mathrm{Na}$ resonance ascribed to site II, in the spectrum of the photooxidation product, Figure 7.7(c), since twice as many $\mathrm{Na}^{+}$cations were anchored in the parent precursor material, $16\left\{\mathrm{~W}(\mathrm{CO})_{6}\right\}-\mathrm{Na}_{56} \mathrm{Y}$, see Figure 7.5. The signal associated with site II 

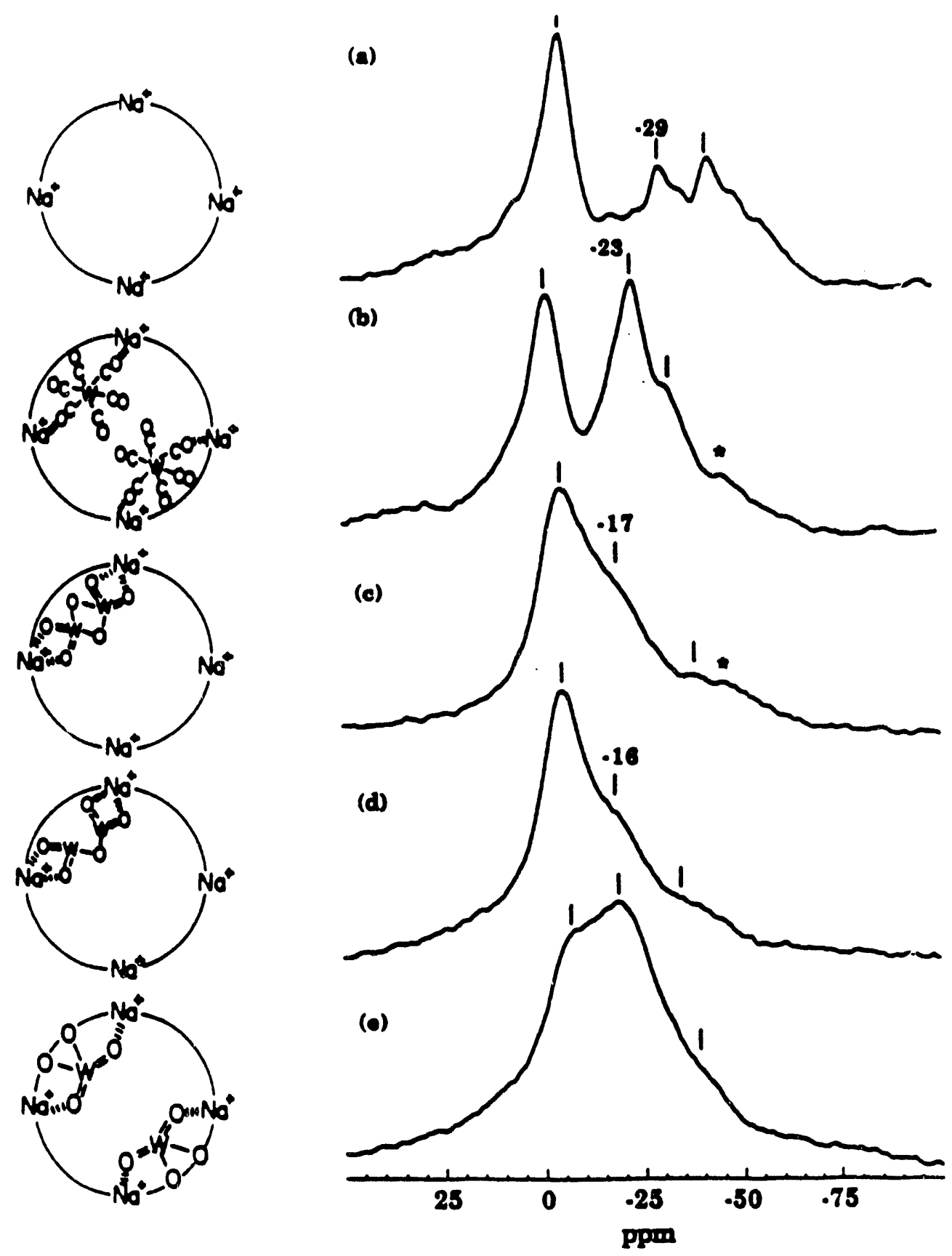

Figure 7.7: ${ }^{23} \mathrm{Na}$ DOR spectra of (a) dehydrated $\mathrm{Na}_{56} \mathrm{Y}$; (b) $16\left\{\mathrm{~W}(\mathrm{CO})_{6}\right\}-$ $\mathrm{Na}_{56} \mathrm{Y}$; and oxidation products: (c) $16\left\{\mathrm{WO}_{3}\right\}-\mathrm{Na}_{56} \mathrm{Y}$; (d) $16\left\{\mathrm{WO}_{2.5}\right\}-\mathrm{Na}_{56} \mathrm{Y}$; (e) $16\left\{\mathrm{WO}_{2}\right\}-\mathrm{Na}_{56} \mathrm{Y}$. The asterisks indicate spinning sidebands of the outer rotor. Schematic illustrations of the strucrural arrangement of the guest molecules in the supercage are shown on the left of each spectrum. 
$\mathrm{Na}^{+}$cations in $16\left\{\mathrm{WO}_{3}\right\}-\mathrm{Na}_{56} \mathrm{Y}$, Figure $7.7(\mathrm{c})$, appears as a shoulder, at around $-17 \mathrm{ppm}$, of the prominent downfield resonance. This pronounced downfield shift from the original ${ }^{23} \mathrm{Na}$ position at around $-23 \mathrm{ppm}$, in the precursor material, Figure 7.7(b), probably corresponds to the structural transformation undergone by the $\mathrm{W}(\mathrm{CO})_{6}$ complexes inside the supercage. The formation of the $\mathrm{W}_{2} \mathrm{O}_{6}$ dimer might significantly alter the environment of the anchoring $\mathrm{Na}^{+}$cations at site II.

The first-stage thermal reduction product $16\left\{\mathrm{WO}_{2.5}\right\}-\mathrm{Na}_{56} \mathrm{Y}$, Reaction 7.3 , consists of a supralattice of superexchange coupled $\left(\mathrm{W}^{5+} / \mathrm{W}^{5+}\right) \mathrm{W}_{2} \mathrm{O}_{5}$ dimers, whereas the final product, $16\left\{\mathrm{WO}_{2}\right\}-\mathrm{Na}_{5 \mathrm{i}} \mathrm{Y}$, exists as separate $\mathrm{WO}_{2}$ monomers $[155,163]$, see in Figure 7.5. The DOR spectra in Figure 7.7 support this structural picture. Hardly any difference is observed between the ${ }^{23} \mathrm{Na}$ DOR spectra of the $\mathrm{W}_{2} \mathrm{O}_{6^{-}}$, and $\mathrm{W}_{2} \mathrm{O}_{5}$-loaded samples, Figure 7.7(c) and (d), respectively. This, in fact, is anticipated, since the basic dimer structure is retained in both materials. On the other hand, the thermally reduced sample, $16\left\{\mathrm{WO}_{2}\right\}-\mathrm{Na}_{56} \mathrm{Y}$, contains $\mathrm{WO}_{2}$ monomers, each of which interacts with two $\mathrm{Na}^{+}$anchoring cations, turice as many as the tungsten oxide dimers. Indeed, the ${ }^{23} \mathrm{~V}$. DOR spectrum of the final product, shown in Figure 7.7(e), features a prominent peak at around $-17 \mathrm{ppm}$ which is ascribed to the anchoring $\mathrm{Na}^{+}$cations at sit II.

The ${ }^{23} \mathrm{Na}$ resonance associatod with the $\mathrm{Na}^{+}$cations at site II, Figure 7.7(e), is relatively broad, however, particularly in comparison to the respective site II ${ }^{23} \mathrm{Na}$ peak at around $-23 \mathrm{ppm}$ in the parent material $16\left\{\mathrm{~W}(\mathrm{CO})_{6}\right\}-\mathrm{Na}_{56} \mathrm{Y}$, Figure $7.7(\mathrm{~b})$. This broadening might be brought about because of a relatively weak anchoring interaction between the oxygens of the oxo-tungsten bonds of $\mathrm{WO}_{2}$ and the $\mathrm{Na}^{+}$cations, compared to the carbonyl group in the $\mathrm{W}(\mathrm{CO})_{6}$ guest molecules. 

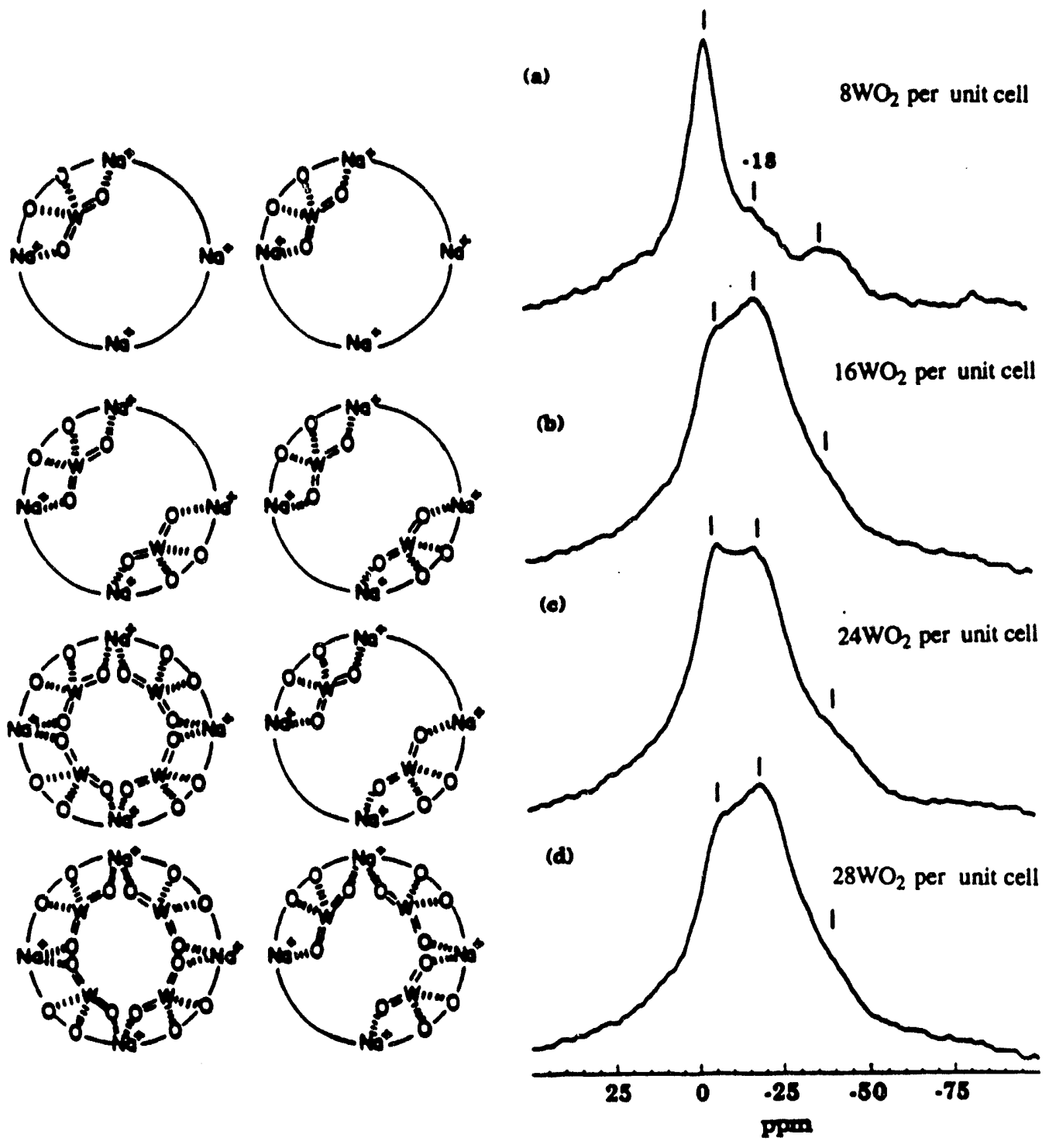

Figure 7.8: ${ }^{23} \mathrm{Na}-\mathrm{DOR}$ spectra of $\mathrm{Na}_{56} \mathrm{Y}$ loaded with: (a) $8\left\{\mathrm{WO}_{2}\right\}-\mathrm{Na}_{56} \mathrm{Y}$ guest molecules per unit cell; (b) $16\left\{\mathrm{WO}_{2}\right\}-\mathrm{Na}_{56} \mathrm{Y}$ guest molecules per unit cell; (c) $24\left\{\mathrm{WO}_{2}\right\}-\mathrm{Na}_{56} \mathrm{Y}$ guest molecules per unit cell; (d) $28\left\{\mathrm{WO}_{2}\right\}-\mathrm{Na}_{56} \mathrm{Y}$ guest molecules per unit cell. Schematic illustrations of the strucrural arrangement of the guest species in two adcjacent supercages are shown on the left of each spectrum. 
This might allow a greater distribution of $\mathrm{Na}^{+}$environments, and broadening of the spectral lines [see discussion concerning broad ${ }^{23} \mathrm{Na}$ signals in dehydrated $\mathrm{Na}_{56} \mathrm{Y}$, Chapter 6].

Further evidence of the proposed structural arrangement of the intrazeolite $\mathrm{WO}_{2}$ monomers is shown in Figure 7.8. Figure 7.8 features $\mathrm{Na}_{56} \mathrm{Y}$-zeolite samples loaded with various amounts of $\mathrm{WO}_{2}$ guest molecules. Since each $\mathrm{WO}_{2}$ guest molecule is anchored to two $\mathrm{Na}^{+}$cations at site II, all the four available $\mathrm{Na}^{+}$cations inside the supercages will already be anchored by the guest clusters in $16\left\{\mathrm{WO}_{2}\right\}-\mathrm{Na}_{56} \mathrm{Y}$ [the sample which contains $2 \mathrm{WO}_{2}$ guest molecules per supercage, see Figure 7.5]. Indeed, inspection of Figure 7.8(b)-(d) reveals that there is essentially no difference between the ${ }^{23} \mathrm{Na}$ DOR spectra of the samples loaded with 16 or more $\mathrm{WO}_{2}$ monomers per unit cell. The intensity, as well as the shape, of the resonances ascribed to $\mathrm{Na}^{+}$ cations at site II at around $-18 \mathrm{ppm}$ hardly change, since the arrangements of the anchored $\mathrm{Na}^{+}$cations at the highest-loading samples, $\mathrm{n}\left\{\mathrm{WO}_{2}\right\}-\mathrm{Na}_{56} \mathrm{Y}[\mathrm{n}=16,24$, 28] are similar. 


\section{Chapter 8}

\section{Conclusions}

The main objective of this work is to obtain a comprehensive and detailed information on chemical processes and atomic environments within crystalline porous aluminosilicates and aluminphosphates. The use of NMR has a distinct advantage in the study of zeolites and aluminophosphate molecular sieves, since these materials usually exhibit only short range ordering. Abundant quadrupolar nuclei, such as ${ }^{23} \mathrm{Na}$ and ${ }^{27} \mathrm{Al}$, play a significant role in determining the chemical properties of zeolites. However, reduced spectral resolution in solid state NMR experiments * of quadrupolar nuclei have limited their usefulness in zeolite research. The newly developed double rotation (DOR) technique removes the anisotropic broadening in NMR spectra of quadrupolar nuclei, thus providing an excellent, direct analytical tool for the investigation of zeolites' internal surfaces and cavities.

The experiments described in this work can be divided into two groups: studies which concentrate on characterizing framework aluminum sites, using ${ }^{27} \mathrm{Al}$ DOR, and the application of ${ }^{23} \mathrm{Na}$ DOR to detect changes in the environments of extraframework sodium cations, throughout intrazeolite processes. Some chemical 
and physical similarities as well as differences exist between framework aluminum, on one hand, and extraframework sodium cations, on the other, although both atoms are directly involved in processes within zeolite pores. Parameters such as the distribution of atomic constituents, site occupancies, and sensitivity to adsorbed species, become apparent in the DOR spectra and affect the symmetry and electronic charge distributions around the nuclear sites, as well as the shapes and positions of the ${ }^{23} \mathrm{Na}$ and ${ }^{27} \mathrm{Al}$ resonances.

Aluminum environments in porous aluminophosphate molecular sieves are significantly affected by adsorption of water. The appearance of distinct five-, and six-coordinated framework aluminum sites in hydrated aluminophosphates is detected by ${ }^{27} \mathrm{Al} \mathrm{DOR}$. The NMR experiments additionally verify the reversibility of the adsorption process. The ordering and symmetries of the ${ }^{27} \mathrm{Al}$ nuclear sites also seem to be related to the topologies and sizes of the channels. VPI-5, for example, which has the widest channel openings among the aluminophosphates examined here, features highly ordered aluminum environments upon adsorption of $\mathrm{H}_{2} \mathrm{O}$, while the ${ }^{27} \mathrm{Al}$ sites in hydrated $\mathrm{AlPO}_{4}-5$, which has much narrower channels, give rise to broad and featureless spectral lines.

The organization and ordering of extrafrar ework $\mathrm{Na}^{+}$cations is also a prominent issue in sodalites and zeolite $\mathrm{Y}$, and has been studied here using ${ }^{23} \mathrm{Na}$ DOR. ${ }^{23} \mathrm{Na}$ and ${ }^{27} \mathrm{Al} \mathrm{DOR}$, complemented by ${ }^{29} \mathrm{Si}$ and ${ }^{81} \mathrm{Br} \mathrm{MAS}, \mathrm{X}$ ray diffraction, and infra red measurements, provide insight into the synthesis, assembly, and cation/anion distributions in sodium, halo-sodalites. ${ }^{23} \mathrm{Na}$ DOR experiments enable the close examination of $\mathrm{Ag}^{+}$cation exchange of sodium, bromo-sodalite, which produces sodalite-encapsulated semiconductor component superlattices. Two-field 
DOR experiments indicate an abrupt change in the charge distribution around the $\mathrm{Na}^{+}$cations inside the sodalite cages, beyond substitution of $25 \%$ of the cations. This interesting result is corroborated by other spectroscopic measurements.

Extraframework $\mathrm{Na}^{+}$cations are directly involved in the adsorption and intrazeolitic reactions within the cavities of sodium zeolite $\mathrm{Y} .{ }^{23} \mathrm{Na}$ DOR experiments reveal the existence of anchoring interactions between extraframework $\mathrm{Na}^{+}$cations and the guest molecules in the supercages of zeolite Y. The capability of the DOR technique to distinguish, for the first time, the three distinct $\mathrm{Na}^{+}$cation sites in $\mathrm{Na}_{56} \mathrm{Y}$-zeolite, facilitates the investigation of site specific effects within the pores of the zeolite. Among the chemical processes examined are the cation-exchange of $\mathrm{Na}^{+}$with $\mathrm{Tl}^{+}$and $\mathrm{Ca}^{2+}$, and the ligand substitution and photooxidation of transition-metal carbonyls, encapsulated within the porous framework of $\operatorname{Na}_{56} \mathrm{Y}-$ zeolite. Dynamical information is additionally provided by estimating the spinlattice relaxation rates of the ${ }^{23} \mathrm{Na}$ nuclei in $\mathrm{Na}_{56} \mathrm{Y}$-zeolite.

In conclusion, this work demonstrates the power of ${ }^{27} \mathrm{Al}$ and ${ }^{23} \mathrm{Na} \mathrm{DOR}$ experiments, and the DOR technique in general, to give a direct and detailed insight into : atomic arrangements in zeolites. Future application of DOR experiments involving ${ }^{27} \mathrm{Al}$ and ${ }^{23} \mathrm{Na}$ nuclei, as well as other quadrupolar nuclei, would undoubtedly increase our understanding of zeolite properties, and contribute to the scientific and technological uses of this unique class of materials. 


\section{Appendix A}

\section{Spin Interactions and Motional}

\section{Averaging}

\section{A.1 Introduction}

The wealth of structural and dynamical information in NMR experiments of solid materials arises from the contributions of various nuclear spin interactions, which affect the energy levels of the systems investigated, and the observed spectra. Several books give a general discussion concerning the principles of nuclear magnetic resonaice $[13,167,158,168]$, on specific issues in NMR of solid materials $[7,169]$, and the study of quadrupolar nuclei [171]. A general expansion upon the discussion presented here can be found in ref. [172].

Specifically, the spin Hamiltonians, and their effects in NMR experiments of half-integer quadrupolar nuclei in solid materials are discussed in this chapter. The chemical shift and quadrupolar Hamiltonians are explicitly written and analyzed. The anisotropic spectral broadening which occurs in static powder samples 
is explained, and the method of averaging the anisotropic line-broadening using fast sample rotation is presented and discussed. Finally, it is demonstrated that for quadrupolar nuclei, fast spinning around a single axis fails to completely average out the anisotropic broadening, and the double rotation method is introduced.

\section{A.2 Spin Hamiltonians}

The total nuclear spin Hamiltonian can be divided into two parts:

$$
\begin{gathered}
\mathcal{H}=\mathcal{H}_{\text {ext }}+\mathcal{H}_{\text {int }} \\
\mathcal{H}_{\text {ext }}=\mathcal{H}_{z}+\mathcal{H}_{\text {rf }},
\end{gathered}
$$

The external part, $\mathcal{H}_{\text {ext }}$, is controlled by the experimenter, and essentially consists of the Zeeman Hamiltonian, $\mathcal{H}_{z}$, and the Hamiltonian associated with the radiofrequancy (If) pulse, $\mathcal{H}_{r f}$ :

$$
\begin{aligned}
& \mathcal{H}_{z}=-\gamma_{I} \hbar I_{z} B_{0} \\
& \mathcal{H}_{r f}=\gamma B_{1}\left[I_{x} \cos (\omega \tau+\phi)+I_{y} \sin (\omega \tau+\phi)\right] .
\end{aligned}
$$

The internal part of the Hamiltonian, $\mathcal{H}_{\text {int }}$, contains all the relevant magnetic and electronic interactions of the nucleus, such as the electron-nucleus couplings, the dipolar and quadrupolar interactions, and others:

$$
\mathcal{H}_{\text {int }}=\mathcal{H}_{c s}+\mathcal{H}_{D}+\mathcal{H}_{Q}+\ldots
$$

All internal Hamiltonians can be expressed in a general form [170]:

$$
\mathcal{H}_{\lambda, i}=C^{\lambda} \mathbf{I}_{i} \tilde{\mathbf{R}}_{i}^{\lambda} \mathbf{A}_{i}^{\lambda}
$$

where the indice $i$ refers to the particular spin under consideration, and $\lambda$ stands for the different spin interactions. I and $\mathbf{A}$ are row and column vectors, respectively, 
one of which is always the nuclear spin vector, whereas the other one can be either the same nuclear spin vector (quadrupolar coupling), another nuclear spin vector (dipolar coupling), or the external magnetic field (chemical shift). $\tilde{\mathbf{R}}$ are second rank tensors that depend parametrically on geometric configurations, and/or the electronic, vibrational and rotational levels of the atom.

The $C^{\lambda}$ in Equation A.5 depend only on the fundamental constants $\hbar$ and $e$, and properties of the nuclei relevant to the specific interaction:

$$
C^{\lambda}= \begin{cases}\gamma_{I} \hbar & \text { chemical shift } \\ \frac{e Q}{2 I(2 I-1)} & \text { quadrupolar } \\ -\frac{2 \mu_{0}}{4 \pi} \gamma_{I} \gamma_{S} \hbar^{2} & \text { dipolar }\end{cases}
$$

An equivalent way of writing Equation A.5 is as a product of two cartesian tensors [170]:

$$
\mathcal{H}_{\lambda}=C^{\lambda} \sum_{\alpha, \beta=1}^{3} T_{\beta \alpha}^{\lambda} R_{\alpha \beta}^{\lambda} .
$$

All averaging techniques in NMR, whether in spin or real space, as will be shown below, rely on performing rotations on the internal Hamiltonians. Thus, it is geometrically clearer, and easier to manipulate mathematically, to express the various internal Hamiltonians in an irreducible spherical tensors representation:

$$
\mathcal{H}_{\lambda}=C^{\lambda} \sum_{l=0}^{2} \sum_{m=-l}^{l}(-1)^{m} T_{l m}^{\lambda} R_{l-m}^{\lambda} .
$$

The transformation from cartesian to spherical tensors is provided in standard text books [170]. The irreducible spherical tensors form a complete basis set for rotation. This means that the spherical tensors transform like the 2nd rank spherical harmonics, into a linear combination of themselves upon any rotation of their axis system [173]. 

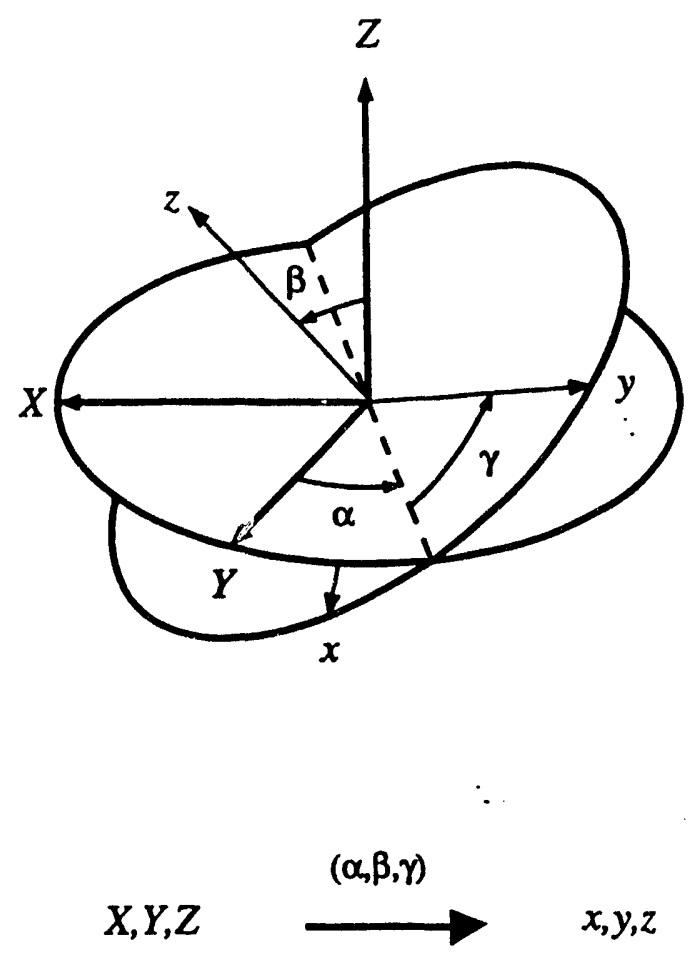

Figure A.1: The Euler angles $\alpha, \beta, \gamma$ which describe the transformation between two axis systems.

Specifically, rotations of the spherical tensors between two reference frames are performed with the Wigner rotation matrices [173]:

$$
D_{m^{\prime} m}^{l}(\alpha, \beta, \gamma)=e^{-m^{\prime} \alpha} d_{m^{\prime} m}^{(l)}(\beta) e^{-m \gamma}
$$

where $\alpha, \beta, \gamma$ are the Euler angles which define the rotations between the two axis systems, see Figure A.1. $d_{m^{\prime} m}^{(l)}(\beta)$ are the reduced matrix elements. and are explicitly written in Table A.1.

$R_{l-m}^{\lambda}$ in Equation A.8 contain the spatial parts of the interactions. These are 
Table A.1: Reduced Wigner rotation matrix elements $d_{m^{\prime} m}^{(l)}(\beta)$

\begin{tabular}{|c||c|c|c|c|c|}
\hline \hline & \multicolumn{5}{|c|}{$\mathrm{m}$} \\
\hline $\mathrm{m}$ & 2 & 1 & 0 & -1 & -2 \\
\hline \hline 2 & $\left(\frac{1+\cos \beta}{2}\right)^{2}$ & $-\frac{1+\cos \beta}{2} \sin \beta$ & $\sqrt{\frac{3}{8}} \sin ^{2} \beta$ & $-\frac{1-\cos \beta}{2} \sin \beta$ & $\left(\frac{1-\cos \beta}{2}\right)^{2}$ \\
\hline 1 & $\frac{1+\cos \beta}{2} \sin \beta$ & $\cos ^{2} \beta-\frac{1-\cos \beta}{2}$ & $-\sqrt{\frac{3}{8}} \sin 2 \beta$ & $\frac{1+\cos \beta}{2}-\cos ^{2} \beta$ & $\frac{1-\cos \beta}{2} \sin \beta$ \\
\hline 0 & $\sqrt{\frac{3}{8}} \sin ^{2} \beta$ & $\sqrt{\frac{3}{8}} \sin 2 \beta$ & $\frac{3 \cos ^{2} \beta}{2}$ & $-\sqrt{\frac{3}{8}} \sin 2 \beta$ & $\sqrt{\frac{3}{8}} \sin ^{2} \beta$ \\
\hline-1 & $\frac{1-\cos \beta}{2} \sin \beta$ & $\frac{1+\cos \beta}{2}-\cos \beta$ & $\sqrt{\frac{3}{8}} \sin 2 \beta$ & $\cos \beta-\frac{1-\cos \beta}{2}$ & $-\frac{1+\cos \beta}{2} \sin \beta$ \\
\hline-2 & $\left(\frac{1-\cos \beta}{2}\right)^{2}$ & $\frac{1-\cos \beta}{2} \sin \beta$ & $\sqrt{\frac{3}{8}} \sin ^{2} \beta$ & $\frac{1+\cos \beta}{2} \sin \beta$ & $\left(\frac{1+\cos \beta}{2}\right)^{2}$ \\
\hline
\end{tabular}

Table A.2: Spherical tensor representation of the spin operators $\left(I_{ \pm}=I_{x} \pm I_{y}\right)$

\begin{tabular}{|c||cccccc|}
\hline & $T_{00}$ & $T_{10}$ & $T_{1 \pm 1}$ & $T_{20}$ & $T_{2 \pm 1}$ & $T_{2 \pm 2}$ \\
\hline Chemical chift & $-\frac{1}{\sqrt{3}} I_{z} B_{0}$ & 0 & $-\frac{1}{2} I_{ \pm} B_{0}$ & $\sqrt{\frac{2}{3}} I_{z} B_{0}$ & $\pm \frac{1}{2} I_{ \pm} B_{0}$ & 0 \\
\hline Dipolar & 0 & 0 & 0 & $\frac{1}{\sqrt{6}}\left(3 I_{z} S_{z}-\mathbf{I} \cdot \mathbf{S}\right)$ & $\mp \frac{1}{2}\left(I_{z} S_{ \pm}+I_{ \pm} S_{z}\right)$ & $\frac{1}{2} I_{ \pm} S_{ \pm}$ \\
\hline Quadrupolar & 0 & 0 & 0 & $\frac{1}{\sqrt{6}}\left(3 I_{z}^{2}-I(I+1)\right)$ & $\mp \frac{1}{2}\left(I_{z} I_{ \pm}+I_{ \pm} I_{z}\right)$ & $\frac{1}{2} I_{ \pm} I_{ \pm}$ \\
\hline
\end{tabular}


symmetrical 2 nd rank tensors; thus only $R_{l-m}^{\lambda}$ with $l=0,2$ are non-zero. In addition, the $R_{l-m}^{\lambda}$ are initially expressed in the principle axis system (PAS) of the interaction considered. Consequently, only the components with $\mathrm{m}=0, \pm 2$ survive. Specifically, one defines the following parameters in the PAS of the individual spins [170]:

$$
\begin{array}{ll}
\sigma=\frac{1}{3} \operatorname{Tr}\{\tilde{\mathbf{R}}\} & \text { isotropic component } \\
\delta=R_{z z}-\sigma & \text { anisotropy } \\
\eta=\frac{R_{x x}-R_{w y}}{\delta} & \text { asyemmtry parameter }
\end{array}
$$

where $R_{x x}, R_{v v}, R_{z z}$ are the diagonal elements in the PAS, and the convention used is:

$$
\left|R_{x x}-\sigma\right| \leq\left|R_{y \nu}-\sigma\right| \leq\left|R_{z z}-\sigma\right|
$$

The $T_{l m}^{\lambda}$ are the spherical tensor representation of the spin operators, written explicitly for the chemical shift, dipolar, and quadrupolar Hamiltonians, in Table A.2.

It should be emphasized that up to this point, the effect of a high magnetic field has not been considered in the discussion. The dipolar and quadrupolar Hamiltonians, for example, can obviously be manifested even without any external magnetic field present, in nuclear quadrupolar resonance (NQR) [158], and zero field NMR experiments [174]. The use of a high external magnetic field, however, offers several significant advantages, as shown below. In the following sections, the modifications of the chemical shift and quadrupolar Hamiltonians which occur upon placing nuclei in a high magnetic field, are explicitly outlined. The dipole-dipole coupling is not adressed in this discussion. This is a homogeneous, multibody interaction, and is analyzed in great detail in other textbooks $[158,168]$. In the experiments which are described in this work, the effect of the dipolar Hamiltonian is essentially a Gaussian broadening of the NMR signal. 


\section{A.3 Internal Hamiltonians in a High External}

\section{Field}

The effect of placing the sample in an external high magnetic field is essentially to establish an arbitrary quantization axis. The internal Hamiltonians are then said to be "truncated" by the external high field along that axis. Fundamental approaches to the problem include the average Hamiltonian theory (AHT) [170, 175], and static perturbation theory (SPT) [168]. General results using the latter method are discussed here. For a more detailed treatment the aforementioned references, as well as other, more recent. analyses $[172,176,177]$ are recommended.

We begin by considering the internal Hamilionian as a small perturbation to the external, Zeeman Hamiltonian:

$$
\mathcal{H}=\mathcal{H}_{Z}+\mathcal{H}_{\text {int }}
$$

where the standard expressions for the energy and the eigenstates are given by the perturbation theory expansion: [178]:

$$
\begin{aligned}
& \mathcal{H}\left|\nu_{j}\right\rangle=E_{j}\left|\nu_{j}\right\rangle \\
& \mathcal{H}_{Z}|j\rangle=-\hbar \omega_{0}|j\rangle \\
& E_{j}=-\hbar \omega_{0}+E_{j}^{(1)}+E_{j}^{(2)}+\ldots \\
& \nu_{j}=|j\rangle+\left|\nu_{j}^{(1)}\right\rangle+\ldots
\end{aligned}
$$

The first and second energy corrections are given by:

$$
\begin{aligned}
& E_{j}^{(1)}=\left\langle j\left|\mathcal{H}_{i n t}\right| j\right\rangle \\
& E_{j}^{(2)}=\sum_{k \neq j} \frac{\left\langle j\left|\mathcal{H}_{i n t}\right| k\right\rangle\left\langle k\left|\mathcal{H}_{\text {int }}\right| j\right\rangle}{E_{j}^{(0)}-E_{k}^{(0)}}
\end{aligned}
$$


However, one usually uses the diagonal, or "effective" Hamiltonian:

$$
\begin{aligned}
& \mathcal{H}_{\text {eff }}=\mathcal{H}_{i}+\mathcal{H}_{\text {eff }}^{(1)}+\mathcal{H}_{\text {eff }}^{(2)}+\ldots \\
& \mathcal{H}_{\text {eff }}^{(1)}=\sum_{j}|j\rangle E_{j}^{(1)}\langle j| \\
& \mathcal{H}_{\text {eff }}^{(2)}=\sum_{j}|j\rangle E_{j}^{(2)}\langle j|
\end{aligned}
$$

and the general expression for the observed resonance frequency:

$$
\omega_{m+1 \leftrightarrow m}=\frac{1}{\hbar}\left[\left\langle m+1\left|\mathcal{H}_{e f f}\right| m+1\right\rangle-\left\{m\left|\mathcal{H}_{\text {eff }}\right| m\right\rangle\right]
$$

The perturbation treatment results for the chemical shift interaction are now examined, and the magic angle spinning (MAS) technique, which averages out its contribution to the anisotropic broadening of the spectral lines, is introduced.

\section{A.3.1 Chemical Shift}

The chemical shift Hamiltonian is written in the irreducible spherical tensor representation as:

$$
\mathcal{H}_{c s}=\gamma_{I} \hbar \sum_{l=0,2} \sum_{m=-l}^{l}(-1)^{m} T_{l m}^{c s} R_{l-m}^{c s} .
$$

The $R_{l-m}^{c s}$ are expressed in the principle axis system (PAS) of the interaction as:

$$
\begin{aligned}
& \rho_{00}=\sigma_{c s} \\
& \rho_{20}=\sqrt{\frac{2}{3}} \delta_{c s} \\
& \rho_{2 \pm 1}=0 \\
& \rho_{2 \pm 2}=\frac{\delta_{c s} \eta_{c s}}{3}
\end{aligned}
$$

where $\sigma_{c s}$ is defined as the isotropic chemical shift, $\delta_{c s}$ is the chemical shift anisotropy, and $\eta_{c s}$ is the asymmetry parameter of the chemical shift tensor. 
In the first order approximation for the energy correction, Equations A.14, only the diagonal terms in the Zeeman eigenbasis are retained. Accordingly, the firstorder effective Hamiltonian is [Equation A.15]:

$$
\begin{aligned}
\mathcal{H}_{\text {eff }} & =\gamma_{I} \hbar T_{00}^{c s} R_{00}^{c s}+\gamma_{I} \hbar T_{20}^{c s} R_{20}^{c s} \\
& =\gamma_{I} \hbar \sigma_{c s} B_{0} I_{Z}+\gamma_{I} \hbar \sqrt{\frac{2}{3}} B_{0} I_{Z} R_{20}^{c s}
\end{aligned}
$$

The first part of the effective Hamiltonian, Equation A.19, is isotropic, i.e., invariant to any orientation of the spins with respect to the external magnetic field. The second term, which contains the $R_{20}^{c s}$, however, depends on the relation between the PAS in each crystallite, and the direction of the external magnetic field, or the laboratory reference frame (LAB).

Specifically, the transformation between the PAS and LAB axis systems is conducted with the Wigner rotation matrices [Equation A.9]:

$$
\begin{aligned}
R_{20}^{c s} & =\sum_{m=-2}^{2} D_{m 0}^{(2)}(\alpha, \beta, \gamma) \rho_{2 m}^{c s} \\
& =\frac{1}{\sqrt{6}} \delta_{c s}\left[\left(3 \cos ^{2} \beta-1\right)+\eta_{c s} \sin ^{2} \beta \cos 2 \alpha\right]
\end{aligned}
$$

where $\alpha, \beta, \gamma$ are the Euler angles, Figure A.1. The resonance frequency [Equa- * tion A.16] is thus:

$$
\omega_{m+1 \rightarrow m}^{c s}=\omega_{0}\left(1-\sigma_{c s}\right)+\frac{\omega_{0} \delta_{c s}}{3}\left[\left(3 \cos ^{2} \beta-1\right)+\eta_{c s} \sin ^{2} \beta \cos 2 \alpha\right] .
$$

Upon examining Equation A.21, one notices that the resonance frequency contains an anisotropic term, which depends on the relative orientation of the chemical shift tensor in the PAS and the direction of the external magnetic field. It may be recalled that in a powder sample, which is the situation one encounters with the materials investigated in this study, all possible orientations of the crystallites, are possible, and randomly distributed. This essentially gives rise to a "powder 


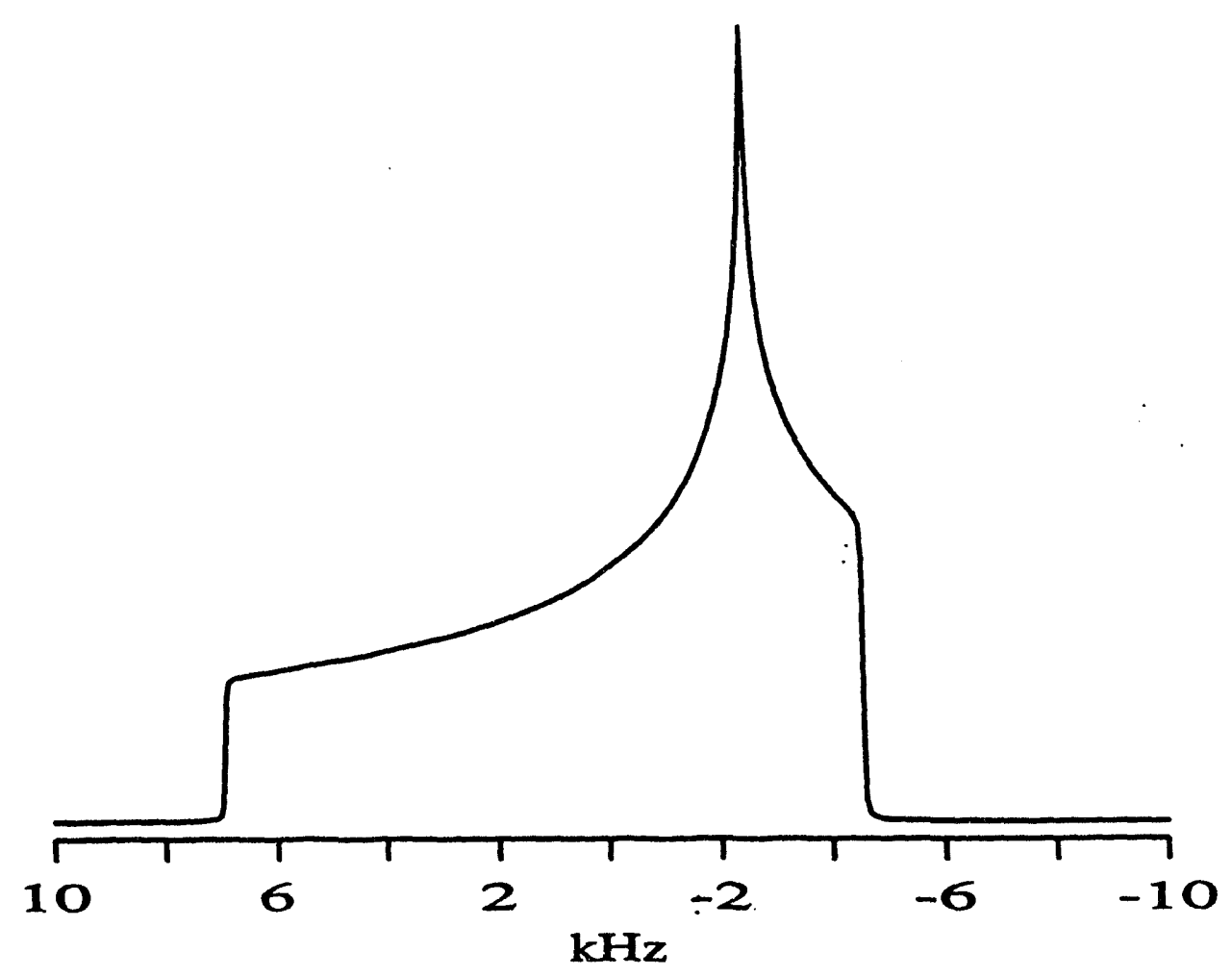

Figure A.2: Numerical simulation of chemical shift powder pattern. The parameters used in the simulation were: $\omega_{0}=99.5 \mathrm{MHz}, \delta_{c s}=6.9 \mathrm{kHz}$ $(\approx 70 \mathrm{ppm})$, and $\eta_{c s}=0.3$.

pattern", since each crystallite would contribute a slightly different value to the resonance frequency. Figure A.2 shows a chemical shift powder pattern, simulated using parameters commonly found for ${ }^{29} \mathrm{Si}$ nuclei in aluminosilicate materials. In the simulation one accounts for the random distribution of crystallite orientations by performing a weighted sum of all solid angles over a sphere.

\section{Motional Averaging-Magic Angle Spinning}

As was demonstrated in the last section, the relevant chemical shift parameters can be extracted from experimental powder patterns by spectral simulations. Problems do arise, however, when there are more than a single site in the material 
investigated, or when other interactions, such as dipolar and quadrupolar couplings, affect the spectrum. In such cases, overlapping intensities of resonances from different sites, combined with additional line-broadening, severely limit the potential of NMR experiments. Nevertheless, one method to overcome the anisotropic broadening is to perform a spinning experiment, first demonstrated by Andrew et al [11].

The principle of the technique is shown schematically in Figure A.3. The powder sample is contained in a "rotor" which is rapidly spinning around an axis, tilted by an angle $\theta$ from the direction of the external magnetic field. The three axis systems in this case are shown in Figure A.3: the PAS of the relevant interaction, in the reference frame of the crystallite; the rotor frame, aligned from the PAS by the Euler angles; and the laboratory reference frame. Again, the transformation between the different axis systems makes use of the Wigner rotation matrices, Equation A.9. Specifically in this case, the truncated spatial part of the chemical shift Hamiltonian becomes:

$$
\begin{aligned}
R_{20}^{c s} & =\sum_{m=-2}^{2} D_{m^{\prime} m}^{(2)}\left(\omega_{r} t, \theta, 0\right) \sum_{m^{\prime}=-2}^{2} D_{m^{\prime} m}^{(2)}(\alpha, \beta, \gamma) \rho_{2 m^{\prime}}^{c s} \\
& =\frac{\delta_{c c}}{2 \sqrt{6}}\left(3 \cos ^{2} \theta-1\right)\left[\left(3 \cos ^{2} \beta-1\right)+\eta_{c s} \sin ^{2} \beta \cos 2 \alpha\right]+A\left(\omega_{r} t\right) ;
\end{aligned}
$$

where $A\left(\omega_{r} t\right)$ contains sine and cosine terms of $\omega_{r} t$, which give rise to spinning sidebands in the spectrum. The time independent anisotropic part of the chemical shift frequency, upon spinning at an angle $\theta$, becomes:

$$
\omega_{c s, m+1 \sim m}^{\text {aniso }}=\frac{\omega_{0} \delta_{c s}}{3} \cdot \frac{1}{2}\left(3 \cos ^{2} \theta-1\right)\left[\left(3 \cos ^{2} \beta-1\right)+\eta_{c s} \sin ^{2} \beta \cos 2 \alpha\right] .
$$

The appearance here of the second rank Legendre polynomial is noteworthy:

$$
P_{2}(\cos \theta)=\frac{1}{2}\left(3 \cos ^{2} \theta-1\right) \text {. }
$$




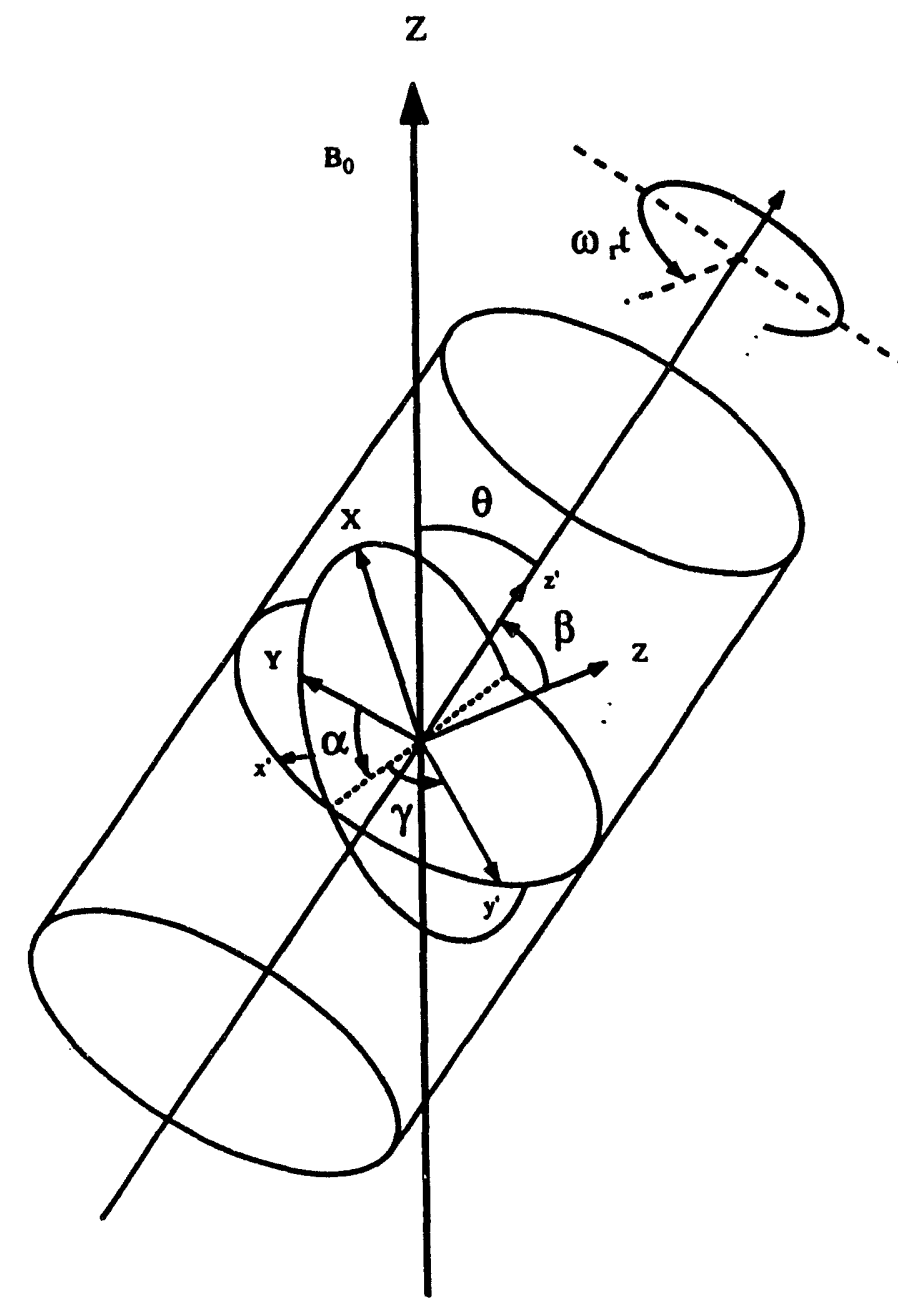

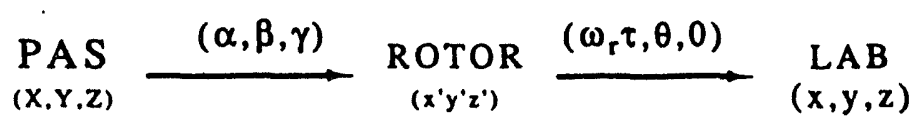

Figure A.3: The angular transformation between the PAS, the rotor frame, and the laboratory frame in a spinning experiment. $\alpha, \beta, \gamma$ are the Euler angles, $\theta$ is the angle between the spinning axis and the magnetic field direction, $B_{0}$, and $\omega_{r}$ is the spinning speed 
It is clear now that by choosing the angle

$$
\theta=\cos ^{-1} \frac{1}{\sqrt{3}} \approx 54.74^{\circ}
$$

which is the root of $P_{2}(\cos \theta)=0$, one can average the chemical shift anisotropy to zero. The angle $\theta=54.74^{\circ}$ is commonly denoted as the "magic angle". The "magic angle spinning" (MAS) technique has been used to remove anisotropic broadening in spin-half nuclei, such as ${ }^{13} \mathrm{C}$ and ${ }^{29} \mathrm{Si}$, in solid materials, and contributes to the widespread use of NMR in studies of proteins, polymers, silicate glasses, minerals, and other materials.

Most of the nuclei in the periodic table, however, have spin greater than 1, and possess quadrupolar moment. In the following section the anisotropic properties of the quadrupolar Hamiltonian, and the effect of MAS on the spectra of half-integer quadrupolar nuclei, are discussed.

\section{A.3.2 Quadrupolar In. .tion}

\section{First Order Correction}

The first order correction in the perturbation expansion requires the retention of only diagonal terms of the quadrupolar Hamiltonian, Equation A.14. The truncated, effective Hamiltonian is thus, Equation A.15:

$$
\begin{aligned}
\mathcal{H}_{\text {eff }}^{(1 Q)} & =\frac{e Q}{2 I(2 I-1)} T_{20}^{(Q)} R_{20}^{(Q)} \\
& =\frac{1}{\sqrt{6}}\left[\frac{e Q}{2 I(2 I-1)}\right]\left(3 I_{Z}^{2}-I^{2}\right) R_{20}^{(Q)}
\end{aligned}
$$

The $R_{20}^{(Q)}$ is tranformed from the PAS to the laboratory frame using the Euler angles and the Wigner rotation matrices, Figure A.1 and Equation A.9:

$$
R_{20}^{(Q)}=\sum_{m=-2}^{2} D_{m 0}^{(2)}(\alpha, \beta, \gamma) \rho_{2 m}^{(Q)}
$$


The quadrupolar $\rho_{2 m}$ in the PAS are defined:

$$
\begin{aligned}
& \rho_{20}=\sqrt{\frac{3}{2}} e q \\
& \rho_{2 \pm 1}=0 \\
& \rho_{2 \pm 2}=\frac{1}{2} e q \eta_{Q}
\end{aligned}
$$

where $e q$ is the electric field gradient at the nucleus, and $\eta_{Q}$ is the asymmetry parameter. The resulting equation for the effective first order quadruplar Hamiltonian is:

$$
\mathcal{H}_{e f f}^{(1 Q)}=\frac{e^{2} q Q}{8 I(2 I-1)}\left[\left(3 \cos ^{2} \beta-1\right)+\eta_{Q} \sin ^{2} \beta \cos 2 \alpha\right]\left(3 I_{Z}^{2}-I^{2}\right)
$$

The frequency correction caused by the effective first order quadrupolar Hamiltonian is given by:

$$
\begin{aligned}
\omega_{m+1 \leftrightarrow m}^{(1 Q)} & =\frac{1}{\hbar}\left[\left\langle m+1\left|\mathcal{H}_{e f f}^{(1 Q)}\right| m+1\right\rangle-\left\langle m\left|\mathcal{H}_{\text {eff }}^{(1 Q)}\right| m\right\rangle\right] \\
& =(2 m+1) \frac{3 e^{2} q Q}{8 I(2 I-1) \hbar}\left[\left(3 \cos ^{2} \beta-1\right)+\eta_{Q} \sin ^{2} \beta \cos 2 \alpha\right]
\end{aligned}
$$

Examining Equations A.29 and A.30 reveals that the resonance energy of the central transition, or $\frac{1}{2} \leftrightarrow-\frac{1}{2}$, is not perturbed to first order. Single quantum transitions other than the $\frac{1}{2} \leftrightarrow-\frac{1}{2}$ [for example the $\frac{3}{2} \leftrightarrow \frac{1}{2}$ transition in a spin $-\frac{3}{2}$ system], denoted $\uparrow$ as the "satellite transitions", are nevertheless anisotropically shifted to first order, see Figure A.4. The spread of resonance frequencies of the satellite transitions, due to first order effects, is usually substantial in powder materials, causing broadening of the signal beyond detection in standard solid state NMR experiments [171].

\section{Second Order Correction}

In inany solid materials, the magnitude of the quadrupolar interaction gives rise to second order effects in the perturbation analysis. The second order energy term 


$\begin{array}{lll}\mathrm{B}_{0}>0 & \mathrm{~B}_{0}>0 & \mathrm{~B}_{0}>0 \\ \mathrm{H}_{\mathrm{Q}}=0 & \mathrm{HQ}>0 & \mathrm{H}_{\mathrm{Q}}>0 \\ \text { zero order } & \text { first order } & \text { second order }\end{array}$

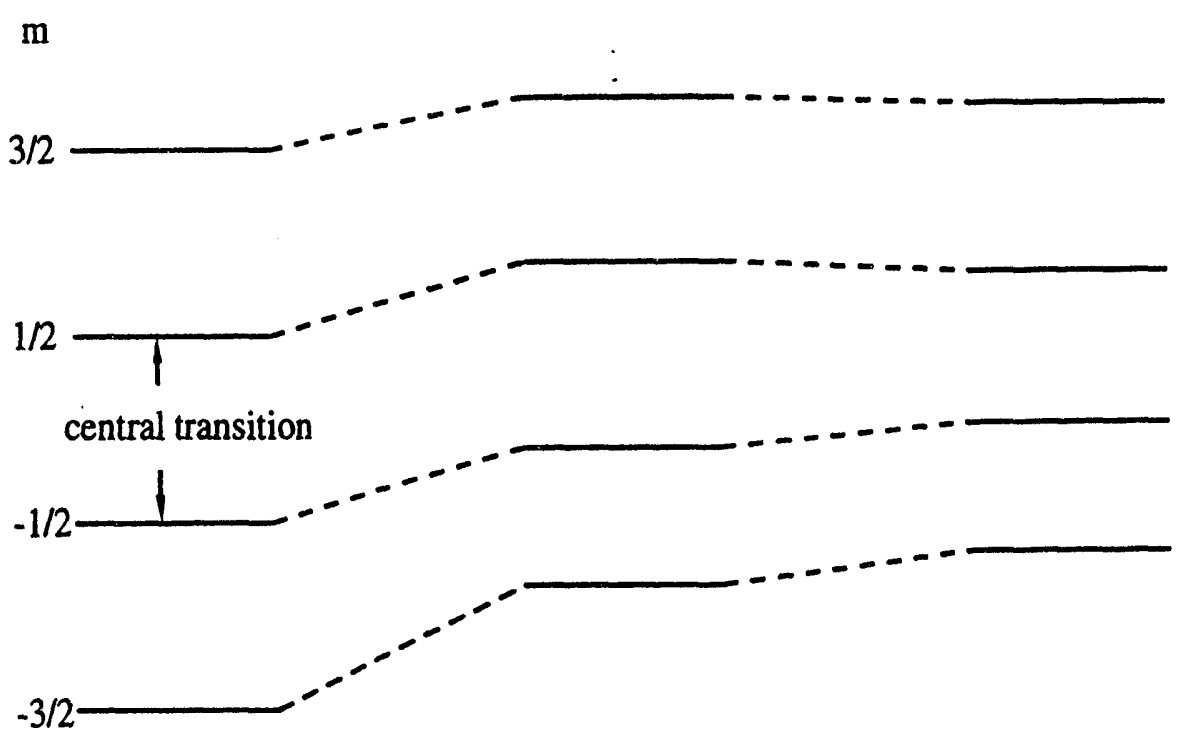

Figure A.4: Shifts of the energy levels of a $I=\frac{3}{2}$ spin system, for a given crystallite, in a high magnetic field. The first-and second-order shifts are demonstrated. The size of the level shifts may be exaggerated for the sake of clarity. 
in the perturbation expression, Equation A.14, is:

$$
\begin{aligned}
E_{j}^{(2)} & =\frac{1}{\omega_{Z}} \sum_{j \neq k} \frac{\left\langle j\left|\mathcal{H}_{Q}\right| k\right\rangle\left\langle k\left|\mathcal{H}_{Q}\right| j\right\rangle}{k-j} \\
& =\left(\frac{e Q}{2 I(2 I-1)}\right)^{2} \frac{1}{\omega_{Z}} \sum_{m, m^{\prime}}(-1)^{m+m^{\prime}} R_{2-m} R_{2 m} \sum_{j \neq k} \frac{\left\langle j\left|T_{2 m}\right| k\right\rangle\left\langle k\left|T_{2 m^{\prime}}\right| j\right\rangle}{k-j} .
\end{aligned}
$$

Making use of the relation [176]

$$
\left\langle j\left|T_{2 m}\right| k\right\rangle=\delta_{k, j+m}\left\langle j+m\left|T_{2 m}\right| k\right\rangle
$$

one obtains:

$$
k=j+m^{\prime} ; k=j-m ; \text { and } m+m^{\prime}=0
$$

which leads to:

$$
E_{j}^{(2)}=-\left(\frac{e Q}{2 I(2 I-1)}\right)^{2} \cdot \frac{1}{\omega_{Z}} \sum_{m \neq 0} \frac{\dot{R_{2-m}} R_{2 m}}{m}\left\langle j\left|T_{2 m} T_{2-m}\right| j\right\rangle
$$

and the effective second order Hamiltonian:

$$
\mathcal{H}_{\text {eff }}^{(2 Q)}=\left(\frac{e Q}{2 I(2 I-1)}\right)^{2} \cdot \frac{1}{\omega_{z}} \sum_{m>0} \frac{R_{2 m} R_{2-m}\left[T_{2-m}, T_{2 m}\right]}{m} .
$$

Computation of the commutation relations of the spin tensor operators [173], and the matrix elements of $\mathcal{H}_{e f f}^{(2 Q)}$ for $m=-\frac{1}{2}, \frac{1}{2}$, Equation A.16, yield the second order correction for the central transition, [177]:

$$
\omega_{\frac{1}{2} \rightarrow-\frac{1}{2}}^{(2 Q)}=\left(\frac{e Q}{4 I(2 I-1) \hbar}\right)^{2} \frac{[4 I(I+1)-3]}{\omega_{0}}\left[2 R_{21}^{(Q)} R_{2-1}^{(Q)}+R_{22}^{(Q)} R_{2-2}^{(Q)}\right] .
$$

The products of the second rank spatial tensors in the frequency term should be noted. Their transformation between the PAS and the LAB frames, using the Euler angles and the Wigner rotation matrices, gives rise to the following expression:

$$
\omega_{\frac{1}{2} \rightarrow-\frac{1}{2}}^{(2 Q)}=\left(\frac{e^{2} q Q}{4 I(2 I-1) \hbar}\right)^{2} \frac{[4 I(I+1)-3]}{8 \omega_{0}} \cdot A\left(\eta_{Q}, \alpha, \beta\right)
$$


Numerical simulation of Equation A.37 yields the central transition powder pattern shown in Figure A.5(a). The powder pattern was calculated for ${ }^{27} \mathrm{Al}$ [spin- $\frac{5}{2}$ ], with typical quadrupolar parameters encountered in highly distorted sites within a zeolite framework.

The second order quadrupolar frequency contains an isotropic term, given by:

$$
\omega_{\frac{1}{2} \leftrightarrow-\frac{1}{2}}^{(2 Q, i s o)}=-\frac{3}{10}\left(\frac{e^{2} q Q}{4 I(2 I-1) \hbar}\right)^{2} \frac{[4 I(I+1)-3]}{\omega_{0}}\left(1+\frac{1}{3} \eta_{Q}^{2}\right) .
$$

The appearance of an isotropic term in the second order quadrupolar frequency correction arises from the products of the second rank spatial tensors in the effective quadrupolar Hamiltonian, Equation A.35. According to tensor multiplication rules [173], the product of two second rank tensors yields tensors between ranks zero [isotropic term], and four. The second order shift of the quadrupolar energy levels for a single crystallite is demonstrated in Figure A.4.

\section{Single Axis Spinning}

The effect of spinning around an axis, tilted from the direction of the external field by an angle $\theta$, on the second order quadrupolar frequency of the central transition, is now examined. The second rank spherical tensors are first transformed from the PAS to the rotor frame, and then to the LAB frame, in a similar way described above for the chemical shift interaction, Figure A.3.

Explicitly, each tensor in the frequency expression, Equation A.36, is independently transformed, yielding the overall product expression:

$$
\begin{aligned}
R_{2 m}^{(Q)} R_{2-m}^{(Q)}= & \sum_{m^{\prime}=-2}^{2} D_{m^{\prime} m}^{(2)}\left(\omega_{r} t, \theta, 0\right) \sum_{n^{\prime}=-2}^{2} D_{n^{\prime} m^{\prime}}^{(2)}(\alpha, \beta, \gamma) \rho_{2 n^{\prime}}^{(Q)} \\
& \times \sum_{m^{\prime \prime}=-2}^{2} D_{m^{\prime \prime}-m}^{(2)}\left(\omega_{r} t, \theta, 0\right) \sum_{n^{n}=-2}^{2} D_{n^{\prime \prime} m^{n}}^{(2)}(\alpha, \beta, \gamma) \rho_{2 n^{\prime \prime}}^{(Q)}
\end{aligned}
$$




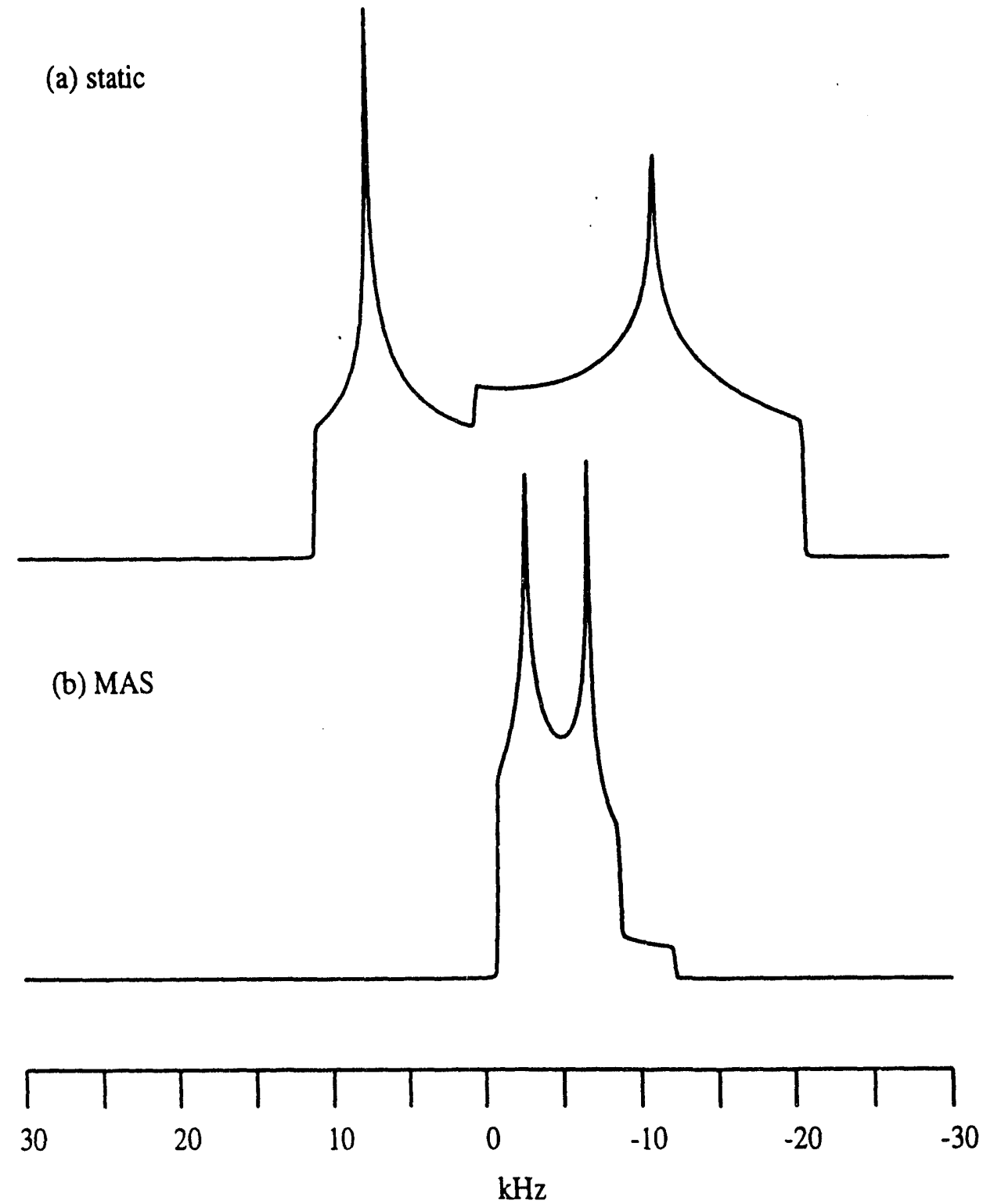

Figure A.5: Numerical simulation of a (a)static and (b)MAS powder pattern of a quadrupolar central transition. The parameters used in the simulation were: $\omega_{0}=130.3 \mathrm{MHz}\left[{ }^{27} \mathrm{Al}\right.$ in an 11.7 Tesla magnetic field], $\frac{e^{2} q Q}{\hbar}=5 \mathrm{MHz}$, and $\eta_{Q}=0.3$. 
After calculation of the matrix elements and applying the selection rules for the various indices [172], the central transition resonance is finally given by:

$$
\omega_{\frac{1}{2} \leftrightarrow-\frac{1}{2}}^{(2 Q)}=\left(\frac{e^{2} q Q}{4 I(2 I-1) \hbar}\right)^{2} \frac{[4 I(I+1)-3]}{8 \omega_{0}} \cdot\left[A_{0}+A_{2} P_{2}(\cos \theta)+A_{4} P_{4}(\cos \theta)\right]
$$

where $A_{2}$ and $A_{4}$ contain terms which depend on the Euler angles $\alpha, \beta$, and the asymmetry parameter $\eta_{Q} . A_{0}$ is independent of the Euler and spinning angles, respectively, and contains the isotropic part of the quadrupolar frequency. $P_{2}(\cos \theta)$ is the second rank Legendre polynomial, Equation A.24, while

$$
P_{4}(\cos \theta)=\frac{1}{8}\left(35 \cos ^{4} \theta-30 \cos ^{2} \theta+3\right)
$$

is the fourth rank Legendre polynomial.

The appearance of the fourth rank Legendre polynomial is again due to the product of two second rank spherical tensors in the frequency expression, Equation A.36. The product would generate spherical tensors between the ranks zero and four, as indeed is demonstrated in Equation A.40.

Examining Equation A.40 reveals the fundamental problem of the second order quadrupolar frequency: There exists no single angle $\theta$, which is simultaneously the root of both the second rank Legendre polynomial, $P_{2}(\cos \theta)$, and the fourth rank Legendre polynomial, $P_{4}(\cos \theta)$. This is shown in Figure A.6: The root of $P_{2}(\cos \theta)=0$ is the angle $\theta=54.74^{\circ}$, while the solution to $P_{4}(\cos \theta)=0$ is $\theta=$ $30.56^{\circ}$ or $70.12^{\circ}$. Thus, even spinning at the "magic angle" $54.74^{\circ}$ [or similarly the angles $30.56^{\circ}$ or $70.12^{\circ}$ ], cannot remove competely the anisotropic broadening of quadrupolar central transitions. This is numerically simulated in Figure A.5; narrowing of the resonance is achieved by MAS, but the line in still anisotropically broadened. 


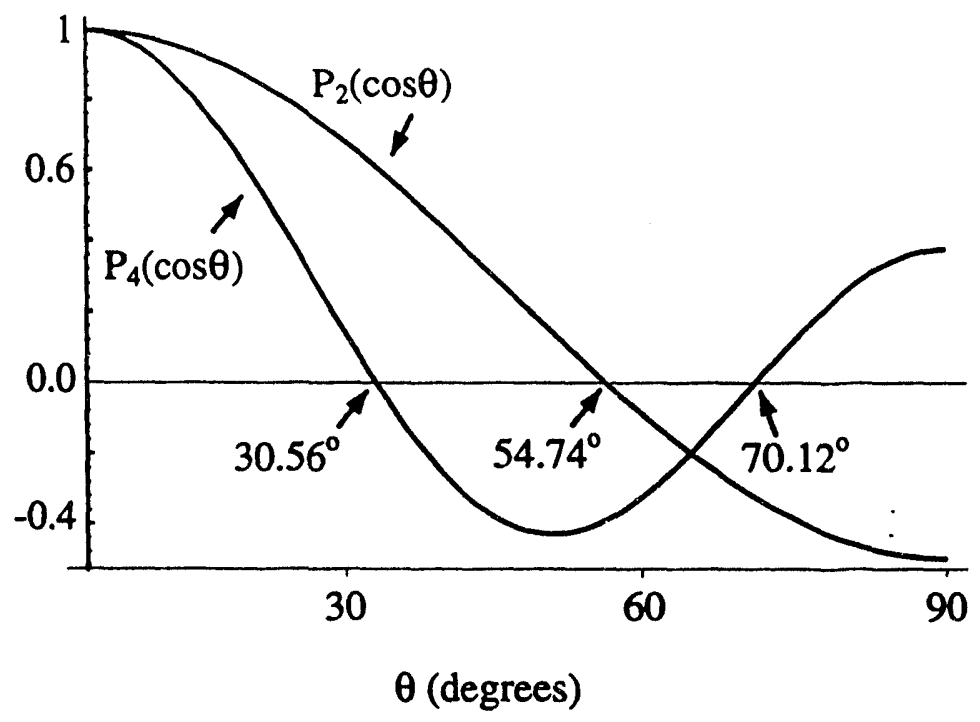

Figure A.6: A graph describing the angular dependence of the second and fourth Legendre polynomials

The second order anisotropic broadening of the central transition has limited the usefulness of NMR experiments on quadrupolar nuclei, for the same reasons discussed above regarding the chemical shift anisotropy. Some half-integer, $I>\frac{1}{2}$, nuclei exhibit quadrupolar couplings in the order of several $\mathrm{MHz}$, which might give rise to second order patterns that are up to tens of $\mathrm{kHz}$ wide, even with the application of MAS. This significantly decreases the resolution of the NMR spectra, particularly in materials where the quadrupolar nuclei occupy several crystallographically distinct sites.

The quadrupolar broadening can be reduced upon carrying out the NMR experiment in a higher riagnetic field strength, see Equation A.40. However, for several quadrupolar nuclei, such as ${ }^{27} \mathrm{Al},{ }^{23} \mathrm{Na},{ }^{71} \mathrm{Ga}$ and others in zeolite materials, the second order anisotropic broadening is apparent even at the highest instrumentally available magnetic field strengths. 


\section{A.3.3 Double Rotation}

An ingenious technique where the sample is spun simultaneously around two axes, enables the elimination of even the second order anisotropic broadening of the central transition $[8,179]$. The method was denoted "double rotation" (DOR) and a schematic diagram of which is shown in Figure A.7.

Transformation of the spatial tensors, Equation A.36, is performed now between the following reference frames, after sufficient number of transients have been acquired to ensure complete averaging of the phase between the two rotors [180]:

$\begin{array}{llll} & (\alpha, \beta, \gamma) & \left(\omega_{r 2} t, \theta_{2}, 0\right) & \left(\omega_{r 1} t, \theta_{1}, 0\right) \\ \text { PAS } \longrightarrow \text { Small Rotor } \longrightarrow \text {. Big Rotor } \longrightarrow \text { Lab Frame }\end{array}$

where $\alpha, \beta, \gamma$ are the Euler angles, and $\omega_{r 1}, \omega_{r 2}$ are the spinning speeds of the big and small rotors, respectively. Using the appropriate Wigner rotation matrices for the above transformation one obtains the expression for the time independent terms of the central transition frequency $[8,172]$ :

$$
\omega_{\frac{1}{2} \rightarrow-\frac{1}{2}}^{(2 Q)}=\left(\frac{e^{2} q Q}{4 I(2 I-1) \hbar}\right)^{2} \frac{[4 I(I+1)-3]}{8 \omega_{0}} \times \sum_{l=0,2,4} A_{l} P_{l}\left(\cos \theta_{1}\right) P_{l}\left(\cos \theta_{2}\right)
$$

where the coefficients $A_{l}$ are identical to those which appeared in Equation A.40, and contain terms which depend on the Euler angles $\alpha, \beta$, and the asymmetry parameter $\eta_{Q}$

The terms containing $P_{2}(\cos \theta)$, and $P_{4}(\cos \theta)$ appeared also in the second order quadrupolar correction for a single axis spinning, Equation A.40. Equation A.42 reveals that double rotation essentially gives rise to products of the second and 


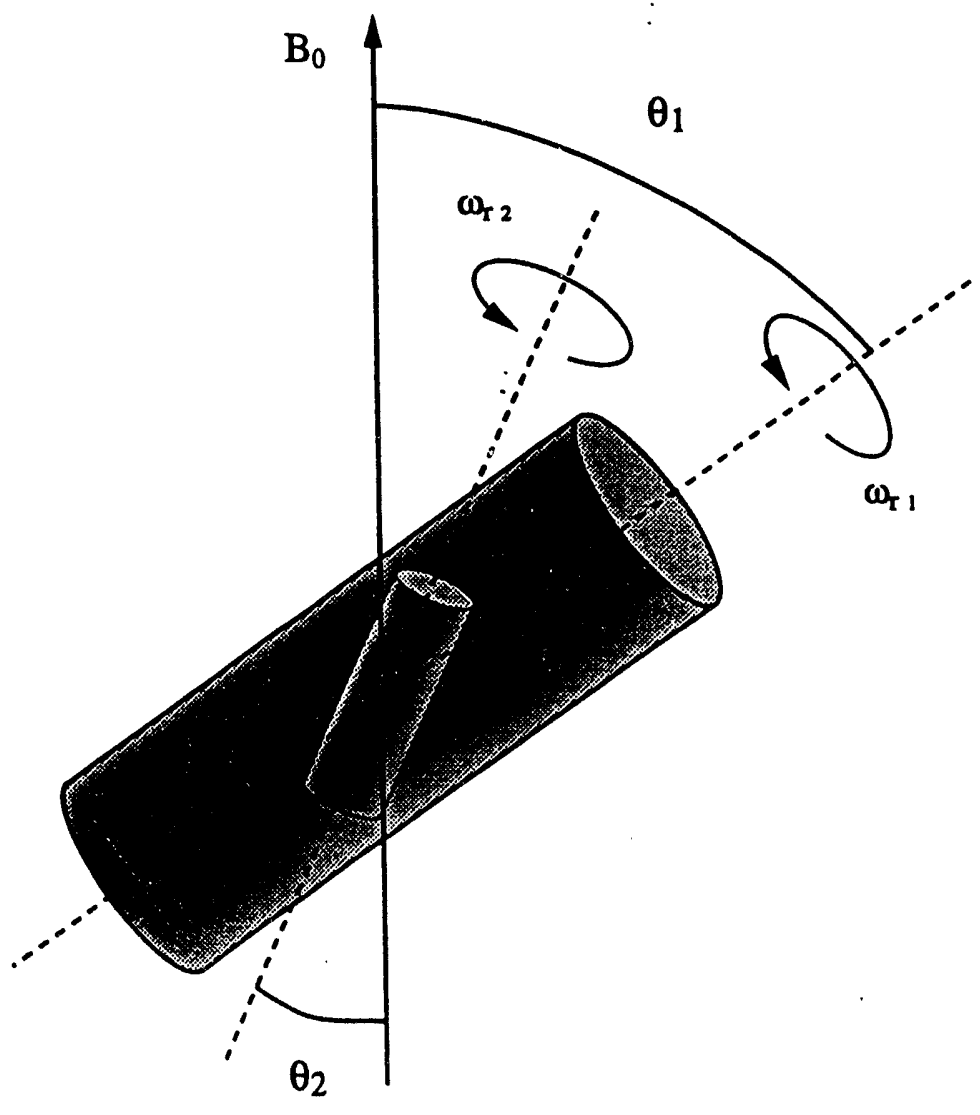

Figure A.7: A schematic drawing of the double rotation (DOR) technique. The angle between the spinning axis of the big rotor and the external magnetic field is $\theta_{1}=54.74^{\circ}$, while the angle between the spinning axes of the small and big rotors, respectively, is $\theta_{2}=30.56^{\circ}$ 
fourth rank Legendre polynomials of the two angles, respectively. The isotropic part of the second order correction is given by the $l=0$ term:

$$
\omega_{\frac{1}{2} \rightarrow-\frac{1}{2}}^{(2 Q, i s o)}=-\frac{3}{10}\left(\frac{e^{2} q Q}{4 I(2 I-1) \hbar}\right)^{2} \frac{[4 I(I+1)-3]}{\omega_{0}}\left(1+\frac{1}{3} \eta_{Q}^{2}\right) .
$$

It is obvious now, that $k$, setting the angles $\theta_{1}$ and $\theta_{2}$, Figure A.7, as the roots of $P_{2}\left(\cos \theta_{1}\right)=0$, and $P_{4}\left(\cos \theta_{2}\right)=0$, respectively, [or equivalently $P_{2}\left(\cos \theta_{2}\right)=$ 0 , and $P_{4}\left(\cos \theta_{1}\right)=0$ ], one completely averages out the second order anisotropic broadening of the central transition.

The most favorable angle combination from an experimental point of view is the set

$$
\left(\theta_{1}, \theta_{2}\right)=\left(54.74^{\circ}, 30.56^{\circ}\right)
$$

These angles cause less torque to be exerted on the small rotor [99] than any of the other four angle-combinations, thus providing the fastest simultaneous spinning rates for the small and the big rotor, respectively. Some aspects of DOR experiments, and technical drawings of the DOR rotor parts, are provided in Appendix 2 and 3 , respectively. 


\section{Appendix B}

\section{Practical Aspects of DOR}

\section{Experiments}

Double rotation experiments are "inherently" more mechanically difficult than other spinning experiments, such as MAS and DAS, because of the simultaneous rotation around two spinning axes. Thus, factors which one must consider to achieve successful single-axis experiments, such as balancing the rotor, and friction between the spinning body and its surroundings, have consequently more significant, intertwined effects in DOR.

Spinning in DOR experiments is achieved by blowing high pressure air throughout the bearing and drive openings within the "stator" (for spinning of the big outer rotor), and the big rotor (providing the air-pressure for spinning of the small inner

rotor), see drawings in Appendix 3. Successful double-rotation can be achieved by carefully balancing the bearing and drive air pressures on the small, inner rotor. The upper limit for double rotation of the two rotors has usually been the "crashing" of the inner rotor, beyond certain speeds of the outer rotor. In this con- 
text, imbalances of the spinning small rotor, due to either inhomogeneous packing of the sample, dust within the spinning sleeve, and/or uneciual bearing/drive air pressures, might significantly reduce the DOR spinning speeds. An additional parameter which should be adjusted is the balance of the big rotor upon fast spinning. A "wobbly" big rotor might again cause crashing of the small spinner at relatively low spinning speeds.

The rotor design used in this study utilizes Macor pins positioned at the center of the caps of the small rotor sleeve, above the center of the flat edges of the small spinnor, see drawings in Appendix 3. Macor, a hard ceramic material, is chosen to minimize the friction between the two spinning rotors. Softer materials, such as Kel-F and Vespel were found to wear out much faster, thus increasing the friction and reducing the double rotation speeds. Indeed, it is highly important that the contact between the spinning small rotor, and the Macor pins on the caps, be kept minimal; the pins should be replaced once every $25-50$ hours of spinning.

Overall, the limiting factor in most DOR experiments presented in this work, was generally the crashing of the small rotor due to the extensive torques exerted upon it. Trial and error adjustments were usually performed until optimal double rotation speeds were obtained. Standard spinning speeds were usually $600-700 \mathrm{~Hz}$ for the outer rotor, and $4-5 \mathrm{kHz}$ for the inner rotor. In a few cases the spinning of the big rotor exceeded $800 \mathrm{~Hz}$, without crashing of the small rotor. 


\section{Appendix C}

\section{Technical Drawings of the Double}

\section{Rotation Apparatus}

This appendix contains a complete set of technical drawings used in the machine shop of the Department of Chemistry, University of California at Berkeley, to construct the DOR apparatus. A detailed discussion of the performance of the DOR probe is given in ref. [99]. 


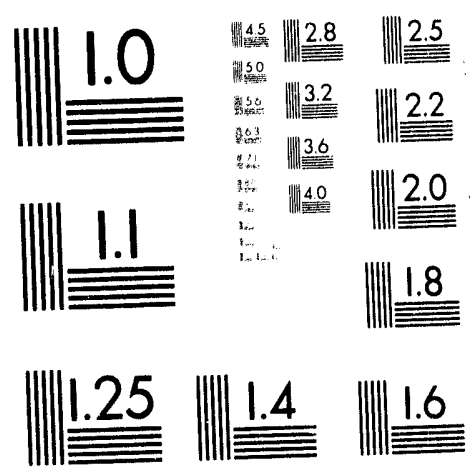



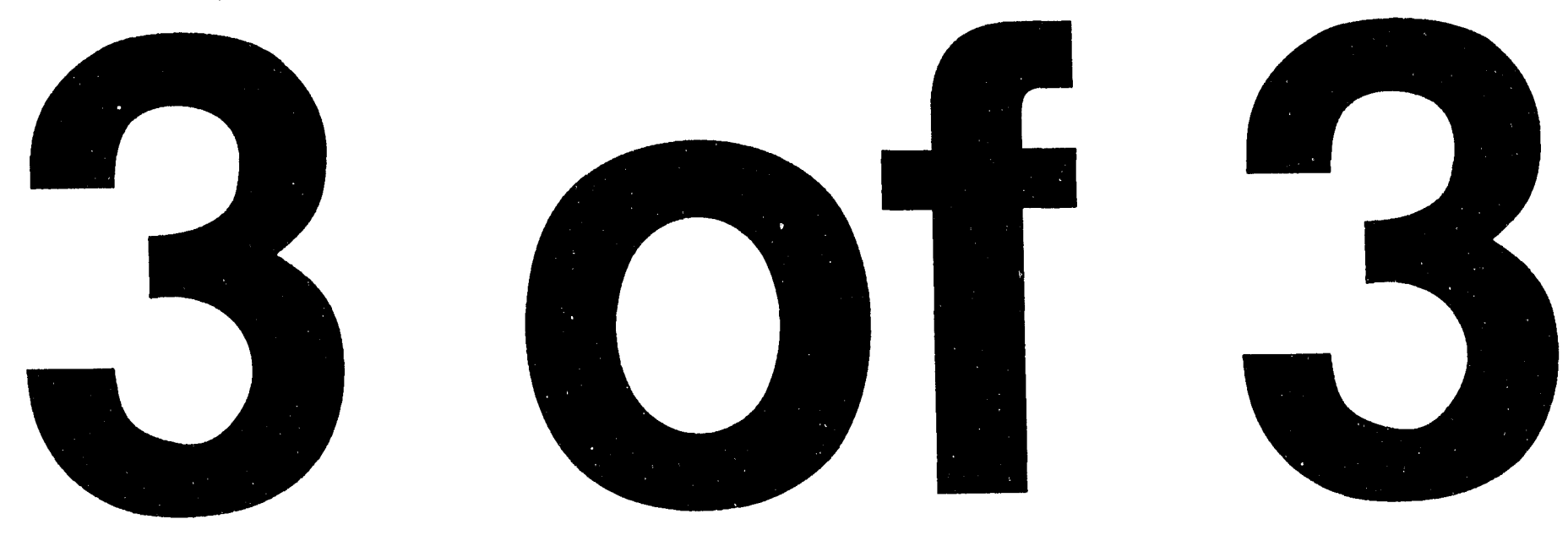
(A)

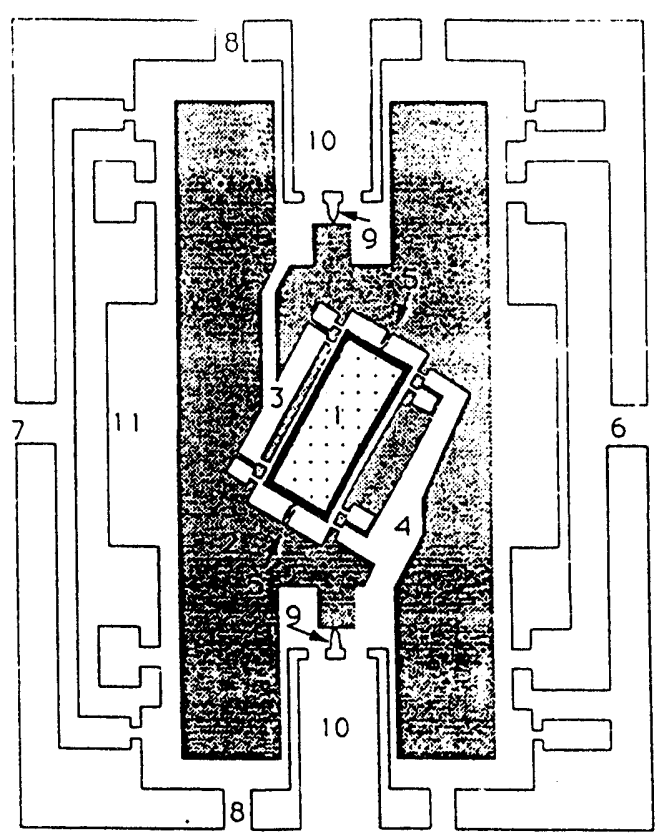

(B)

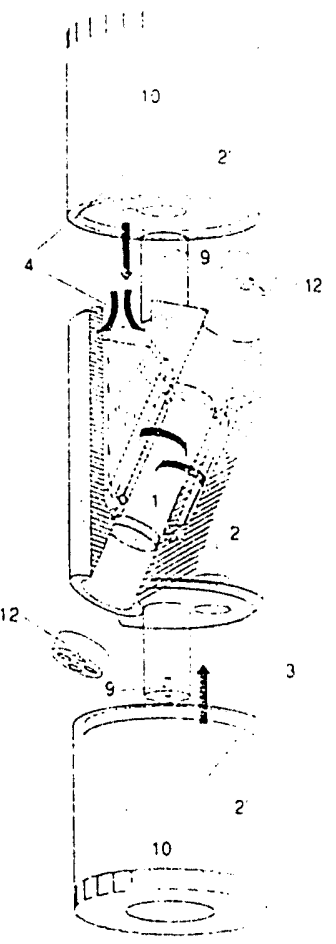

Figure C.1: (A) A schematic drawing of the stator and double rotor apparatus; and $(B)$ details of the big outer-rotor. The numbers in the drawings refer to: (1) the small inner-rotor; (2) the big outer-rotor; (3) and (4) air channels for bearing and drive system of the inner-rotor; (5) axis-pins of the inner-rotor; (6) and (7) air channels for bearing and drive system of the outer-rotor; (8) air exhaust holes for the outer-rotor; (9) axis-pins of the outer-rotor; (10) air passage for the inner-rotor; (11) space for $\mathrm{rf}$ coil; (12) caps of the inner-rotor sleeve. The drawings are adapted from ref. [99]. 


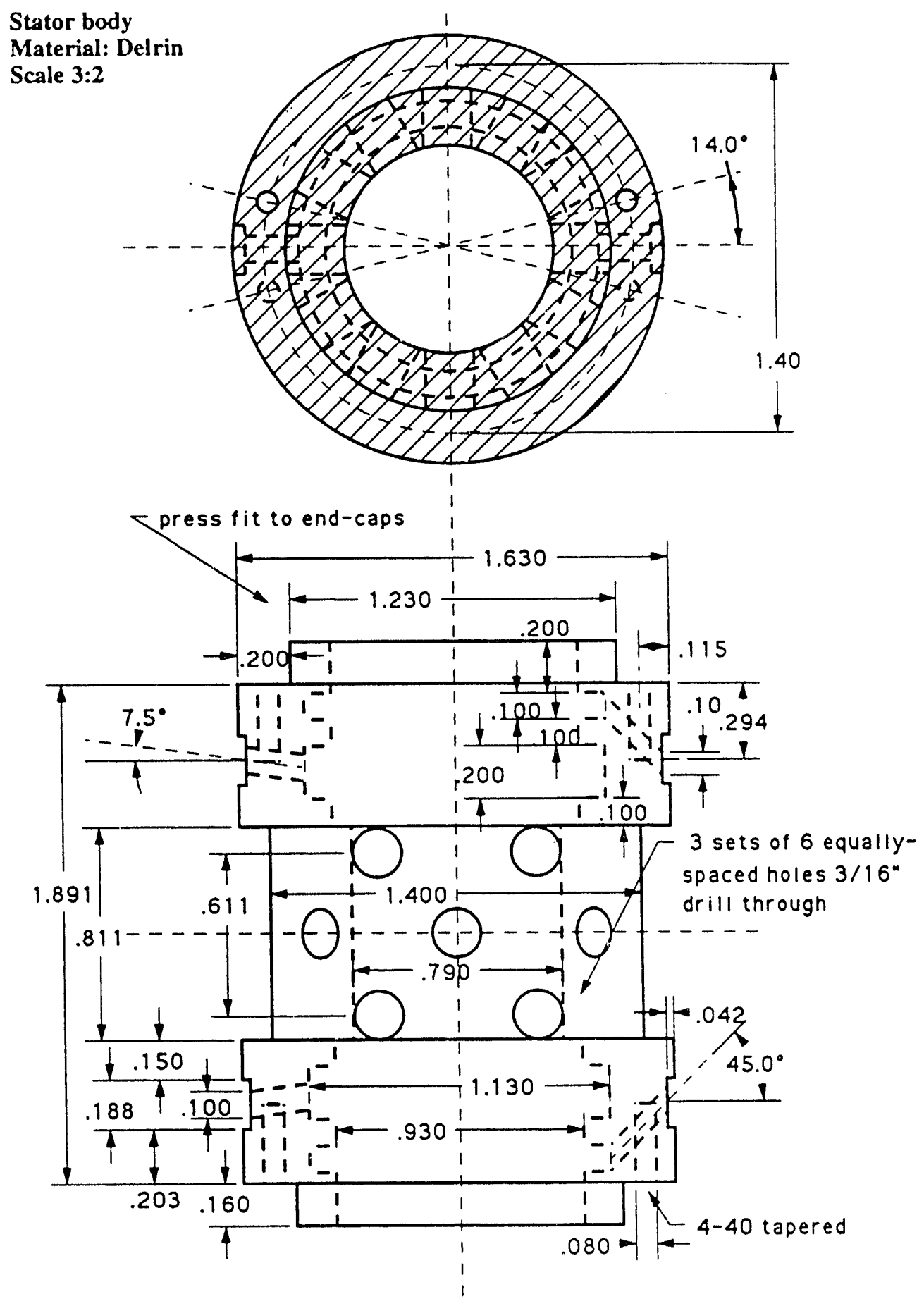

Figure C.2: Technical drawing of the stator body, all dimensions are in inches. 
Stator End Caps

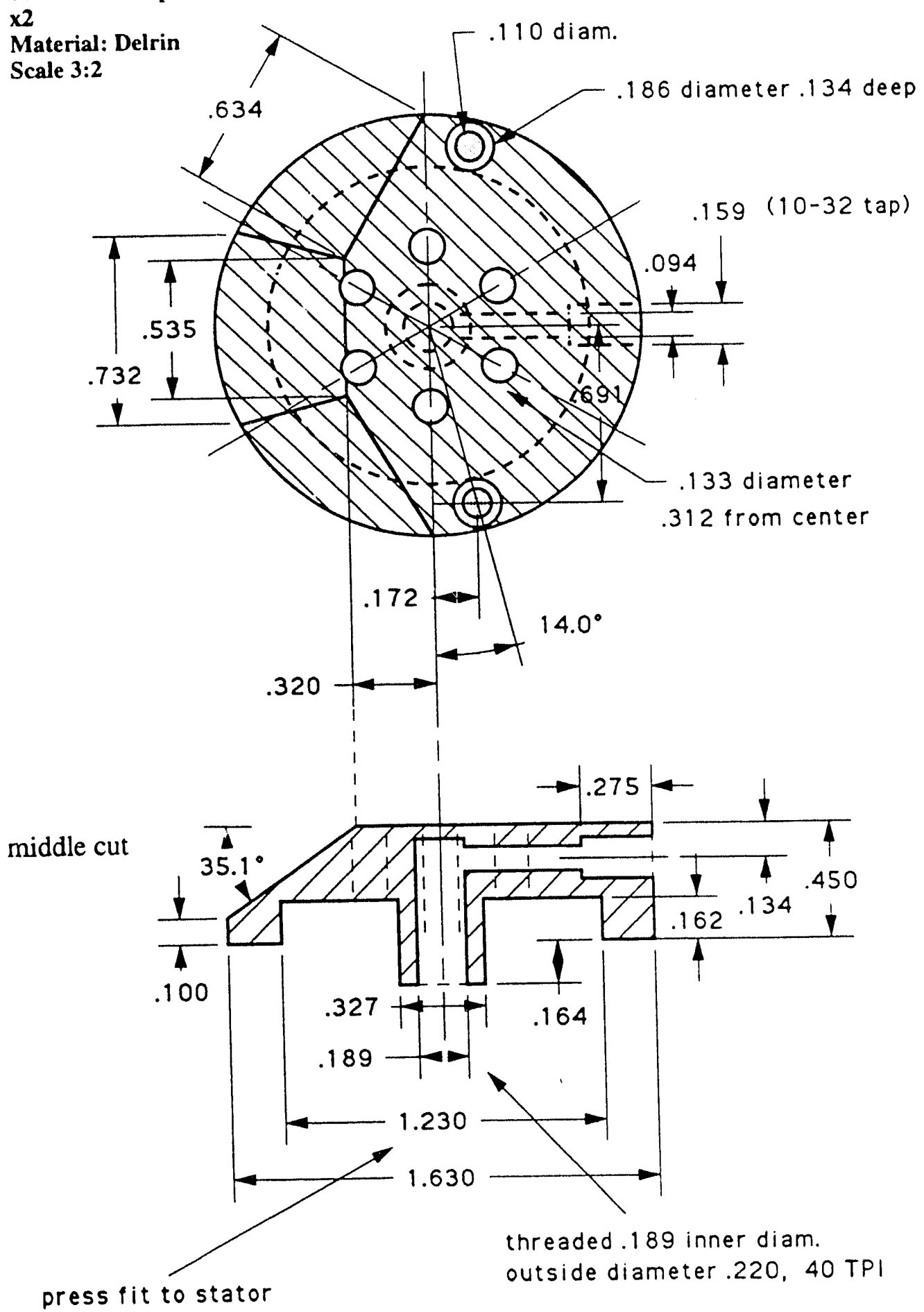

Figure C.3: Technical drawing of the stator caps, all dimensions are in inches. 

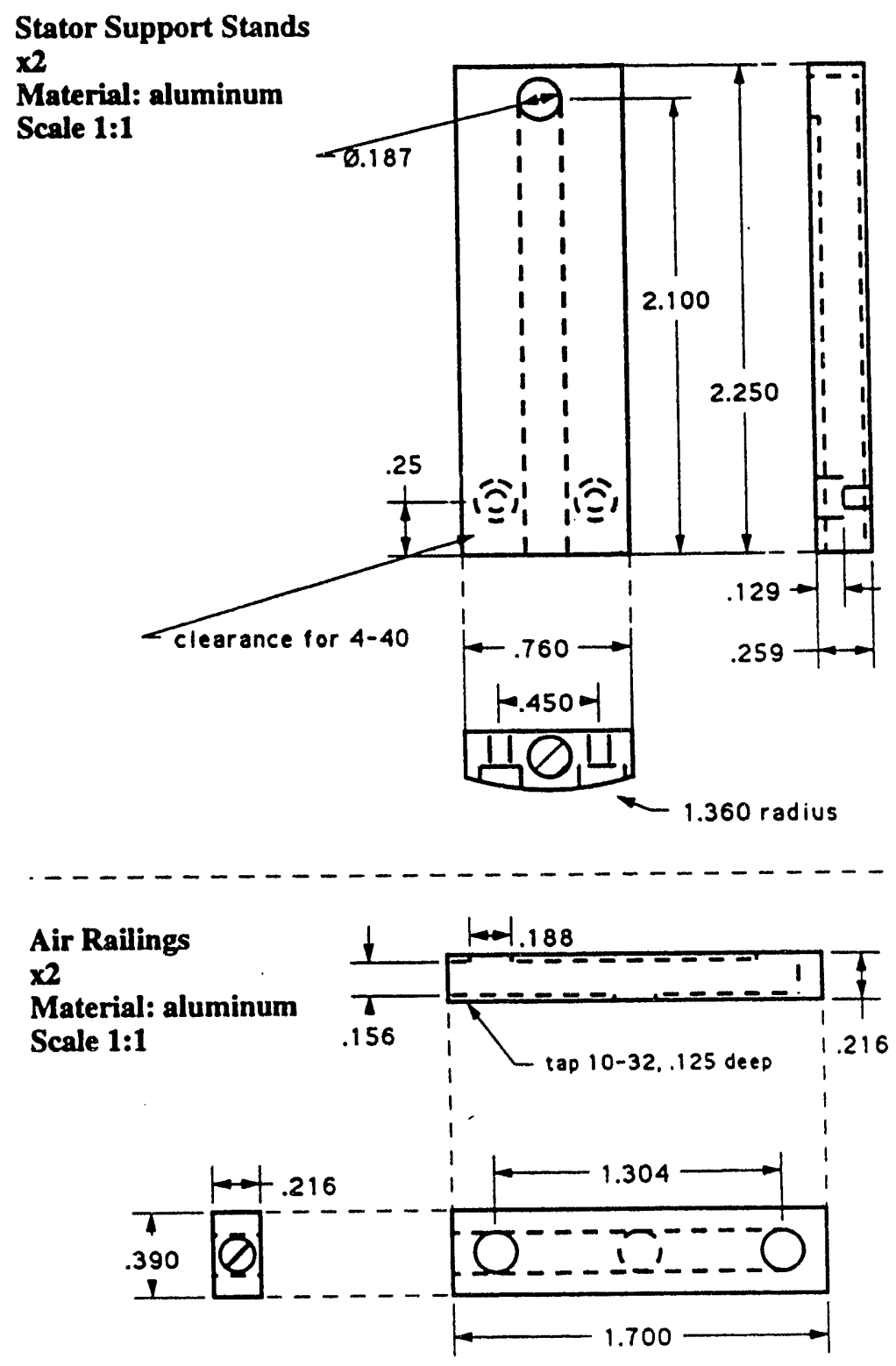

Figure C.4: Technical drawings of the stator supports and air railings, all dimensions are in inches. 
Bushings for Stator Side $(6 \& 7)$

\section{x6}

Material: Teflon Scale 6:1
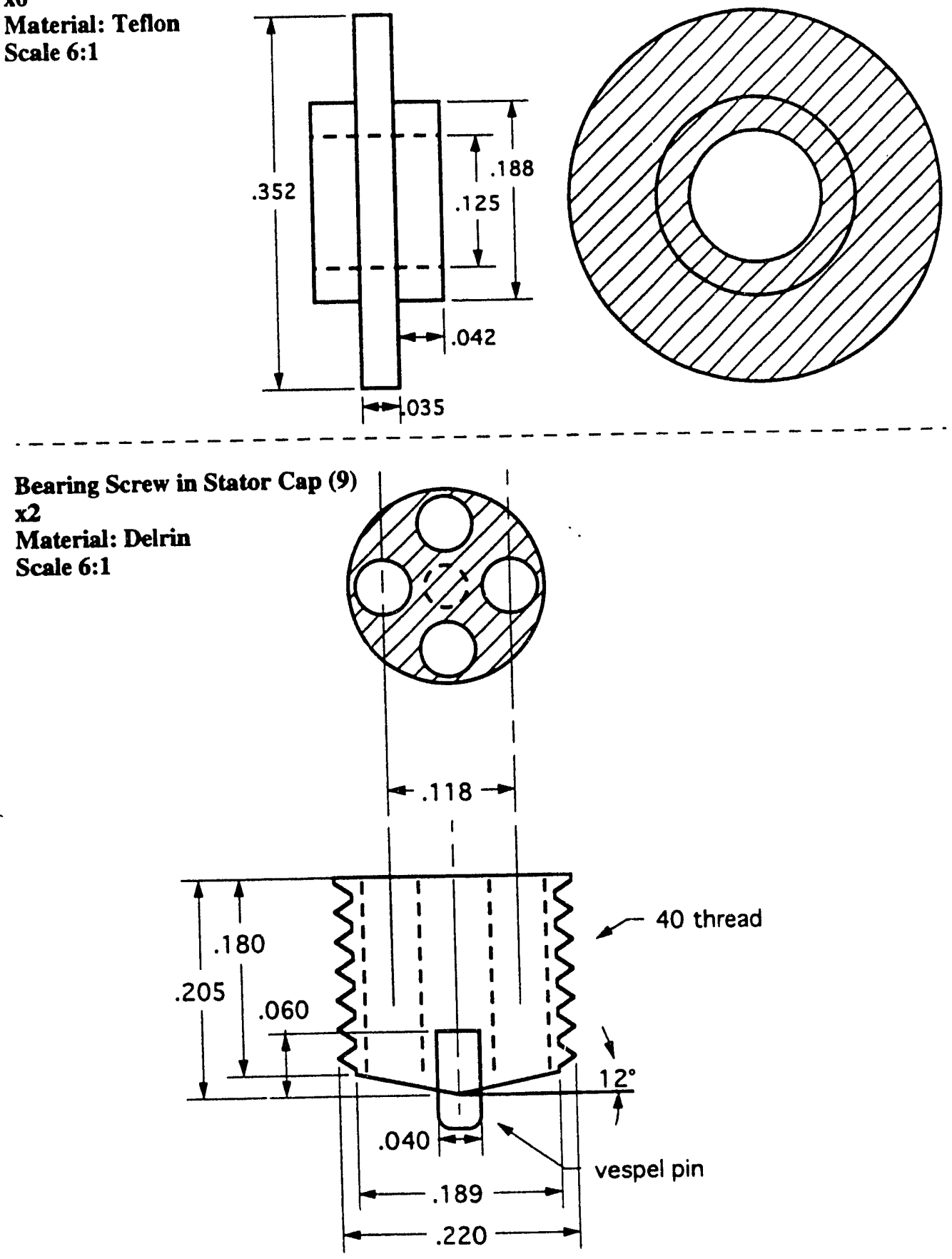

Figure C.5: Technical drawings of the air bushings, and bearing screws in the stator caps, all dimensions are in inches. 


\section{Big Rotor (2)}

Material: Vespel

\section{Scale 4:1}

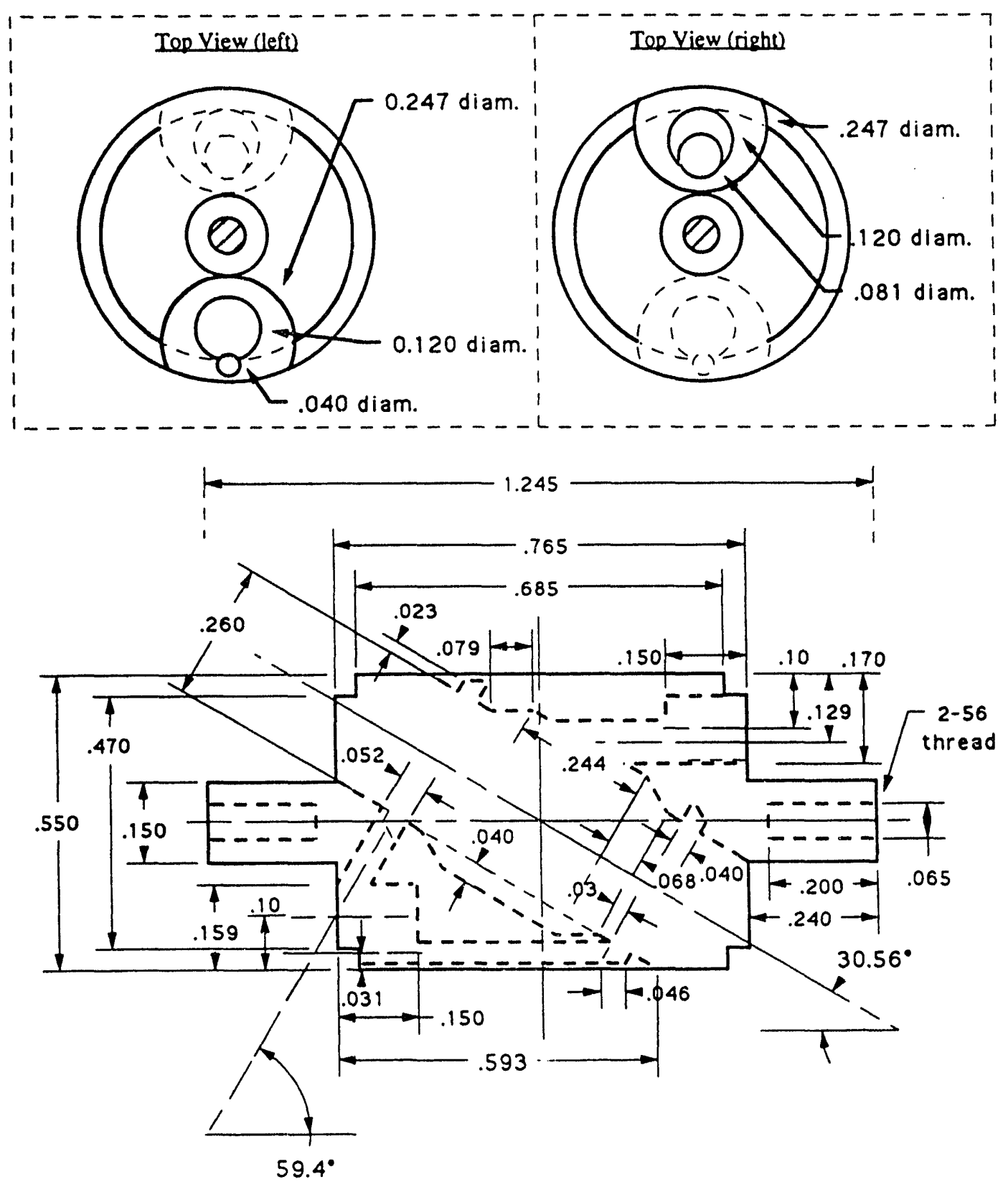

Figure C.6: Technical drawing of the outer rotor body, all dimensions are in inches. 
Big Rotor End Pieces (2')

Material: Vespel

Scale 3:1

\section{two mirror images needed}

four 0.045"

noles

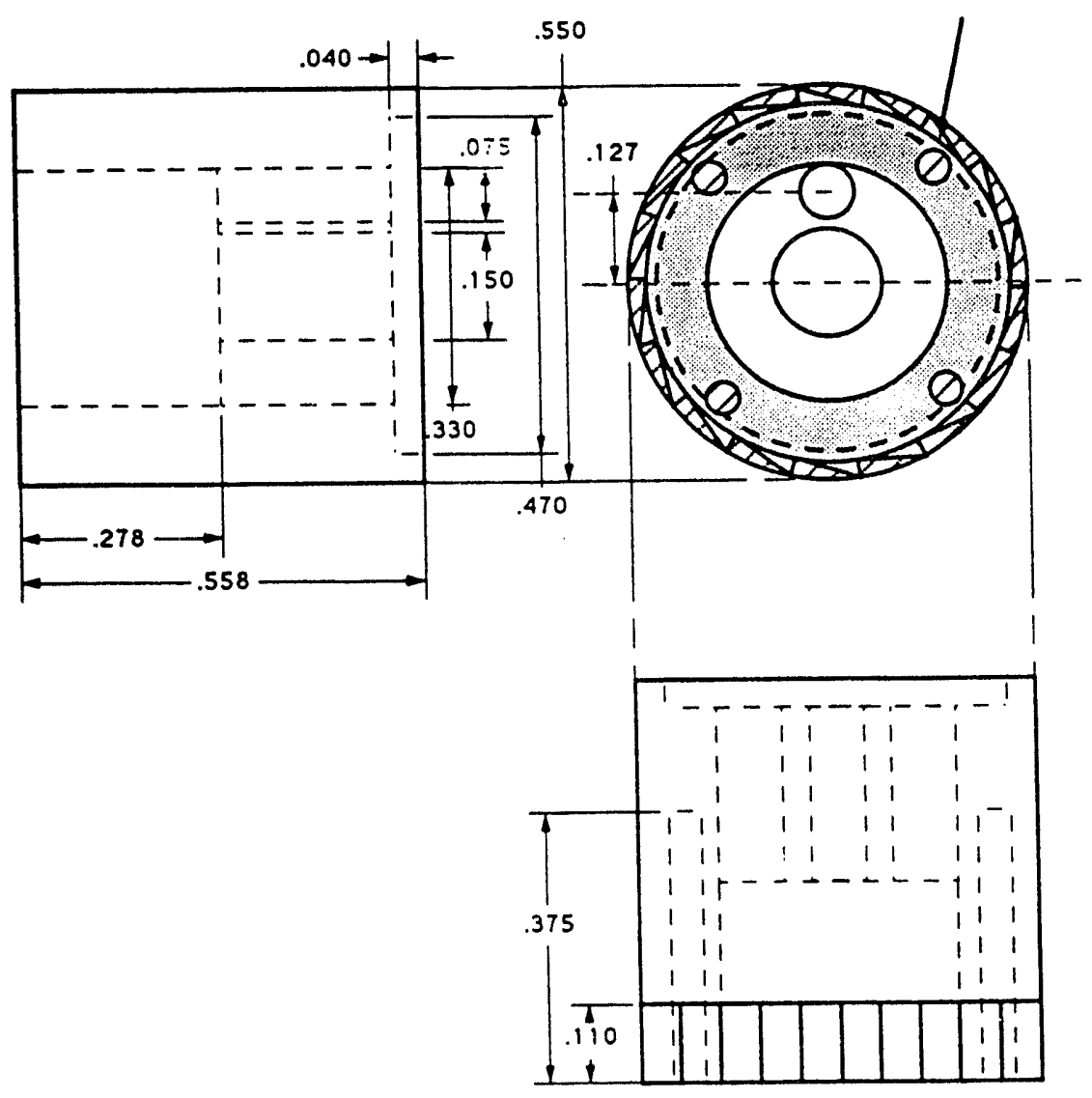

Figure C.7: Technical drawing of the end pieces of the outer rotor, all dimensions are in inches. 


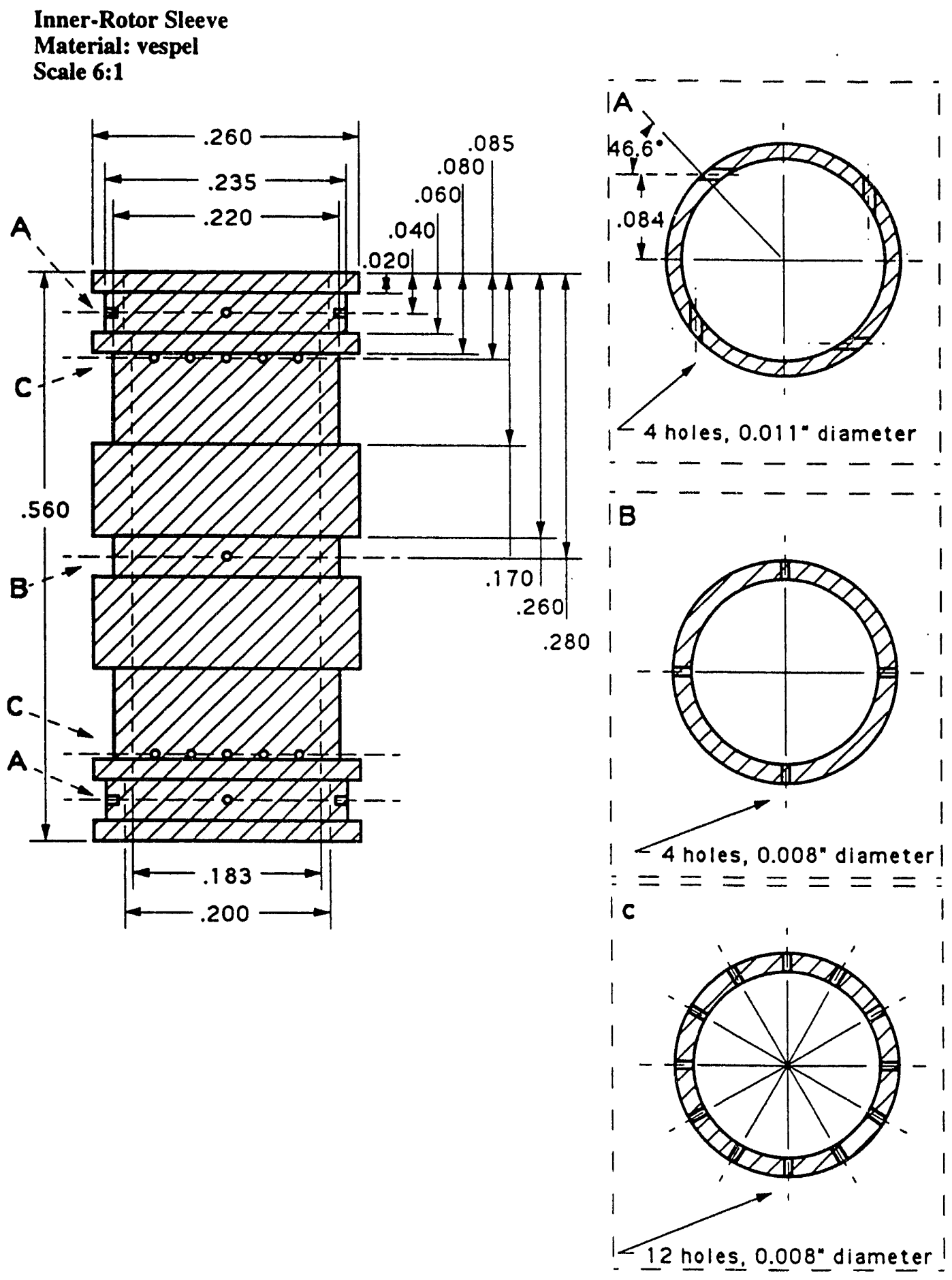

Figure C.8: Technical drawing of the sleeve of the inner rotor, all dimensions are in inches. 


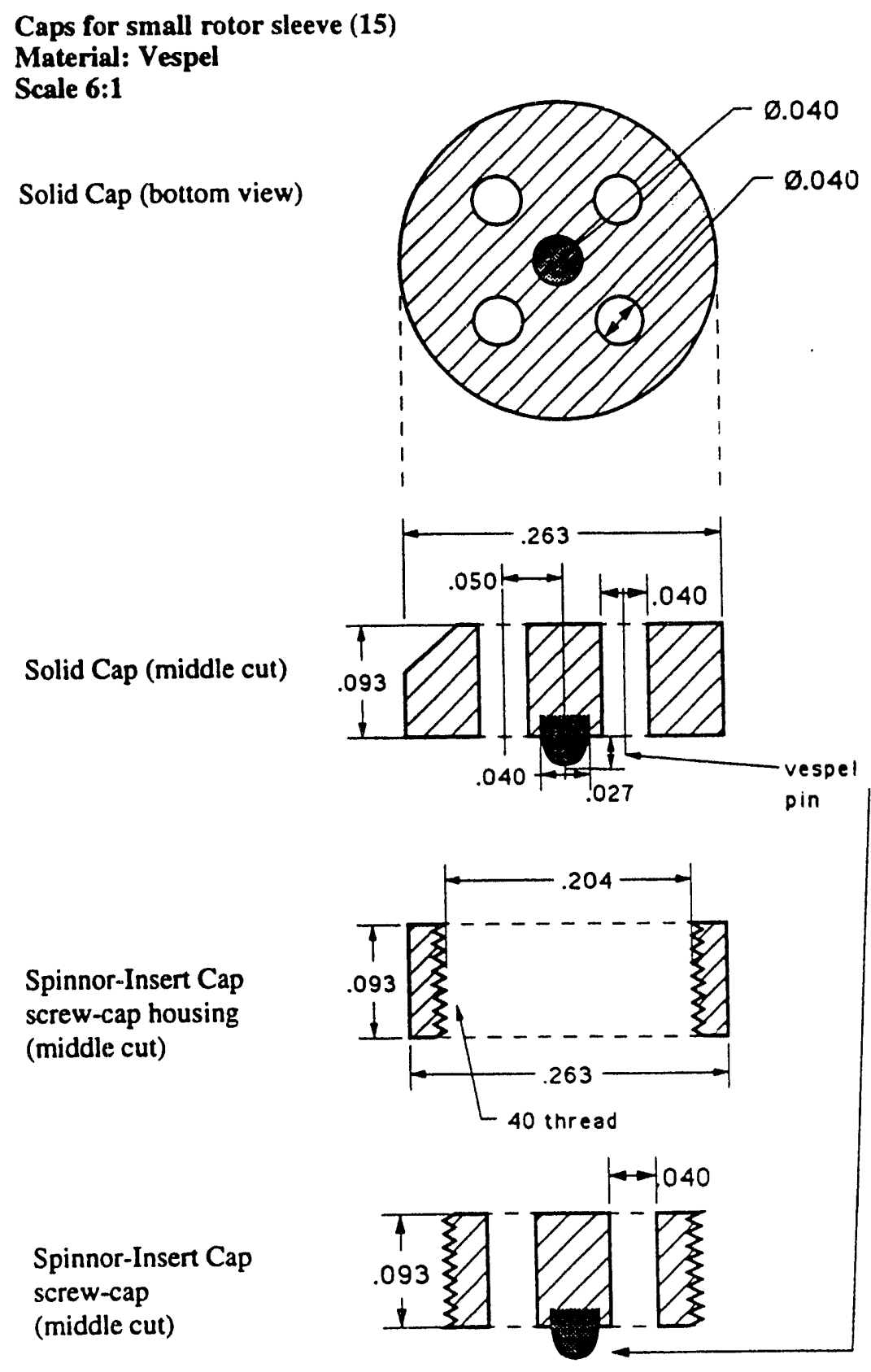

Figure C.9: Technical drawing of the inner rotor' sleeve caps, all dimensions are in inches. 


\section{Small Rotor (1)}

Material: Vespel (Including Two Macor Pins)

Scale 4:1

Side View

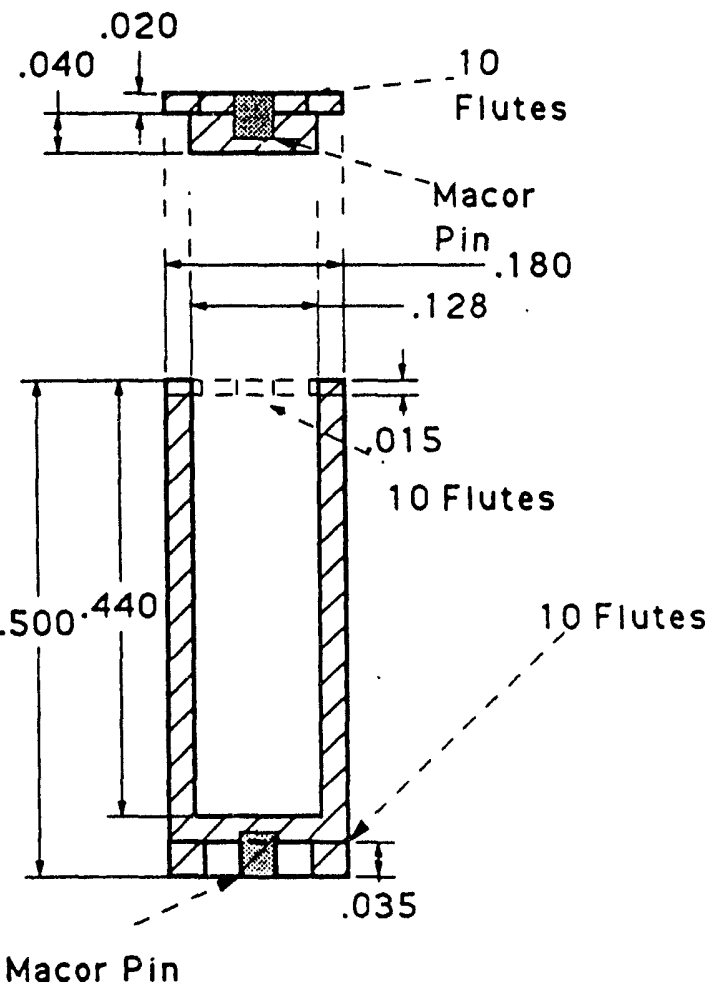

Top/Bottom View

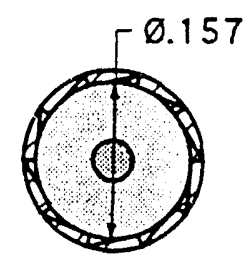

Macor Pin [x2]

(cap+bottom)

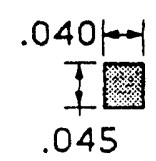

Figure C.10: Technical drawing of the inner rotor, all dimensions are in inches. 

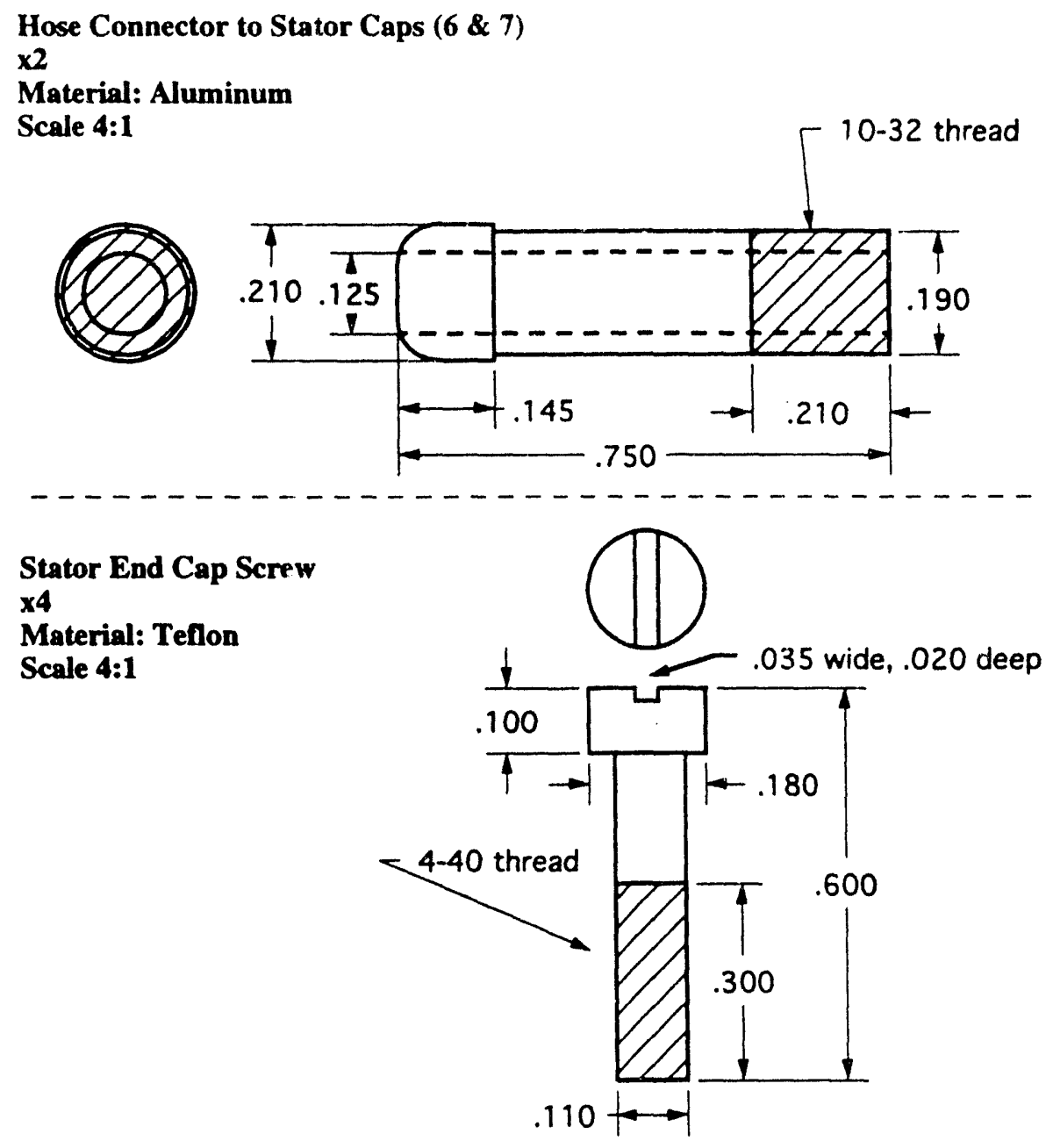

\section{Big Rotor Screw (9') \\ $\times 2$ \\ Material: Vespel \\ Scale 4:1}

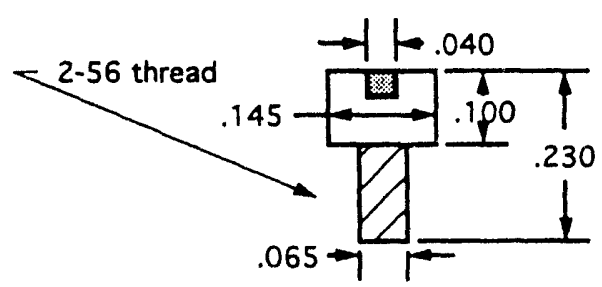

Figure C.11: Technical drawings of screws and air-connectors, all dimensions are in inches. 


\section{Magic Angle Adjuster}

Material: aluminum

\section{Scale 2:1}

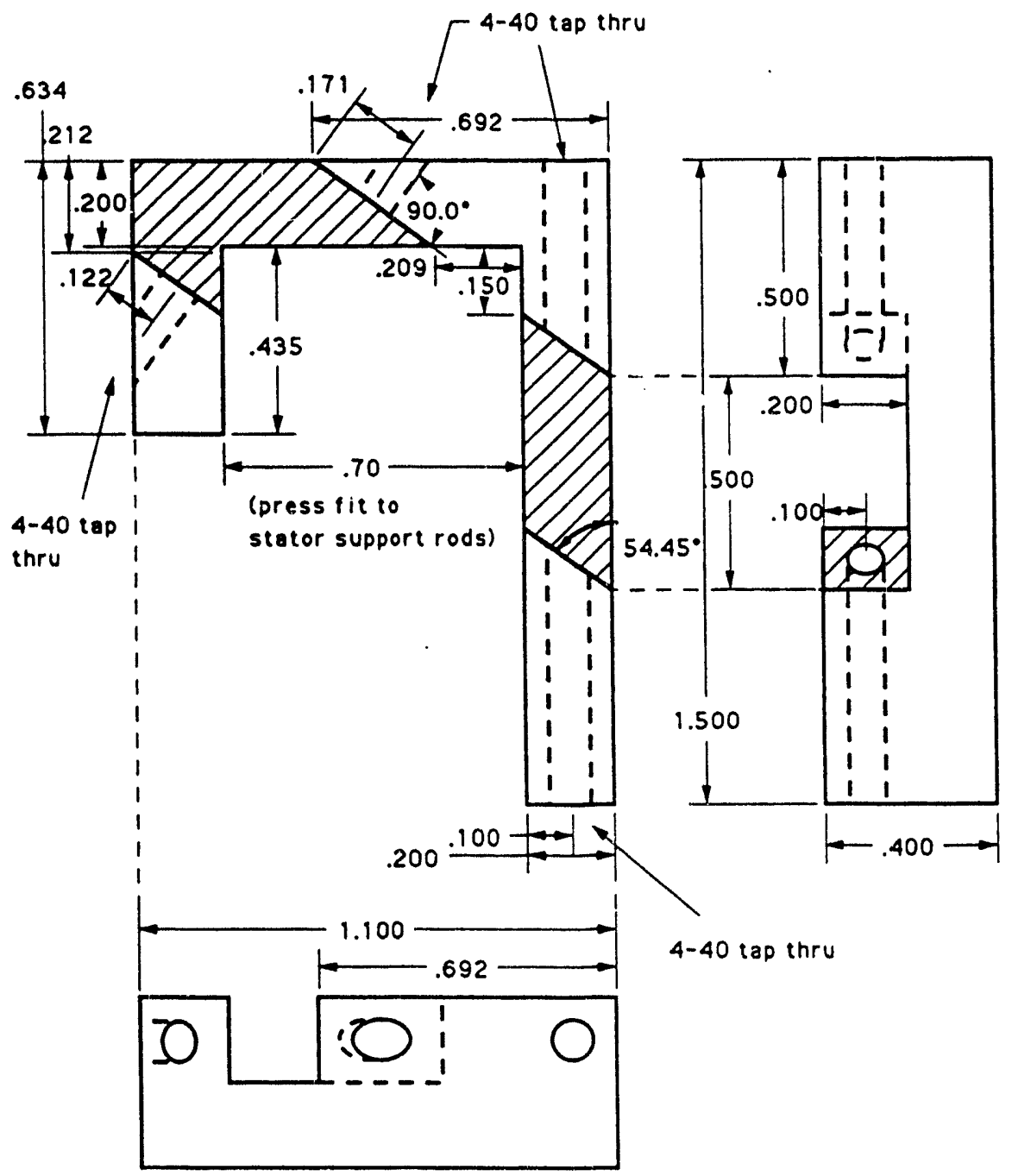

Figure C.12: Technical drawing of the magic angle adjustment device, all dimensions are in inches. 


\section{Bibliography}

[1] Breck, D.W. Zeolite Molecular Sieves, John Wiley \& Sons, New York:1974.

[2] Stucky, G.D.; Mac Dougall, J.E., "Quantum Confinement and Host/Guest Chemistry: Probing a New Dimension", Science, 1990, 247, 669.

[3] Barrer, R.M. Hydrothermal Chemistry of Zeolites, Academic Press, London: 1982.

[4] Thomas, J.M.; Vaughan, D.E.W., "Methodologies to Establish the Structure and Composition of New Zeolitic Molecular Sieves", J. Phys. Chem. Solids, $1989,50,449$.

[5] Klinowski, J., "Nuclear Magnetic Resonance Studies of Zeolites", Prog. NMR Spectroscopy, 1984, 16, 237.

[6] Engelhardt, G.; Michel, D. High-Resolution Solid-State NMR of Silicates and Zeolites, John Wiley \& Sons, Chichester: 1987.

[7] Mehring, M. Principles of High Resolution NMR in Solids, Springer-Verlag, Berlin:1983.

[8] Samoson, A.; Lippmaa, E.; Pines, A., "High Resolution Solid State NMR, Averaging of Second-Order Effects by Means of a Double-Rotor", Mol. Phys., 1988, 65, 1013.

[9] Meier, W.M.; Olson, D.H. Atlas of Zeolite Structure Types, 3rd Ed., Butterworth-Heinemann, Stoneham, MA: 1992.

[10] Zimmerman, J.R.; Holmes, B.G.; Lasater, J.A., "A Study of Adsorbed Water on Silica Gel by Nuclear Resonance Techniques", J. Phys. Chem., 1956, 60, 1157.

[11] Andrew, E.R.; Bradbury, A.; Eades, R.G., "Nuclear Magnetic Resonance Spectra from a Crystal Rotated at High Speed", Nature, 1958, 182, 1659. 
[12] Ernst, R.R.; Anderson, W.A., "Application of Fourier Transform Spectroscopy to Magnetic Resonance", Rev. Sci. Instrum., 1966, 37, 93.

[13] Harris, R.K. Nuclear Magnetic Resonance Spectroscopy, Longman Scientific and Technical, New York:1986.

[14] Akkit, J.W., "Nuclear Magnetic Resonance Spectroscopy in Liquids Containing Compounds of Aluminum and Gallium", Annu. Rev. NMR Spec., 1973, 5A, 465.

[15] Genser, E.E., "NMR Studies of ${ }^{7} \mathrm{Li},{ }^{23} \mathrm{Na}$, and ${ }^{27} \mathrm{Al}$ in Y-Faujasite", J. Chem. Phys., 1971, 54, 4612.

[16] Kundla, E.; Samoson, A.; Lippmaa, E., "High-Resolution NMR of Quadrupolar Nuclei in Rotating Solids", Chem. Phys. Lett., 1981, 83, 229.

[17] Müller, D.; Gessner, W.; Behrens, H.J.; Scheler, G., "Determination of the Aluminum Coordination in Aluminum-Oxygen Compounds by Solid-State HighResolution ${ }^{27}$ Al NMR", Chem. Phys. Lett., 1981, 79, 59.

[18] Fyfe, C.A.; Gobbi, G.C.; Hartman, J.S.; Klinowski, J.; Thomas, J.M., "SolidState Magic-Angle Spinning Aluminum-27 Nuclear Magnetic Resonance Studies of Zeolites Using a 400-MHz High-Resolution Spectrometer", J. Phys. Chem., 1982, 86, 1247.

[19] Wilson, S.T.; Lok, B.M.; Messina, C.A.; Cannan, T.R.; Flannigen, E.M., "Aluminophosphate Molecular Sieves: A New Class of Microporous Crystalline Inorganic Solids", J. Am. Chem. Soc., 1982, 104, 1146.

[20] Blackwell, C.S.; Patton, R.L., "Aluminum-27 and Phosphorus-31 Nuclear Magnetic Resonance Studies of Aluminophosphate Molecular Sieves", J. Phys. Chem., 1984, 88, 6135 .

[21] Kellberg, L.; Linsten, M.; Jacobsen, H.J., "27 Al $\left\{{ }^{1} \mathrm{H}\right\}$ Cross-Polarization and Ultrahigh-Speed ${ }^{27} \mathrm{Al}$ MAS NMR Spectroscopy in the Characterization of USY Zeolite", Chem. Phys. Lett., 1991, 182, 120.

[22] van Eck, E.R.H.; Janssen, R.; Maas, W.E.J.R.; Veeman, W.S., "A Novel Application of Nuclear Spin-Echo Double-Resonance to Aluminophosphates and Aluminosilicates", Chem. Phys. Lett., 1990, 174, 428.

[23] Geurts, F.M.M.; Kentgens, A.P.M.; Veeman, W.S., "27 Al Nutation NMR of Zeolites", Chem. Phys. Lett., 1985, 120, 206. 
[24] Jakobsen, H.J.; Skibsted, J.; Bildsoe, H.; Nielsen, N.C., "Magic-Angle Spinning NMR Spectra of Satellite Transitions of Quadrupolar Nuclei in Solids", J. Magn. Kies., 1989, 85, 173.

[25] Freude, D.; Fröhlich, T.; Pfeifer, H.; Scheler, G., "N.M.R. Studies of Aluminum in Zeolites", Zeolites, 1983, 3, 171.

[26] Klinowski, J.; Anderson, M.W.; Thomas, J.M., "On the siting of Aluminum in Zeolite Omega", J. Chem. Soc., Chem. Commun., 1983, 525.

[27] Klinowski, J.; Thomas, J.M.; Fyfe, C.A.; Gobbi, G.C.; Hartman, J.S., "A Highly Siliceous Structural Analogue of Zeolite Y: High-Resolution Solid-State ${ }^{29} \mathrm{Si}$ and ${ }^{27} \mathrm{Al}$ NMR Studies", Inorg. Chem., 1983, 22, 63.

[28] Nagy, J.B.; Gabelica, Z.; Debras, G.; Derouane, E.G.; Gilson, J.-P.; Jacobs, P.A., " ${ }^{27} \mathrm{Al}-$ N.M.R. Characterization of Natural and Synthetic Zeolites", Zeolites, 1984, 4, 133.

[29] Samoson, A.; Lippmaa, E.; Engelhardt, G.; Lohse: U.; Jerschkewitz, H.-G., "Quantitative High-Resolution ${ }^{27} \mathrm{Al}$ NMR: Tetrahedral Non-Framework Aluminum in Hydrothermally Treated Zeolites", Chem. Phys. Lett., 1987, 134, 589.

[30] Engelhardt, G.; Lohse, U.; Mägi, M.; Lippmaa, E., "Solid State ${ }^{29} \mathrm{Si}$ and ${ }^{27}$ Al NMR Studies of Decationized and Dealuminated Zeolites", Stud. Surf. Sci. Catal., 1984, 18, 23.

[31] Freude, D.; Fröhlich, T.; Hunger, M.; Pfeifer, H.; Scheler, G., "NMR Studies Concerning the Dehydroxylation of Zeolites HY", Chem. Phys. Lett., 1983, 98, 263.

[32] Klinowski, J.; Thomas, J.M.; Anderson, M.W.; Fyfe, C.A.; Gobbi, G.C., "Dealumination of Mordenite Using Silicon Tetrachloride Vapour", Zeolites, 1983, 3,5 .

[33] Gilson, J.-P.; Edwards, G.C.; Peters, A.W.; Rajagopalan, K.; Wormsbecher, R.F.; Roberie T.G.; Shatlock, M.P., "Penta-Coordinated Aluminum in Zeolites and Aluminosilicates", J. Chem. Soc., Chem. Commun., 1987, 91.

[34] Alemany, L.B.; Kirker, G.W., "First Observation of 5-Coordinate Aluminum by MAS ${ }^{27} \mathrm{Al}$ NMR in Well-Characterized Solids", J. Am. Chem. Soc., 1986, 108,6158 . 
[35] Bennet, J.M.; Cohen, J.M.; Artioli, G.; Pluth, J.J.; Smith, J.S., "Crystal Structure of $\mathrm{AlPO}_{4}-21$, a Framework Aluminophosphate Containing Tetrahedral Phosphorus and hoth Tetrahedral and Trigonal-Bipyramidal Aluminum in 3-, 4-, 5-, and 8-rings", Inorg. Chem., 1985, 24, 188.

[36] Alemany, L.B.; Timken; H.K.C.; Johnson, I.D., "Aluminum-27 NMR study of $\mathrm{AlPO}_{4}-21$ and Andalusite. Advantages of High-Field and Very Fast MAS", $J$. Magn. Res., 1988, 80, 427.

[37] Blackwell, C.S.; Patton, R.L., "Solid State NMR of Silicoaluminophosphate Molecular Sieves and Aluminophosphate Materials", J. Phys. Chem., 1988, 92, 3965.

[38] Rocha, J.; Liu, X.; Klinowski, J., "Solid-State ${ }^{27} \mathrm{Al}$ NMR Studies of $\mathrm{AlPO}_{4}-8$ ", Chem. Phys. Lett., 1991, 182, 531.

[39] Meinhold, R.H.; Tapp, N.J., "An NMR Study of the Reaction of Water with $\mathrm{AlPO}_{4}-5$ ", J. Chem. Soc., Chem. Commun., 1990, 219.

[40] Tapp, N.J.; Milestone, N.B.; Bowden, M.E.; Meinhold, R.H., "Water Adsorption on $\mathrm{AlPO}_{4}-11$ : Structural Changes", Zeolites, 1990, 10, 105.

[41] Stöcker, M.; Akporiaye, D.; Lillerud, K.-P., "Solid-State NMR Investigations of $\mathrm{AlPO}_{4}-8$. Its Transformation from VPI-5 and Interaction with Water", Appl. Catalysis, 1991, 69, L7.

[42] Goldfarb, D.; Li, H.-X.; Davis, M.E., "Dynamics of Water Molecules in VPI-5 and $\mathrm{AlPO}_{4}-5$ Studied by ${ }^{2} \mathrm{H}$ NMR Spectroscopy", J. Am. Chem. Soc., 1992, 114,3690 .

[43] Davis, M.E.; Saldarriaga, C.; Montes, C.; Garces, J.; Crowder, C., "VPI-5: The First Molecular Sieve with Pores Larger Than 10 Angstroms", Zeolites, 1988, 10, 362 .

[44] Davis, M.E.; Montes, C.; Hathaway, P.E.; Arhancet, J.P.; Hasha, D.L.; Garces, J.M., "Physicochemical Properties of VPI-5", J. Am. Chem. Soc., 1989, 111, 3919.

[45] Grobet, P.J.; Martens, J.A.; Balakhrishnan, I.; Martens, M.; Jacobs, P.A., "The Very Large Pore Molecular Sieve VPI-5: An Aluminophosphate Hydrate!", Appl. Catalysis, 1989, 56, L21.

[46] Perez, J.O.; Chu, P.J.; Clearfield, A., "Solid-State NMR Study of 18-Ring Large Pore Aluminophosphate Molecular Sieves", J. Phys. Chem., 1991, 95, 9994. 
[47] Martens, J.A.; Feijen, E.; Lievens, J.L.; Grobet, P.J.; Jacobs, P.A., "Structure and Effective Pore Size of the Dehydrated Forms of the Molecular Sieve VPI5", J. Phys. Chem., 1991, 95, 10025.

[48] Fyfe, C.A.; Grondey, H.; Mueller, K.T.; Wong-Moon, K.C.; Markus, T., "Coherence Transfer Involving Quadrupolar Nuclei in Solids: ${ }^{27} \mathrm{Al} \leftrightarrow{ }^{31} \mathrm{P}$ CrossPolarization NMR in the Molecular Sieve VPI-5", J. Am. Chem. Soc., 1992, $114,5876$.

[49] McCusker, L.B.; Baerlocher, C.; Jahn, E.; Bülow, M., "The Triple Helix Inside the Large-Pore Aluminophosphate Molecular Sieve VPI-5", Zeolites, 1991, 11,308 .

[50] Wu, Y.; Chmelka, B.F.; Pines, A.; Davis, M.E.; Grobet, P.J.; Jacobs, P.A., "High-Resolution ${ }^{27} \mathrm{Al}$ Spectroscopy of the Aluminophosphate Molecular Sieve VPI-5", Nature, 1990, 346, 550.

[51] Müller, D.; Jahn, E.; Ladwig, G.; Haubenreisser, U., "High-Resolution SolidState ${ }^{27} \mathrm{Al}$ and ${ }^{31} \mathrm{P}$ NMR: Correlation Between Chemical Shift and Mean AlO-P Angle in $\mathrm{AlPO}_{4}$ Polymorphs", Chem. Phys. Lett., 1984, 109, 332.

[52] Müller, D.; Jahn, E.; Fahlke, B.; Ladwig, G.; Haubenreisser, U., "High Resolution ${ }^{27} \mathrm{Al}$ and ${ }^{31} \mathrm{P}$ NMR Studies of the Aluminum Phosphate Molecular Sieve $\mathrm{AlPO}_{4}-5$ ", Zeolites, 1985, 5, 53.

[53] Lippmaa, E.; Mägi, M.; Samoson, A.; Tarmak, M.; Engelhardt, G., "Investigation of the Structure of Zeolites by Solid-State High-Resolution ${ }^{29} \mathrm{Si}$ NMR Spectroscopy", J. Am. Chem. Soc., 1981, 103, 4992.

[54] Lowenstein, W., "The Distribution of Aluminum in the Tetrahedra of Silicates and Aluminates", Am. Mineral., 1953, 39, 92.

[55] Ramdas, S.; Thomas, J.M.; Klinowski, J.; Fyfe, C.A.; Hartman, J.S., "Ordering of Aluminum and Silicon in Synthetic Faujasites", Nature, 1981, 292, 228.

[56] Lippmaa, E.; Samoson, A.; Mägi, M., "High-Resolution ${ }^{27}$ Al NMR of Aluminosilicates", J. Am. Chem. Soc., 1986, 108, 1730.

[57] Engelhardt, G.; Radeglia, R., "A Semi-Empirical Quantum-Chemical Rationalization of the Correlation Between SiOSi Angles and ${ }^{29} \mathrm{Si}$ NMR Chemical Shifts of Silica Polymorphs and Framework Aluminosilicates (Zeolites)", Chem. Phys. Lett., 1984, 108, 271. 
[58] van der Klink, J.J.; Veeman, W.S.; Schmid, H., "27 Al NMR Studies of the Aluminate Sodalites $\mathrm{Sr}_{8}\left[\mathrm{Al}_{12} \mathrm{O}_{24}\right]\left(\mathrm{CrO}_{4}\right)_{2}$ and $\mathrm{Ca}_{8}\left[\mathrm{Al}_{12} \mathrm{O}_{24}\right]\left(\mathrm{WO}_{4}\right)_{2}$ ", J. Phys. Chem., 1991, 95, 1508.

[59] Thomas, J.M.; Bursill, L.A.; Lodge, E.A.; Cheetham, A.K.; Fyfe, C.A., "A Reassessment of Zeolite A: Evidence that the Structure is Rhombohedral with Unexpected Ordering in the Aluminosilicate Framework", J. Chem. Soc., Chem. Comm., 1981, 276.

[60] Engelhardt, G.; Fahlke, B.; Mägi, M.; Lippmaa, E., "High-Resolution SolidState ${ }^{29} \mathrm{Si}$ and ${ }^{27} \mathrm{Al} \mathrm{NMR}$ of Aluminosilicate Intermediates in Zeolite A Synthesis", Zeolites, 1983, 3, 292.

[61] Jacobsen, H.S.; Norby, P.; Bildsoe, H.; Jakobsen, H.J., "1:1 Correlation Between ${ }^{27} \mathrm{Al}$ and ${ }^{29} \mathrm{Si}$ Chemical Shifts and Correlations with Lattice Structures for Some Aluminosilicate Sodalites", Zeolites, 1989, 9, 491.

[62] Engelhardt, G.; Felsche, J.; Sieger, P., "The Hydrosodalite System $\mathrm{Na}_{6+x}\left[\mathrm{SiAlO}_{4}\right]_{6}(\mathrm{OH})_{x} \cdot \mathrm{H}_{2} \mathrm{O}$ : Formation, Phase Composition, and De- and Rehydration Studied by ${ }^{1} \mathrm{H},{ }^{23} \mathrm{Na}$, and ${ }^{29} \mathrm{Si}$ MAS-NMR Spectroscopy in Tandem with Thermal Analysis, X-ray Diffraction, and IR Spectroscopy", J. Am. Chem. Soc., 1992, 114, 1173.

[63] Rocha, J.; Carr, S.W.; Klinowski, J., ${ }^{{ }^{\star 27}} \mathrm{Al}$ Quadrupole Nutation and ${ }^{1} \mathrm{H}-$ ${ }^{27} \mathrm{Al}$ Cross-Polarization Solid-State NMR Studies of Ultrastable Zeolite $Y$ with Fast Magic-Angle Spinning", Chem. Phys. Lett., 1991, 187, 401.

[64] Pfeifer, H., "Heterogeneous Catalysis and NMR Spectroscopy of Spin $1 / 2 \mathrm{Nu}-$ clei", Colloids and Surfaces, 1990, 45, 1.

[65] Jünger, I.; Meiler, W.; Pfeifer, H., "Carbon-13 and Nitrogen-15 Nuclear Magnetic Resonance Studies of Acetonitrile Adsorbed in Various CationExchanged X Zeolites", Zeolites, 1982, 2, 310.

[66] Barrie, P.J.; Klinowski, J., "Xe-129 NMR as a Probe for the Study of Microporous Solids-A Critical Review", Prog. NMR Spectr., 1992, 24, 91.

[67] Kentgens, A.P.M.; Scholle, K.F.M.G.J.; Veeman, W.S., "Effect of Hydration on the Local Symmetry Around Aluminum in ZSM-5 Zeolites Studied by Aluminum-27 Nuclear Magnetic Resonance", J. Phys. Chem., 1983, 87, 4357.

[68] Luz, Z.; Vega, A.J., "Interaction of H-rho Zeolite with Water and Methanol Studied by Multinuclear NMR Spectroscopy", J. Phys. Chem., 1987, 91, 374. 
[69] Chu, P.-J.; de Mallmann, A.; Lunsford, J.H., "A Solid State NMR Study of Aluminum Lewis Acid Adducts with Trimethylphosphine in Zeolite Y: Magic Angle Spinning Sideband Analysis of Dipolar and J-Coupled Multiplet System", J. Phys. Chem., 1991, 95, 7362.

[70] Timken, H.K.C.; Turner, G.L.; Gilson, J.-P.; Welsh, L.B.; Oldfield, E., "SolidState Oxygen-17 Nuclear Magnetic Resonance Spectroscopic Studies of Zeolites and Related Systems. 1", J. Am. Chem. Soc., 1986, 108, 7231.

[71] Timken, H.K.C.; Janes, N.; Turner, G.L.; Lambert, S.L.; Welsh, L.B.; Oldfield, E., "Solid-State Oxygen-17 Nuclear Magnetic Resonance Spectroscopic Studies of Zeolites and Related Systems. 2", J: Am. Chem. Soc., 1986, 108, 7236.

[72] Shirley, W.M.; Powers, C.A.; Tway, C.L., "Chromium and Molybdenum Carbonyls on NaX Zeolite: ${ }^{13} \mathrm{C}$ and ${ }^{17} \mathrm{O}$ NMR", Colloids and Surfaces, 1990, 45, 57.

[73] Parise, J.B., "Some Gallium Phosphate Frameworks Related to the Aluminum Phosphate Molecular Sieves: X-Ray Structural Characterization", J. Chem. Soc., Chem. Comm., 1985, 606.

[74] Gaffney, T.R.; Pierantozzi, R.; Segar, M.R., "Isomorphous Substitution of Boron in Mordenite and Zeolite Y", in "Zeolite Synthesis", Occelli, M.L.; Robson, H.E. (Eds.), ACS Symp. Ser. 398, 1989.

[75] Sayed, M.B.; Auroux, A.; Vedrine, J.C., "The Effect of Boron on ZSM-5 Zeolite Shape Selectivity and Activity", J. Catal., 1989, 116, 1.

[76] Timken, H.K.C.; Oldfield, E., "Solid-State Gallium-69 and Gallium-71 Nuclear Magnetic Resonance Spectroscopic Studies of Gallium Analogue Zeolites and Related Systems", J. Am. Chem. Soc., 1987, 109, 7669.

[77] Kentgens, A.P.M.; Bayense, C.R.; van Hooff, J.H.C.; de Haan, J.W.; van de Ven, L.J.M., "A ${ }^{69} \mathrm{Ga}$ and ${ }^{71} \mathrm{Ga}$ MAS NMR Study of the Gallium Analogue Zeolite ZSM-5", Chem. Phys. Lett., 1991, 176, 399.

[78] Bayense, C.R.; Kentgens, A.P.M.; de Haan, J.W.; van de Ven, L.J.M.; van Hooff, J.H.C., "Determination of Gallium in $\mathrm{H}(\mathrm{Ga})$ ZSM5 Zeolites by ${ }^{71} \mathrm{Ga}$ MAS NMR Spectroscopy", J. Phys. Chem., 1992, 96, 775.

[79] Estermann, M.; McCusker, L.B.; Baerlocher, C.; Merrouche, A.; Kessler, H., "A Synthetic Gallophosphate Molecular Sieve with a 20-Tetrahedral-Atom Pore Opening", Nature, 1991, 352, 320. 
[80] Freude, D.; Hunger, M.; Pfeifer, H., "Study of Brønsted Acidity of Zeolites Using High-Resolution Proton Magnetic Resonance with Magic-Angle Spinning", Chem. Phys. Lett., 1982, 91, 307.

[81] West, G.W., "Nuclear Magnetic Resonance in Zeolites", Zeolites, 1981, 1, 150.

[82] Ahn, M.-K.; Iton, L.E., "Cesium-133 NMR Studies of Cation Siting and Site Exchange Dynamics in Hydrated CsNa-A Zeolite", J. Phys. Chem., 1989, 93, 4924.

[83] Herden, H.; Einicke, W.-D.; Schöllner, R.; Dyer, A., "Investigations of the Arrangement and Mobility of Li Ions in X-and Y-Zeolites and the Influence of Mono- and Divalent Cations on It", J. Inor. Nucl. Chem., 1981, 43, 2533.

[84] Melchior, M.T.; Vaughan, D.E.W.; Jacobson, A.J.; Pictroski, C.F., "Study of Cation Effects in Li,NaA Zeolites by Silicon-29 and Lithium-7 NMR", Proceedings of the 6th Intl. Zeolite Conference, Reno: 1983 (Olson, D.; Bisio, A., Eds.).

[85] Tokuhiro, T.; Iton, L.E.; Peterson, E.M., "Nuclear Magnetic Resonance Study of Li-Exchanged Zeolites. I. Cation Spin Dynamics: ${ }^{7} \mathrm{Li}$ in Hydrated A, X, and Y Zeolites", J. Chem. Phys., 1983, 78, 7473.

[86] Ozin, G.A.; Baker, M.D.; Godber, J.; Gil, C.J., "Intrazeolite Site-Selective Far-IR Cation Probe", J. Phys. Chem., 1989, 93, 2899.

[87] Welsh, L.B.; Lambert, S.L., "Analysis of Cation Position in Ion-Exchanged Y Zeolites by ${ }^{23} \mathrm{Na}$ NMR", in "Perspective in Molecular Sieve Science" (Flank, W.H.; Whyte, T.E., Eds.), ACS Symp. Ser. 368, 1988.

[88] Welsh, L.B.; Lambert, S.L., "Characterization of Y Zeolites by ${ }^{23} \mathrm{Na}$ Magic Angle-Spinning NMR Spectroscopy", in "Characterization and Catalyst Development" (Bradley, S.A.; Gattuso, M.J.; Bertolacini, R.J., Eds.), ACS Symp. Ser. 411, 1989.

[89] Challoner, R.; Harris, R.K., "Evidence for Slow Tumbling of Sodium Ions from the ${ }^{23} \mathrm{Na}$ NMR Spectrum of Hydrated NaY Zeolite", Zeolites, 1991, 11, 265.

[90] Mortier, W.J. Compilations of Extra-framework Sites in Zeolites, Butterworths, Guildford, UK: 1982.

[91] Janssen, R.; Tijink, G.A.H.; Veeman, W.S., "Rotary Echo Nutation NMR", J. Chem. Phys., 1987, 88, 518. 
[92] Janssen, R.; Breuer, R.E.H.; de Boer, E.; Geismar, G., "23Na -NMR Experiments on Sodalites", Zeolites, 1989, 9, 59.

[93] Nielsen, N.C.; Bildsoe, H.; Jakobsen, H.J.; Norby, P., ${ }^{47} \mathrm{Li},{ }^{23} \mathrm{Na}$, and ${ }^{27} \mathrm{Al}$ Quadrupolar Interactions in Some Aluminosilicate Sodalites from MAS NMR Spectra of Satellite Transitions", Zeolites, 1991, 11, 622.

[94] Godber, J.; Ozin, G.A., "Cation Dynamics in Sodalite, Cubic and Rhombohedral Zeolite A, and Faujasite: Fourier Transform Far-Infrared Probe of Densely and Dispersely Packed Cations", J. Phys. Chem., 1988, 92, 2841.

[95] Borbély, G.; Beyer, H.K.; Radics, L.; Sándor, P.; Karge, H.G., "Solid-State Ion Exchange in Zeolites: Part IV. Evidence for Contact-Induced Ion Exchange Between Hydrated NaY Zeolite and Metal Chlorides", Zeolites, 1989, 9, 428.

[96] Lin, C.-F.; Chao, K.-J., "Cation Location in La,Na-Y Zeolites by TwoDimensional ${ }^{23} \mathrm{Na}$ Nutation NMR", J. Phys. Chem., 1991, 95, 9411.

[97] Haase, J.; Park, K.D.; Guo, K.; Timken, H.K.C.; Oldfield, E., "Nuclear Magnetic Resonance Spectroscopic Study of Spin-Lattice Relaxation of Quadrupolar Nuclei in Zeolites", J. Phys. Chem., 1991, 95, 6996.

[98] Wilson, S.T.; Lok, B.M.; Flanigen, E.M. U.S. Patent 4,310,440, 1982.

[99] Wu, Y.;Sun, B.Q.; Pines, A.; Samoson, A.; Lippmaa, E., "NMR Experiments with a New Double Rotor", J. Magn. Res., 1990, 89, 297.

[100] Parise, J.B.; Day, C.S., "The Structure of Trialuminum Tris(orthophosphate) Hydrate, $\mathrm{AlPO}_{4}-21$, with Clathrated Ethylenediamine, $\mathrm{Al}_{3}\left(\mathrm{PO}_{4}\right)_{3} \cdot \mathrm{C}_{2} \mathrm{H}_{8} \mathrm{~N}_{2}$. $\mathrm{H}_{2} \mathrm{O}$, and Pyrrolidine, $\mathrm{Al}_{3}\left(\mathrm{PO}_{4}\right)_{3} \cdot \mathrm{C}_{2} \mathrm{H}_{9} \mathrm{~N} \cdot \mathrm{H}_{2} \mathrm{O}$ ", Acta Cryst., 1985, C41, 515 .

[101] Bennett, J.M.; Cohen, J.M.; Artioli, G.; Pluth, J.J., Smith, J.V., "Crystal Structure of $\mathrm{AlPO}_{4}-21$, a Framework Aluminophosphate Containing Tetrahedral Phosphorus and Both Tetrahedral and Trigonal-Pyramidal Aluminum in 3-, 4-, 5-, and 8-Rings", Inorg. Chem. 1985, 24, 188.

[102] Richardson Jr., J.W.; Smith, J.V.; Pluth, J.J., "AlPO 4-25: Framework Topology, Topotactic Transformation from $\mathrm{AlPO}_{4}-21$, and High-Low Displacive Transition", J. Phys. Chem. 1990, 94, 3365.

[103] Endoh, A.; Mizoe, K.; Tsutsumi, K.; Takaishi, T., "Reactivity of $\mathrm{AlPO}_{4}-5$ and the Origin of its Hydrophylic Property", J. Chem. Soc., Faraday Trans. $1,1989,85,1327$. 
[104] He, H.; Kolodziejski, W.; Klinowski, J., "NMR Studies of the Molecular Sieve VPI-5 Containing Only "Framework" Water", Chem. Phys. Lett., 1992, 200, 83.

[105] Handbook of Chemistry and Physics, 66th Ed., CRC Press; Boca Raton, FL: 1985-86.

[106] Grobet, P.J.;Samoson, A.;Geertz, H.;Martens, J.A.;Jacobs, P.A., "Crystallographic Site Discrimination in Aluminophosphate Molecular Sieves by Solid State NMR - Influence of the High Field-Dependent Isotropic 2nd-Order Quadrupolar Shift on High-Resolution Al-27 DOR NMR", J. Phys. Chem., 1991, 95, 9620.

[107] Richardson Jr., J.W.;Pluth, J.J.;Smith, J.V., "Aluminophosphate Number 5: Time of Flight Neutron Powder Diffraction Study of Calcined Powder at 295K", Acta Crystallogr., 1987, C43, 1469.

[108] Jelinek, R.; Chmelka, B.F.; Wu, Y.; Grandinetti, P.J.; Pines, A.; Barrie, P.J.; Klinowski, J., "Study of the Aluminophosphates $\mathrm{AlPO}_{4}-21$ and $\mathrm{AlPO}_{4}-25$ by ${ }^{27}$ Al Double-Rotation NMR", J. Am. Chem. Soc., 1991, 113, 4097.

[109] Davis, M.E.; Hathaway, P.E.; Montes, C., "VPI-5, $\mathrm{AlPO}_{4}-8$, and MCM-9: Similarities and Differences", Zeolites, 1989, 9, 436.

[110] Dessau, R.M.;Schlenker, H.L.;Higgins, J.B., "Framework Topology of $\mathrm{AlPO}_{4}{ }^{-}$ 8-The 1st 14-Ring Molecular Sieve", Zeolites, 1990, 10, 522.

[111] Rocha, J.; Liu, X.; Klinowski, J., "Solid-State ${ }^{27} \mathrm{Al}$ NMR Studies of $\mathrm{AlPO}_{4}$ 8", Chem. Phys. Lett., 1991, 182, 531.

[112] Wu, Y.; Lewis, D.; Frye, J.S.; Palmer, A.R.; Wind, R.A., "Cross-Polarization Double-Rotation NMR", J. Magn. Res., 1992, 100, 425.

[113] Vinje, K.;Ulan, J.;Szostak, R.;Gronsky, R., "Stacking Disorders in VPI-5 and $\mathrm{AlPO}_{4}-8$ and the Related Loss of Adsorption Capacity", Appl. Catal., 1991, 72,361 .

[114] Ozin, G.A.; Kuperman, A.; Stein, A., "Advanced Zeolite Materials Science", Angew. Chem. Int. Ed. Engl., 1989, 3, 359.

[115] Ozin, G.A.; Kirkby, S.; Meszaros, M.; Özkar, S.; Stein, A.; Stucky, G.D., "Intrazeolite Semiconductor Quantum Dots and Quantum Supralattices: New Materials for Nonlinear Optical Applications", in "Materials for Nonlinear Optics", Marder, S.M.; Sohn, J.E.; Stucky, G.D. (Eds.), ACS Symp. Ser. 455, $1991,551$. 
[116] Zhu, Y.;Huang, D.;Feng, S., "Tunneling Plasmon Excitations in Quasi-ZeroDimensional Superlattices Composed of Quantum Dots", Phys. Rev. B, 1989, 40, 3169 .

[117] Ozin, G.A., "Nanochemistry-Synthesis in Diminishing Dimensions", Adv. Mater., 1992, 4, 612.

[118] Stein, A.;Ozin, G.A.;Stucky, G.D., "From the Molecule to an Expanded Semiconductor Quantum Superlattice: Silver,Sodium Halo-Sodalites", J. Am. Chem. Soc.,1990,112, 904.

[119] Stein, A.;MacDonald, P.M.;Ozin, G.A.;Stucky, G.D., "Assembling a Semiconductor Quantum Supralattice One Atom at a Time: Nonstoichiometric Silver, Sodium Bromosodalites", J. Phys. Chem., 1990, 94, 6943.

[120] Godber, J.;Ozin, G.A., "Fourier Transform Far-Infrared Spectroscopic Study of Cation and Anion Dynamics in $\mathrm{M}, \mathrm{X}$-Sodalites, Where $\mathrm{M}=\mathrm{Li}^{+}, \mathrm{Na}^{+}, \mathrm{K}^{+}$, $\mathrm{Rb}^{+}, \mathrm{Ca}^{2+} ; \mathrm{X}=\mathrm{Cl}^{-}, \mathrm{Br}^{-}, \mathrm{I}^{-}, \mathrm{ClO}_{4}^{-}, \mathrm{OH}^{-}$, J. Phys. Chem., 1988, 92, 4980.

[121] Stein, A.;Mezsaros, M.;Macdonald, P:M.;Ozin, G.A.;Stucky, G.D., "Mixed Semiconductor Component Quantum Supralattices: Silver, Sodium, Chloro, Iodo-sodalites", Adv. Mater., 1991, 3, 306.

[122] Stein, A., "Synthesis, Characterization, and Opto-Electronic Properties of Sodalite-Encapsulated Insulator, Semiconductor Components, and Metals", Ph. D. Thesis, University of Toronto, November, 1991.

[123] Weller, M.T.; Wong, G., "New Limits of Silicon-29 Solid State NMR Chemical Shifts", J. Chem. Soc., Chem. Commun., 1988, 1103.

[124] Smeulders, J.B.A.F.; Hefni, M.A.; Klaasen, A.A.K.; de Boer, E.; Westphal, U.; Geismar, G., "Na ${ }_{4}^{3+}$ Clusters in Sodalite", Zeolites, 1987, 7, 347.

[125] Shannon, R.D., "Revised Effective Ionic Radii and Systematic Studies of Interatomic Distances in Halides and Chalcogenides", Acta Crystallog., 1976, A32, 751 .

[126] Ramdas, S.;Klinowski, J., "A Simple Correlation Between Isotropic ${ }^{29}$ Si NMR Chemical Shifts and T-O-T Angles in Zeolite Framework", Nature, 1984, $308,521$.

[127] Hassan, I.;Buseck, P.R., "Incommensurate-Modulated Structure of Nosean, a Sodalite-Group Mineral", Am. Mineral., 1989, 74, 394. 
[128] Cotton, F.A.; Wilkinson, G. Advanced Inorganic Chemistry, 4th Ed.; Wiley: New York, 1980. p. 255.

[129] Jelinek, R.; Stein, A.; Ozin, G.A., ${ }^{\text {"81 }} \mathrm{Br}$ and ${ }^{35} \mathrm{Cl}$ NMR Investigation of Sodium,Silver,Halo-Sodalite Semiconductor Supralattices", J. Am. Chem. Soc., in press.

[130] Özkar, S.; Ozin, G.A.; Moller, K.; Bein, T., "Intrazeolite Metal Carbonyl Topotaxy. A Comprehensive Structural and Spectroscopic Study of Intrazolite Group VI Metal Hexacarbonyls and Subcarbonyls", J. Am. Chem. Soc., 1990, $112,9575$.

[131] Ozin, G.A.; Özkar, S.; Pastore, H.O.; Poë, A.J.; Vichi, E.J.S., "Topotactic Kinetics in Zeolite Nanoreaction Chambers", in "Supramolecular Architecture in Two and Three-Dimensions", ACS Symp. Ser. 499, 1992, 314.

[132] Ben Taarit, Y.;Wicker, G.; Naccache, C., "An NMR and EPR Investigation of the Interaction of Chromium and Molybdenum with Faujasite Type Y Zeolites", in "Magnetic Resonance in Colloid and Interface Science", Resing, H.A.; Fraissard, J.P. (Eds.), 1980, 497.

[133] Abdo, S.; Howe, R.F., "Preparation of Molybdenum Zeolites from Molybdenum Hexacarbonyl. 1. Infrared Studies", J. Phys. Chem., 1983, 87, 1713; Abdo, S.; Howe, R.F., "Preparation of Molybdenum Zeolites from Molybdenum Hexacarbonyl. 2. Electronic Paramagnetic Resonance Studies", ibid., 1722.

[134] Okamoto, Y.; Maezawa, A.; Kane, H.; Mitsushima, I.; Imanaka, T., "Thermal Stabilities of Hexacarbonyls and Subcarbonyls of Molybdenum Encapsulated in NaY and NaX Zeolites", J. Chem. Soc., Faraday Trans. 1, 1988, 84, 851.

[135] Ozin, G.A.; Özkar, S.; Pastore, H.O.; Poë, A.J.; Vichi, E.J.S., "Intrazeolite Metal Carbonyl Kinetics: ${ }^{12} \mathrm{CO}$ Substitution in $\mathrm{Mo}\left({ }^{12} \mathrm{CO}\right)_{6}-\mathrm{Na}_{56} \mathrm{Y}$ by $\mathrm{PMe}_{3}$ and ${ }^{13}$ CO", J. Chem. Soc., Chem. Commun., 1991, 141.

[136] Eulenberger, G.R.; Shoemaker, D.P.; Keil, J.G., "The Crystal Structures of Hydrated and Dehydrated Synthetic Zeolites with Faujasite Aluminosilicate Frameworks. I. The Dehydrated Sodium, Potassium, and Silver Forms", J. Phys. Chem., 1967, 71, 1812.

[137] Fitch, A.N.; Jobic, H.; Renouprez, A., "Localization of Benzene in Sodium-Y Zeolite by Powder Neutron Diffraction", J. Phys. Chem., 1986, 90, 1311. 
[138] Samoson, A.; Lippmaa, E., "Central 'Transition NMR Excitation Spectra of Half-Integer Quadrupole Nuclei", Chem. Phys. Lett., 1983, 100, 205.

[139] Fenzke, D.; Freude, D.; Fröhlich, T; Haase, J., "NMR Intensity Measurements of Half-Integer Quadrupole Nuclei", Chem. Phys. Lett., 1984, 111, 171.

[140] Maricq, M.M.;Waugh, J.S., "NMR in Rotating Solids", J. Chem. Phys., 1979, 70,3300 .

[141] Godber, J.;Baker, M.D.;Ozin, G.A., "Far-IR Spectroscopy of Alkali-Metal and Alkaline-Earth Cations in Faujasite Zeolites", J. Phys. Chem., 1989, 93, 1409.

[142] McMurray, L.;Holmes, A.J.;Kuperman, A.;Ozin, G.A.;Özkar, S., "Intrazeolite Semiconductors- Na-23 MAS NMR, Tl+ Luminescence Quenching, and FarIR Studies of Acid Base Precursor Chemistry in Zeolite-Y", J. Phys. Chem., 1991, 95, 9448 .

[143] Tokuhiro, T; Mattingly, M.; Iton, L.E.; Ahn, M.K., "Variable-Temperature Magic-Angle-Spinning Technique for Studies of Mobile Species in Solid-State NMR", J. Phys. Chem., 1989, 93, 5584.

[144] Lunsford, J.H.; Rothwell, W.P.; Shen, W., "Acid Sites in Zeolite Y: A Solid-State NMR and Infrared Study Using Trimethylphosphine as a Probe Molecule", J. Am. Chem. Soc., 1985, 107, 1540.

[145] Lunsford, J.H.; Tutunjian, P.N.; Chu, P.; Yeh, E.B.; Zalewski, D.J., "SolidState NMR Study Using Trimethylphosphine as a Probe of Acid Sites in Normal and Dealuminated Zeolite Y", J. Phys. Chem., 1989, 93, 2590.

[146] Zalewski, D.J.; Chu, P.; Tutunjian, P.N.; Lunsford, J.H., "Oxidation of Trimethylphosphine in Zeolite-Y: A Solid-State NMR Study", Langmuir, 1989, 5, 1026.

[147] Sun, T.; Seff, K.; Heo, N.H.; Petranovskii, V.P., "A Cationic Cesium Continuum in Zeolite X", Science, 1993, 259, 495.

[148] Wang, Y.; Herron, N., "Optical Properties of CdS and PbS Clusters Encapsulated in Zeolites", J. Phys. Chem., 1987, 91, 257.

[149] Mac Dougall, J.E.; Eckert, H.; Stucky, G.D.; Herron, N.; Wang, Y.; Moller, K.; Bein, T.; Cox, D., "Synthesis and Characterization of III-V Semiconductor Clusters: GaP in Zeolite Y", J. Am. Chem. Soc., 1989, 111, 8006. 
[150] Liu, X.; Iu, K.-K.; Thomas, J.K., "Encapsulation of $\mathrm{TiO}_{2}$ in Zeolite Y", Chem. Phys. Lett., 1992, 195, 163.

[151] Borvornwattananont, A.; Moller, K.; Bein, T., "Transition Metal Germylene Complexes in Zeolite Cages: Anchoring and Stability", J. Phys. Chem., 1992, 96, 6713 .

[152] Bein, T.; Brown, K.; Frye, G.C.; Brinker, C.J., "Molecular Sieve Sensors for Selective Detection at the Nanogram Level", J. Am. Chem. Soc., 1989, 111, 7640 .

[153] Ozin, G.A.; Özkar, S., "Intrazeolite Metal Carbonyl Phototopotaxy: From Tungsten(VI) Oxide Quantum Dots to a Zero-Dimensional Semiconductor Quantum Supralattice", J. Phys. Chem., 1990, 94, 7556.

[154] Özkar, S.; Ozin, G.A.; Prokopowicz, R.A., "Photo-Oxidation of Hexacarbonylmolybdenum $(0)$ in Sodium Zeolite $Y$ Yields Redox Interconvertible Molybdenum(VI) Oxide and Molybdenum(IV) Oxide Monomers", J. Am. Chem. Soc., in press.

[155] Ozin, G.A.; Özkar, S.; Macdonald, P.M.; Moller, K.; Bein, T., "Doping and Band-Gap Engineering of an Intrazeolite Tungsten(VI) Oxide Supralattice", MRS Symp. Ser. 233, 1991, 109.

[156] Ozin, G.A.; Prokopowicz, R.A.; Özkar, S., "Intrazeolite Nonstoichiometric Tungsten Oxides $\mathrm{n}\left[\mathrm{WO}_{3-x}\right]-\mathrm{Na}_{56} \mathrm{Y}(0<\mathrm{n} \leq 32,0 \leq \mathrm{x} \leq 1)$ ", J. Am. Chem. Soc., $1992,114,8953$.

[157] Vold, R.L.;Waugh, J.S.;Klein, M.P.;Phelps, D.E., "Measurement of SpinRelaxation in Complex Systems", J. Chem. Phys., 1968, 48, 3831.

[158] Abragam, A. The Principles of Nuclear Magnetism, Clarendon, Oxford: 1961.

[159] Hubbard, P.S., "Nonexponential Nuclear Magnetic Relaxation by Quadrupole Interactions", J. Chem. Phys., 1970, 53, 985.

[160] Haase, J.;Pf-ifer, H.;Oehme, W.;Klinowski, J., "Longitudinal NMR Relaxation of ${ }^{27} \mathrm{Al}$ Nuclei in Zeolites", Chem. Phys. Lett, 1988, 150, 189.

[161] Petit, D.; Korb, J.-P., "Fictitious Spin- $\frac{1}{2}$ Operators and Multitransition Nuclear Relaxation in Solids: General Theory", Phys. Rev. B., 1988, 37, 5761.

[162] Haase, J.; Oldfield, O., "Spin-Echo Behavior of Non-Integral Spin Quadrupolar Nuclei in Inorganic Solids", J. Magn. Res. Ser. A, 1993, 101, 30. 
[163] Moller, K.; Bein, T.; Özkar, S.; Ozin, G.A., "Intrazeolite Phototopotaxy: EXAFS Analysis of Precursor $8\left\{\mathrm{~W}(\mathrm{CO})_{6}\right\}-\mathrm{Na}_{56} \mathrm{Y}$ and Photo-Oxidation Products $16\left(\mathrm{WO}_{3}\right)-\mathrm{Na}_{56} \mathrm{Y}$ and 28$\left(\mathrm{WO}_{3}\right)-\mathrm{Na}_{56} \mathrm{Y}^{\prime \prime}$, J. Phys. Chem., 1991, 95, 5276.

[164] Ozin, G.A.; Özkar, S.; Prokopowicz, R.A., "Smart Zeolites: New Forms of Tungsten and Molybdenum Oxides", Accts. Chem. Res., in press.

[165] Ozin, G.A.; Özkar, S.; Macdonald, P., " ${ }^{23} \mathrm{Na}$ MAS-NMR and FT-Mid-FarIR Cation/Proton Probes of the Phototopotactic Oxidation of Intrazeolite Hexacarbonyltungsten(0) to Tungsten(VI) Oxide Quantum Dots and Supralattices: Exploring Anchoring Sites and Aggregation Processes", J. Phys. Chem., 1990, 94, 6939 .

[166] Ozin, G.A.; Özkar, S., "Intrazeolite Topotaxy", Adv. Mater., 1992, 4, 11.

[167] Fukushima, E.; Roeder, S.B.W. Experimental Pulse NMR: A Nuts and Bolts Approach, Addison-Wesley, Reading, MA: 1981.

[168] Slichter, C.P. Principles of Magnetic Resonance, 3rd edition, Springer-Verlag, Berlin:1990.

[169] Fyfe, C.A. Solid State NMR for Chemists, C.F.C. Press, Guelph, Ontario: 1983.

[170] Haeberlen, U. High Resolution NMR in Solids: Selective Averaging, in Advances in Magnetic Resonance, Suppl. 1, Waugh, J.S., Ed., Academic Press, New York:1976.

[171] Cohen, M.H.; Reif, F., "Quadrupolar Effects in Nuclear Magnetic Resonance" Studies of Solids", Solid State Phys., 1957, 5, 321.

[172] Mueller, K.T., "Dynamic Angle Spinning and Double Rotation of Quadrupolar Nuclei", Ph. D. Thesis, Berkeley, July 1991.

[173] Rose, M.E. Elementary Theory of Angular Momentum, John Wiley \& Sons, New York:1957.

[174] Thayer, A.M.; Pines, A., "Zero-field NMR", Accts. Chem. Res., 1987, 20, 47.

[175] Haeberlen, U; Waugh, J.S., "Coherent Averaging Effects in Magnetic Resonance", Phys. Rev., 1968, 175, 453.

[176] Goldman, M.; Grandinetti, P.J.; Llor, A.; Olejniczak, Z.; Sachleben, J.R.; Zwanziger, J.W., "Theoretical Aspects of Higher-Order Truncations in Solid State NMR", J. Chem. Phys., 1992, 97, 8947. 
[177] Grandinetti, P.J.; Lee, Y.K.; Baltisberger, J.H.; Sun, B.Q.; Pines, A., "Sideband Patterns in Dynamic-Angle Spinning NMR", J. Magn. Res., in press.

[178] Cohen-Tannoudji, C.; Diu, B.; Laloë, F. Quantum Mechanics, John Wiley \& Sons, Paris:1977.

[179] Llor, A; Virlet, J., "Towards High-Resolution NMR of More Nuclei in Solids: Sample Spinning with Time-Dependent Spinner Axis Angle", Chem. Phys. Lett., 1988, 152, 248.

[180] Sun, B.Q.; Baltisberger, J. H.; Wu, Y.; Samoson, A.; Pines, A., "Sidebands in Dynamic Angle Spinning (DAS) and Double Rotation (DOR) NMR", Solid State Nuclear Magnetic Resonance, 1992, 1, 267. 

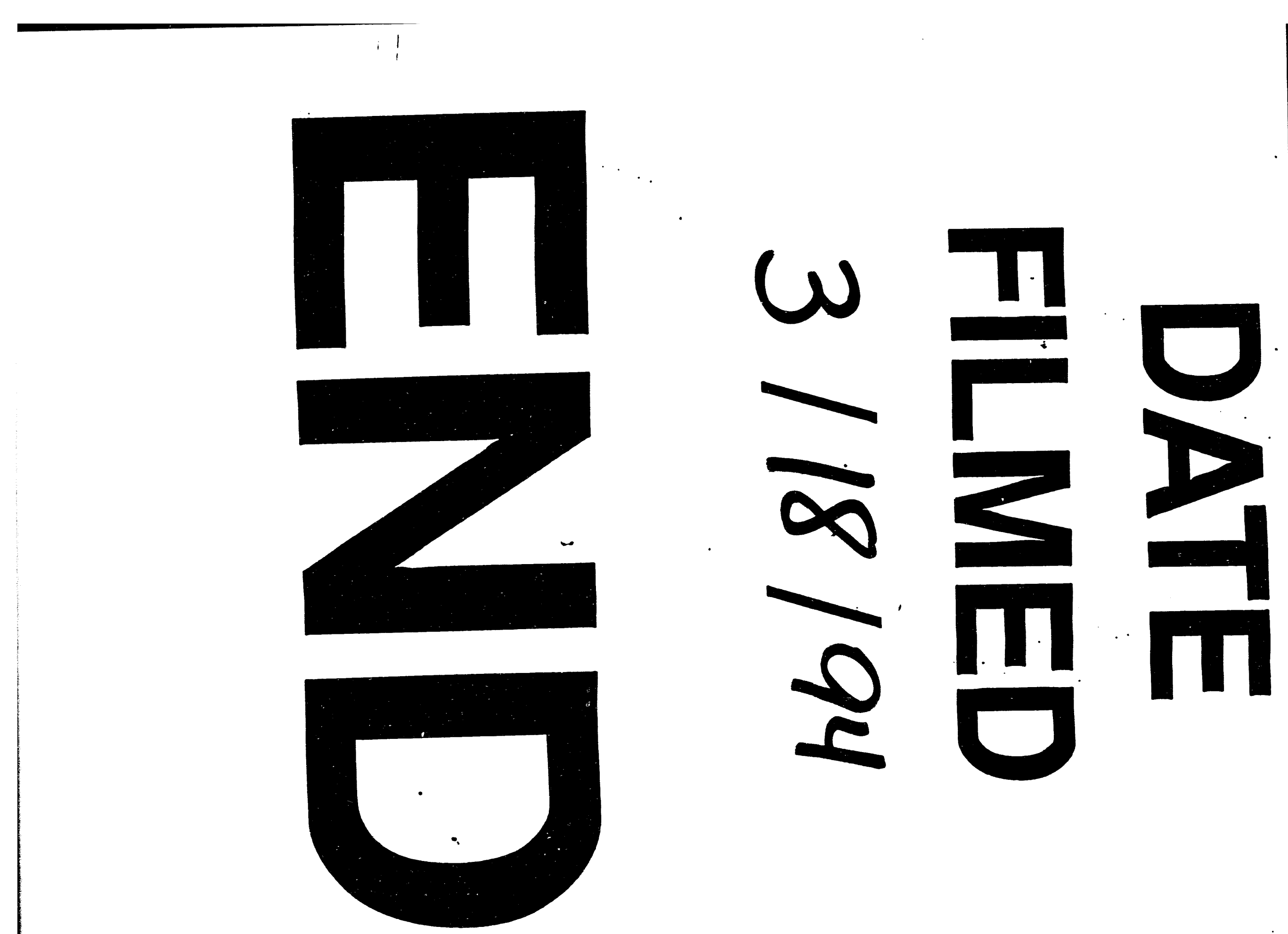
